\title{
Application of Spatial Data Modeling and Geographical Information Systems (GIS) for Identification of Potential Siting Options for Various Electrical Generation Sources
}

May 2012

Prepared by

G. T. Mays (Project Manager)

R. J. Belles

B. R. Blevins

S. W. Hadley

T. J. Harrison

W. C. Jochem

B. S. Neish

O. A. Omitaomu

A. N. Rose

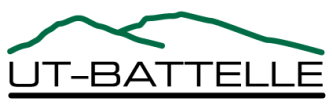




\section{DOCUMENT AVAILABILITY}

Reports produced after January 1, 1996, are generally available free via the U.S. Department of Energy (DOE) Information Bridge.

Web site $\mathrm{http}: / / w w w . o s t i . g o v / b r i d g e$

Reports produced before January 1, 1996, may be purchased by members of the public from the following source.

National Technical Information Service

5285 Port Royal Road

Springfield, VA 22161

Telephone 703-605-6000 (1-800-553-6847)

TDD 703-487-4639

Fax 703-605-6900

E-mail info@ntis.gov

Web site http://www.ntis.gov/support/ordernowabout.htm

Reports are available to DOE employees, DOE contractors, Energy Technology Data Exchange (ETDE) representatives, and International Nuclear Information System (INIS) representatives from the following source.

Office of Scientific and Technical Information

P.O. Box 62

Oak Ridge, TN 37831

Telephone 865-576-8401

Fax 865-576-5728

E-mail reports@osti.gov

Web site http://www.osti.gov/contact.html

This report was prepared as an account of work sponsored by an agency of the United States Government. Neither the United States Government nor any agency thereof, nor any of their employees, makes any warranty, express or implied, or assumes any legal liability or responsibility for the accuracy, completeness, or usefulness of any information, apparatus, product, or process disclosed, or represents that its use would not infringe privately owned rights. Reference herein to any specific commercial product, process, or service by trade name, trademark, manufacturer, or otherwise, does not necessarily constitute or imply its endorsement, recommendation, or favoring by the United States Government or any agency thereof. The views and opinions of authors expressed herein do not necessarily state or reflect those of the United States Government or any agency thereof. 
ORNL/TM-2011/157

Reactor and Nuclear Systems Division

Computational Sciences \& Engineering Division

Energy \& Transportation Science Division

\title{
APPLICATION OF SPATIAL DATA MODELING AND GEOGRAPHICAL INFORMATION SYSTEMS (GIS) \\ FOR IDENTIFICATION OF POTENTIAL SITING OPTIONS FOR VARIOUS ELECTRICAL GENERATION SOURCES
}

\author{
G. T. Mays (Project Manager) \\ R. J. Belles \\ B. R. Blevins \\ S. W. Hadley \\ T. J. Harrison \\ W. C. Jochem \\ B. S. Neish \\ O. A. Omitaomu \\ A. N. Rose
}

Date Published: May 2012

Prepared for

Electric Power Research Institute (EPRI)

Prepared by

OAK RIDGE NATIONAL LABORATORY

Oak Ridge, Tennessee 37831-6283

managed by

UT-BATTELLE, LLC

for the

U.S. DEPARTMENT OF ENERGY

under contract DE-AC05-00OR22725 



\section{CONTENTS}

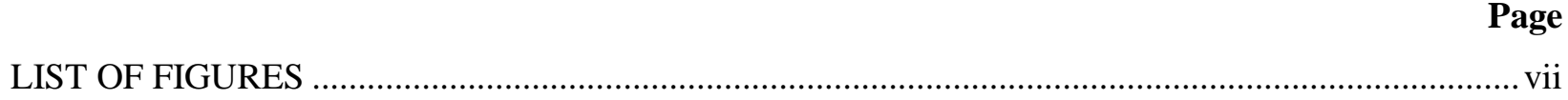

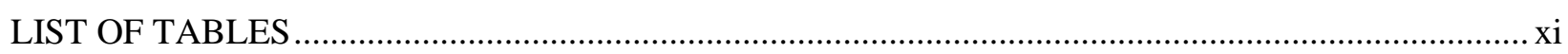

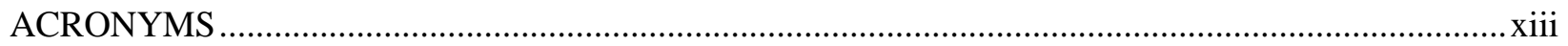

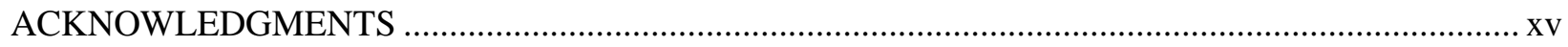

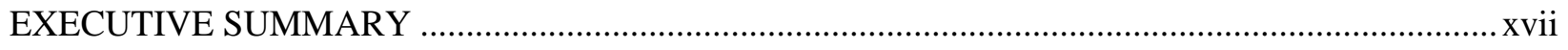

1. Background, Introduction, and Methodology …................................................................... 1

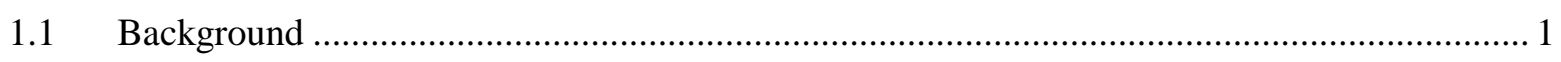

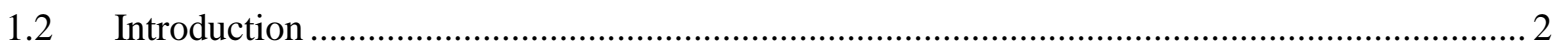

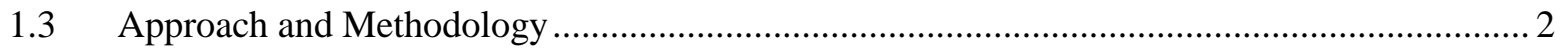

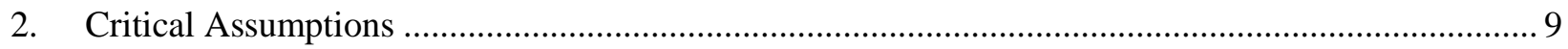

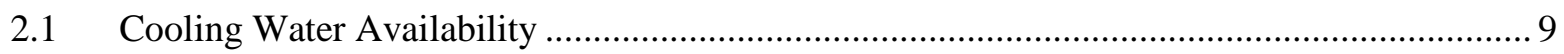

2.1.1 Creation of a 7-Day, 10-Year Low Flow Data Layer.............................................. 9

2.1.2 Calculation Process ....................................................................................... 10

2.1.3 Composite Stream Flow GIS Layer .................................................................... 11

2.1.4 Impact of the Selection of Cooling Water Flow Calculation .................................... 11

2.2 Methodology for Aggregating Land for the Typical Plant Size ......................................... 16

2.2.1 Basic Approach to Collect GIS Cells ..................................................................... 16

2.2.2 Alternative Approach to Collect GIS Cells ............................................................ 18

2.3 Plant Placement Algorithm for Water-Dependent Power Sources ....................................... 21

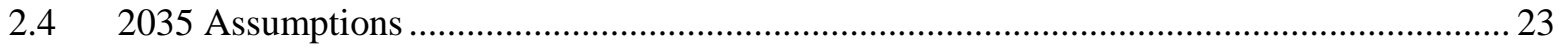

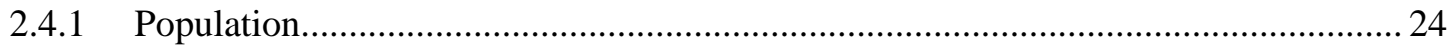

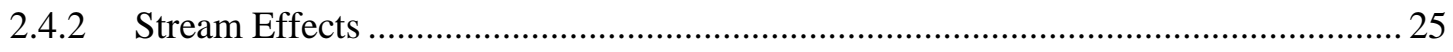

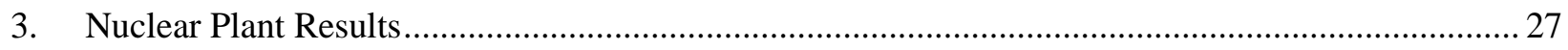

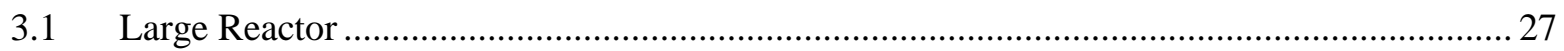

3.1.1 Site Selection and Evaluation Criteria..................................................................... 27

3.1.2 Key Assumptions ........................................................................................ 34

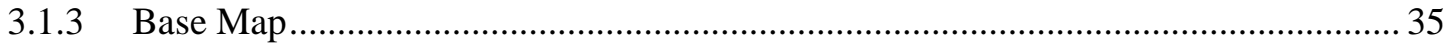

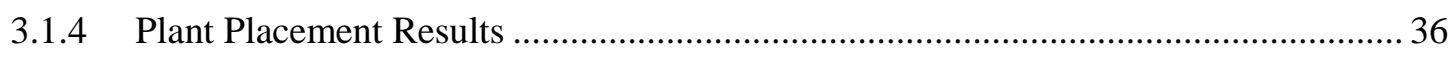

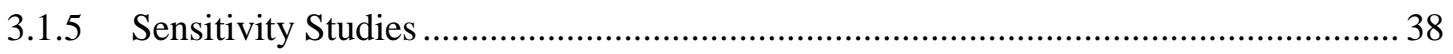

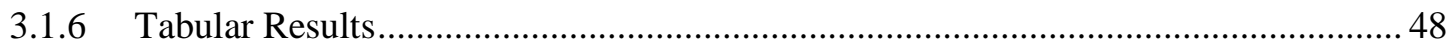

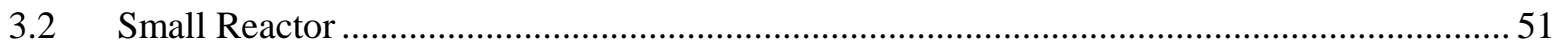

3.2.1 Site Selection and Evaluation Criteria.................................................................. 51

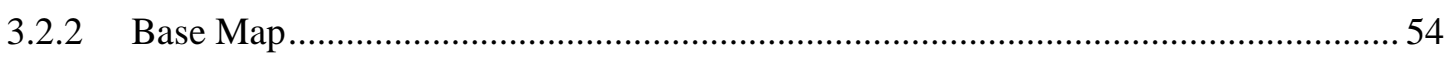

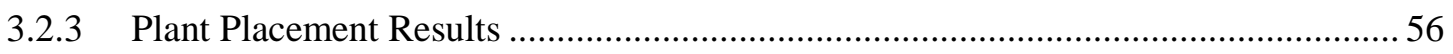




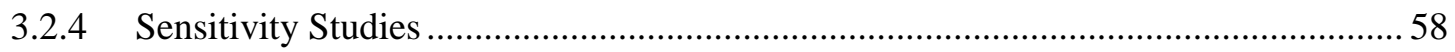

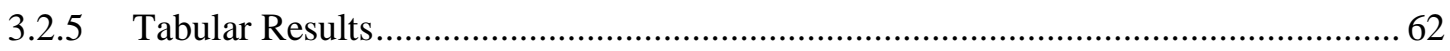

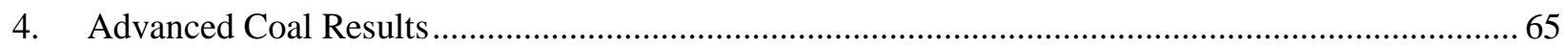

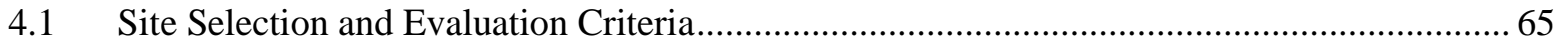

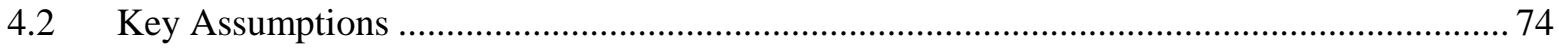

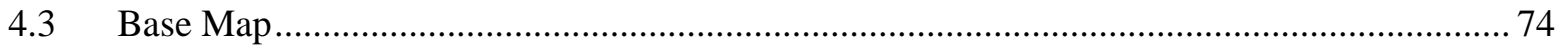

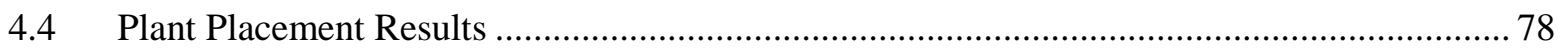

4.5 Consideration of Advanced Coal and Nuclear Plant Combined Placement........................... 79

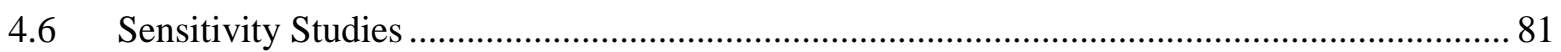

4.6.1 Distance Carbon is Piped to a Geological Formation .............................................. 81

4.6.2 Removal of the EPA Nonattainment Data SSEC Layer............................................. 84

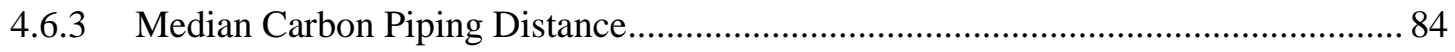

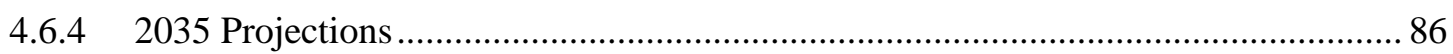

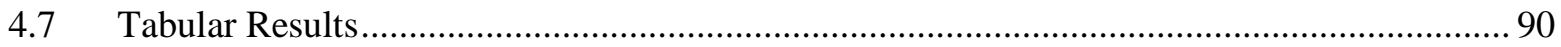

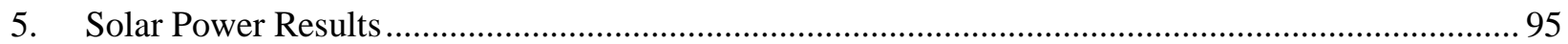

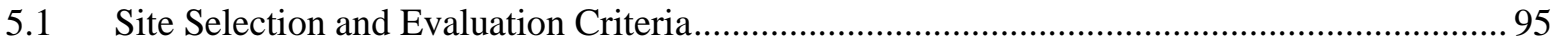

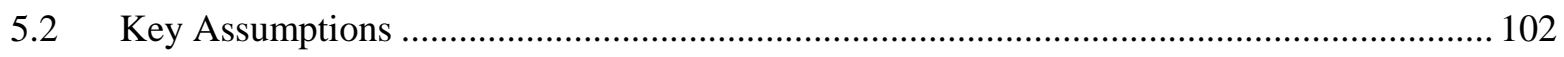

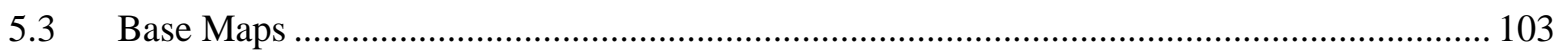

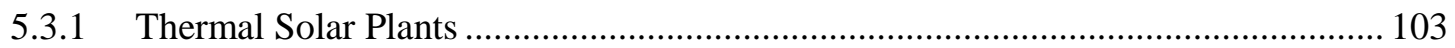

5.3.2 Dry Solar Plants (Requiring Only Cleaning Water) .............................................. 105

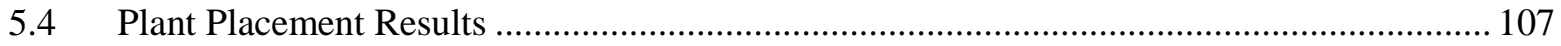

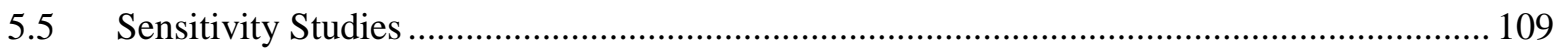

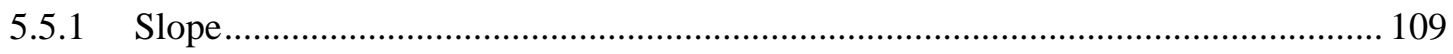

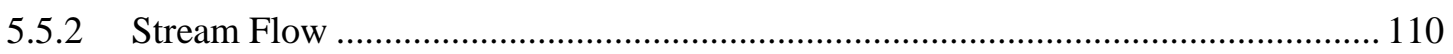

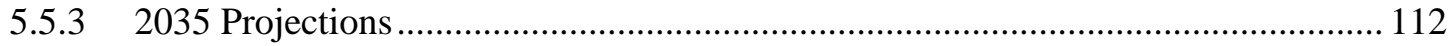

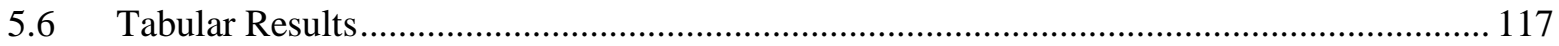

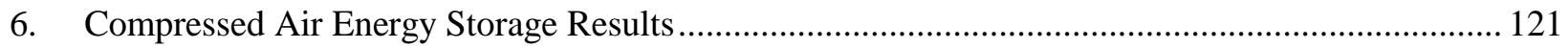

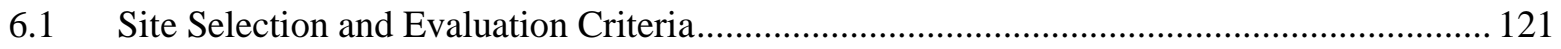

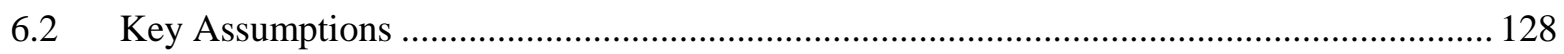

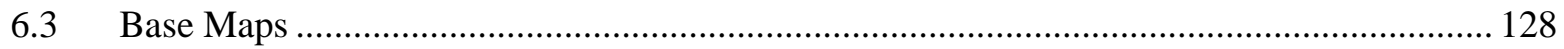

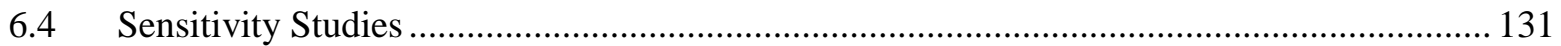

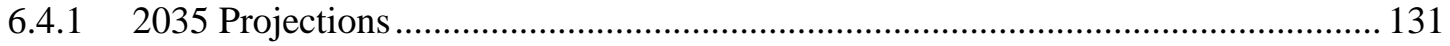

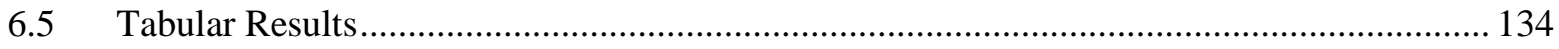

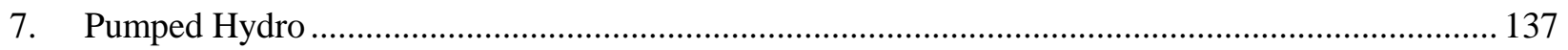

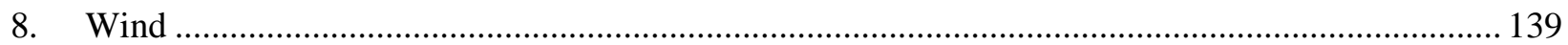

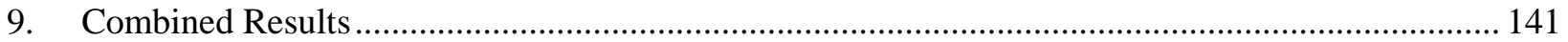




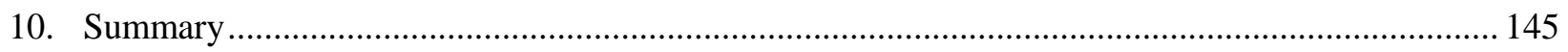

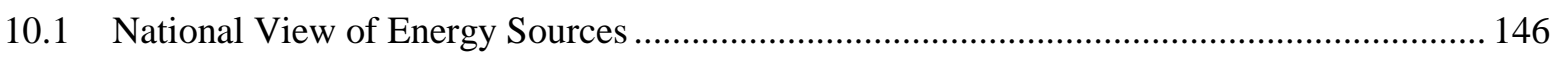

10.2 Other Possible Energy Sources to Include in the OR-SAGE Tool Kit ................................ 146

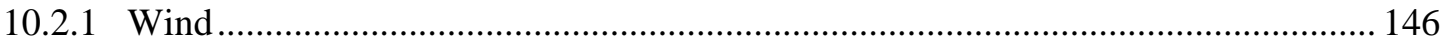

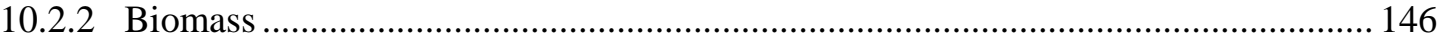

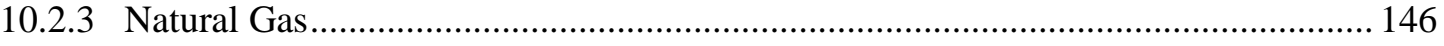

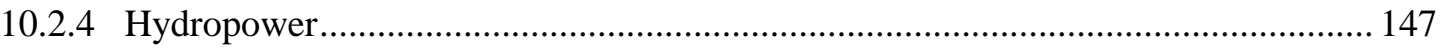

10.2.5 Pumped Hydropower (Future Reexamination) ................................................. 147

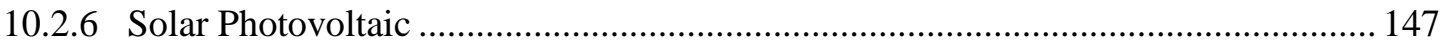

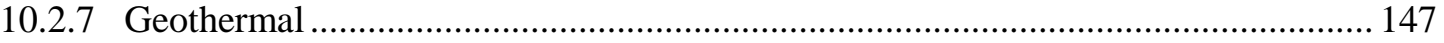

10.3 Other Possible Studies to Conduct Using the OR-SAGE Tool ........................................... 147

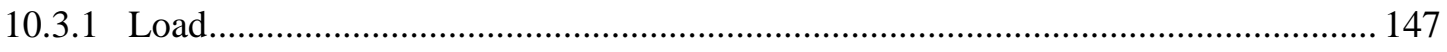

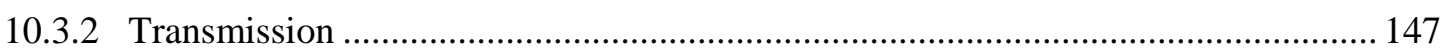

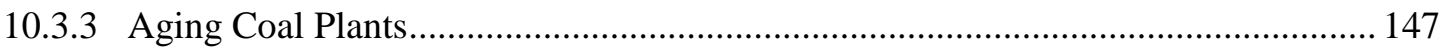

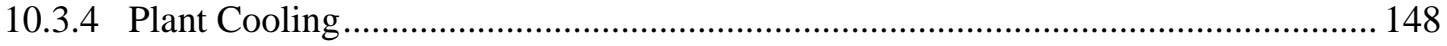

10.3.5 Coupling with an Economic Model..................................................................... 148

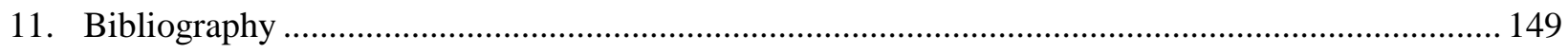

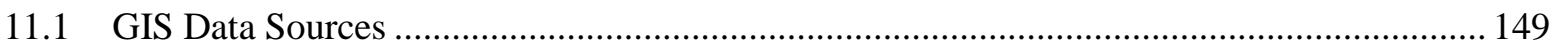

11.2 Energy Source Materials that Provided Insights on Selecting SSEC ................................. 151 



\section{LIST OF FIGURES}

Figure $\quad$ Page

ES-1 Large reactor plant placement capacity estimate by state...................................................

ES-2 Advanced coal plant placement capacity estimate by state ..................................................xix

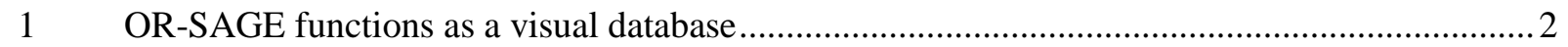

2 Overview of the OR-SAGE tool process ....................................................................... 4

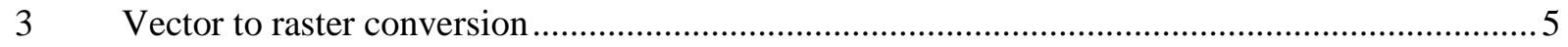

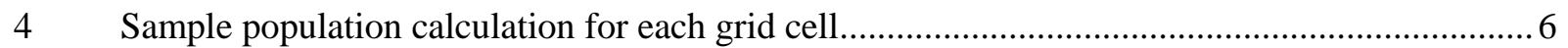

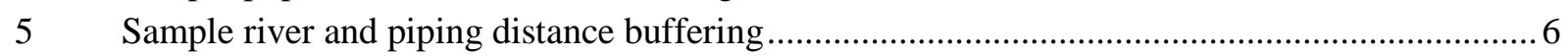

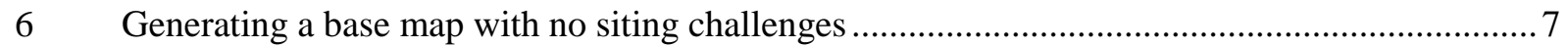

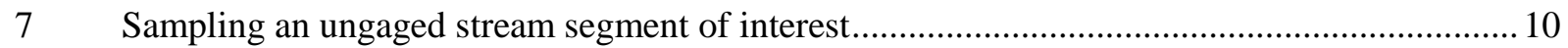

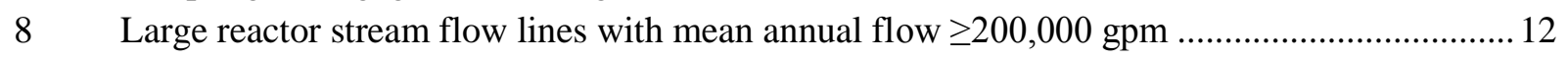

$9 \quad$ Large reactor base map using mean annual flow SSEC $\geq 200,000 \mathrm{gpm}$................................ 12

10 Large reactor stream flow lines with calculated 7-day, 10-year low flow $\geq 200,000 \mathrm{gpm}$......... 13

11 Large reactor base map using calculated 7-day, 10-year low flow SSEC $\geq 200,000$ gpm.......... 14

12 Large reactor stream flow lines with composite flow $\geq 200,000 \mathrm{gpm}$.................................. 15

13 Large reactor base map using composite flow SSEC $\geq 200,000$ gpm....................................15

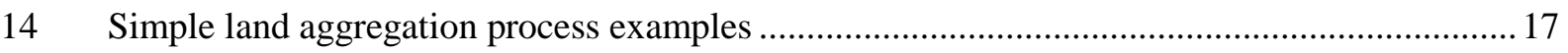

15 Sample land aggregation process results over a larger area ................................................ 18

16 Land aggregation example results with consideration for small flaws................................... 19

17 Sample 500-acre aggregation results with no cells with siting challenges ................................20

18 Sample 500-acre aggregation results with less than $10 \%$ cells with siting challenges ...............20

19 Flowchart for thermoelectric power source placement algorithm .........................................22

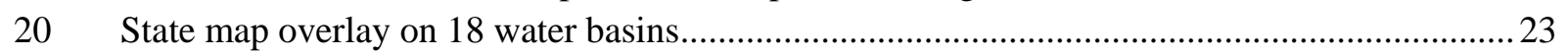

212035 areas with estimated population increases above 500 people per square mile .................25

222035 population detail map showing increases (red) and decreases (yellow) .........................26

23 Large/small nuclear high population SSEC layer...............................................................28

24 Large/small reactor safe shutdown earthquake SSEC layer ..................................................28

25 Large/small reactor wetlands and open water SSEC layer .....................................................29

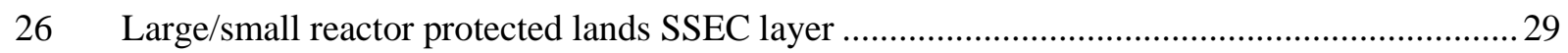

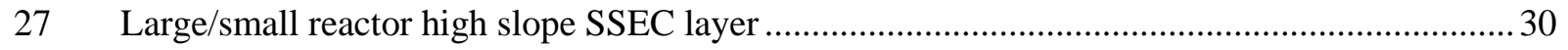

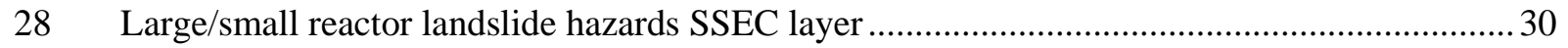

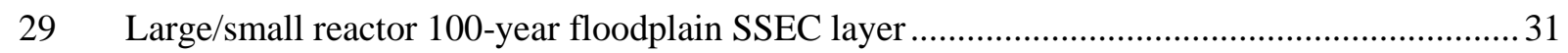

$30 \quad$ Large reactor minimum low stream flow SSEC layer ........................................................... 31

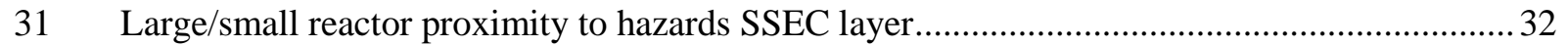

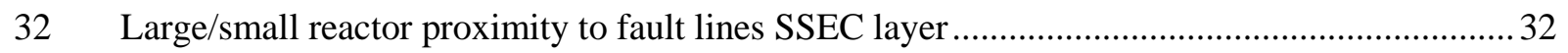

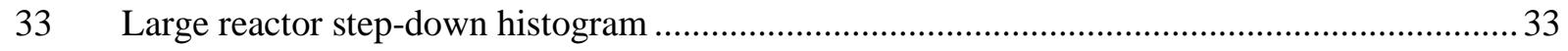

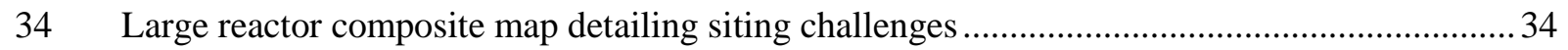

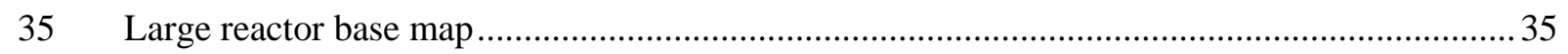

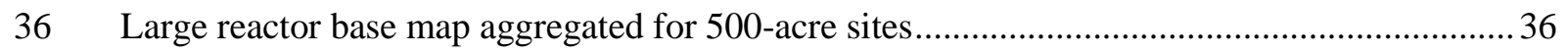

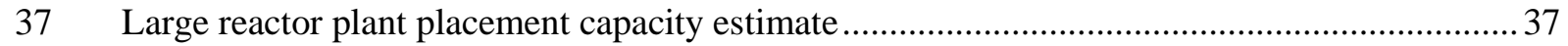

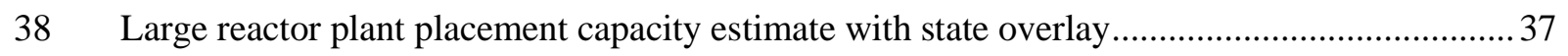

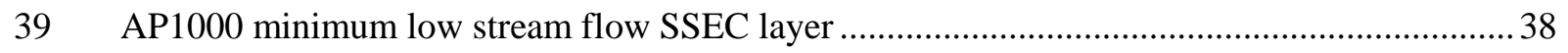


West Valley City, UT, with an example potential nuclear site using gray water...

Small reactor composite map detailing siting challenges...

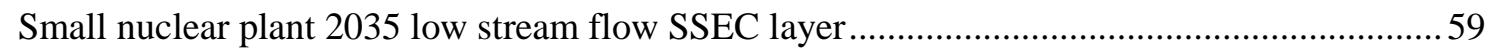

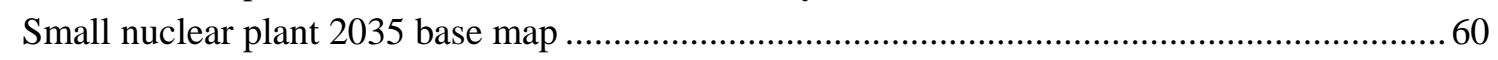

mall reactor plant 2035 siting aggregated at $90 \%$ for 50 acre facility

63 Small reactor plant visual comparison of 2010 and 2035 aggregated land results ...................61

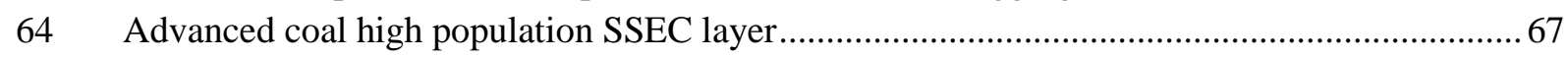

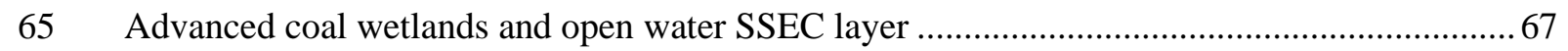

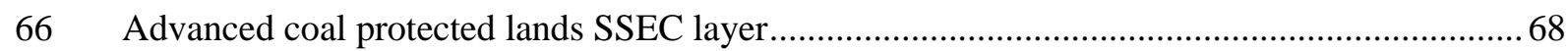

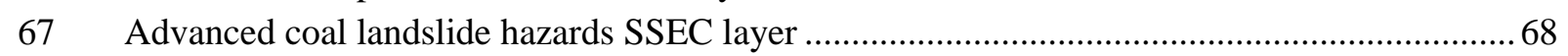

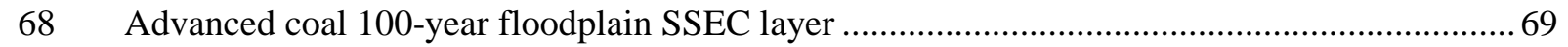

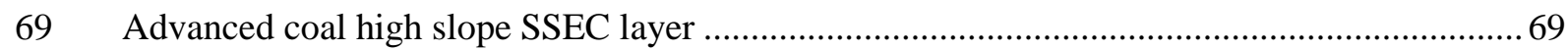

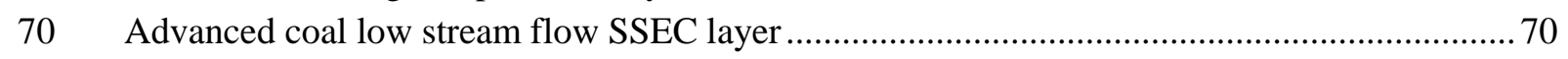

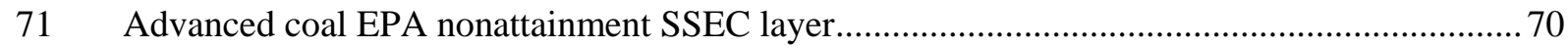

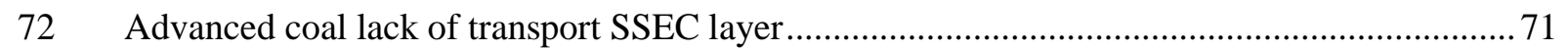

73 Advanced coal lack of access to saline formations SSEC layer .............................................. 71

74 Advanced coal carbon pipeline restrictions SSEC layer ….................................................... 72

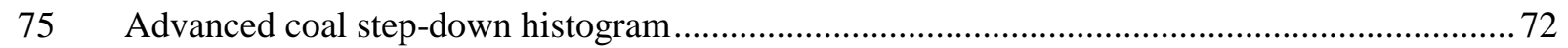

76 Advanced coal composite map detailing siting challenges .................................................... 73

77 Geological formations amenable to carbon storage .......................................................... 75

78 Advanced coal sites that sit directly over a geological formation (no aggregation

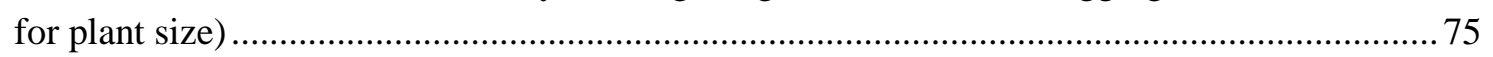

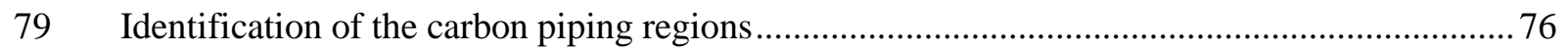

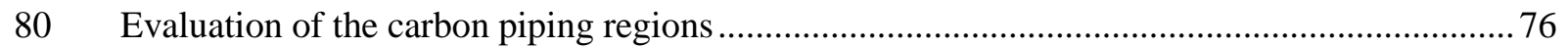

81 Combined advanced coal base map after applying carbon piping limitations...........................77

82 Advanced coal plant siting aggregated at $90 \%$ for 300 acre facility ..................................... 77 
83 Advanced coal plant placement results by water region.................................................. 78

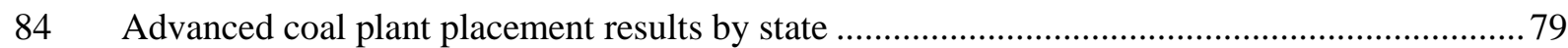

85 Combined aggregated land for advanced coal and large nuclear plants .................................... 80

86 Combined advance coal and nuclear plant placement results............................................. 81

87 Advanced coal plant saline formations with a 25-mile piping buffer zone ............................. 82

88 Advanced coal plant siting options with 25-mile carbon piping limit..................................... 82

89 Advanced coal plant saline formations with a 200-mile piping buffer zone ........................... 83

90 Advanced coal plant siting options with 200-mile carbon piping limit................................... 83

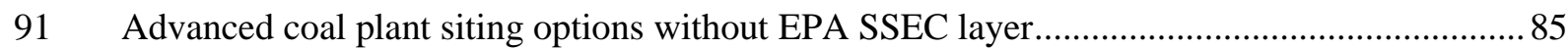

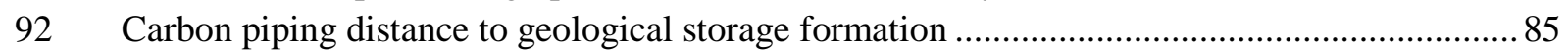

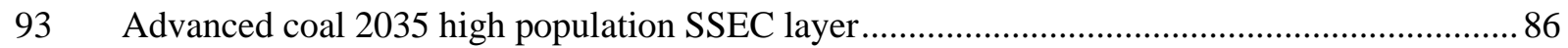

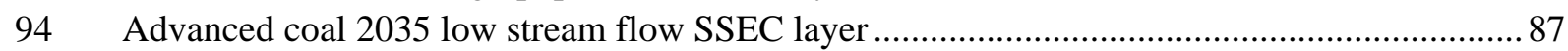

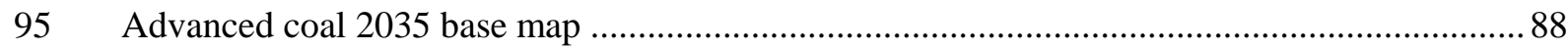

96 Advanced coal plant 2035 siting aggregated at $90 \%$ for 300 acre facility ............................. 89

97 Advanced coal plant visual comparison of 2010 and 2035 aggregated land results.................. 89

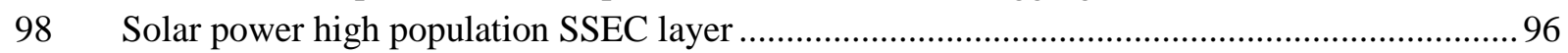

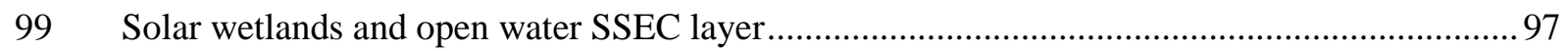

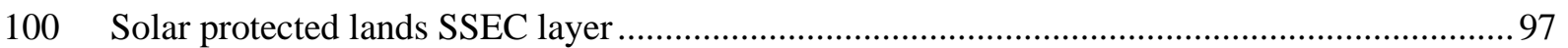

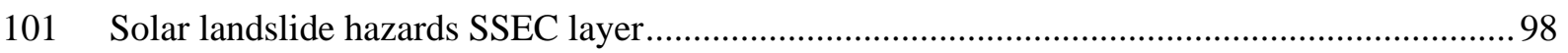

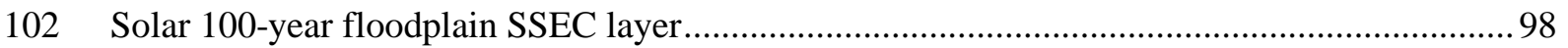

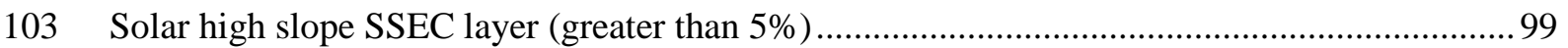

104 Solar low stream flow cooling SSEC layer (water-cooled CSP only) ......................................99

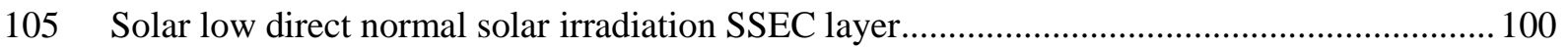

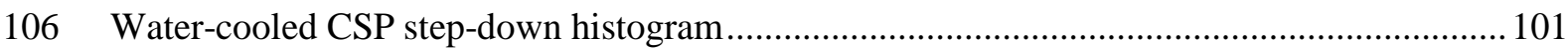

107 Water-cooled CSP composite map detailing siting challenges............................................ 102

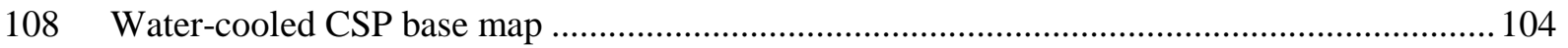

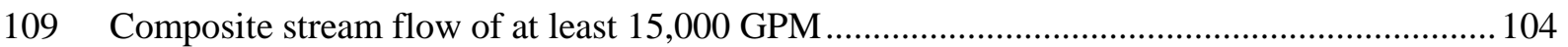

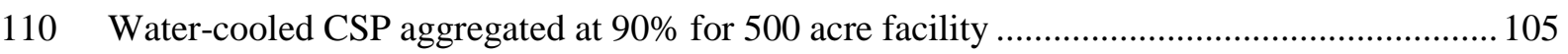

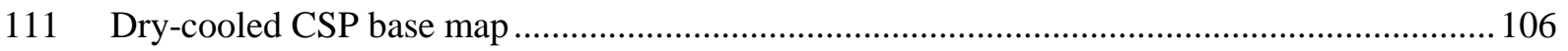

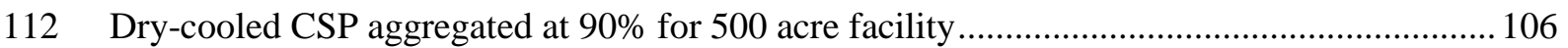

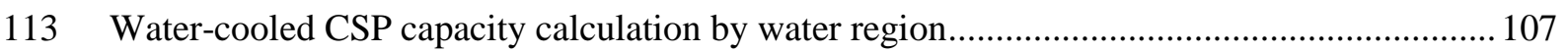

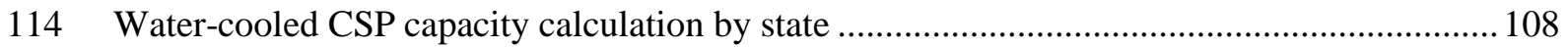

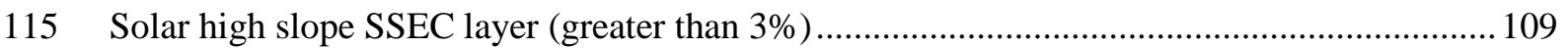

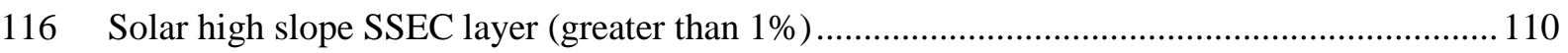

117 Solar low stream flow SSEC layer (6,000 gpm within 20 miles) (water-cooled

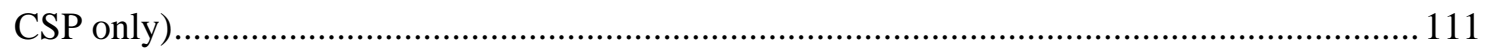

118 Water-cooled CSP sensitivity considering 40\% capacity factor (aggregated land result)........ 112

119 Solar power 2035 high population SSEC layer .................................................................... 113

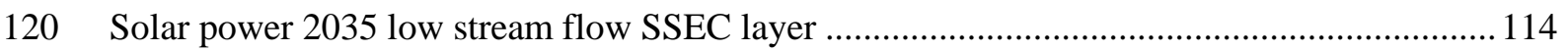

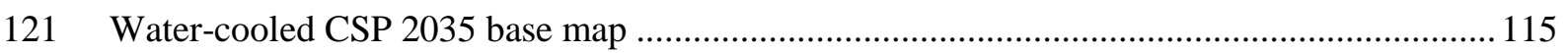

122 Water-cooled CSP 2035 siting aggregated at $90 \%$ for 500 acre facility ............................... 116

123 Solar power visual comparison of 2010 and 2035 aggregated land results .............................. 116

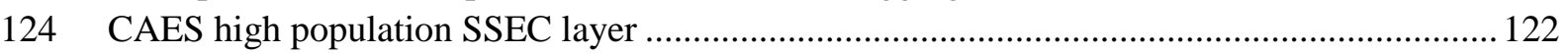

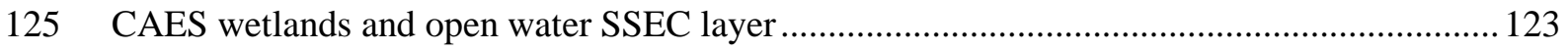




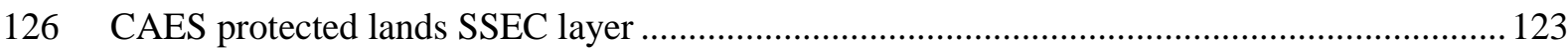

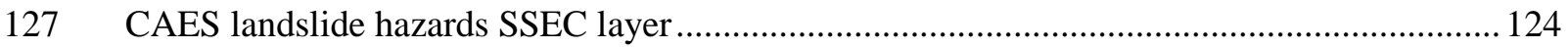

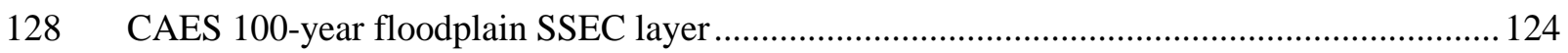

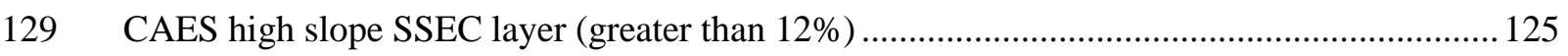

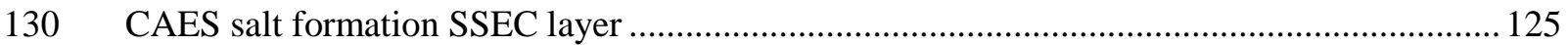

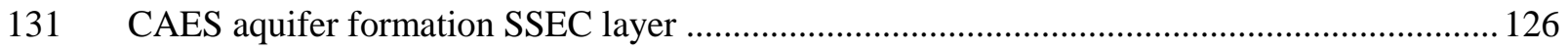

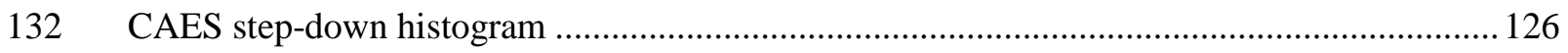

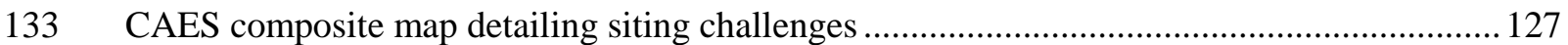

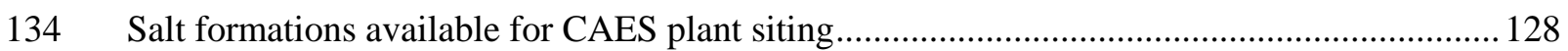

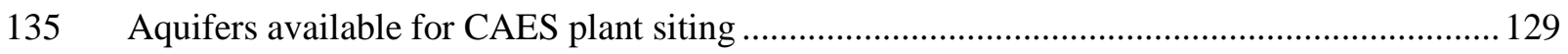

136 Combined compressed air storage geology available for CAES plant siting ........................ 130

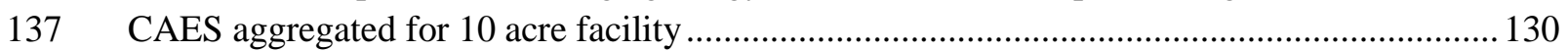

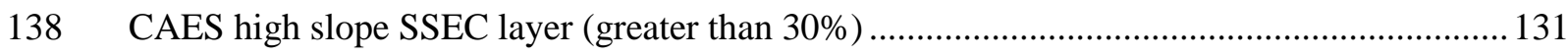

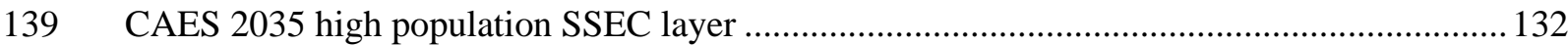

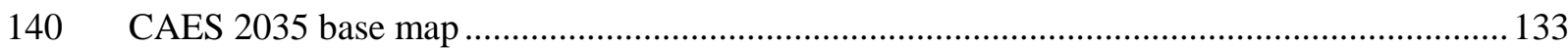

141 CAES 2035 siting aggregated for 10 acre facility ............................................................ 133

142 CAES visual comparison of 2010 and 2035 aggregated land results ................................... 134

143 Areas of the country where nuclear power is the only option of those power sources

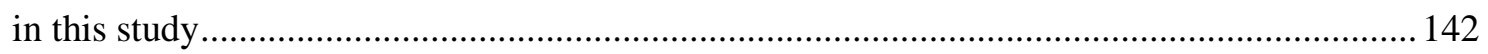

144 Areas of the country where solar power is the only option of those power sources in this study

145 Areas of the country where advanced coal is the only option of those power sources

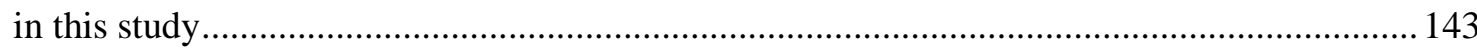

146 Areas of the country where CAES is the only option of those power sources in this study..... 143

147 Areas of the country where more than one power source considered in this study is viable ... 144

148 Areas of the country where no power source considered in this study is viable ..................... 144 


\section{LIST OF TABLES}

Table

Page

$1 \quad$ Unaggregated power source land based on various stream flow values.................................. 16

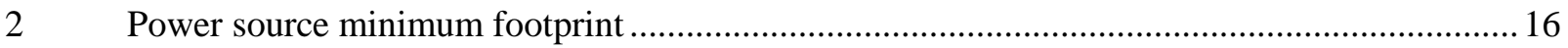

3 Contiguous US land available for two sample power sources.............................................21

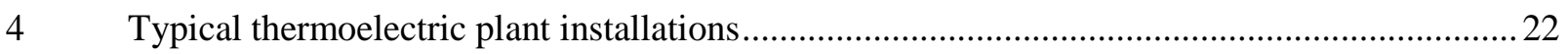

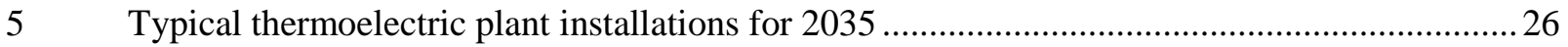

$6 \quad$ Large nuclear plant results by state (no siting challenges, selected SSEC values)...................49

$7 \quad$ Large reactor plant results by region (no siting challenges, selected SSEC values) .................50

$8 \quad$ Comparison of independent large reactor and small reactor siting results .............................58

$9 \quad$ Small reactor plant results by state (no siting challenges, selected SSEC values) ...................62

10 Small reactor plant results by region (no siting challenges, selected SSEC values) .................64

11 Available percentage of contiguous US in carbon piping distance sensitivity study ................84

12 Advanced coal results by state (no siting challenges, selected SSEC values) .........................90

13 Advanced coal plant results by region (no siting challenges, selected SSEC values) ...............92

14 Combined advanced coal and large nuclear plant evaluation (no siting challenges, selected

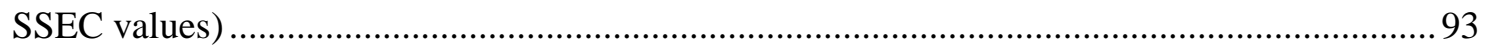

15 Available percentage of contiguous US in slope sensitivity study ........................................ 110

16 Water-cooled CSP results by state (no siting challenges, selected SSEC values) ................... 117

17 Water-cooled CSP results by region (no siting challenges, selected SSEC values) ................. 119

18 CAES results by state (no siting challenges, selected SSEC values) .................................... 134 



\section{ACRONYMS}

7Q10

BLM

CAES

$\mathrm{CCC}$

CSP

DOE

EIA

EPA

EPRI

ESP

FAA

GIS

GW(e)

MW(e)

NETL

NHDPlus

NRC

NREL

ORNL

OR-SAGE

PV

SSEC

SMR

US EPR

USGS 7-day, 10-year low flow

Bureau of Land Management

compressed air energy storage

closed cycle cooling

concentrated solar plant or concentrated solar power

US Department of Energy

Energy Information Administration

Environmental Protection Agency

Electric Power Research Institute

early site permit

Federal Aviation Administration

Geographic Information Systems

gigawatt electrical

megawatt electrical

National Energy Technology Laboratory

National Hydrography Database Plus

Nuclear Regulatory Commission

National Renewable Energy Laboratory

Oak Ridge National Laboratory

Oak Ridge Siting Analysis for Power Generation Expansion

photovoltaic

site selection and evaluation criteria

small modular reactor

US Evolutionary Power Reactor

US Geological Survey 



\section{ACKNOWLEDGMENTS}

The authors wish to thank the following people:

- Michael Howard, President and Chief Executive Officer at the Electric Power Research Institute (EPRI), for believing that OR-SAGE could benefit ongoing research at EPRI and initiating this project.

- Rosa Yang, Senior Technical Executive, Nuclear Sector at EPRI (currently coordinating collaborative activities with EPRI's Asian members), for her technical coordination of the project to meet the varied needs of EPRI staff research.

- Francisco C. de La Chesnaye, Program Manager, Energy and Climate Analysis Group at EPRI, for his technical analysis and feedback on all aspects of the project.

- Tom J. Mulford, Managing Director, Advanced Nuclear Technology at EPRI, for his technical analysis and feedback on the nuclear aspects of the project.

- Sherrell Greene, Director, Research Reactors Development Programs at Oak Ridge National Laboratory, for his vision in seeing a need to evaluate power generation siting capacity on a national level. 



\section{EXECUTIVE SUMMARY}

Oak Ridge National Laboratory (ORNL) initiated an internal National Electric Generation Siting Study, which is an ongoing multiphase study addressing several key questions related to our national electrical energy supply. This effort has led to the development of a tool, OR-SAGE (ㅁak Ridge Siting Analysis for power Generation Expansion), to support siting evaluations. The objective in developing OR-SAGE was to use industry-accepted approaches and/or develop appropriate criteria for screening sites and employ an array of Geographic Information Systems (GIS) data sources at ORNL to identify candidate areas for a power generation technology application. The initial phase of the study examined nuclear power generation. These early nuclear phase results were shared with staff from the Electric Power Research Institute (EPRI), which formed the genesis and support for an expansion of the work to several other power generation forms, including advanced coal with carbon capture and storage (CCS), solar, and compressed air energy storage (CAES). Wind generation was not included in this scope of work for EPRI.

The OR-SAGE tool is essentially a dynamic visualization database. The results shown in this report represent a single static set of results using a specific set of input parameters. In this case, the GIS input parameters were optimized to support an economic study conducted by EPRI. A single set of individual results should not be construed as an ultimate energy solution, since US energy policy is very complex. However, the strength of the OR-SAGE tool is that numerous alternative scenarios can be quickly generated to provide additional insight into electrical generation or other GIS-based applications.

The screening process divides the contiguous United States into $100 \times 100 \mathrm{~m}$ (1-hectare) squares (cells), applying successive power generation-appropriate site selection and evaluation criteria (SSEC) to each cell. There are just under 700 million cells representing the contiguous United States. If a cell meets the requirements of each criterion, the cell is deemed a candidate area for siting a specific power generation form relative to a reference plant for that power type. Some SSEC parameters preclude siting a power plant because of an environmental, regulatory, or land-use constraint. Other SSEC assist in identifying less favorable areas, such as proximity to hazardous operations. All of the selected SSEC tend to recommend against sites. The focus of the ORNL electrical generation source siting study is on identifying candidate areas from which potential sites might be selected, stopping short of performing any detailed site evaluations or comparisons. This approach is designed to quickly screen for and characterize candidate areas.

Critical assumptions supporting this work include the supply of cooling water to thermoelectric power generation; a methodology to provide an adequate siting footprint for typical power plant applications; a methodology to estimate thermoelectric plant capacity while accounting for available cooling water; and a methodology to account for future ( 2035) siting limitations as population increases and demands on freshwater sources change. OR-SAGE algorithms were built to account for these critical assumptions. Stream flow is the primary thermoelectric plant cooling source evaluated in this study. All cooling was assumed to be provided by a closed-cycle cooling (CCC) system requiring makeup water to account for evaporation and blowdown. Limited evaluations of shoreline cooling and the use of municipal processed water (gray) cooling were performed.

Using a representative set of SSEC as input to the OR-SAGE tool and employing the accompanying critical assumptions, independent results for the various power generation sources studied were calculated.

These calculations, based on a single set of input parameters, show that sufficient stream flow cooling is available to support the placement of $515 \mathrm{GW}(\mathrm{e})$ in large reactor plants. State-by-state results are affected by the unbiased nature of the initial plant placement in any given water basin, the use of single plant sites, and the arbitrary limit of 20 miles between placement of hypothetical units. However, the OR-SAGE plant capacity estimate indicates that states in a significant portion of the country can support siting at least $10 \mathrm{GW}(\mathrm{e})$ in large reactor facilities with no siting challenges (Fig. ES-1). 


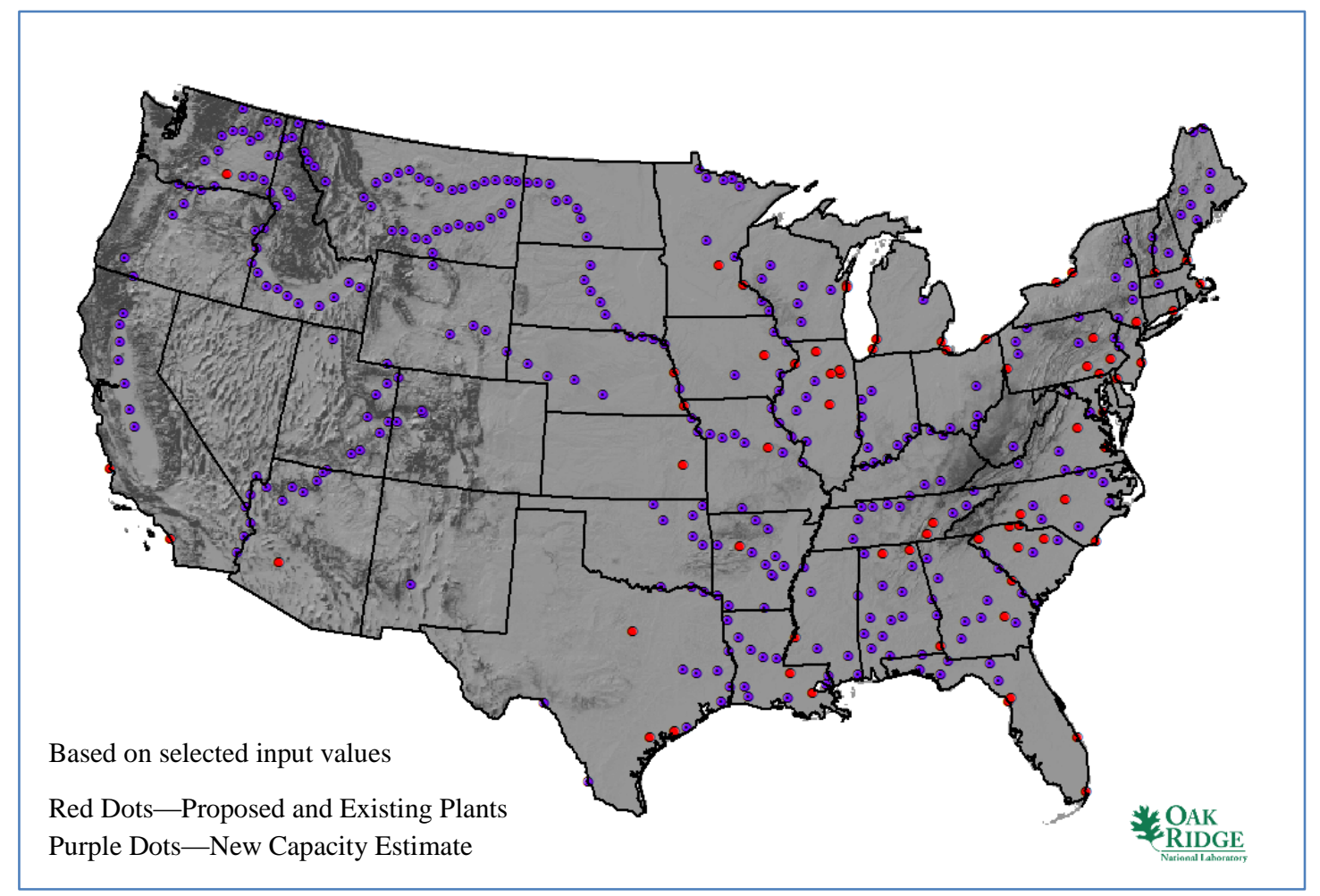

Fig. ES-1. Large reactor plant placement capacity estimate by state.

Likewise, calculations independent of the large reactor results show that sufficient stream flow cooling is available to support placement of at least $201 \mathrm{GW}(\mathrm{e})$ in small reactor plants. The small reactor capacity estimate of $201 \mathrm{GW}(\mathrm{e})$ is a minimum value based on the constraints of the plant generation capacity estimate algorithm. For calculational purposes, a direct replacement of a single large reactor projected site with four small reactor sites would provide slightly less capacity per site while using the same amount of water on a smaller footprint based on the input parameters provided to the OR-SAGE model. In this alternative, sufficient stream flow cooling is available to support placement of $451 \mathrm{GW}(\mathrm{e})$ in small reactor plant generation. Thus, a range of small reactor generation capacity is possible depending on how these plants are deployed.

The OR-SAGE plant capacity estimate projects a gross capacity of $216 \mathrm{GW}(\mathrm{e})$ for new advanced (clean) coal generation. Assuming a parasitic load for scrubbing and carbon capture, this represents a net capacity of approximately $158 \mathrm{GW}(\mathrm{e})$. The states with the strongest projection for advanced coal plant installations and capacity are Montana, Illinois, Missouri, Arkansas, Texas, Louisiana, Tennessee, Alabama, and Georgia (Fig. ES-2).

Concentrated solar power (CSP) can power a water-cooled thermoelectric generation plant or a drycooled generation plant. The OR-SAGE plant capacity estimate projects a total capacity of $20 \mathrm{GW}(\mathrm{e})$ in water-cooled CSP generation. The states with the strongest projection for plant installations and capacity (more than 15 sites each) are California, Idaho, Montana, Utah, Colorado, and Wyoming. States with good capacity (6 to 15 sites each) are Oregon, Nevada, Arizona, New Mexico, Nebraska, and Texas. Drycooled CSP generation does not require placement near a cooling water source, and the tracking of available water by the OR-SAGE plant capacity estimate algorithm is not required. A simple comparison of the available dry-cooled CSP land to the water-cooled CSP land indicates that there would be at least $70 \mathrm{GW}(\mathrm{e})$ of dry-cooled CSP capacity. 


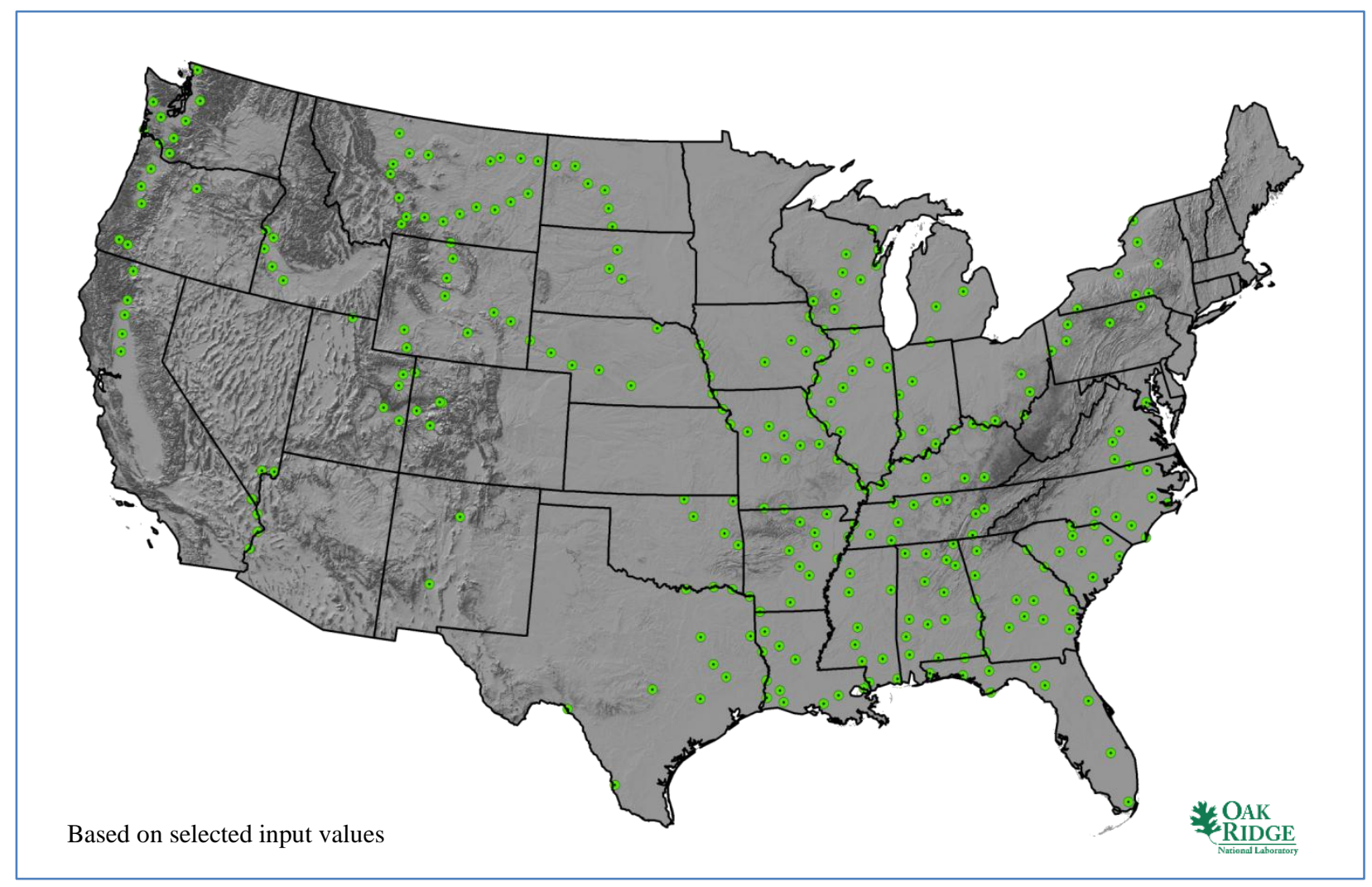

Fig. ES-2. Advanced coal plant placement capacity estimate by state.

The combined CAES plant siting opportunities based on all geological storage methods are 38\% (645 million acres) of the contiguous United States land. This land is primarily in the middle portion of the contiguous United States, but most states show at least some siting capacity. This includes regions where solar and wind generation is viable. Using solar and wind generation for air compression in a CAES plant would provide a reasonable energy storage mechanism. As with the dry-cooled CSP case, the OR-SAGE plant capacity estimate algorithm is not amenable to the air-cooled CAES facilities because no cooling water is required. Therefore, no generation capacity is estimated for CAES. However, based on available land, one could speculate a capacity that is quite large.

The scope of work for this geospatial study is aimed at identifying candidate site areas for a variety of electrical generation plants and further characterizing these sites to support comparing and contrasting them; e.g., for a given site, which type of plant is best suited for that site, how far is it to existing electrical transmission capacity, what is the distance to underground geological formations suitable for carbon sequestration, and what should the mix of generation be under certain conditions. The results provide insight into certain advantages one generation source may have over the others. This is typically a regional debate. Often, the generation source with the best advantage is not conveniently located near any load demand. Such situations necessitate a coordinated energy policy to generate and deliver power where it is needed. The OR-SAGE siting analysis tool provides the capability to evaluate a variety of power generation sources simultaneously. This capability can factor into policy and economic decision making. The geospatial analysis of additional power generation sources should be included in follow-on studies when possible to maintain a well-rounded policy and economic viewpoint. 


\section{BACKGROUND, INTRODUCTION, AND METHODOLOGY}

\subsection{Background}

In 2009, Oak Ridge National Laboratory (ORNL) staff completed an internal "Energy Assurance" study examining the key issues associated with the country's future energy needs, focusing on generation sources, base load options, transmission and distribution, reduction of greenhouse gases, and overall energy security issues. In examining the various generation sources, including nuclear power and renewables, one principal finding was that $300 \mathrm{GW}(\mathrm{e})$ of new nuclear electrical generating capacity would be needed by 2050 . With that need identified, an initial, obvious question was whether $300 \mathrm{GW}(\mathrm{e})$ of nuclear capacity can be sited in the United States. In an attempt to address that question and others, ORNL initiated an internal National Electric Generation Siting Study, an ongoing multiphase study addressing several key questions related to our national electrical energy supply. This effort has led to the development of a tool, OR-SAGE (ㅁak iidge $\underline{\text { Siting }}$ Analysis for power Generation Expansion), to support siting evaluations.

The objective in developing OR-SAGE was to use industry-accepted approaches and/or develop appropriate criteria for screening sites and employ an array of Geographic Information Systems (GIS) data sources at ORNL to identify candidate areas for a particular power generation technology application. As a guiding document, ORNL staff employed the general concepts presented in the 2002 Electric Power Research Institute (EPRI) Siting Guide ${ }^{1}$ methodology developed to support early site permit (ESP) applications. The concepts were used to develop exclusionary, avoidance, and suitability criteria for screening sites for nuclear power plants. For a given application, it is necessary to develop site selection and evaluation criteria (SSEC) that encompass a number of key screening criteria that essentially form the site environmental characterization for that application. These SSEC might include population density, slope, seismic activity, proximity to cooling water sources, proximity to hazard facilities, avoidance of protected lands and floodplains, susceptibility to landslide hazards, and others. OR-SAGE is a visual, relational database. The SSEC are the fields of the database, and the GIS data for a given variable represent the values against which searches are performed. Figure 1 demonstrates the visual database concept. The database is tracking just under 700 million 100 by $100 \mathrm{~m}$ ( 2.5 acre) cells.

The initial phase of the study examined the nuclear option. Early nuclear phase results were shared with staff from EPRI, which formed the genesis and support for an expansion of the work to several other power generation forms. Candidate siting data on a mixture of electric power sources will be used to support economic modeling being performed by EPRI.

\footnotetext{
${ }^{1}$ E. Rodwell (Project Manager), Siting Guide: Site Selection and Evaluation Criteria for An Early Site Permit Application,
} 1006878, Final Report, Electric Power Research Institute, March 2002. 


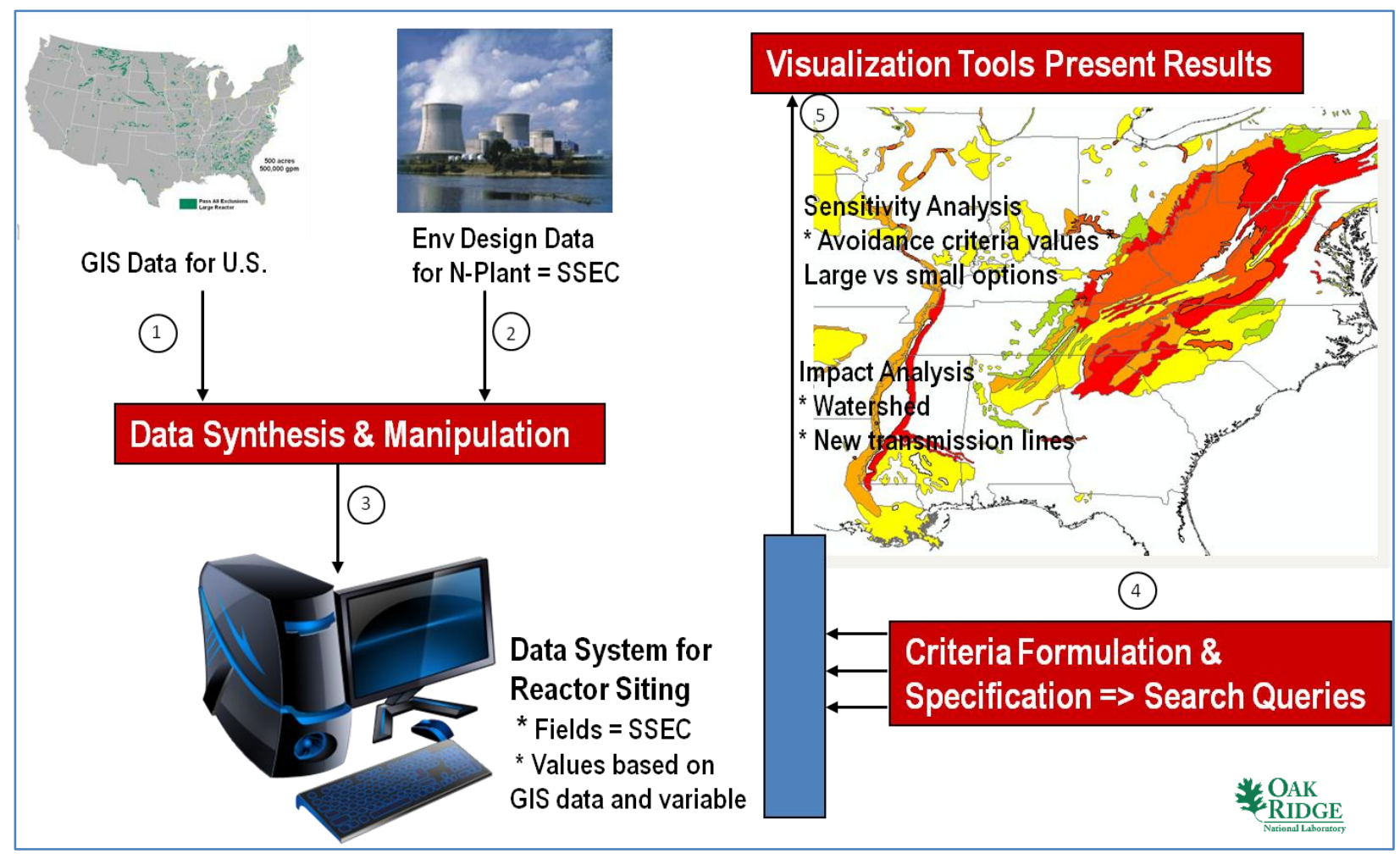

Fig. 1. OR-SAGE functions as a visual database.

\subsection{Introduction}

The objective of this siting study work is to support EPRI in evaluating electrical generation deployment options now and in the future by focusing on identifying potential areas for siting a mixture of new electrical energy resources. The electrical generation deployment options investigated for the EPRI siting study work include large nuclear plants, small nuclear plants, advanced coal plants, commercial solar plants, compressed air energy storage (CAES), and pumped hydropower. ${ }^{2}$ EPRI has made separate arrangements to study wind power applications. This research project is aimed at providing methodologies, information, and insights that inform the process for determining candidate areas for new electrical generation plants to meet projected US electric power demands for the future, based upon appropriate screening criteria and through the application of spatial modeling and GIS.

This report summarizes the approach that ORNL developed for screening the various power supply sites of interest to EPRI; the methodology employed, including spatial modeling; and initial results for the contiguous United States. The objective in conducting this type of siting evaluation is to perform early site characterization of the candidate areas to identify any particular issues for power plant siting; it is not intended to be a definitive assessment per se as to the overall suitability of any particular site.

\subsection{Approach and Methodology}

The objective in structuring the approach for this study was to use industry-accepted practices in screening sites and then employ the proper array of data sources and identify candidate areas through the considerable computational capabilities of GIS technology available at ORNL. Initially, ORNL staff

\footnotetext{
${ }^{2}$ Pumped hydropower was eventually dropped from the study based on the preliminary results of a hydrological survey being performed by other ORNL staff for DOE.
} 
(1) adapted and extended the 2002 EPRI Siting Guide ${ }^{3}$ methodology, developed to support ESP applications, for the purpose of screening sites and (2) employed three of the four steps in the Bechtel site evaluation process ${ }^{4}$ for nuclear plant siting. This process is subsequently applied to all generation sources evaluated in this study. The screening process divides contiguous United States into 100 by $100 \mathrm{~m}$ (1-hectare) squares (cells), applying successive suitability SSEC to each cell. If a cell meets the requirements of each criterion, the cell is deemed a candidate area for siting a power plant of a particular size in terms of power [MW(e)]. Some SSEC parameters preclude siting a plant because of an environmental, regulatory, or land-use constraint. Other SSEC assist in identifying less favorable areas such as proximity to hazardous operations. All of the selected SSEC tend to recommend against sites. At this point, the suitability criteria are employed to assist in evaluating the acceptability of candidate areas and sites. The Bechtel evaluation process includes a successive four-step approach: (1) examining regions of the country, (2) examining regions of interest based on electricity and market projections,(3) identifying candidate areas, and (4) identifying candidate sites using various scoring and weighting factors.

The focus of the ORNL electrical generation source siting study is on identifying candidate areas from which potential sites might be selected, stopping short of performing any detailed site evaluations or comparisons. This approach is designed to quickly screen for and characterize candidate areas. In consideration of the EPRI Siting Guide and Bechtel's Study of Potential Sites, data presented in the 1992 ESP Demonstration Program, ${ }^{5}$ and the ESP applications for North Anna, Clinton, and Grand Gulf sites, ORNL staff first developed a subset of SSEC for nuclear plant siting that were considered to have the most impact on the viability of any given site and were directly amenable to application of GIS techniques. This process is readily applicable to other forms of power generation. Figure 2 provides an overview of the OR-SAGE tool application.

\footnotetext{
${ }^{3}$ E. Rodwell (Project Manager), Siting Guide: Site Selection and Evaluation Criteria for An Early Site Permit Application, 1006878, Final Report, Electric Power Research Institute, March 2002.

${ }^{4}$ Dominion Energy, Inc., and Bechtel Power Corporation, Study of Potential Sites for the Deployment of New Nuclear Plants in the United States, prepared for the U.S. Department of Energy, September 2002.

${ }^{5}$ Bechtel Power Corporation, Early Site Permit Demonstration Program, Plant Parameter Envelopes, Comparison with Ranges of Values for Four Hypothetical Sites, Gaithersburg, MD, 1992.
} 


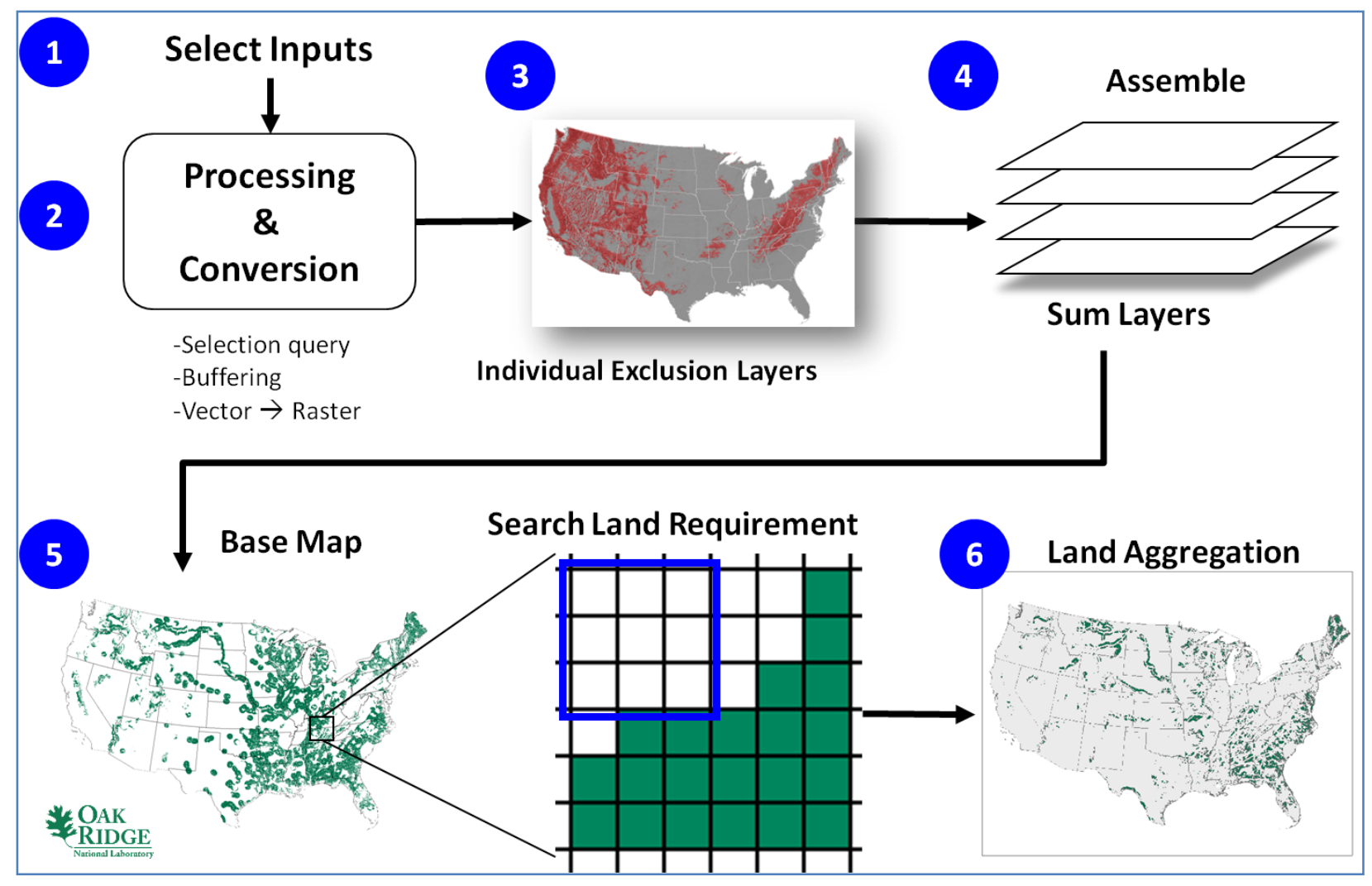

Fig. 2. Overview of the OR-SAGE tool process.

The first step shown in Fig. 2 is to select input datasets. Datasets that provide national or greater coverage with attributes matching the desired SSEC are selected. The specific SSEC identified for each power source are detailed as part of the results discussion for each individual power source. Greater than national coverage is preferred to prevent map "edge-effects." Appropriate scaling and resolution of each dataset must be considered before using a dataset in the study. There are 22 datasets in the nuclear phase of the siting study. The nuclear phase dataset sources include

- US Geological Survey (USGS),

- US National Park Service,

- US Forest Service,

- US Fish and Wildlife Service,

- Department of Transportation,

- Federal Emergency Management Agency,

- Federal Aviation Administration (FAA),

- US Census Bureau,

- ORNL LandScan Data,

- ORNL 7-Day, 10-Year Low Flow Calculated Data, and

- other commercial sources.

Much of the information and experience gained working with the nuclear siting carried over into the subsequent power source siting. Additional data sets brought into the study for other power sources include: 
- National Renewable Energy Laboratory (NREL),

- Bureau of Transportation Statistics,

- Environmental Protection Agency (EPA), and

- Geologic Formation Data.

The next step from Fig. 2 is to process and convert the input datasets. This involves vector to raster conversion and raster reclassification. The datasets are typically not to the same scale. The conversion process allows all the data sets to be represented to the same scale on a common map. In the GIS spatial modeling process, 100 by $100 \mathrm{~m}$ cell sizes were created (approximately 2.5 acres per cell). For comparison, there are more than 1.7 billion acres in the contiguous United States, which excludes Alaska and Hawaii. Figure 3 shows how a vector-based randomly shaped area is converted to raster and the effectiveness of the conversion based on the cell size.
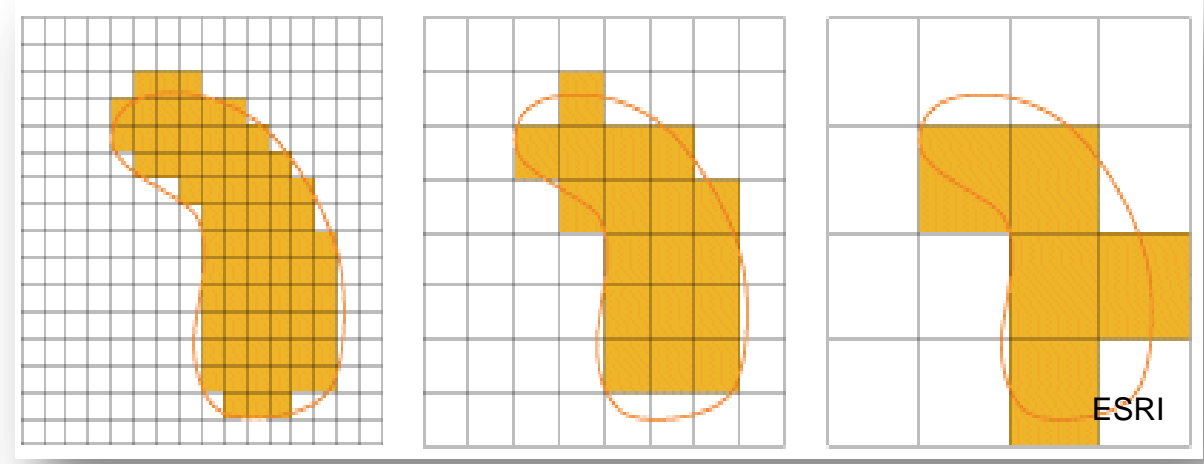

Fig. 3. Vector to raster conversion.

This stage also involves generating an appropriate selection query and applying any required buffer zone. The application of the buffer zone can be a complex process. For example, one of the nuclear power plant SSEC is population density of less than 500 people per square mile. NRC (Nuclear Regulatory

Commission) Regulatory Guide $4.7^{6}$ indicates that "a reactor should preferably be located such that, at the time of initial site approval and within about 5 years thereafter, the population density, including weighted transient population, averaged over any radial distance out to 20 miles (cumulative population at a distance divided by the circular area at that distance), does not exceed 500 persons per square mile." To meet the guidance, each cell in the database is queried for ambient population, which considers the weighted transient population. If a cell is greater than 500 people per square mile, it is immediately excluded. If a cell population is less than 500 people per square mile, the surrounding area is evaluated by calculating the population density in an expanding set of rings out to a maximum of 20 miles (in simple terms, a buffer zone). If any ring is calculated to have a population density above 500 people per square mile, then the center cell is excluded. If no ring around the central cell exceeds a population density of 500 people per square mile, then the cell remains viable with regard to population. Figure 4 shows a representative result of a population dataset query with a standoff distance considered. The maximum search radii can be set to any value to create alternate standoff distances. For other generation sources that do not require a "buffer" zone, no ring calculation is performed.

\footnotetext{
${ }^{6}$ Regulatory Guide 4.7, General Site Suitability Criteria for Nuclear Power Stations, Nuclear Regulatory Commission, April 1998.
} 


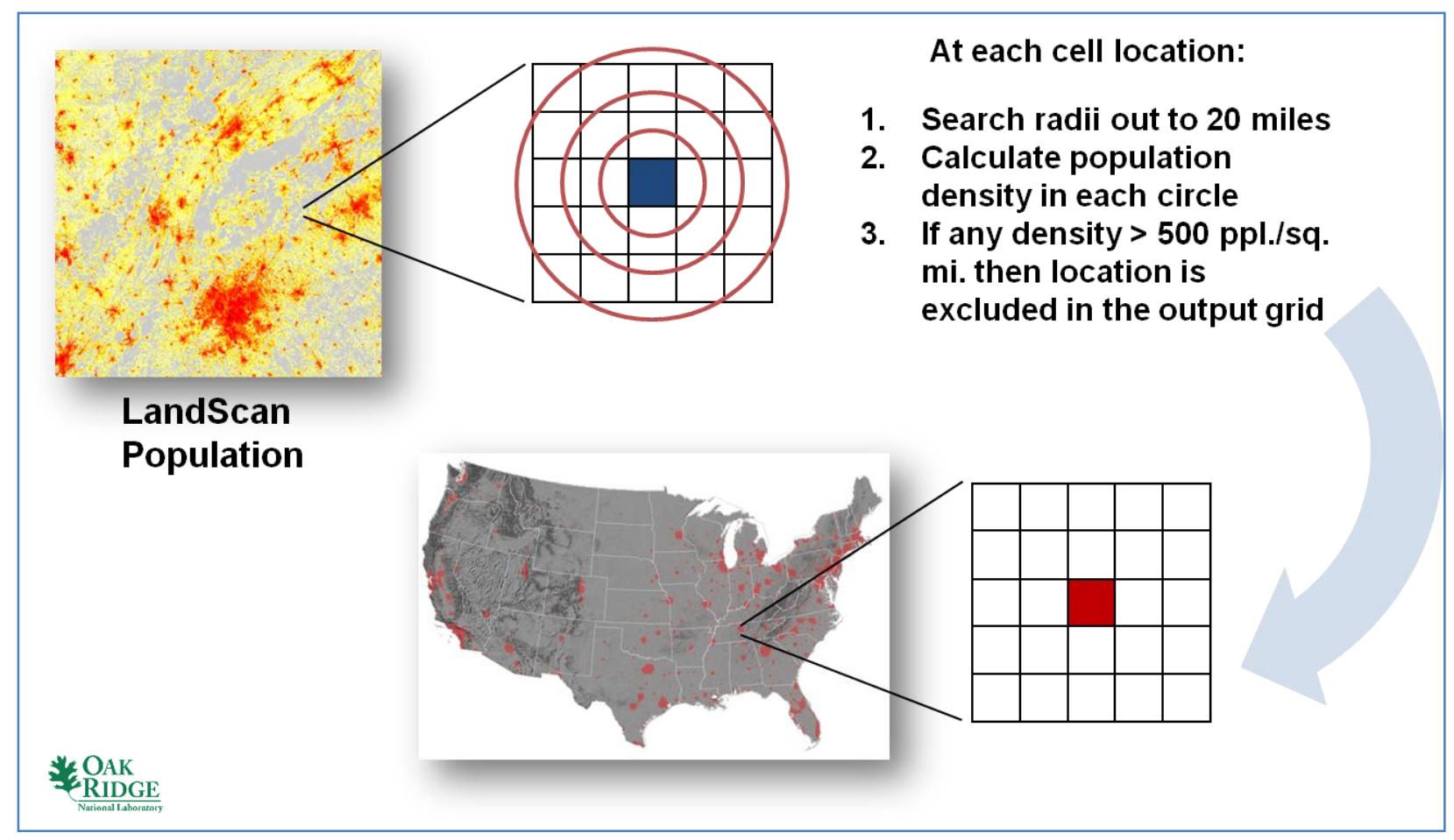

Fig. 4. Sample population calculation for each grid cell.

Buffering can also be a much simpler process, such as applying an area of land around a known geological feature. For example, Fig. 5 shows a stream segment and a 20-mile buffer zone to allow for pumping cooling water to a thermal power plant.

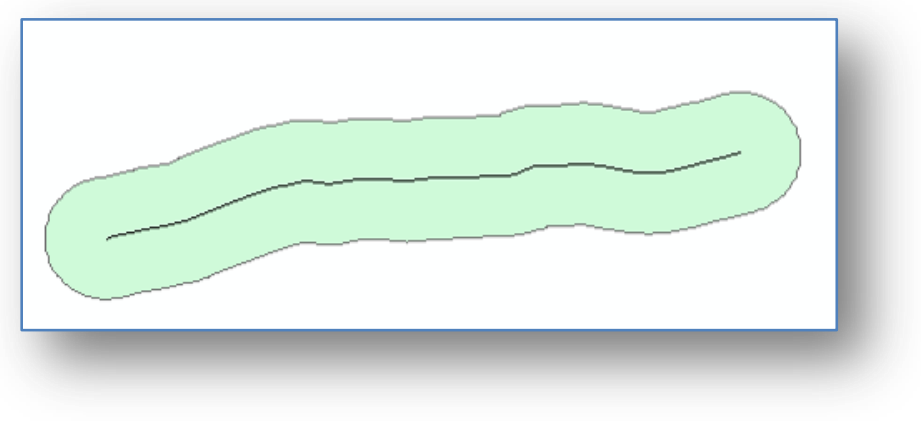

Fig. 5. Sample river and piping distance buffering.

The third step is to create the individual SSEC layers for each power source. Appropriate screening criteria for a given power source are selected and the individual SSEC layers are built based on available data. Some SSEC layers are a direct representation of available data, and some are a composite of information from multiple sources. Areas that do not meet the specific criteria are typically highlighted in red on these individual SSEC layer maps.

Next, in step four, the individual SSEC layers are assembled into a single output. Essentially, the applicable layers are summed cell-by-cell. The result is a highlighted US contiguous map of all the areas that do not pass one or more of the envelope criteria for the power source under consideration. During this step, individual layers can be moved in and out of the study to conduct sensitivity analyses. The limits associated with any given SSEC layer can also be adjusted to conduct sensitivity analyses. 
Since the desired result is to identify candidate areas where a given power source is viable, the highlighted portions of the map are inverted in step five. The result is a highlighted US contiguous map of all the areas that have no siting challenges based on the chosen site selection and evaluation criterion. The result is considered to be the base map for the given power source. In effect, it is a static look in time at a set of criteria that are thought to bound the placement of a given power source. Each individual 100 by $100 \mathrm{~m}$ cell that passes every site SSEC is typically highlighted in green on the base map. Figure 6 depicts the overall concept of the application of OR-SAGE in general by applying the individual SSEC as GIS datasets to exclude areas (red map) leading to the identification of candidate areas (green map). Other considerations are available for map areas that have one or more siting challenges.

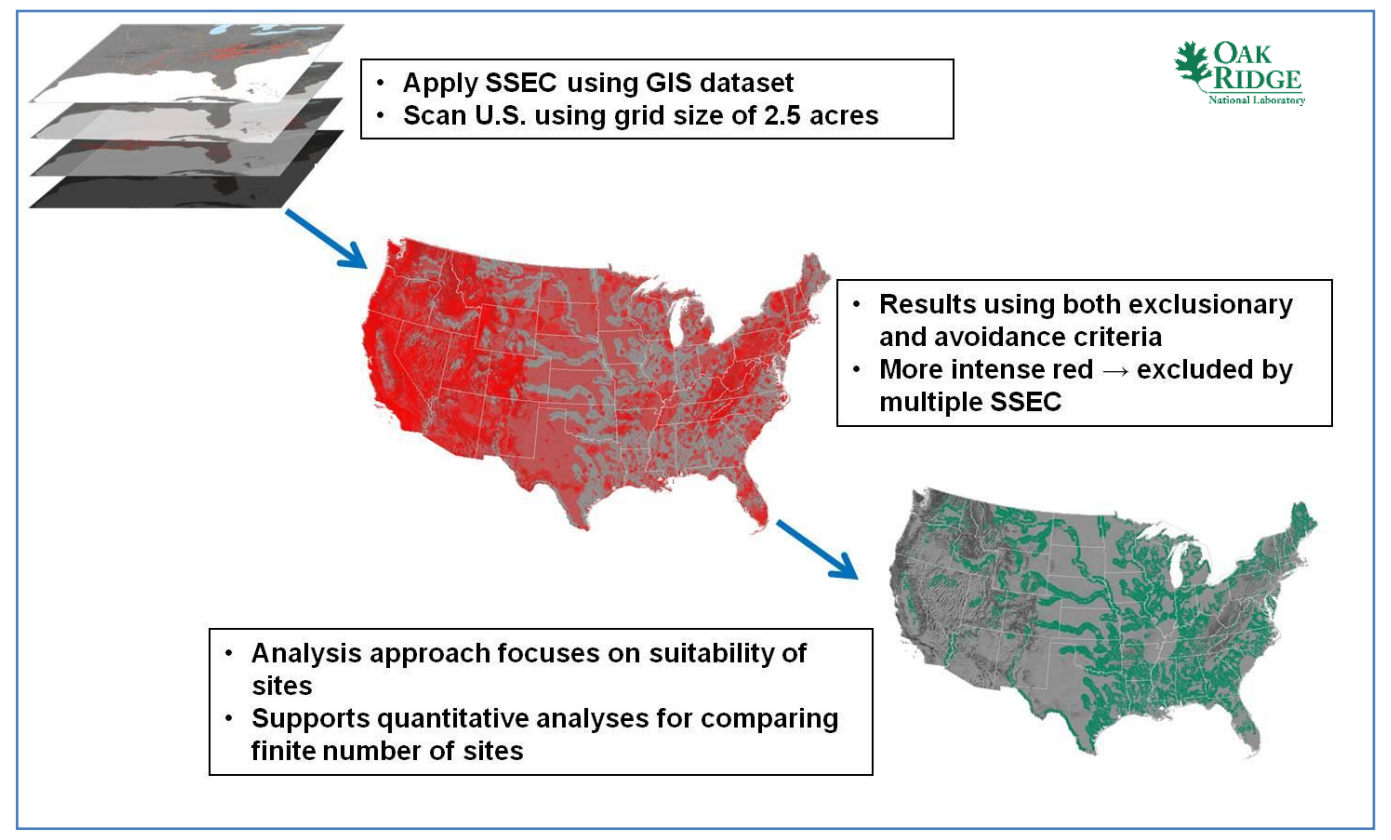

Fig. 6. Generating a base map with no siting challenges.

Given that a single cell represents approximately 2.5 acres of land, a land search must be conducted to identify realistically-sized, connected plots of land that can support the typical size of a given power source. A typical size for a given power source can be highly subjective, and the different power sources have varying land requirements. So the land aggregation process is considered to be the initial sensitivity study for any given power source. Cells that cannot be combined into a larger plot of land to support a representative power plant are "turned off" in the output display. The result is a pared-down base map identifying candidate areas where the power source of interest could realistically be sited. This land aggregation process is discussed in the section titled "Methodology for Aggregating Land for the Typical Plant Size" (Sect. 2.2).

It must be stressed that the net result is a visualization of the candidate areas that could support the power source of interest. This is not meant to suggest an actual plant siting. Little is known of the underlying land ownership, except that the land is generally not in a high-population area, nor in most cases is the land situated on protected land such as a national park or forest. Results are generally stated in the percentage of land amenable to that power source on a contiguous basis, a state basis, or a water basin basis. However, despite these caveats, these candidate area maps are extremely useful because strong estimations of how much energy could subsequently be produced by a given power source are possible using reasonable assumptions. Insights into what power sources are most prevalent or practical in various parts of the contiguous United States are also brought out in this study. 
It should also be noted that in many cases, the actual plant sites selected by a utility would likely be larger. However, not all the land purchased by the utility or an independent power producer needs to meet all the siting SSEC. 


\section{CRITICAL ASSUMPTIONS}

Critical assumptions supporting this work include the supply of cooling water to thermoelectric power generation; a methodology to provide an adequate siting footprint for typical power plant applications; a methodology to estimate thermoelectric plant capacity while accounting for available cooling water; and a methodology to account for future ( 2035) siting limitations as population increases and demands on freshwater sources change.

\subsection{Cooling Water Availability}

A major component of site suitability for thermoelectric power plants is the availability of sufficient cooling water. Stream flow is the primary thermoelectric plant cooling source evaluated in this study. All cooling was assumed to be provided by a closed-cycle cooling (CCC) system requiring makeup water to account for evaporation and blowdown. Limited evaluations of shoreline cooling and the use of municipal processed water (gray) cooling were performed.

The initial phases of work with OR-SAGE considered readily available USGS data on average stream flow to supply the cooling water for all applications of thermoelectric power plants. However, the demands of power generation must be balanced with other consumptive uses, including drinking water needs and industrial and agricultural uses which may draw from those same water sources. With multiple uses, periodic droughts or dry seasons may excessively strain water supplies, which may negatively impact the stream environment and leave a power plant with insufficient cooling water. There are potential economic impacts for thermoelectric power plants running at less than full capacity as a result of cooling water limitations. Therefore, accurate data on stream flows, particularly at low-flow levels, are needed to reasonably evaluate candidate areas for new power plants.

\subsubsection{Creation of a 7-Day, 10-Year Low Flow Data Layer}

USGS has data for 7-day, 10-year low flows (7Q10s) at limited specific locations. A 7-day low flow for a stream location is the average flow measured during the 7 consecutive days of lowest flow during any given year. Subsequently, the 7Q10 is a statistical estimate of the lowest average flow that would be experienced during a consecutive 7-day period with an average recurrence interval of 10 years. Within each calendar year, the annual minimum 7-day mean flow is computed. By collecting all annual minimum flow data together, the lower 10\% quantiles are computed for each selected USGS gage. The 10\% quantile is statistically equivalent to the 10 -year return threshold, in which it represents the lowflow value that is expected to occur once every 10 years. Because it is predicted to recur on average only once in 10 years, it is usually an indicator of low-flow conditions during drought.

As part of the ongoing spatial modeling and suitability analysis work in the ORNL Siting Study, ORNL GIS staff has developed a database of low-flow estimates (7-day annual minimum stream flow average, 10 -year return period) for all segments of most major streams and waterways in the contiguous United States. Low-flow statistics are computed for gages that have at least 10 years of daily stream flow observations (unit in $\mathrm{ft}^{3} / \mathrm{s}$ ). For quality assurance purposes, there must be at least 300 days of valid records within one year; otherwise, the entire year is discarded. USGS has the actual data meeting these requirements at approximately 12,000 selected gages from across the country. USGS has an accepted methodology for estimating ungaged locations, taking into account factors such as drainage area, climate, soil, permeability, and geology. The ORNL GIS staff has applied this USGS methodology to each individual stream segment in the contiguous United States to generate a unique GIS layer for application in this study. 


\subsubsection{Calculation Process}

The low-flow statistics are predicted for ungaged locations using nearby stream gage stations that meet the quality assurance criteria identified earlier. The EPA-USGS National Hydrography Database Plus (NHDPlus) is used as the framework for identifying and spatially locating stream segments and gaging stations, and performing upstream and downstream navigation tasks.

For a given, ungaged stream segment of interest, a list of the nearest gaging stations are identified by navigating upstream into all tributaries and downstream of the stream segment. The closest gages with drainage areas between 0.5 and 1.5 times the drainage area of the location of interest are used. If suitable upstream and downstream gages are found, the flow per unit drainage area at the gages is averaged and multiplied by the drainage area of the ungaged location to estimate the flow. This methodology is similar to the methods described in Ries and Dillow (2006) ${ }^{7}$ and Ries et al. (2009) ${ }^{8}$ and implemented in some USGS StreamStats state applications. The process of identifying suitable gage locations is depicted in Fig. 7.

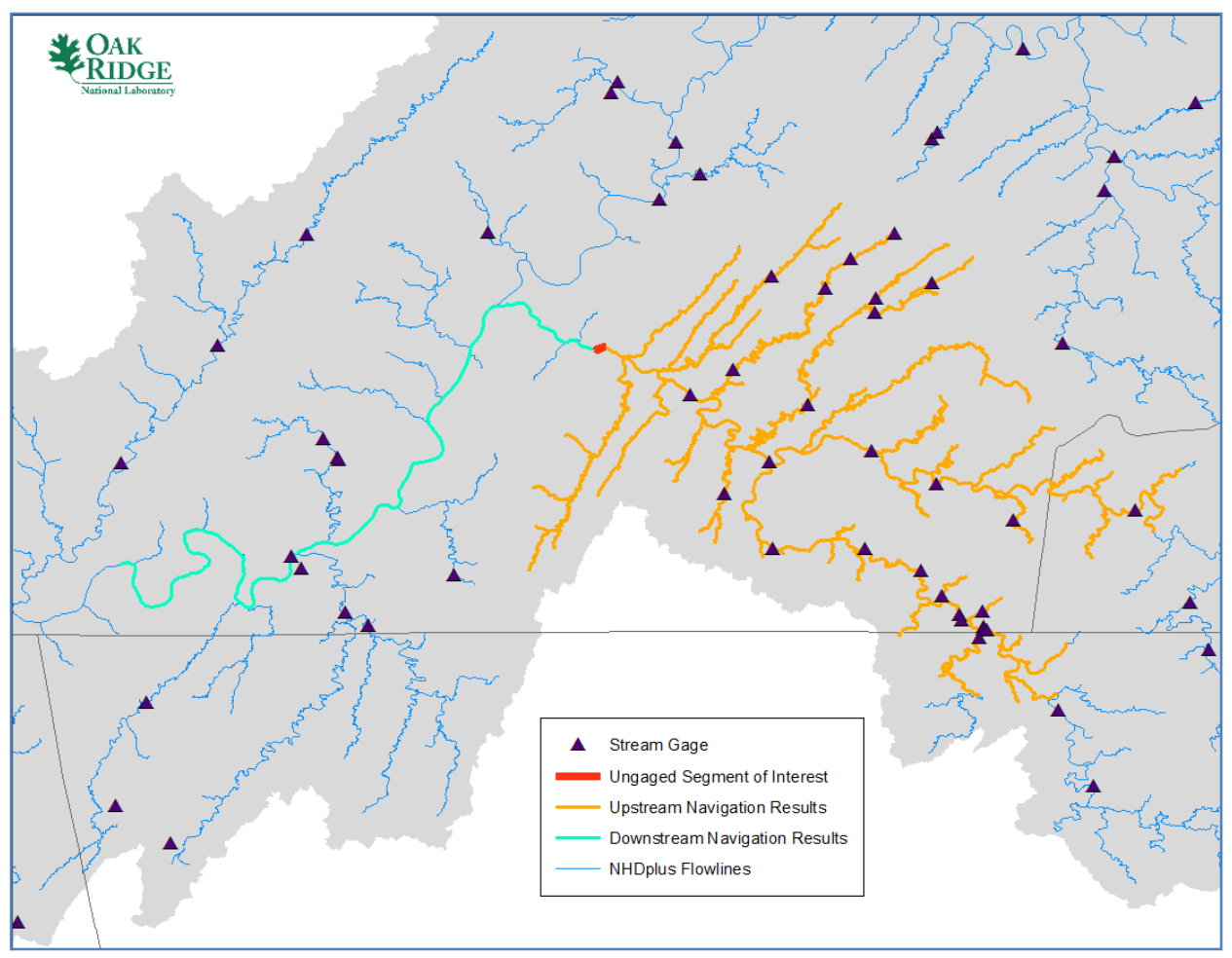

Fig. 7. Sampling an ungaged stream segment of interest.

In order to develop a complete database of flow estimates, the above process is repeated for each stream segment where the NHDPlus predicts a mean annual flow greater than $15 \mathrm{ft}^{3} / \mathrm{s}$ (greater than a small stream). Additionally, low flows are estimated only at locations where suitable gages can be identified.

${ }^{7}$ Ries III, K. G., and Dillow, J. J. A., Magnitude and Frequency of Floods on Nontidal Streams in Delaware, U.S. Geological Survey Scientific Investigations Report 2006-5146, 2006.

${ }^{8}$ Ries III, K. G., Steeves, P. A., Guthrie, J. D., Rea, A. H., and Stewart, D. W., "Stream-Network Navigation in the U.S.

Geological Survey StreamStats Web Application," Proceedings of the 2009 International Conference on Advanced Geographic Information Systems and Web Services, 2009. 
The smaller streams are discarded from consideration as locations of interest because they are unlikely to meet cooling water requirements for power plants.

The results provide a realistic estimate of potentially available stream flows and conditions that could impact site suitability and have been created in a consistent and unified format for the contiguous United States. The methodology assumes a natural flowing stream, so caution should be used on regulated streams where a dam regulation could change the flows.

\subsubsection{Composite Stream Flow GIS Layer}

A drawback to this methodology is that lakes and reservoirs that are suitable for providing cooling water to thermoelectric plants tend to drop out of consideration. This occurs as a result of flow parameters and drainage field differences. If the OR-SAGE tool siting were to rely only on the calculated 7Q10 data, the subsequent candidate area selection would become extremely conservative. Fortunately, the average stream flow USGS data do not preclude lakes and reservoirs. Therefore, to provide a more representative cooling water data set, the USGS average stream flow data in which lakes and reservoirs are identified are combined with the calculated 7Q10 results to provide a composite flow GIS layer with more realistic cooling water provisions. While this composite stream flow dataset is not meant to replace detailed, sitespecific environmental reports, it provides nationally consistent input into screening candidate areas for power generation options and further modeling efforts.

\subsubsection{Impact of the Selection of Cooling Water Flow Calculation}

The selection of an appropriate stream flow SSEC layer has a dramatic effect on the overall available land for each power source. Average stream flow data is readily available, but the data over predict minimum available water. As described in the previous sections, the 7Q10 data tend to more realistically predict the minimum flow conditions, but significant sources of cooling water are not considered. The composite data layer strikes a reasonable stream flow compromise. A comparison of large reactor plant base map results gives insight to the significance of the cooling water flow calculation.

Figure 8 depicts all the stream segments that meet the minimum flow requirement for a large reactor application based on average stream flow results. The minimum flow value is set at $200,000 \mathrm{gpm}^{9} \mathrm{based}$ on the size of the large reactor plant. This SSEC value is discussed further in the large nuclear reactor results section. Figure. 8 indicates that a significant portion of the waterways in the United States meet this minimum flow requirement based on average stream flow.

\footnotetext{
${ }^{9}$ National Energy Technology Laboratory, Water Requirements for Existing and Emerging Thermoelectric Plant Technologies, DOE/NETL-402/080108, prepared for the U.S. Department of Energy, August 2008 (Revised April 2009).
} 


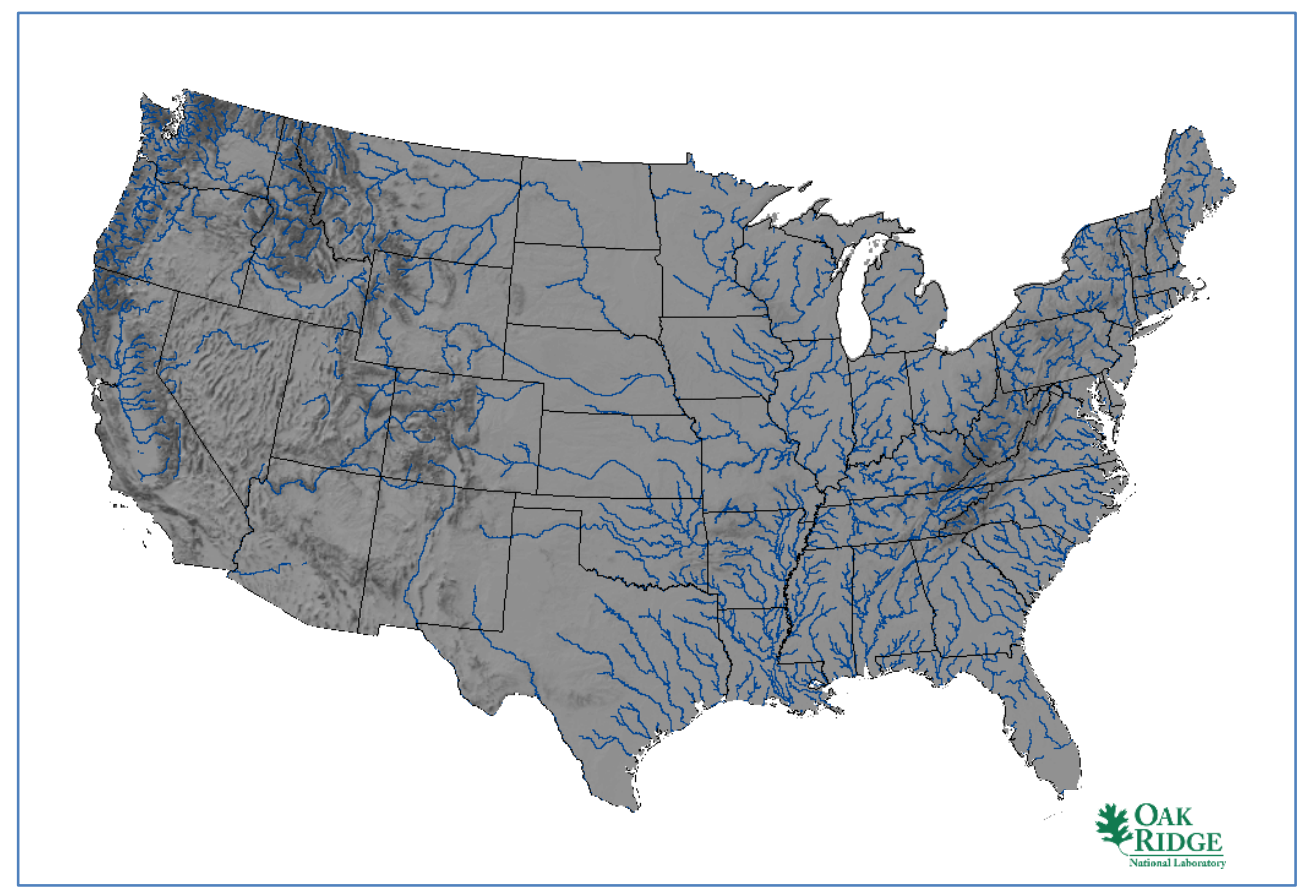

Fig. 8. Large reactor stream flow lines with mean annual flow $\geq 200,000 \mathrm{gpm}$.

The resulting base map developed using average stream flow, as shown in Fig. 9, illustrates that 33\% of the contiguous United States is available as candidate areas to support the siting of a large nuclear power plant based on being within 20 miles $^{1}$ of adequate stream flow. Areas in green represent areas that have no siting challenges based on the selected input criteria. The density of green in Fig. 9 is reflective of how tightly packed the individual cells without siting challenges are situated on the map.

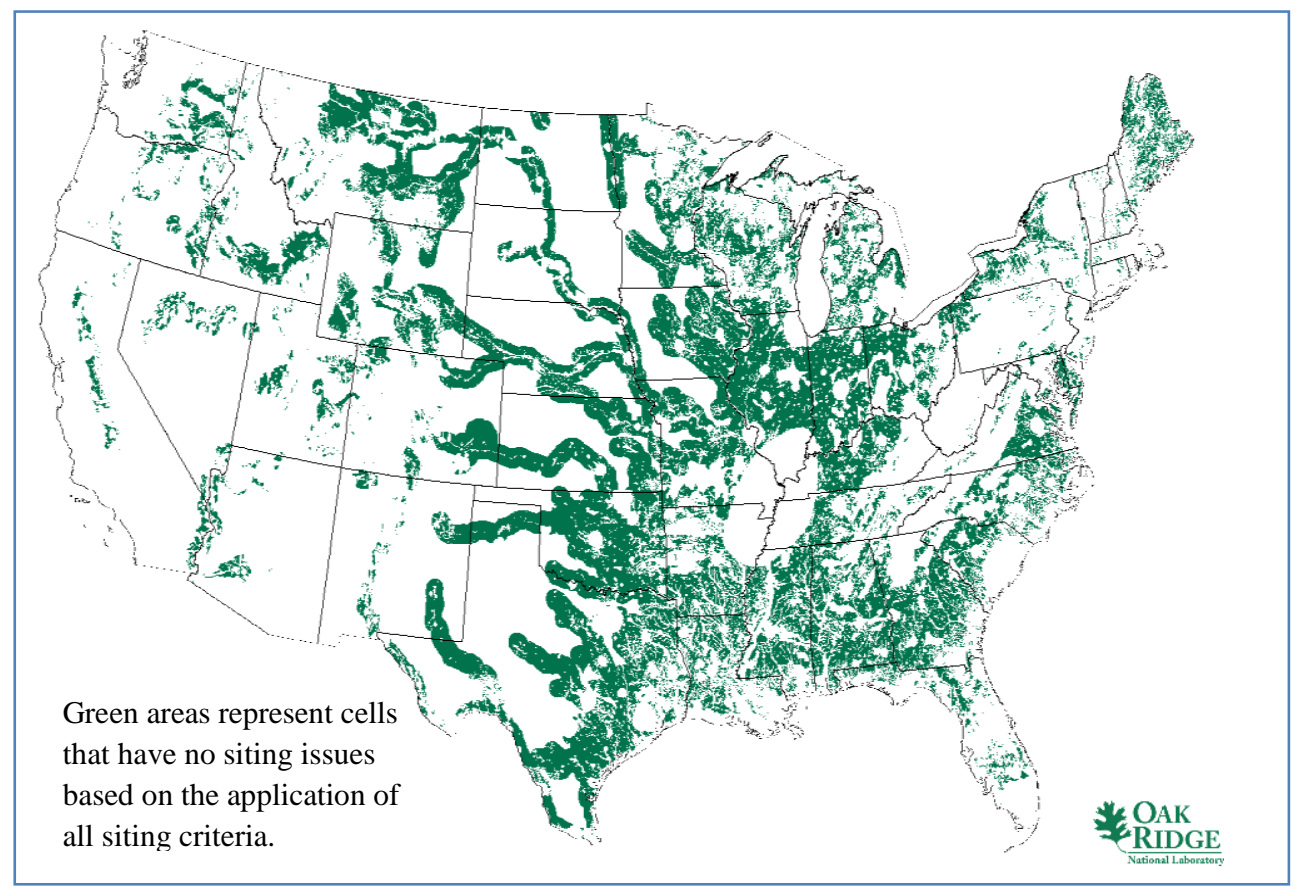

Fig. 9. Large reactor base map using mean annual flow SSEC $\geq 200,000 \mathrm{gpm}$. 
However, the results decrease significantly when the strict 7Q10 stream flow data are substituted for average stream flow. Figure 10 depicts all the stream segments that meet the minimum flow requirement for a large reactor application based on 7Q10 stream flow results. The minimum flow value remains set at $200,000 \mathrm{gpm}$. Figure 10 indicates that only a small portion of the waterways in the United States meet this minimum flow requirement based on 7Q10 stream flow.

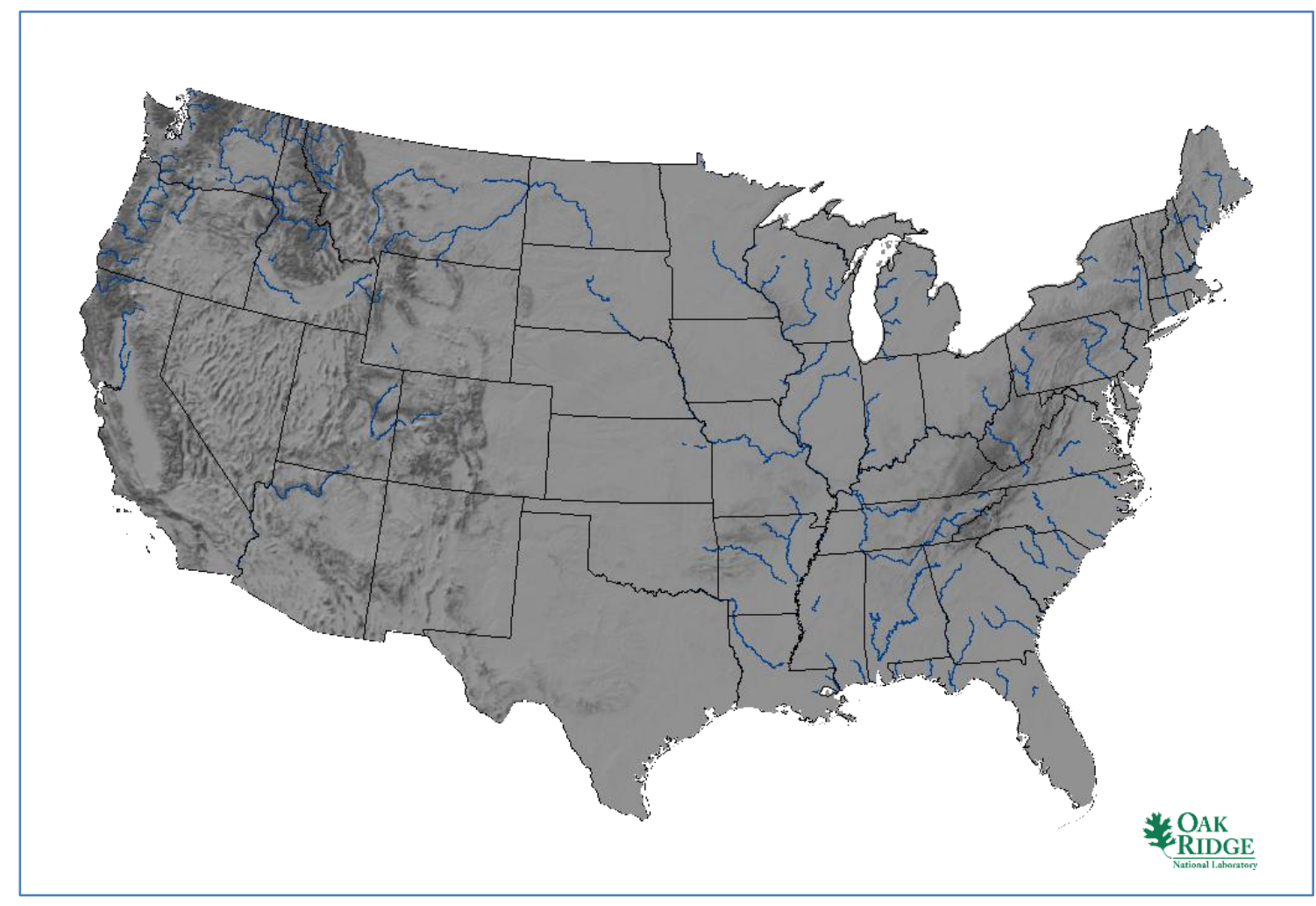

Fig. 10. Large reactor stream flow lines with calculated 7-day, 10 -year low flow $\geq 200,000 \mathrm{gpm}$.

The resulting base map developed using 7Q10 stream flow, as shown in Fig. 11, illustrates that only 12\% of the contiguous United States is available as candidate areas to support the siting of a large nuclear power plant based on being within 20 miles of adequate stream flow. Again, areas in green represent areas that have no siting challenges based on the selected input criteria. This is one-third the available land compared to the base map relying on average stream flow. 


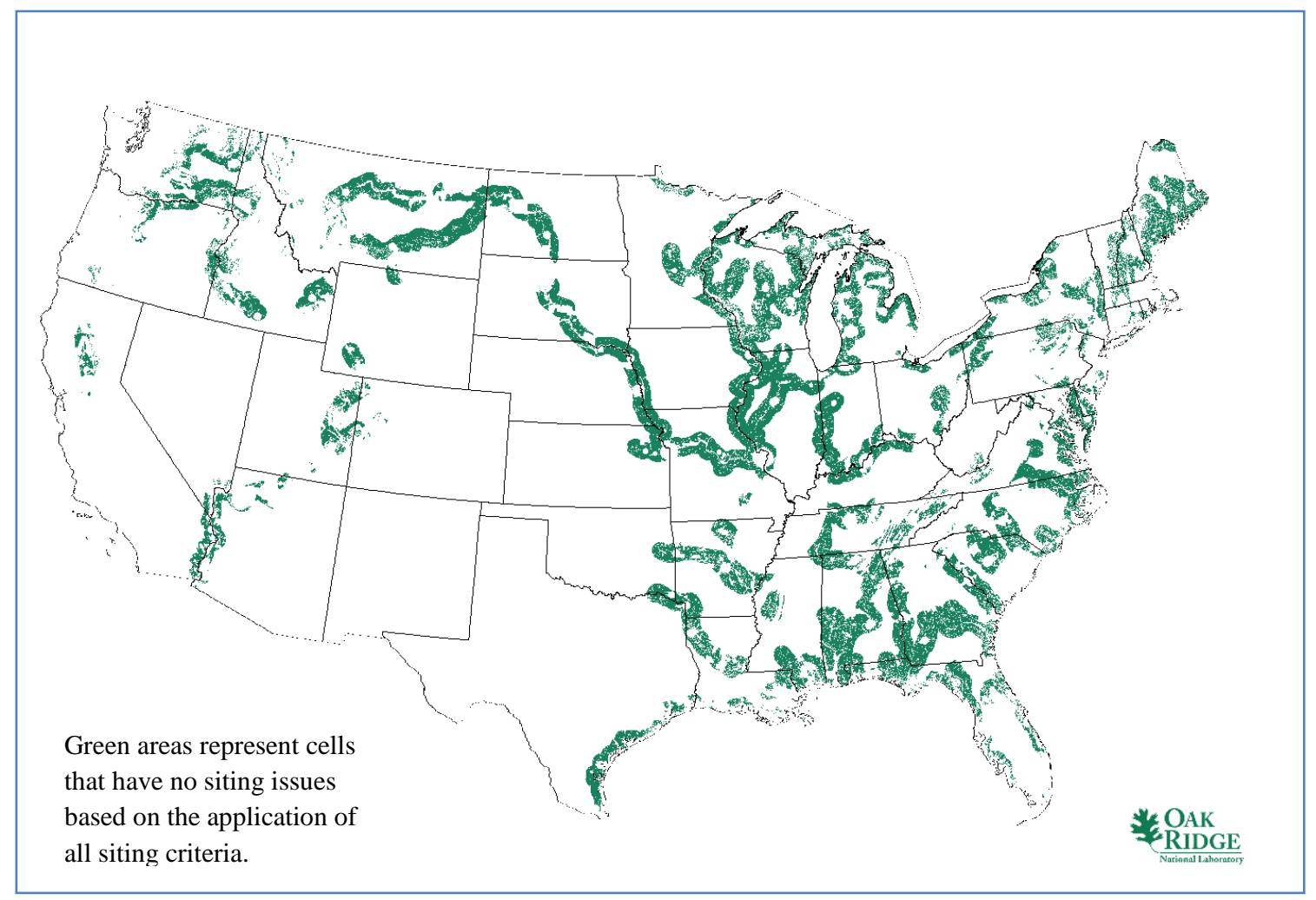

Fig. 11. Large reactor base map using calculated 7-day, 10-year low flow SSEC $\geq 200,000$ gpm.

As expected, the results improve when the composite flow layer is substituted for 7Q10 stream flow. Figure 12 depicts all the stream segments that meet the minimum flow requirement for a large reactor application based on composite stream flow results. As in the previous examples, the minimum flow value remains set at 200,000 gpm. Figure 12 indicates that more of the waterways in the United States now meet this minimum flow requirement based on composite stream flow, though less than the results based strictly on average flow.

The resulting base map developed using 7Q10 stream flow, as shown in Fig. 13, illustrates that 22\% of the contiguous United States is available as candidate areas to support the siting of a large nuclear power plant based on being within 20 miles of adequate stream flow. This splits the results obtained from average stream flow and strict 7Q10 stream flow. By comparing green space with Fig. 9 and Fig. 11, Fig.Fig. 13 provides visual evidence of the compromise between strict use of the average flow data and the low flow data.

Similar results are obtained for the other thermoelectric power plant sources under consideration. So, the low flow (7Q10) calculation provides a lower bounding limit on stream flow, while the average stream flow calculation provides an upper bounding limit on stream flow. Since lakes and reservoirs provide an adequate thermoelectric power plant cooling source that is more drought resistant, especially if flow is controlled, the composite GIS layer for stream flow was determined to be the most realistic representation of stream flow to use for OR-SAGE modeling. The bounding limits provide readily available GIS layers that can be substituted for conducting sensitivity studies. 


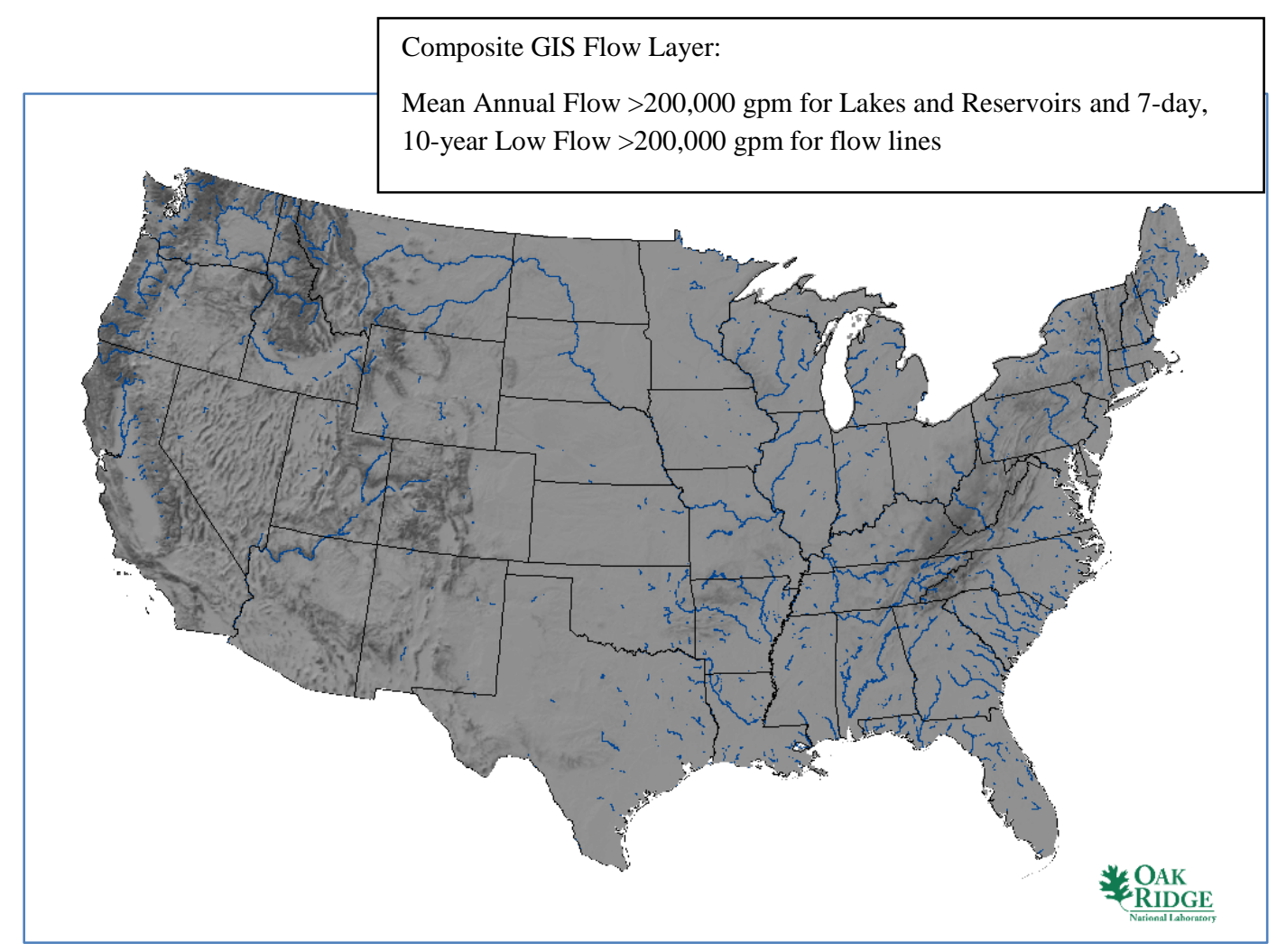

Fig. 12. Large reactor stream flow lines with composite flow $\geq \mathbf{2 0 0 , 0 0 0} \mathbf{g p m}$.

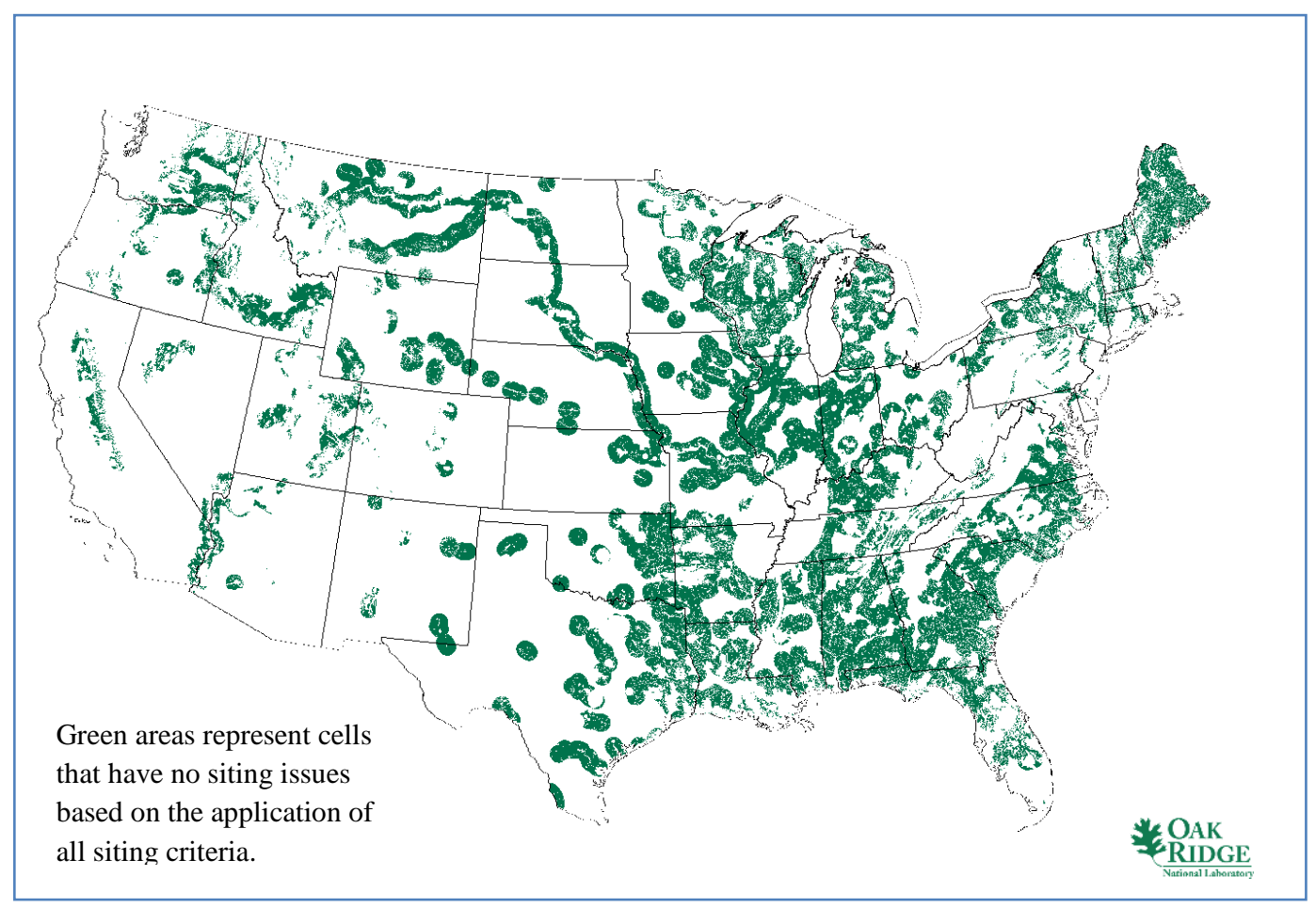

Fig. 13. Large reactor base map using composite flow $\mathrm{SSEC} \geq \mathbf{2 0 0 , 0 0 0} \mathrm{gpm}$. 
Table 1 provides a comparison of the candidate land areas available as a percentage of the total land in the contiguous United States for the various thermoelectric plants under consideration.

Table 1. Unaggregated power source land based on various stream flow values

\begin{tabular}{lcccc}
\hline \multicolumn{1}{c}{ SSEC using } & $\begin{array}{c}\text { Large reactor } \\
\text { \% US land }\end{array}$ & $\begin{array}{c}\text { Small reactor } \\
\text { \% US land }\end{array}$ & $\begin{array}{c}\text { Advanced coal } \\
\text { \% US land }\end{array}$ & $\begin{array}{c}\text { Solar (wet) } \\
\text { \% US land }\end{array}$ \\
\hline $\begin{array}{l}\text { Average stream } \\
\text { flow }\end{array}$ & $33 \%$ & $41 \%$ & & Not Calculated \\
$\begin{array}{l}\text { Strict low stream } \\
\text { flow (7Q10) }\end{array}$ & $12 \%$ & $19 \%$ & & \\
$\begin{array}{l}\text { Composite stream } \\
\text { flow }\end{array}$ & $22 \%$ & $31 \%$ & $21 \%$ & $6 \%$ \\
\hline
\end{tabular}

\subsection{Methodology for Aggregating Land for the Typical Plant Size}

As stated previously, the GIS spatial modeling process reports results based on 100 by $100 \mathrm{~m}$ cell sizes, or approximately 2.5 acres per cell. This does not provide an adequate footprint for most power plant applications. Thus it was necessary to develop an algorithm to aggregate individual cells into a sufficient land size to support the power source under consideration. It was understood that a given utility may choose to purchase and provide a large land mass around a given power production source. However, not all of the utility-owned land would need to meet the specific SSEC to support the chosen power source. Therefore, it was important to propose a reasonable core footprint size to meet all SSEC for a given power source. The core footprint sizes selected for each power source were based on engineering judgment and are shown in Table 2. The land aggregation process is actually the first sensitivity study for a given power source, because the minimum footprint assessment is subjective.

Table 2. Power source minimum footprint

\begin{tabular}{lc}
\hline \multicolumn{1}{c}{ Power source } & Minimum footprint meeting all SSEC (acres) \\
\hline Large nuclear plant & 500 \\
Small nuclear plant & 50 \\
Advanced coal plant & 300 \\
Concentrated solar (commercial application) & 500 \\
CAES & 10 \\
\hline
\end{tabular}

\subsubsection{Basic Approach to Collect GIS Cells}

It was assumed that a square footprint was a reasonable footprint representation. This greatly simplified the algorithm and computation time required to aggregate the GIS cells into blocks of land that could support a given power source. A power source square consists of enough 100 by $100 \mathrm{~m}$ cells on a side to ensure that the minimum footprint size would be captured within the square. For example, a concentrated solar square would be 15 GIS cells on a side and actually encompass approximately 556 acres of land.

Subsequently, all the cells inside the power source core footprint square under evaluation must pass all of the SSEC for that power source, for all of the cells in the entire square to be considered available for the 
power source. Figure 14 shows two simple examples; one clearly fails because no cells in the red square (representing a core footprint for a nondescript power generation source) under consideration pass all the SSEC for that power supply. The second clearly passes because all the cells within the red square pass all the SSEC. This process is repeated for the entire contiguous United States by moving the core footprint land-aggregation square one complete square length (i.e., 9 cells in this simple example) to the right or one complete square height (i.e., 9 cells in this example) down and evaluating the GIS cells within the square.

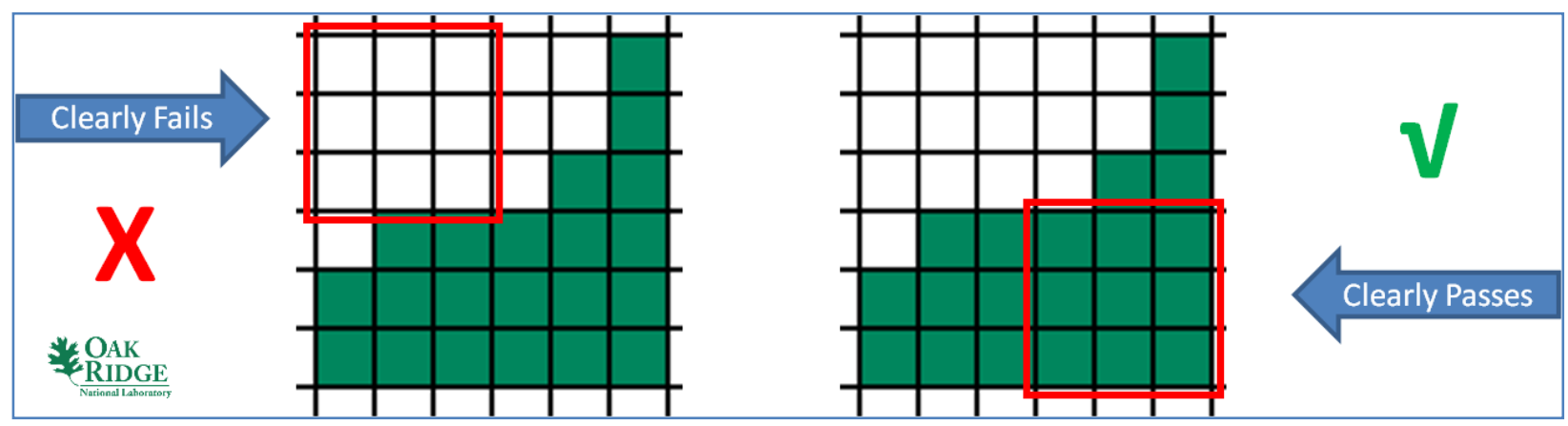

Fig. 14. Simple land aggregation process examples.

If any GIS cells within the land-aggregation square do not pass all of the SSEC for that power source, then all the GIS cells being evaluated are considered to fail the sensitivity analysis for land aggregation. This net result of the sample land aggregation process is shown in Fig. 15. The lower left corner (red square) land aggregation sensitivity evaluation fails because one of the nine cells in the sample case fails at least one SSEC. The upper right corner (red square) land aggregation sensitivity evaluation fails because five of the nine cells in the sample case fail at least one SSEC. The net effect of the land aggregation sensitivity analysis is shown in the lower right corner of Fig. 15. Based on how the landaggregation square hits the region of land under consideration in the example case shown, only the nine GIS cells in the lower right corner of the region pass the land aggregation sensitivity study for the power source under consideration. Therefore, in this 36-cell GIS region, only the nine GIS cells shown in green would continue to be viable for placement of the power source under consideration.

This process causes a very conservative estimation of the land available for the prospective placement of a given power source. Therefore, some less conservative alternatives were considered.

One approach is to move the land-aggregation square one row or one column at a time and repeat the aggregation evaluation. In the sample case shown in Fig. 15, this would result in an additional 6 GIS cells being included in the land aggregation study results. Although this would greatly increase the presumed accuracy of the results, the computational time associated with this approach would also increase substantially. The power of OR-SAGE is its ability to quickly adjust individual SSEC layer limits and reevaluate the results. Despite the presumed increase in accuracy from using this approach, the substantial wait time between results would likely lead to less use of OR-SAGE for the intended purpose of identifying candidate areas for use of a given power source or mix of power sources. 


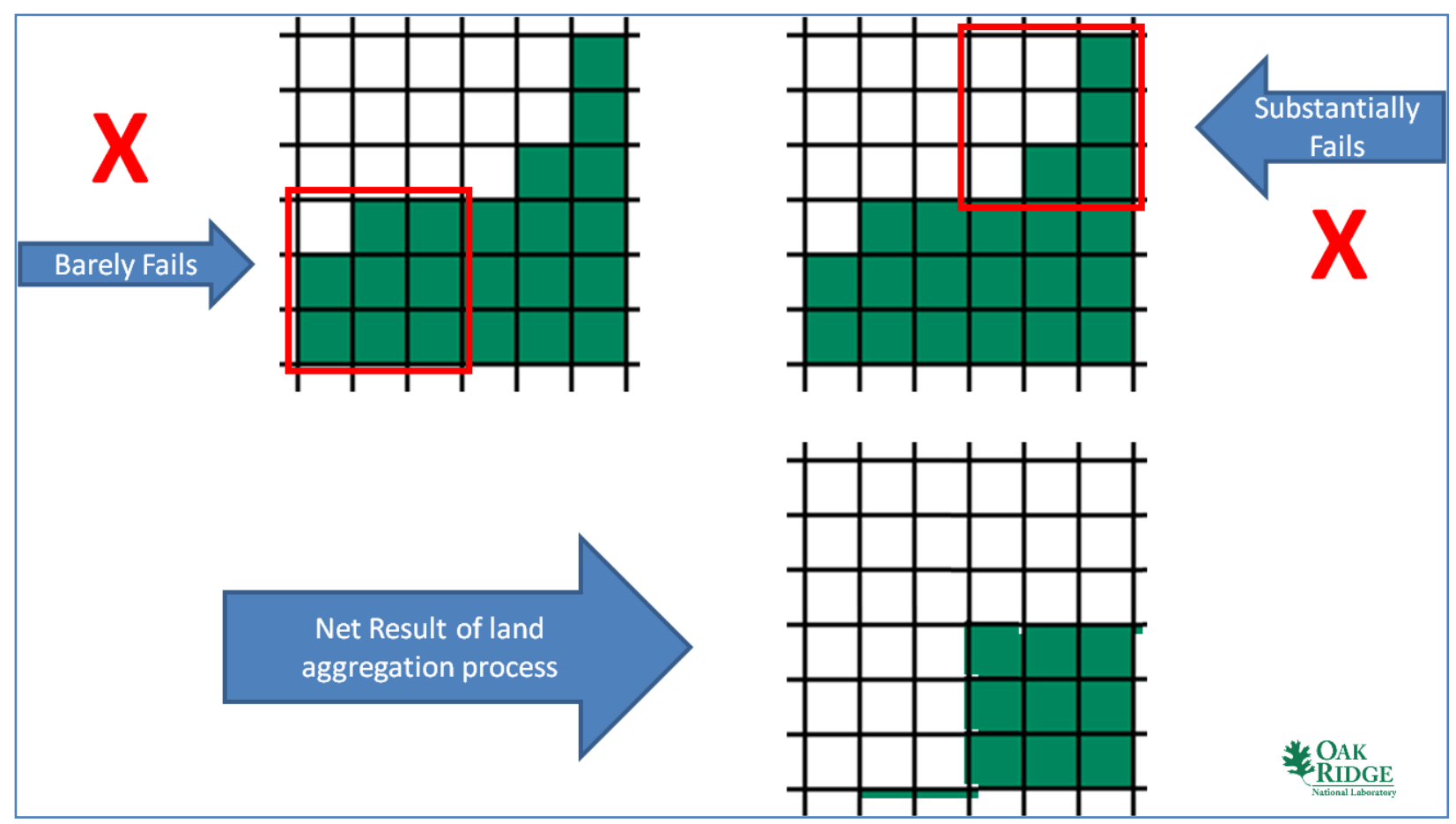

Fig. 15. Sample land aggregation process results over a larger area.

Another approach is to consider each individual GIS cell that passes and draw a different shape, such as a circle, around the cell that encompasses the exact acreage assumed for each power source. This might result in fewer GIS cells evaluated per shape, since the square approach tends to include additional GIS cells to ensure that the minimum acreage is covered. The advantage of this approach would be that fewer near-miss GIS cell eliminations would occur, such as the upper left evaluation in Fig. 15. However, as with the previous approach, this would be computationally intense and, therefore, reduce the effectiveness and efficiency of the OR-SAGE tool.

A third approach was to reconsider the stringent requirements made on the simple square approach that required all GIS cells under consideration to pass in order for the GIS cells to be retained for consideration of potential power plant location. This approach is discussed in the next section.

\subsubsection{Alternative Approach to Collect GIS Cells}

Though the examples shown in Fig. 14 and Fig. 15 are simplified and show only an evaluation of nine GIS cells at a time, it is not unreasonable to consider allowing a handful of failed GIS cells within the land-aggregation evaluation square without failing the entire square. For example, if one square were allowed to fail the land aggregation screening process in the simplified case above without causing all the GIS cells under consideration to be failed, then the revised results would be as shown in Fig. 16. 


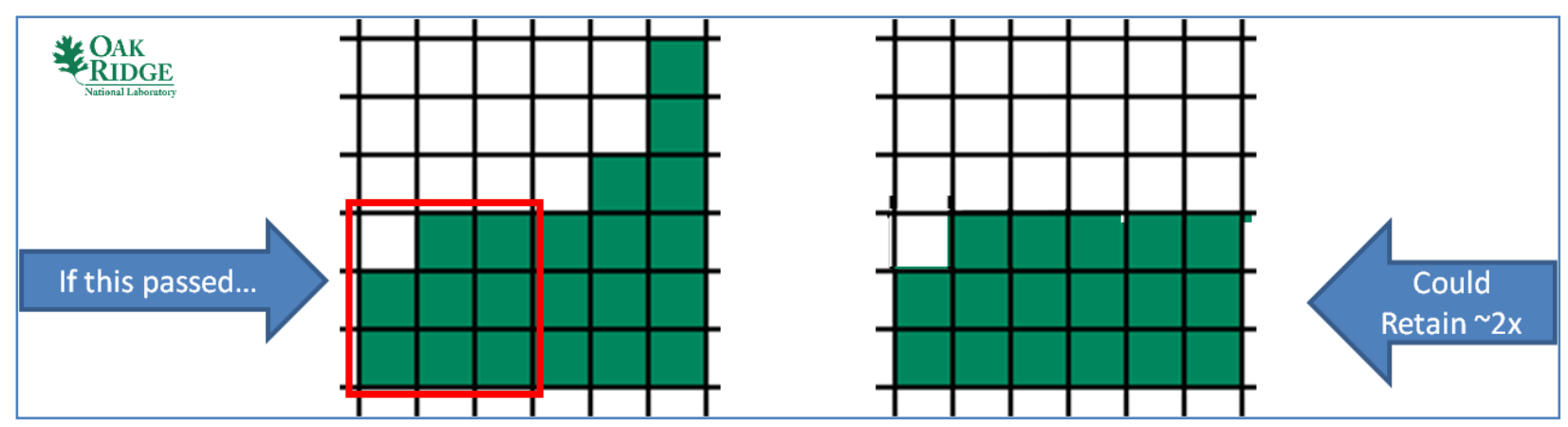

Fig. 16. Land aggregation example results with consideration for small flaws.

Only one cell fails in the left example shown in Fig. 16. Therefore, eight of the nine GIS cells are retained from this land-aggregation square and are added to the nine GIS cells previously retained. This results in a substantial increase in the number of GIS cells available for potential placement of a power source. Note that the single GIS cell or "hole" that fails is not turned green in the land aggregation sensitivity result because it actually failed one or more SSEC for that power source.

For the purposes of this study, it was assumed that if no more than $10 \%$ of the GIS cells failed within the aggregation square for a given power source, then the GIS cells that did pass all SSEC could be retained as part of the land aggregation sensitivity analysis. In the case of a 500 acre land requirement, 556 acres is actually analyzed with each land-aggregation square. If no more than $10 \%$ of this land mass is allowed to fail one or more SSEC, then at least 500 acres is actually retained, albeit with a few holes. However, this allows a significant increase in the retained land for candidate power source areas.

Figure 17 shows the results of a plant aggregation sensitivity analysis on a 500 acre power source. The areas shown in dark green (solid, no white) are land-aggregation square blocks that contain GIS cells that have no siting challenges based on the selected SSEC input parameters. The lighter green areas with white spaces represent land-aggregation square blocks that failed the initial land aggregation screening based on one or more GIS cell SSEC siting challenges within the land aggregation square.

Figure 18 shows the added 500-acre land-aggregation square blocks that pass the land aggregation sensitivity analysis when up to $10 \%$ of the GIS cells within the land aggregation square are allowed to fail one or more SSEC for that power source. The additional 500-acre blocks identified in Fig. 18 are shown in solid light blue for illustration purposes. The individual GIS cells with one or more siting challenges in these light blue areas would actually be retained as failed and would ultimately be shown as white space. The light green areas in Fig. 18 with white space are those 500-acre blocks where more than $10 \%$ of the GIS cells had one or more siting challenges for that power source. 


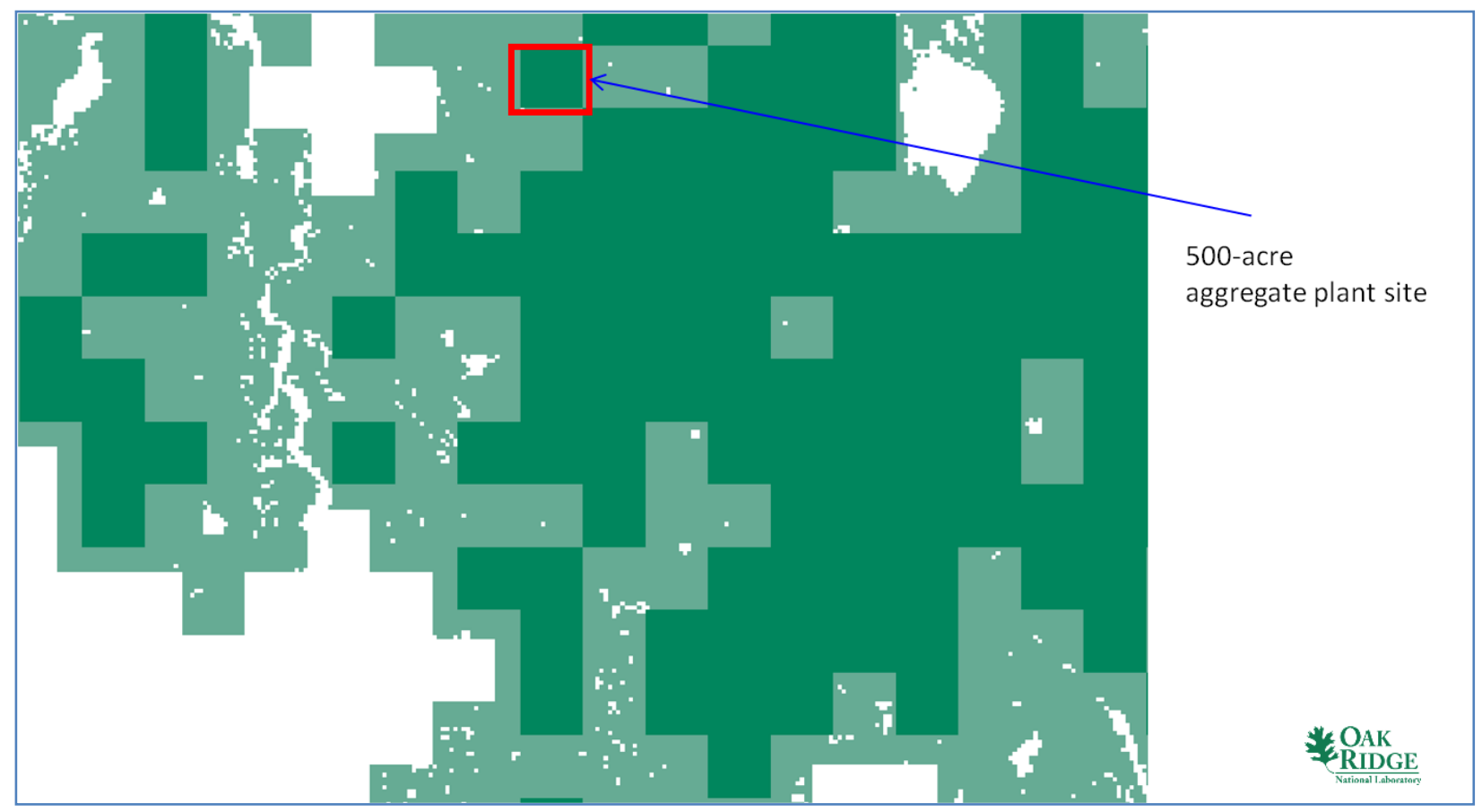

Fig. 17. Sample 500-acre aggregation results with no cells with siting challenges.

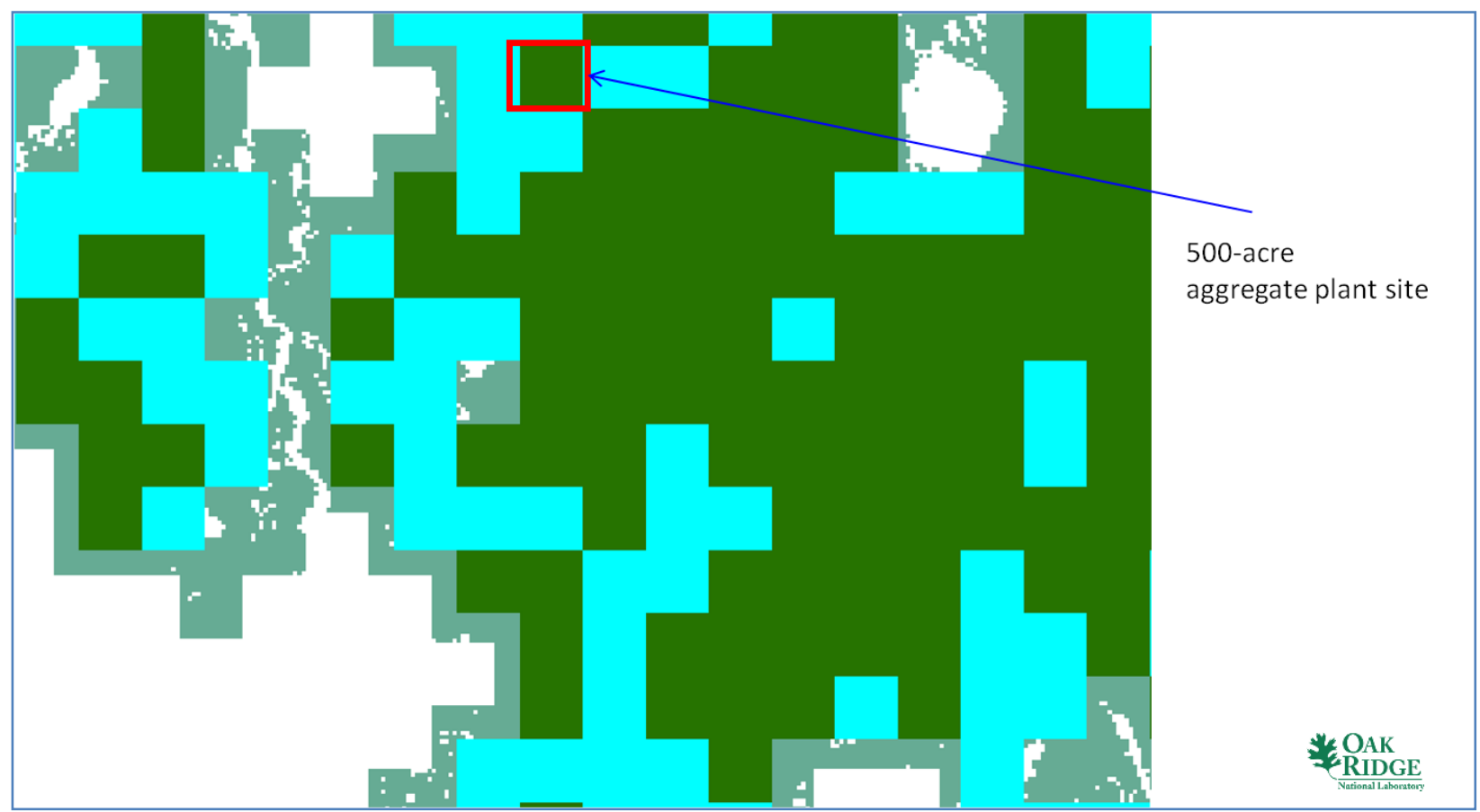

Fig. 18. Sample 500-acre aggregation results with less than $10 \%$ cells with siting challenges.

This alternate land aggregation methodology strikes a reasonable balance between the very conservative requirement that all GIS cells within the land-aggregation square pass all SSEC for the power source, and the more computationally intense alternatives. Therefore, with the exception of the CAES footprint, this is the land aggregation methodology used in this study. The CAES footprint is only 10 acres and is not 
amenable to this approach because of the small number of GIS cells that makeup the CAES footprint. The results of using this approach are shown in Table 3 for all of the power sources considered in this study.

Table 3. Contiguous US land available for two sample power sources

\begin{tabular}{lcccccc}
\hline $\begin{array}{c}\text { Land available for power } \\
\text { plant placement } \mathbf{\%} \\
\text { contiguous US land) }\end{array}$ & $\begin{array}{c}\text { Large } \\
\text { reactor }\end{array}$ & $\begin{array}{c}\text { Small } \\
\text { reactor }\end{array}$ & $\begin{array}{c}\text { Advanced } \\
\text { coal }\end{array}$ & $\begin{array}{c}\text { Water- } \\
\text { cooled } \\
\text { solar }\end{array}$ & $\begin{array}{c}\text { Dry- } \\
\text { cooled } \\
\text { solar }\end{array}$ & CAES \\
\hline Initial base map & $22 \%$ & $31 \%$ & $21 \%$ & $6 \%$ & $18 \%$ & $42 \%$ \\
$\begin{array}{l}\text { Aggregate map-100\% pass } \\
\text { rate }\end{array}$ & $5 \%$ & $19 \%$ & $8 \%$ & $2 \%$ & $7 \%$ & $40 \%$ \\
$\begin{array}{l}\text { Aggregate map-90\% pass } \\
\text { rate }\end{array}$ & $13 \%$ & $24 \%$ & $16 \%$ & $4 \%$ & $12 \%$ \\
\hline
\end{tabular}

Table 3 shows that for the large reactor example, more than $75 \%$ of the GIS cells initially identified as suitable are discarded in the aggregation sensitivity analysis with a requirement that $100 \%$ of the GIS cells within the land-aggregation square must pass all SSEC. Less than half of the large reactor GIS cells are discarded in the sensitivity analysis where at least $90 \%$ of the GIS cells within the land-aggregation square must pass all SSEC. Other power generation results are similar, but less striking. This is a result of the initial size of the base map and the standard plant footprint.

\subsection{Plant Placement Algorithm for Water-Dependent Power Sources}

The principle goal of using the OR-SAGE tool is to evaluate electrical generation deployment options now and in the future by focusing on the identification of potential areas for siting a mixture of new electrical energy resources. This is accomplished by identifying candidate areas for the placement of various power sources and not by promoting the actual siting of any particular power source on a specific site. Nonetheless, a plant placement algorithm was developed to investigate the capacity of various regions in the contiguous United States to host the variety of power sources under review. The algorithm developed for large and small reactor plant placement is shown in Fig. 19. However, the algorithm shown is the same for any thermoelectric plant placement.

The contiguous United States is divided into 18 water regions or basins. Starting at the headwaters, each of these water regions is evaluated for adequate flow to support the cooling makeup water requirements for a typically sized power source of interest, without taking more than $10 \%$ of the available stream flow at any given point to support a given power source. ${ }^{1}$ Where stream flow is adequate to support a typical power plant placement and all other SSEC are satisfied, including appropriate land aggregation for the power source under investigation, a single power plant placement is proposed by the algorithm. The available stream flow is correspondingly debited to account for the makeup water use associated with the nominal power plant placement for the power generation source under review. The algorithm continues to search for the next available downstream spot that again meets the minimum flow requirements, while requiring that at least 20 miles exist between power plant placements. The 20 -mile minimum helps to ensure plant placement is spread throughout a region for a more reasonable prediction of regional capacity by a given power source. While it is not modeled in the capacity estimate algorithm, it is understood that economies of scale may drive a utility toward multiunit siting of a power generation source. This is well bounded by the capacity estimate algorithm, which closely tracks cooling water capacity. The algorithm continues until all stream segments in a given water basin have been evaluated. Typical thermoelectric plant stream flow requirements are shown in Table 4. Each typical thermoelectric plant is evaluated independently by the algorithm. 


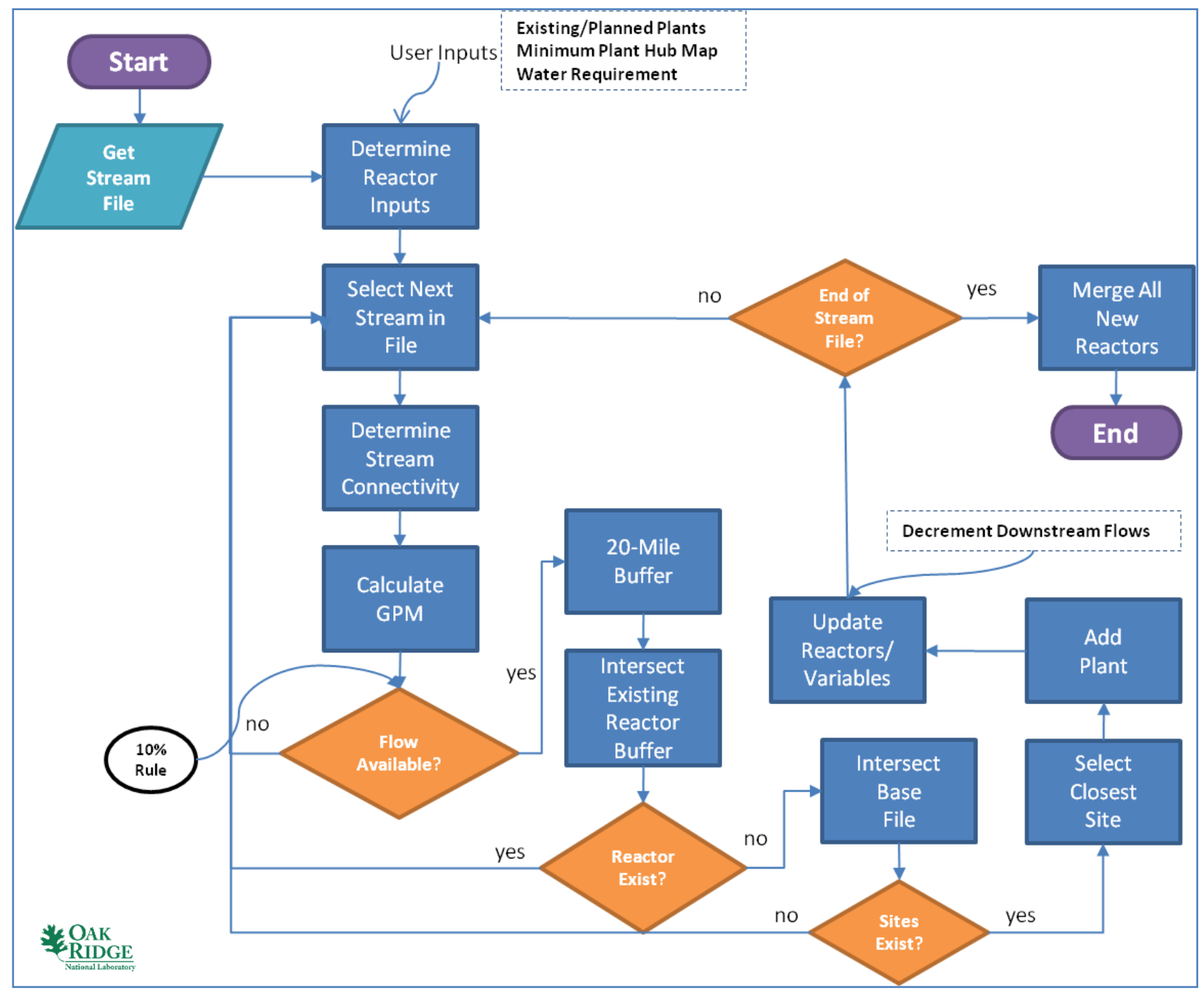

Fig. 19. Flowchart for thermoelectric power source placement algorithm.

Table 4. Typical thermoelectric plant installations

\begin{tabular}{lcc}
\hline \multicolumn{1}{c}{ Typical thermoelectric plants analyzed } & $\begin{array}{c}\text { Makeup water } \\
\text { requirement (gpm) }\end{array}$ & $\begin{array}{c}\text { Stream flow } \\
\text { requirement (gpm) }\end{array}$ \\
\hline $1600 \mathrm{MW}(\mathrm{e})$ nuclear plant & 20,000 & 200,000 \\
$350 \mathrm{MW}(\mathrm{e})$ nuclear plant & 5,000 & 50,000 \\
$550 \mathrm{MW}(\mathrm{e})$ advanced coal plant & 12,500 & 125,000 \\
$100 \mathrm{MW}(\mathrm{e})$ water-cooled concentrated solar plant & 1,500 & 15,000 \\
\hline
\end{tabular}

Plant placement is completely unbiased relative to load demand. The capacity estimate algorithm begins its search at the first available site in the water region headwaters and moves downstream from there. Shifting the initial plant placement upstream or downstream will affect all subsequent proposed plant 
placements and could affect the regional capacity; especially when capacity is broken out by areas defined differently from the water basin that was analyzed, such as a state map overlay. Figure 20 shows a comparison of US states versus the 18 water regions. Subsequent EPRI economic analyses necessitated reporting results on a state level.

In some cases, a water supply provides the boundary between states, and the plant placement projection will choose a specific side of the river. This will affect the estimate of power from that source when viewed on a state level. Note that the algorithm goal is a conservative prediction of regional capacity and not an accurate and efficient placement of typically sized thermoelectric plants. Results based on water regions are considered to have less uncertainty based on the methods used by the OR-SAGE tool.

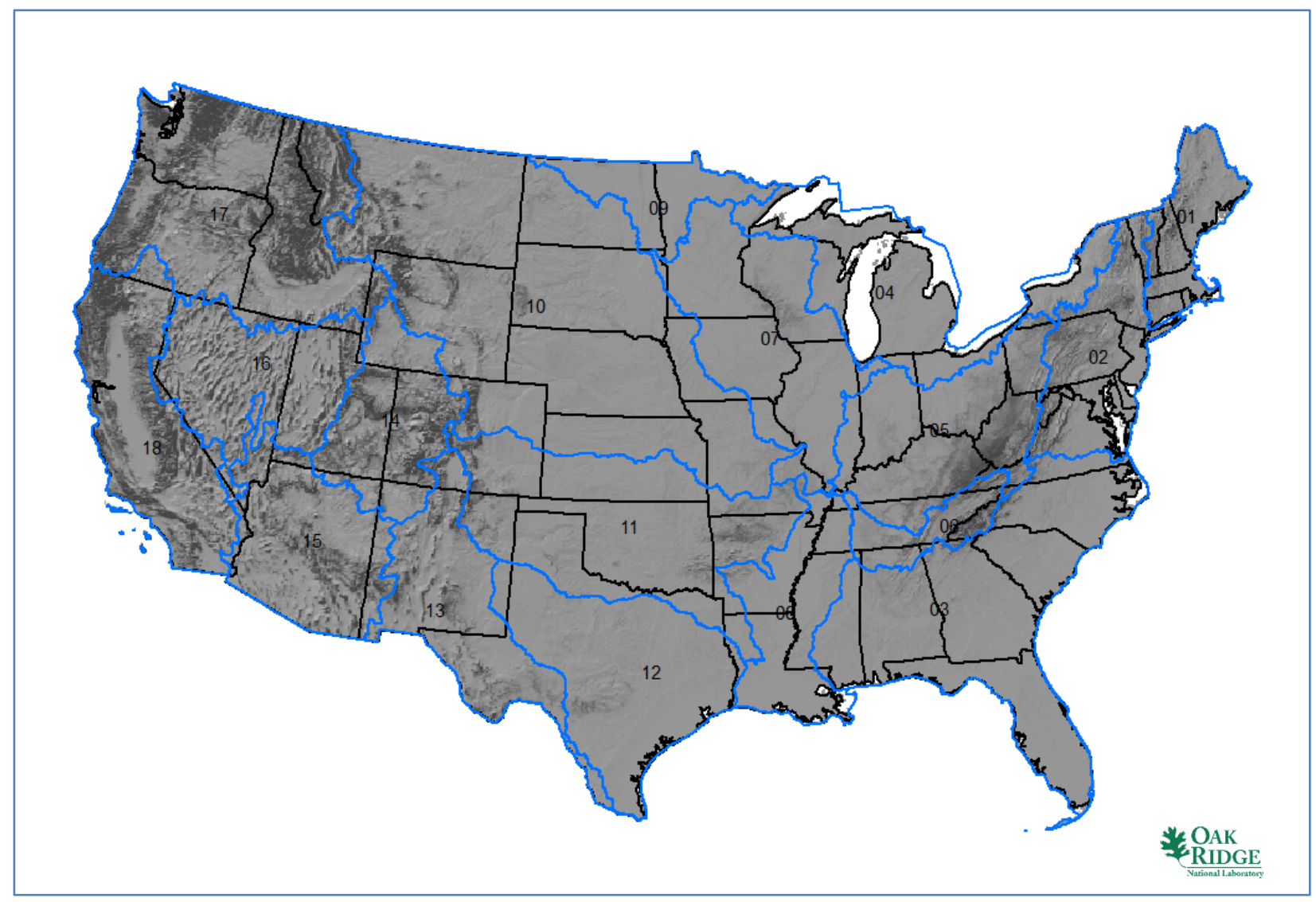

Fig. 20. State map overlay on 18 water basins.

\subsection{Assumptions}

EPRI desired a prediction of candidate plant areas 25 years in the future. Several effects were discussed to characterize 2035, including population shifts and growth, climate change effects, and increased plant hazards, such as new refineries, airports, and pipelines. GIS projections are only as good as the underlying data and trends. US census data are appropriate to estimate population shifts and growth. However, climatologists disagree on the regional effects of climate change in terms of wetter regions and drier regions, which would impact stream flow. Likewise, the specific locations of new hazards 25 years in the future are not known below a regional level. For example, a May 2007 FAA report ${ }^{10}$ on future airport

\footnotetext{
${ }^{10}$ The MITRE Corporation, Capacity Needs in the National Airspace System 2007-2025, prepared for the Federal Aviation Administration, May 2007.
} 
demand and operational capacity cited regions where new airports would likely be necessary, but obviously provided no data that a GIS study could pinpoint and utilize.

\subsubsection{Population}

National level population shifts and trends to 2035 vary widely depending on regional and state fluctuations. While population projections produced at a county level would presumably provide a better account of varying growth trends across a state, this level of information is available only for a small number of counties across the United States. As a result, state-level population projections were used to develop the 2035 data. The US Census currently provides nationwide state-level population projections only out to the year 2030. Although some individual states produce their own projections out to 2035 and beyond, in order to maintain consistency across the United States, the Census projections ${ }^{11}$ were used. As a means to project the data past 2030, the national-level interim projections developed by the US Census ${ }^{12}$ were used as an extrapolation point, assuming similar growth rates for all states from 2030 to 2035. Three annual data points were used from this data: 2009, 2030, and 2035. The 2009 data point was used as a reference point to align with the LandScan 2009 dataset. The 2030 data point was used to align to the sum of the state-level estimates for 2030. The 2035 data were used as the target for extrapolation. State-level data for 2030 were extrapolated to 2035 projections so that the sum of the states normalized to the 2035 total taken from US Census interim projections. ${ }^{12}$

The LandScan 2009 dataset was used as a basis for the dasymetric modeling (a method for mapping population density) of the 2035 data to 30 arc-second resolution (roughly $1 \mathrm{~km}$ ). Developed areas consistent with LandScan 2009 were assumed, and the extrapolated 2035 state-level projections were then distributed to individual 30 arc-second cells. A pychnophylactic interpolation method was used to ensure that the sum of the results of the population distribution at the state level matched the 2035 state-level projections.

Figure 21 shows those areas where the population is currently below 500 people per square mile based on LandScan $2009^{13}$ data and is projected to be above 500 people per square mile in 2035 . These 2035 population increases above 500 people per square mile are shown in red and, as expected, tend to circle those areas that are currently above that mark based on 2010 information.

\footnotetext{
${ }^{11}$ US Bureau of the Census. "State Interim Population Projections by Age and Sex: 2004-2030." Available at http://www.census.gov/population/www/projections/projectionsagesex.html.

${ }^{12}$ US Bureau of the Census."Interim Projections of the U.S Population by Age, Sex, Race, and Hispanic Origin: 2000-2050." Available at http://www.census.gov/population/www/projections/usinterimproj/.

${ }^{13}$ Considered to be the base 2010 population throughout this report.
} 


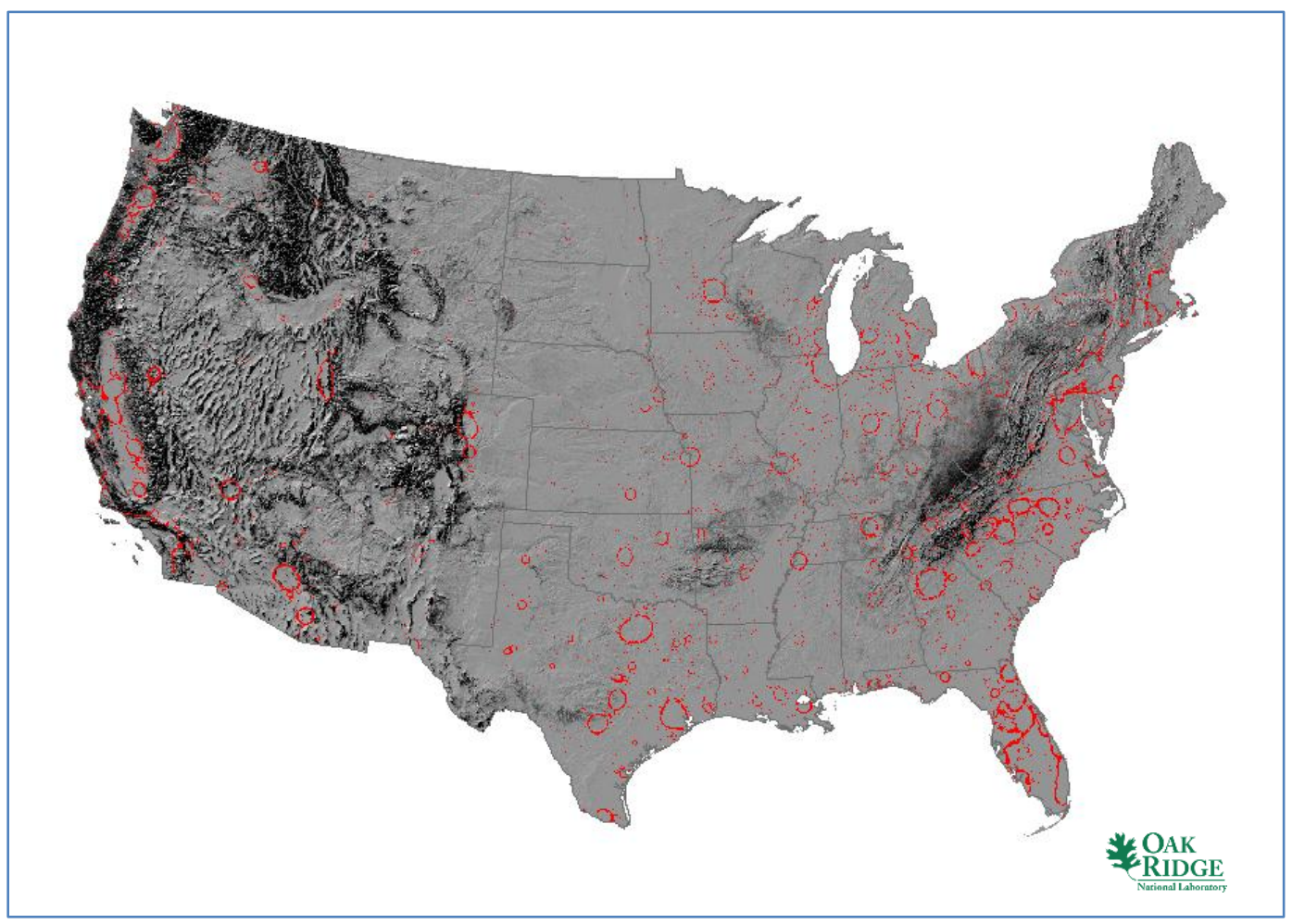

Fig. 21. 2035 areas with estimated population increases above 500 people per square mile.

The 2035 population estimate is quite detailed and provided information regarding decreases in population as well as increases. Specifically, the 2035 estimate predicted areas that are currently above 500 people per square mile in 2010 that are expected to fall below this mark by 2035 . On a national scale, these areas are not prominent enough to stand out on a small figure. However, Fig. 22 provides a detailed map centered on Tennessee on which the population increases above 500 people per square mile, predicted for 2035, are identified in red and the population decreases below 500 people per square mile, estimated for 2035, are identified in yellow. This is typical of the results on a national scale.

\subsubsection{Stream Effects}

Climate change could drastically affect regional runoff and stream flow. However, accurate regional predictions of such effects are not available. Nonetheless, it was assumed that increased population would place additional demands on available stream flow even without climate effects. In the generation of candidate areas for 2010 thermoelectric plant placement, the rule of thumb employed is that a given power source should not take more than $10 \%$ of the available stream flow at a given "new plant" location. To approximate the increased demand on water supplies in the future, it was decided that a simple rule of thumb to apply to the 2035 case would be that a given power source should not take more than $5 \%$ of the available stream flow at a given "new plant" location. An appropriate value for available fresh water to be used for power plant cooling in the future is certainly debatable. However, it was felt that the trend would unquestionably show that less water is available in the future to some degree and $5 \%$ availability will provide insight on the impact. Table 5 shows the resulting effect on stream flow. Sensitivity results are detailed in the individual power source discussions. 


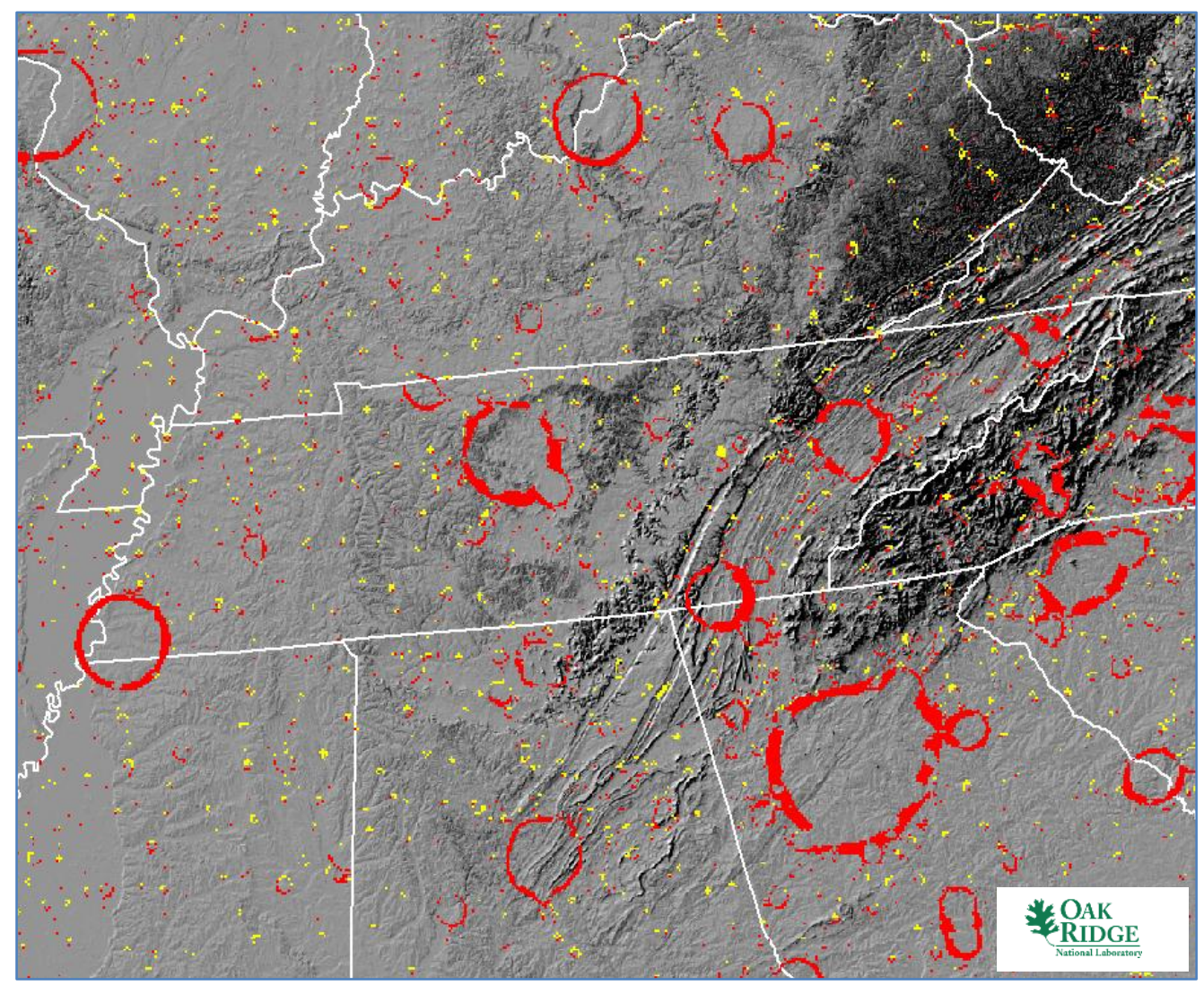

Fig. 22. 2035 population detail map showing increases (red) and decreases (yellow).

Table 5. Typical thermoelectric plant installations for 2035

\begin{tabular}{lcc}
\hline \multicolumn{1}{c}{ Typical thermoelectric plants analyzed } & $\begin{array}{c}\text { Makeup water } \\
\text { requirement (gpm) }\end{array}$ & $\begin{array}{c}\text { Stream flow } \\
\text { requirement (gpm) }\end{array}$ \\
\hline $1600 \mathrm{MW}(\mathrm{e})$ nuclear plant & 20,000 & 400,000 \\
$350 \mathrm{MW}(\mathrm{e})$ nuclear plant & 5,000 & 100,000 or $\sim 0^{*}$ \\
$550 \mathrm{MW}(\mathrm{e})$ advanced coal plant & 12,500 & 250,000 \\
$100 \mathrm{MW}(\mathrm{e})$ concentrated solar steam plant & 1,500 & 30,000 \\
\hline
\end{tabular}

*At least one small modular nuclear power plant design is proposed using air cooling. 


\section{NUCLEAR PLANT RESULTS}

\subsection{Large Reactor}

This analysis characterizes suitable area for "large" reactors. For the purposes of this study, a large reactor is a light-water reactor with a nominal output of $1600 \mathrm{MW}(\mathrm{e})$, representative of a single US Evolutionary Power Reactor (US EPR) or an advanced pressurized water reactor (APWR). In general, this plant size bounds all large Generation 3 plant designs under consideration by the NRC. The power output is used to determine the necessary stream flow to supply makeup water for cooling, which is subsequently reflected in the SSEC modeling application. Plant cooling in all cases is provided by a closed-cycle mechanicaldraft cooling tower with makeup water required for evaporation and blowdown.

\subsubsection{Site Selection and Evaluation Criteria}

There is well defined regulatory guidance for siting a nuclear power plant in the United States. Approximately 50 potential SSEC were identified in various sources related to health and safety, environment, socioeconomic, and engineering factors. The following SSEC were selected for large nuclear power plants based on providing a high level of discrimination and readily available data:

- Land with a population density greater than 500 people per square mile (including a 20-mile buffer) is excluded.

- Land with safe shutdown earthquake peak ground acceleration (2\% chance in a 50 -year return period) greater than $0.3 \mathrm{~g}$ is excluded.

- Land too close to identified fault lines (length determines standoff distance) is excluded.

- Protected lands (e.g., national parks, historic areas, wildlife refuges) are excluded.

- Land with a slope greater than $12 \%\left(\sim 7^{\circ}\right)$ is excluded.

- Land with a moderate or high landslide hazard susceptibility is excluded.

- Wetlands and open water are excluded.

- Land that lies within a 100-year floodplain is excluded.

- Land areas that are more than 20 miles from cooling water makeup sources with at least 200,000 gpm are excluded for large reactor plant applications.

- Land located in proximity to hazardous facilities is avoided.

Based on knowledge of current reactor plant installations, available data on proposed new large reactor designs, and expert judgment, it is assumed that a single or dual plant US EPR can be accommodated on a 500-acre footprint.

Population densities of greater than 500 people per square mile begin to transition into an urban setting. Siting guidance recommends calculating the population density within 20 miles of the site and excluding population densities of greater than 500 people per square mile. In addition, nuclear plants must consider seismic restrictions, proximity to fault lines, and nearby hazardous facilities as a public safety issue. Protected lands are excluded based on their definition.

Cooling water requirements are based on rules of thumb of cooling water required per megawatt of generation. ${ }^{9}$ These rules of thumb are consistent with environmental analyses supporting site evaluations submitted to the NRC. Additionally, it was assumed that cooling water makeup should be limited to taking no more than $10 \%$ of the available stream flow. ${ }^{1}$ This limited the siting of reactor plants to the vicinity of streams with sufficient flow volumes. Twenty miles was considered to be within reasonable proximity to a cooling water source, allowing for pumping. ${ }^{1}$

The remaining nuclear SSEC are related to design and risk considerations. 
The following figures (Figs. 23-32) show the individual SSEC layers for the nominal large reactor plant based on the values provided in the above list. Areas shown in red are excluded based on the selected input parameter value. Excluded areas in each individual layer can be modified based on different assumptions or requirements for the SSEC.

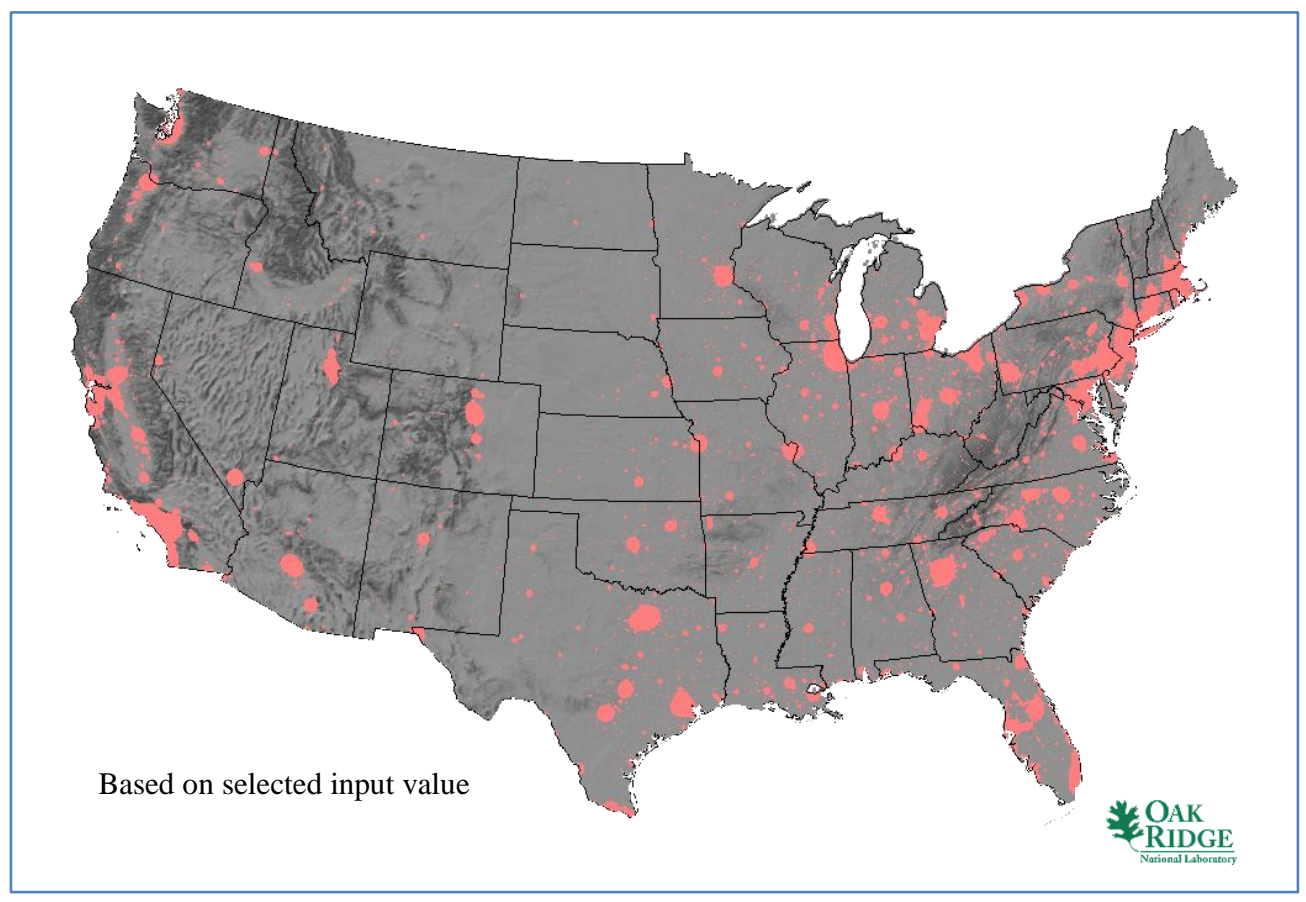

Fig. 23. Large/small nuclear high population SSEC layer.

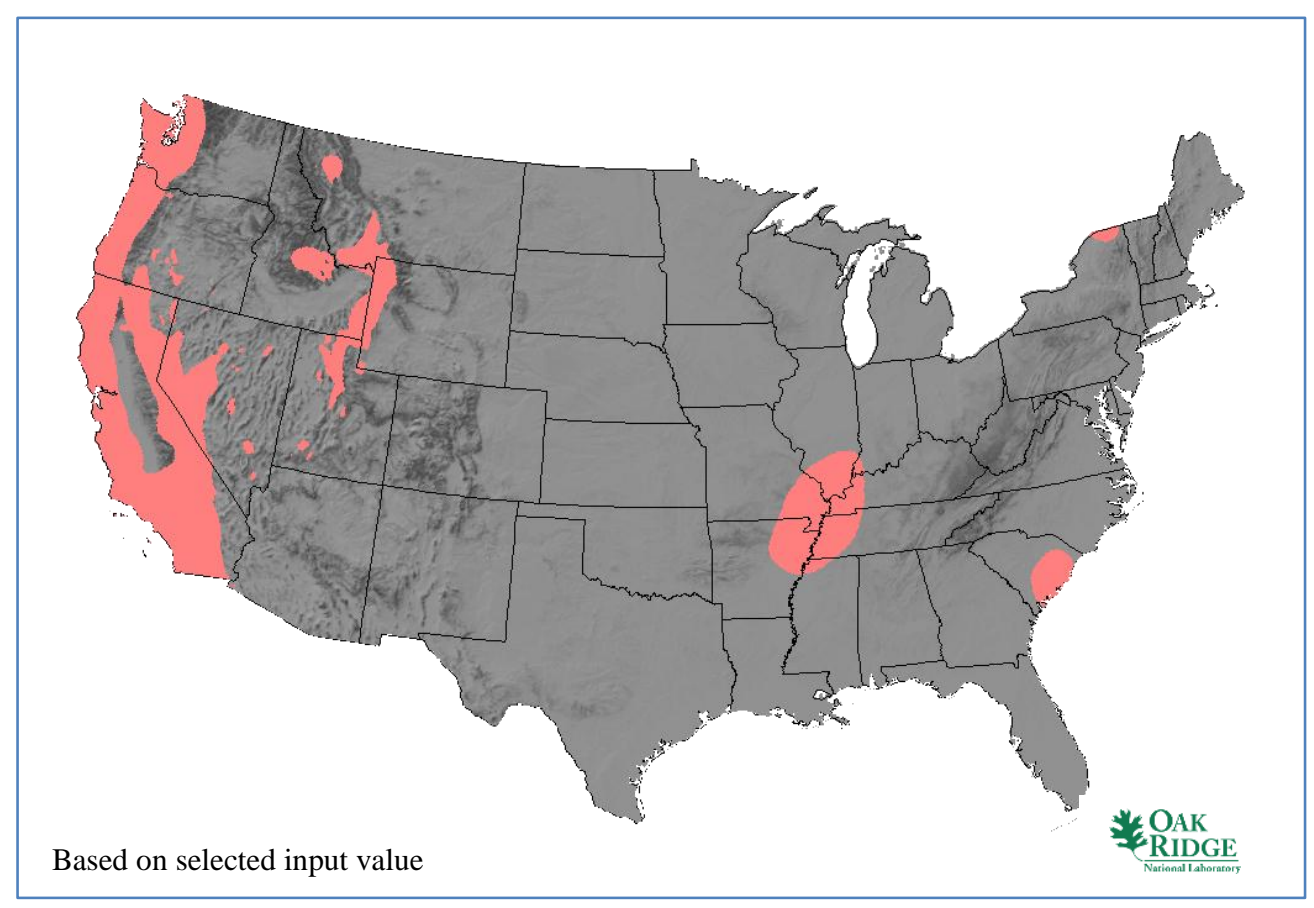

Fig. 24. Large/small reactor safe shutdown earthquake SSEC layer. 


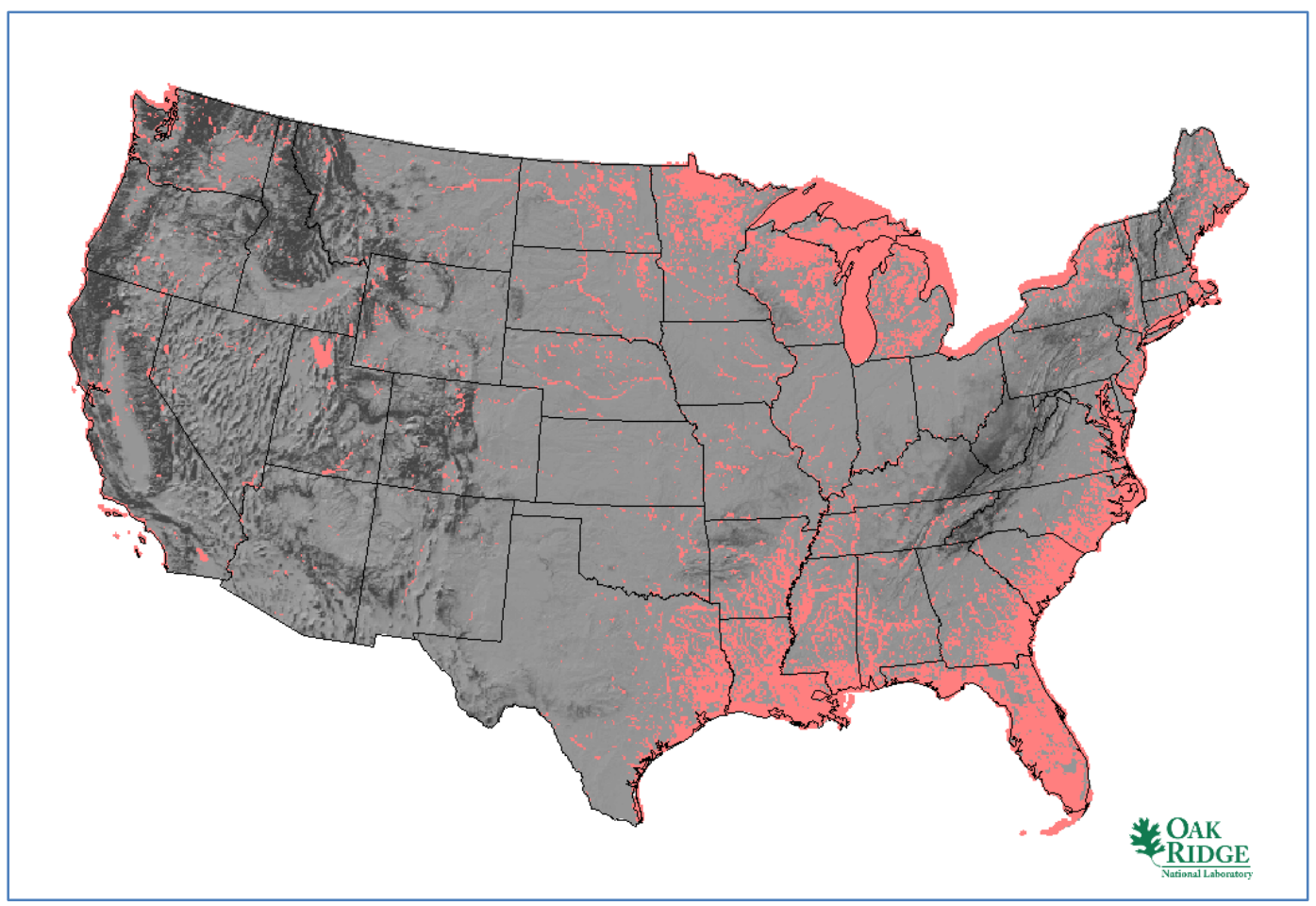

Fig. 25. Large/small reactor wetlands and open water SSEC layer.

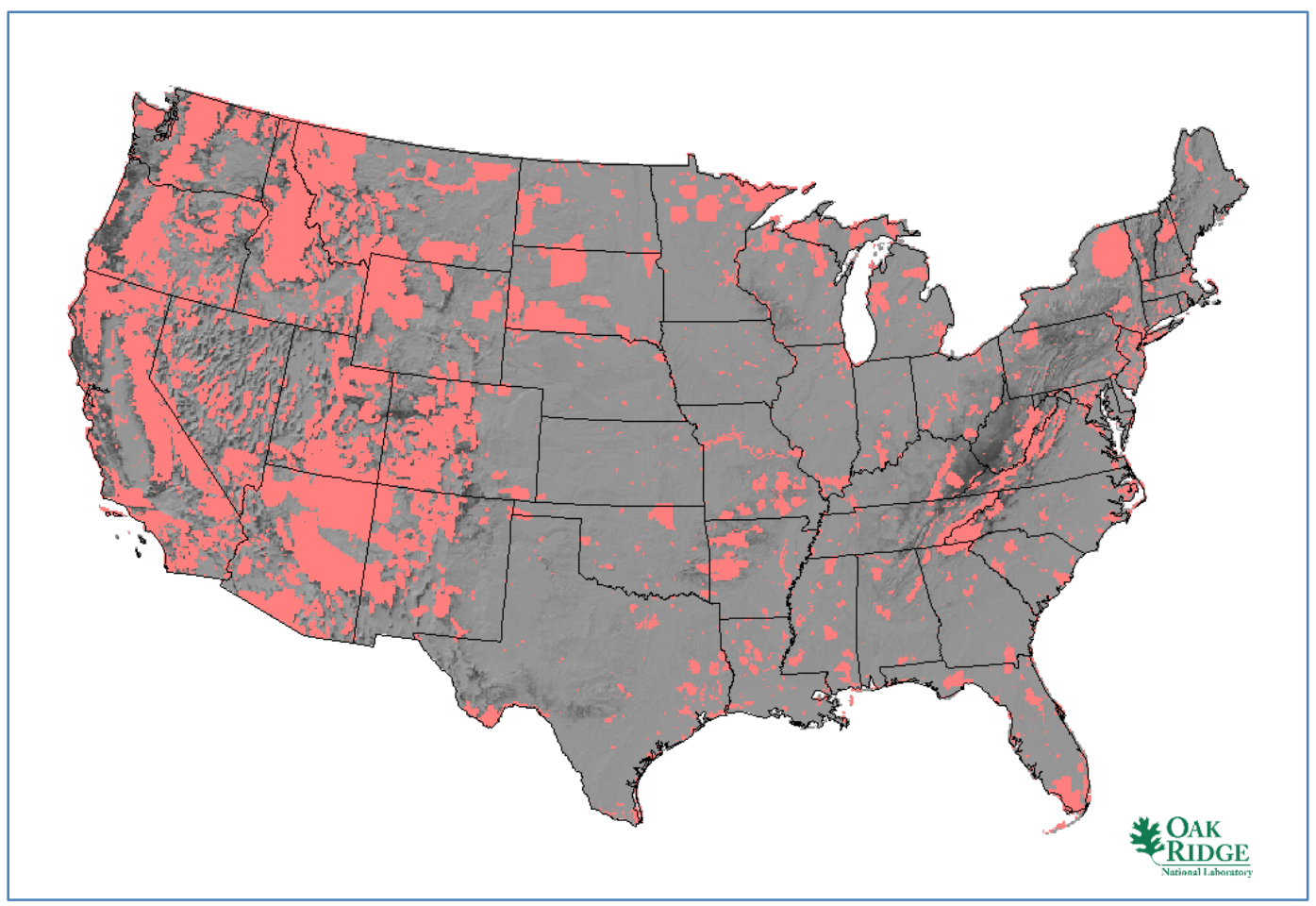

Fig. 26. Large/small reactor protected lands SSEC layer. 


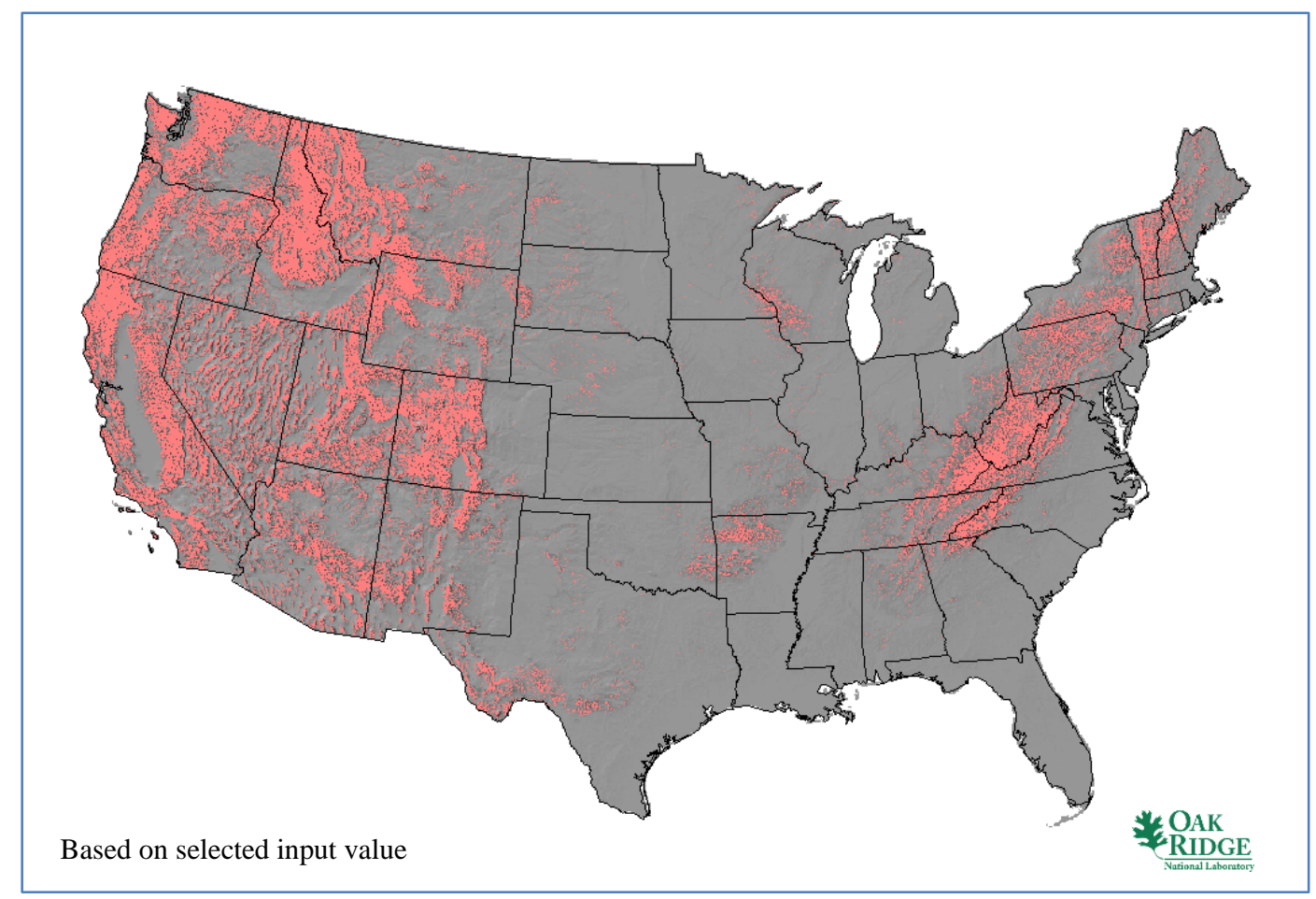

Fig. 27. Large/small reactor high slope SSEC layer.

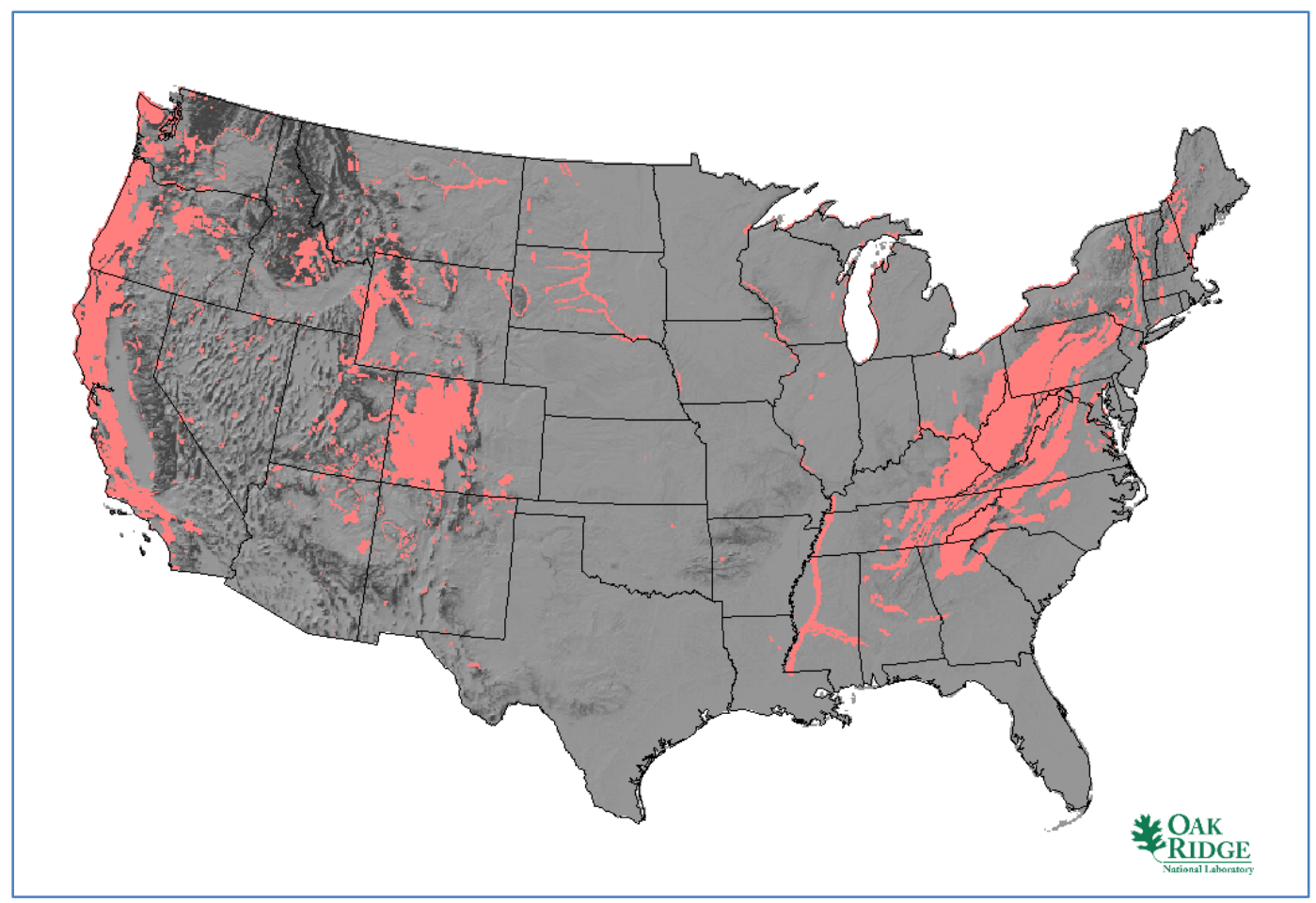

Fig. 28. Large/small reactor landslide hazards SSEC layer. 


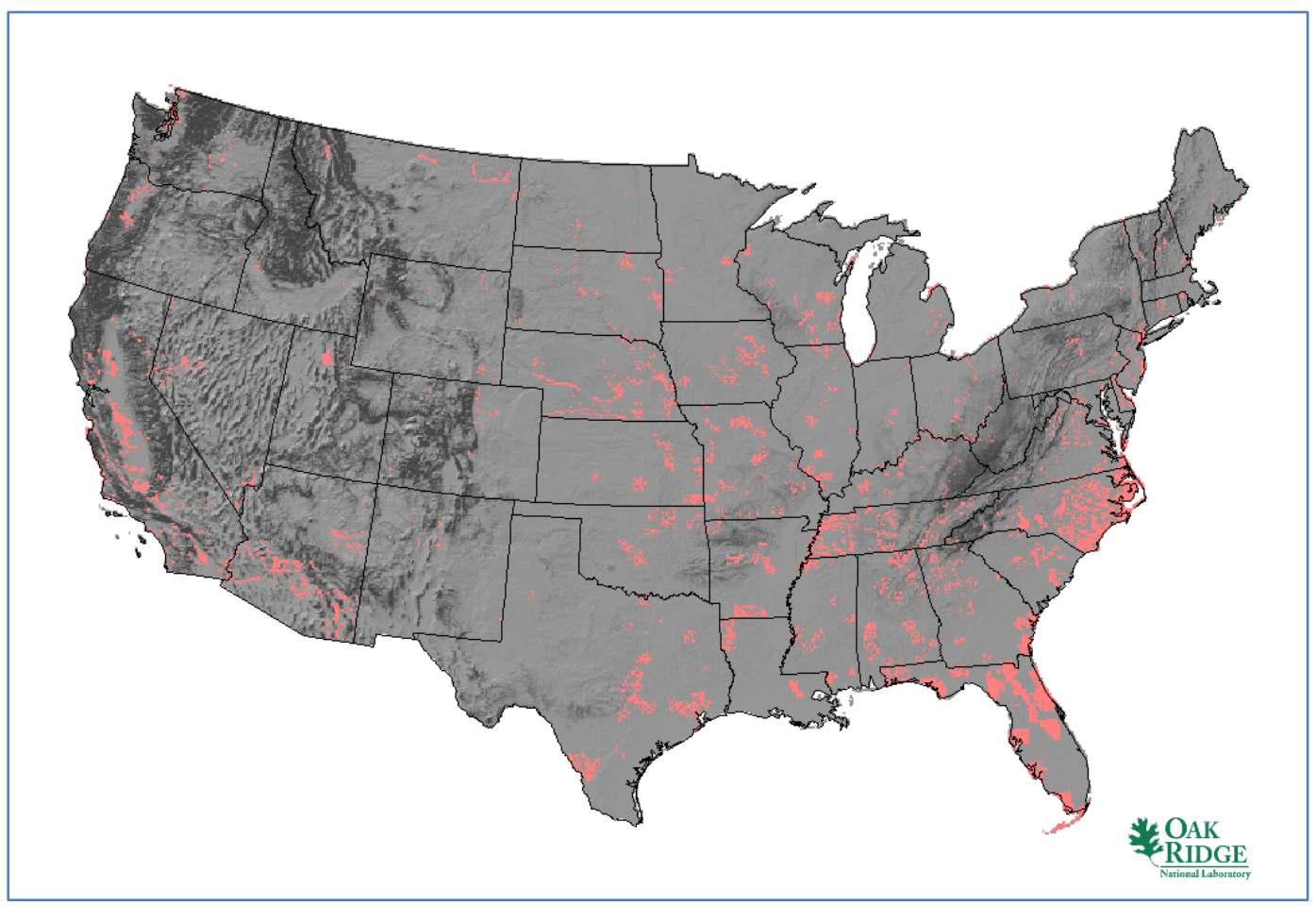

Fig. 29. Large/small reactor 100-year floodplain SSEC layer.

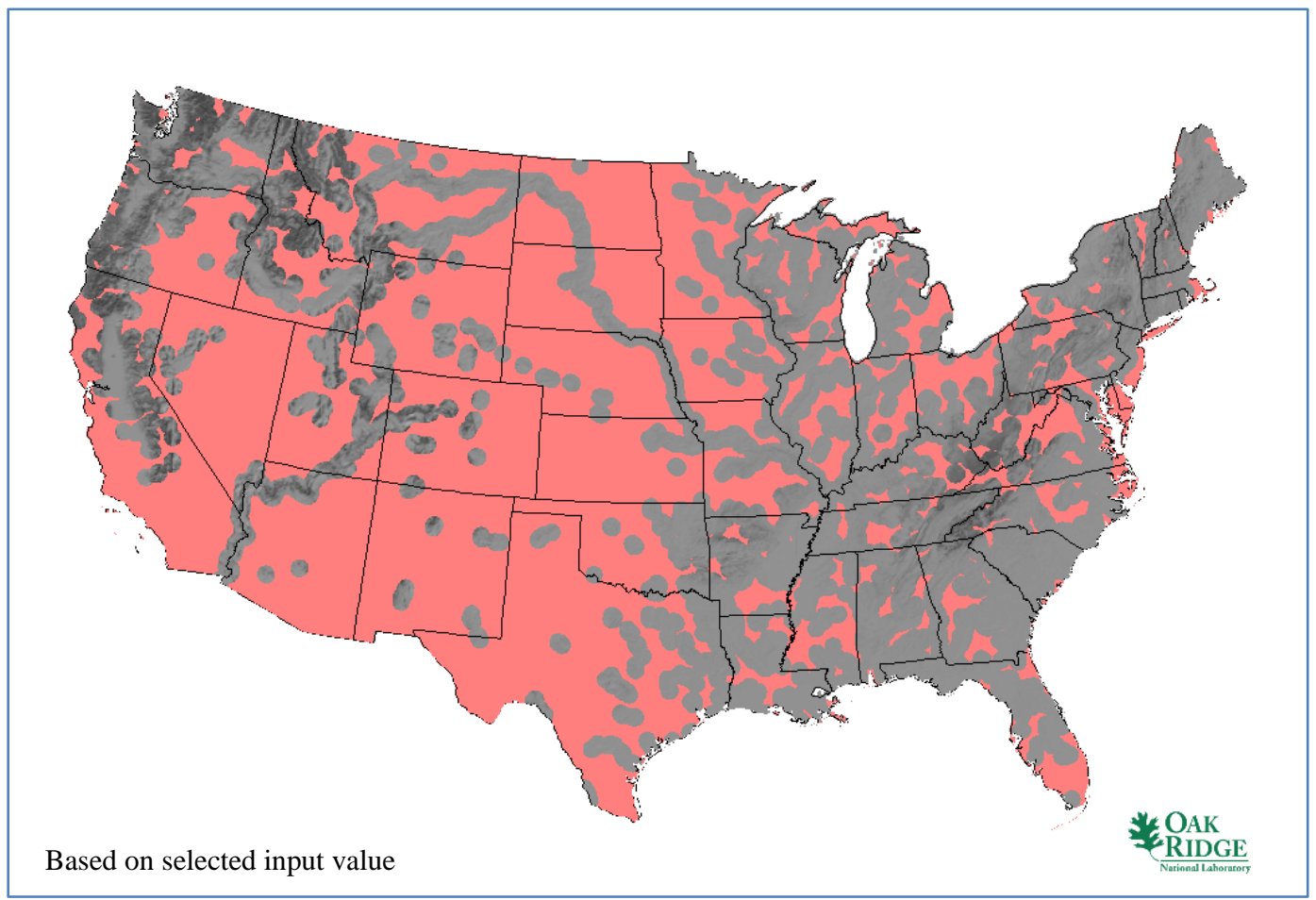

Fig. 30. Large reactor minimum low stream flow SSEC layer. ${ }^{14}$

\footnotetext{
${ }^{14}$ Small reactor minimum low stream flow SSEC layer is shown in Fig. 53 on page 52.
} 


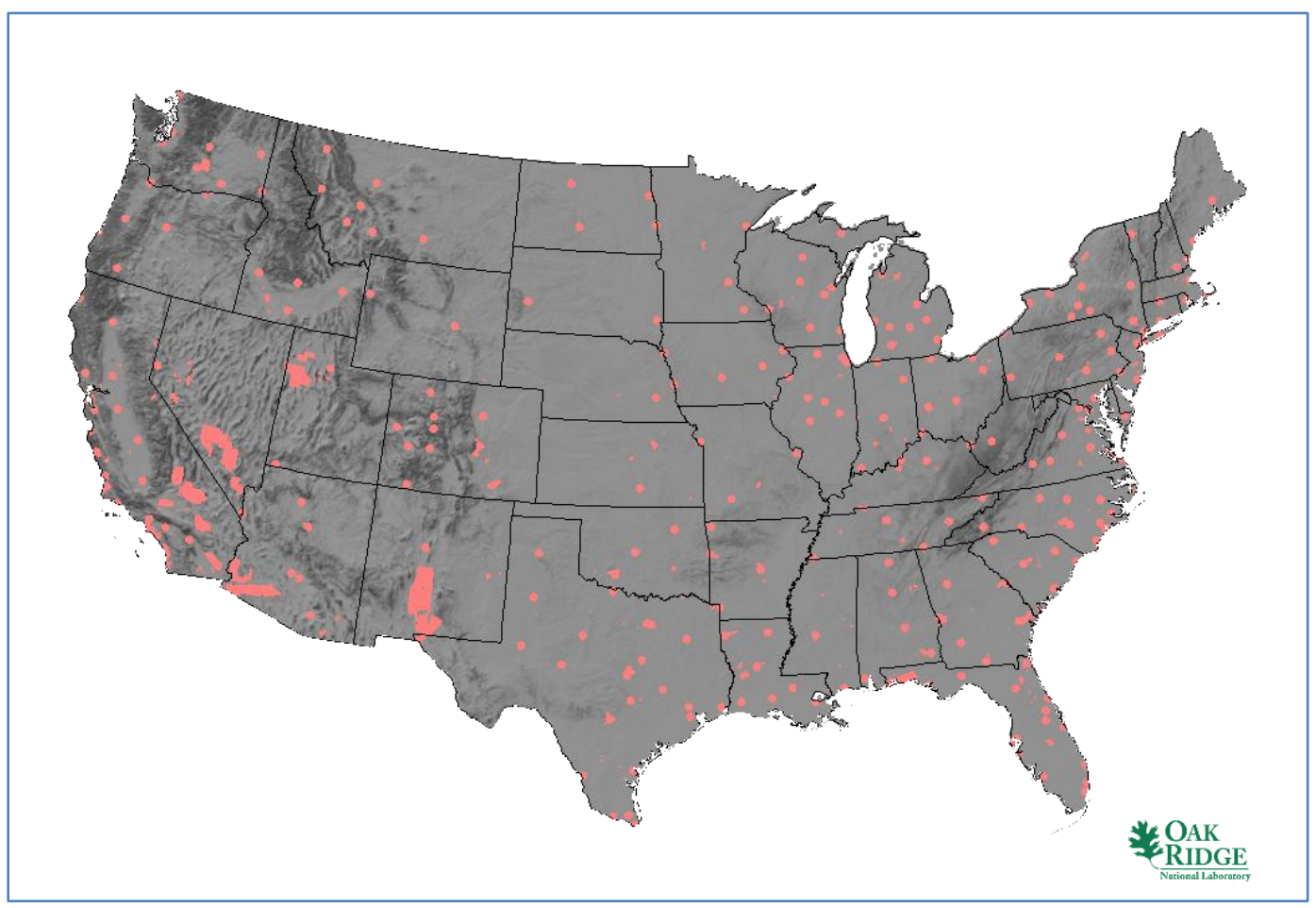

Fig. 31. Large/small reactor proximity to hazards SSEC layer.

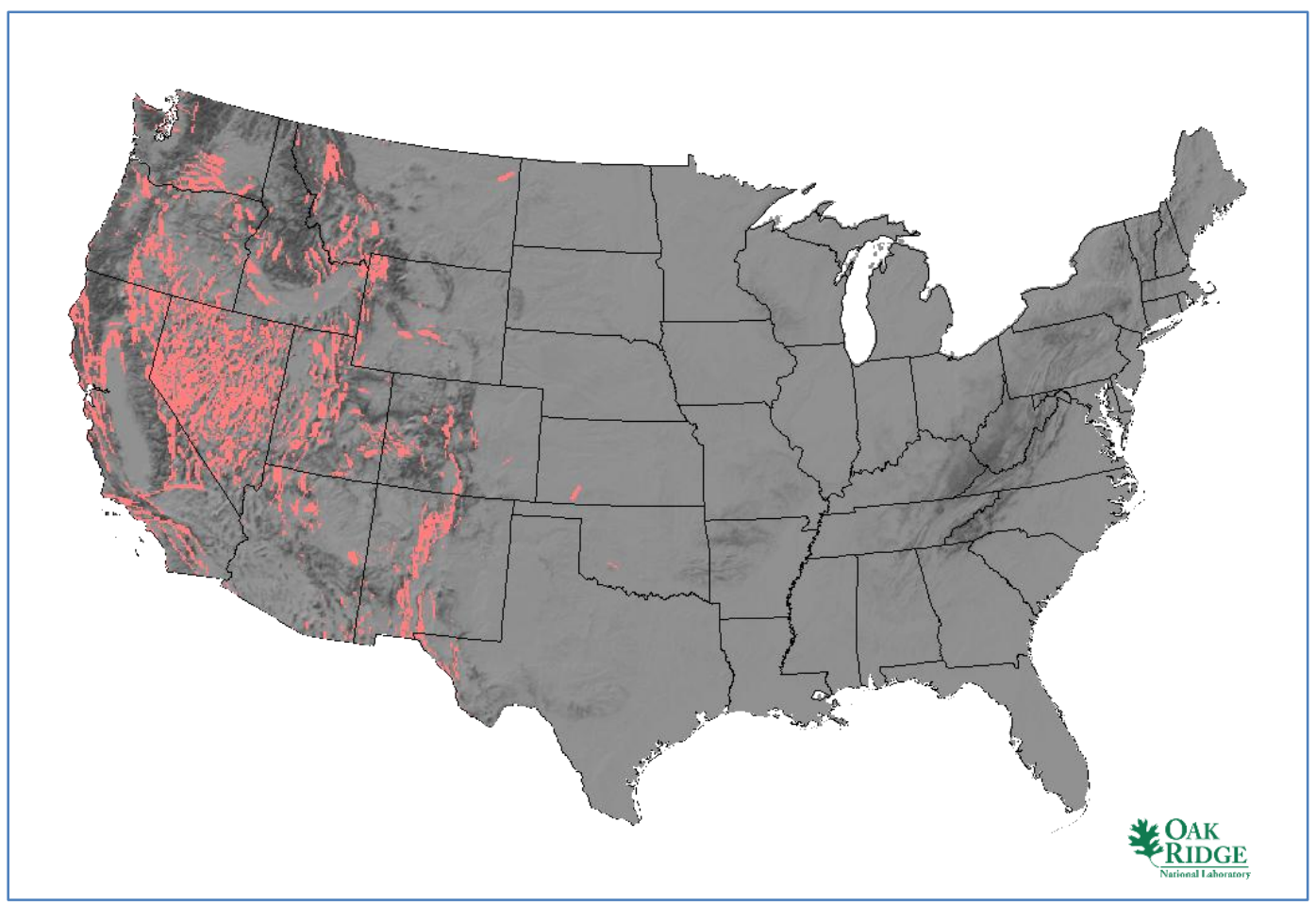

Fig. 32. Large/small reactor proximity to fault lines SSEC layer. 
The successive application of each large reactor SSEC layer to the overall available land in the contiguous United States can be captured as a step-down histogram as shown in Fig. 33. Since the SSEC layers are independent, the shape of the cumulative histogram is strictly determined by the order in which the SSEC layers (steps) are applied. However, the end result at step 10 is the same no matter the SSEC layer application order.

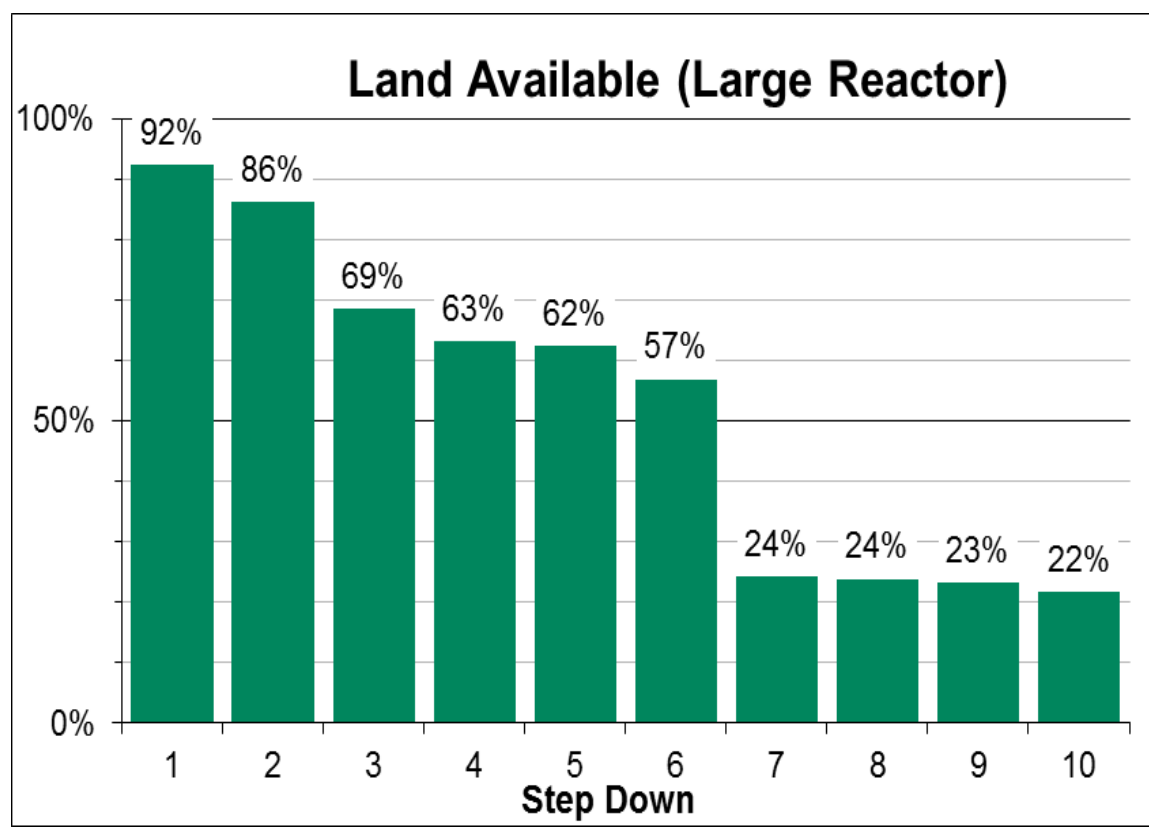

Order of SSEC Layers

1. Population

2. Wetlands/open water

3. Protected lands

4. Landslide hazard

5. 100 year floodplain

6. Slope

7. Stream-flow

8. Fault lines

9. Hazardous facilities

10. Safe shutdown earthquake

Fig. 33. Large reactor step-down histogram.

A review of the individual SSEC layers and the histogram provides the following insights:

- Population is a significant factor in the Northeast and in many coastal areas.

- Protected lands, seismic considerations, and slope are significant factors in the West.

- Cooling water is a significant factor in the west and central portion of the United States.

The OR-SAGE tool tracks the parameters for each individual 100 by $100 \mathrm{~m}$ cell. As a result, not only can the cells that are clear of all the SSEC layer exclusions be displayed visually, but also cells that are tripped by one, two, or three or more exclusions can be tracked and displayed. This is known as the "large reactor composite map," shown in Fig. 34. This is a powerful aspect to the OR-SAGE tool, because it allows areas with a limited number of siting challenges to also be identified. Engineering solutions to areas with limited siting challenges may be available. The areas in green in Fig. 34 have no siting challenges based on the selected values for the large reactor SSEC layers. However, the areas in yellow also include a significant land area and have just a single siting challenge. An examination of the individual layers indicates that inadequate stream flow is the most common siting challenge in the midsection of the contiguous United States. This can lead one to consider alternative methods of cooling, other than stream flow. 


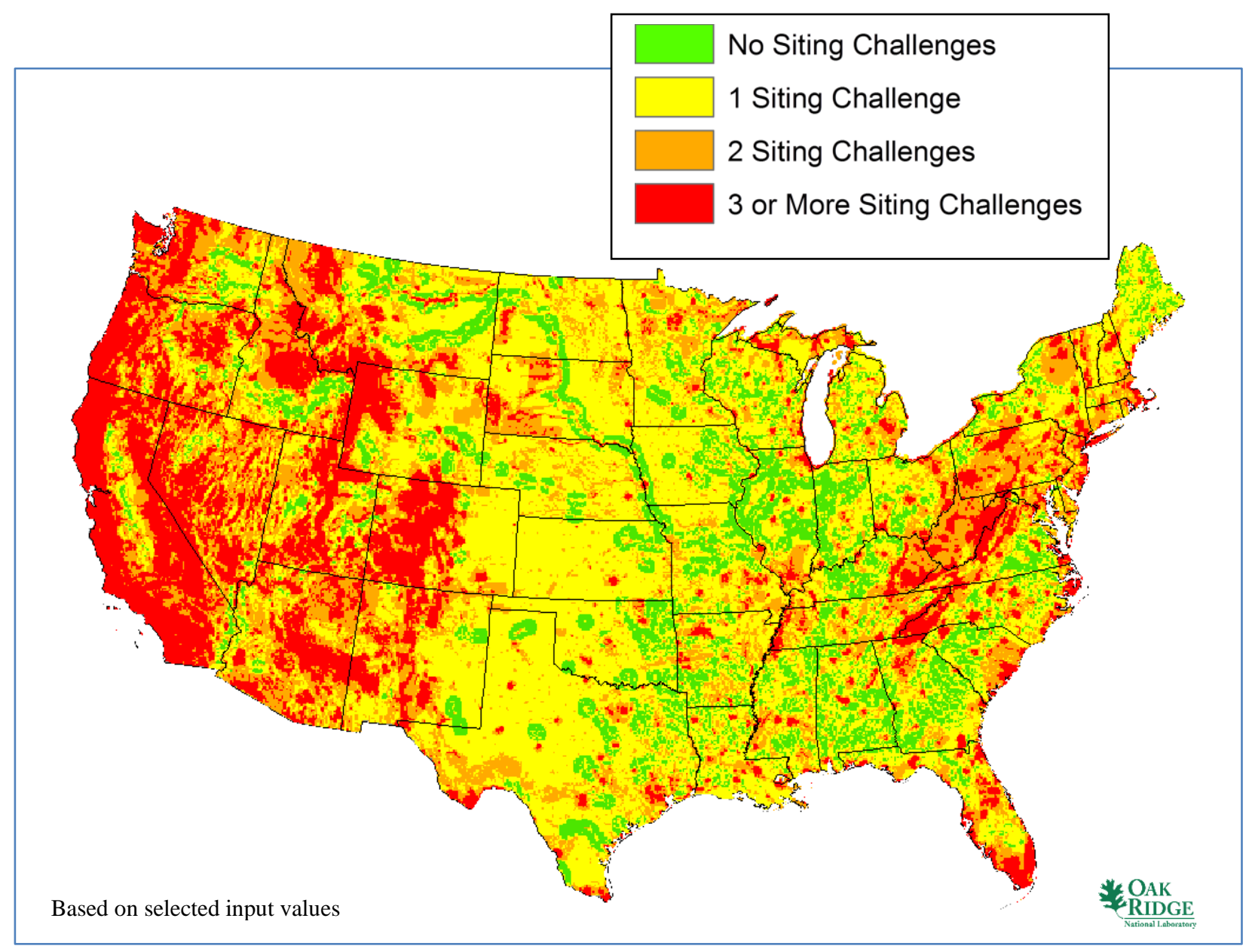

Fig. 34. Large reactor composite map detailing siting challenges.

\subsubsection{Key Assumptions}

In addition to the assumptions detailed in the "Critical Assumptions" section (Sect. 2) of this report regarding stream flow, land aggregation, plant placement projections, and 2035 estimates, there are several key assumptions that bound the nuclear plant results:

1. Political restrictions against nuclear power are not considered. For example, some states have laws prohibiting the use of nuclear power to generate electricity, and other states have nuclear bans until trigger events are reached, such as a spent fuel repository. Likewise, those states with negative public opinion toward nuclear power are not factored into the results.

2. Although most utilities own or control thousands of acres around a nuclear facility, only a minimal land footprint will be required to meet all siting criteria.

3. Plants are limited to $10 \%$ of the available stream flow for makeup water to reflect the overall demands on freshwater resources.

4. Stream flow is based on a composite of 7Q10 data from the USGS and existing lake and reservoir data.

5. Aggregation of GIS land cells into 500-acre parcels requires only $90 \%$ or more of the individual cells to pass SSEC. This allows for small imperfections in a parcel without requiring that it be discarded from consideration. 


\subsubsection{Base Map}

The "Approach and Methodology" section (Sect. 1.3) describes the process of developing a base map. A base map is created to reflect one set of values based on the stated assumptions and nuclear plant SSEC. The base map shows where all SSEC criteria are met. The areas depicted in green from the large reactor composite map shown in Fig. 34 are used to develop the large reactor base map.

The large reactor base map, depicting only the areas that have no siting challenges based on the entire set of large reactor SSEC, is shown in Fig. 35. The area in green represents $22 \%$ of the contiguous United States or 377 million acres, but it has not been aggregated for 500 -acre large reactor sites. Figure 35 shows that the green cells follow rivers in the Northwest and Great Plains states, while the Southeast, Great Lakes, and New England states have sufficient cooling water to have more widespread potential siting areas. The Appalachian and Rocky Mountain ranges, as well as the arid desert regions, generate obvious exclusions.

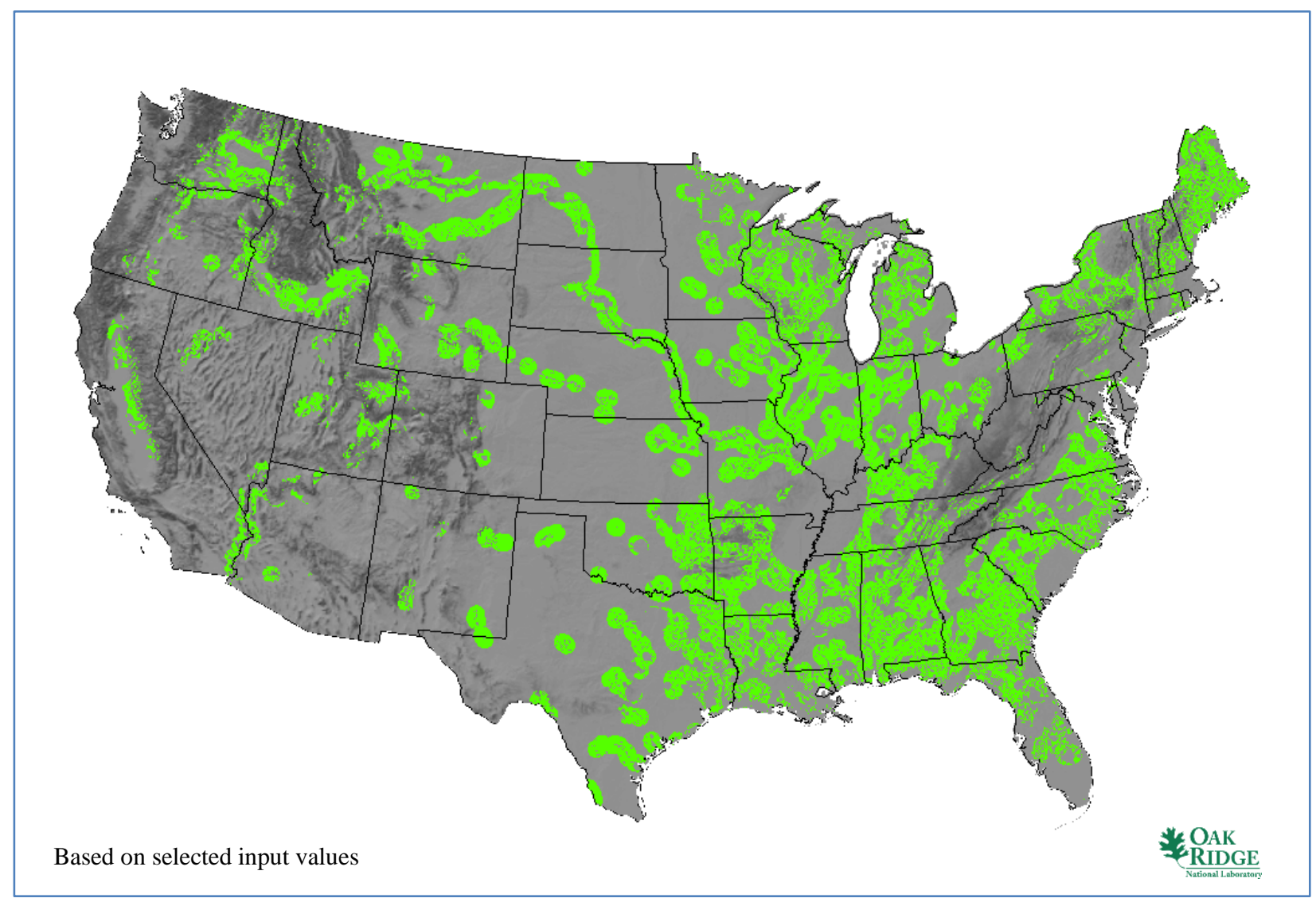

Fig. 35. Large reactor base map.

Figure 36 shows the effect of aggregating the available land from the large reactor base map into 500-acre tracts at a $90 \%$ aggregation rate. The available aggregated land with no siting challenges for large reactor facilities is reduced from $22 \%$ (Fig. 35) to $13.2 \%$ of the contiguous United States, or 226 million acres, based on the stated assumptions and selected values for the large reactor plant SSEC. 


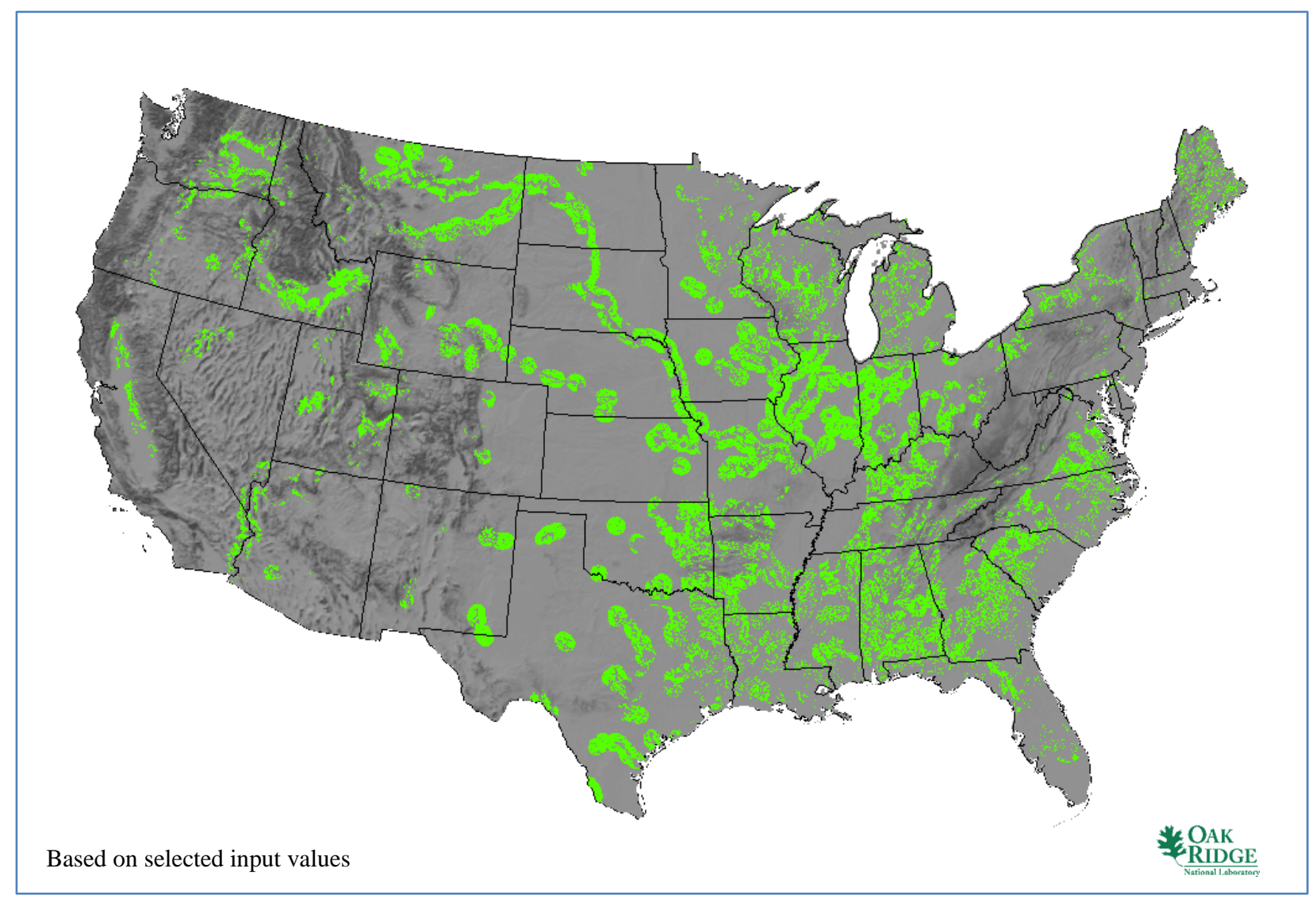

Fig. 36. Large reactor base map aggregated for 500-acre sites.

\subsubsection{Plant Placement Results}

A calculation of large reactor capacity was performed using the methodology described in an earlier section of this report, "Plant Placement Algorithm for Water-Dependent Power Sources." The predictions are based on a nominal $1600 \mathrm{MW}(\mathrm{e})$ large reactor plant installation positioned on 500 acres of land. This estimate is independent of other thermal plant installation predictions and is not tied directly to current estimates of power demand. Therefore, the placement algorithm assumes that a nuclear power plant will be built in all acceptable locations, dependent on the starting point, resources tracking, and initial search parameters (SSEC values).

Figure 37 displays the result of the plant placement algorithm for large reactor plants. The plants are projected based on individual water basins. Using this methodology, space and stream flow cooling are available to support placement of $515 \mathrm{GW}(\mathrm{e})$ in large reactor plants. Purple dots represent a new single large reactor plant placement and red dots show existing and proposed reactor plants of varying sizes. The goal of the plant placement exercise is to predict large reactor plant capacity rather than to predict actual plant sites. The capacity estimate is shown in Fig. 38 with a state map overlay. State-by-state results can be affected by the unbiased nature of the initial plant placement in any given water basin, the use of single plant sites, and the arbitrary limit of 20 miles between unit projections. The plant capacity estimate indicates that states in a significant portion of the country can support siting at least $10 \mathrm{GW}(\mathrm{e})$ in large reactor facilities with no siting challenges.

No political considerations are taken into account regarding states that may currently exclude the siting of nuclear power plants within state boundaries. It is assumed that political decisions can be revised as power needs and public opinion warrant. 


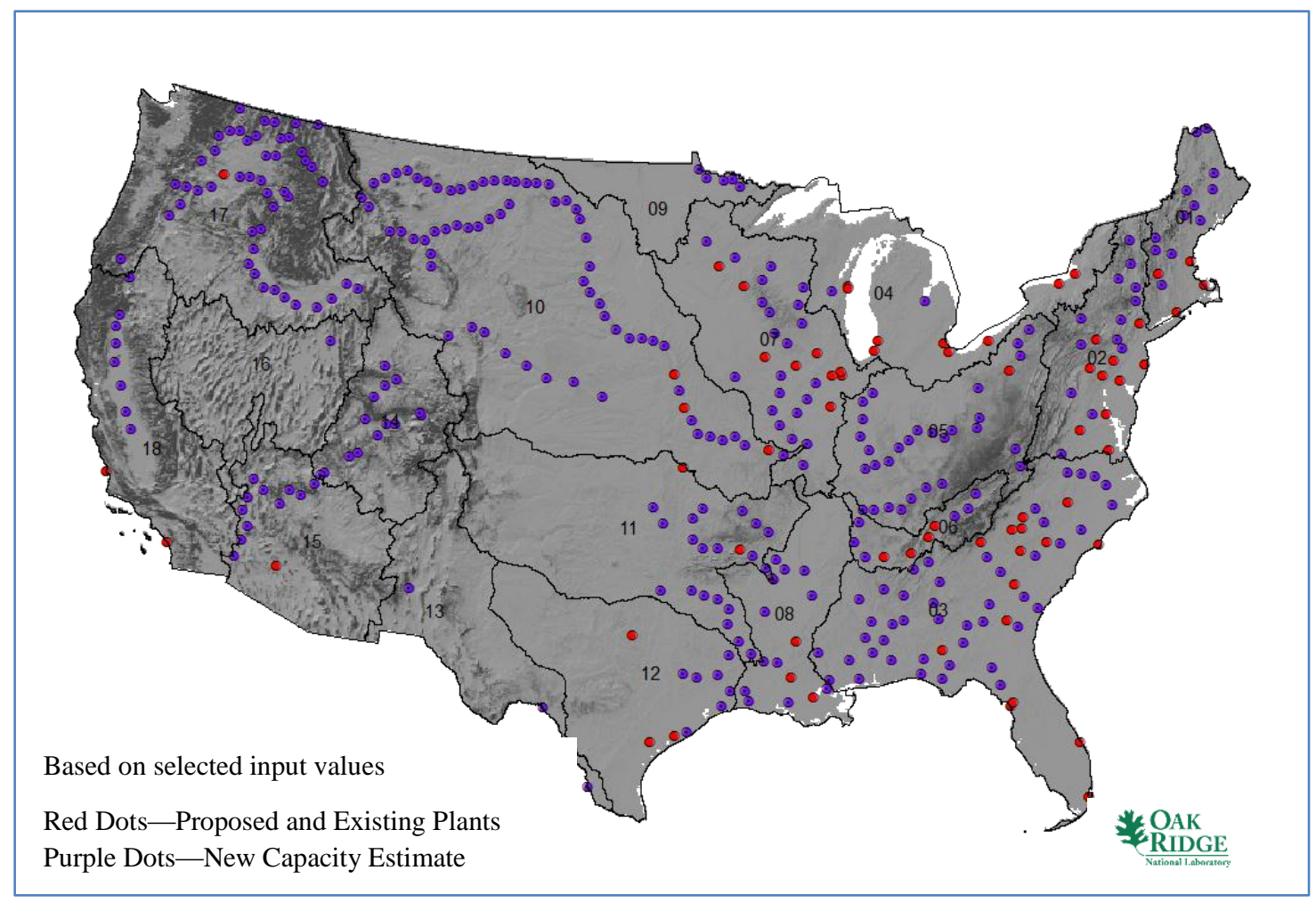

Fig. 37. Large reactor plant placement capacity estimate.

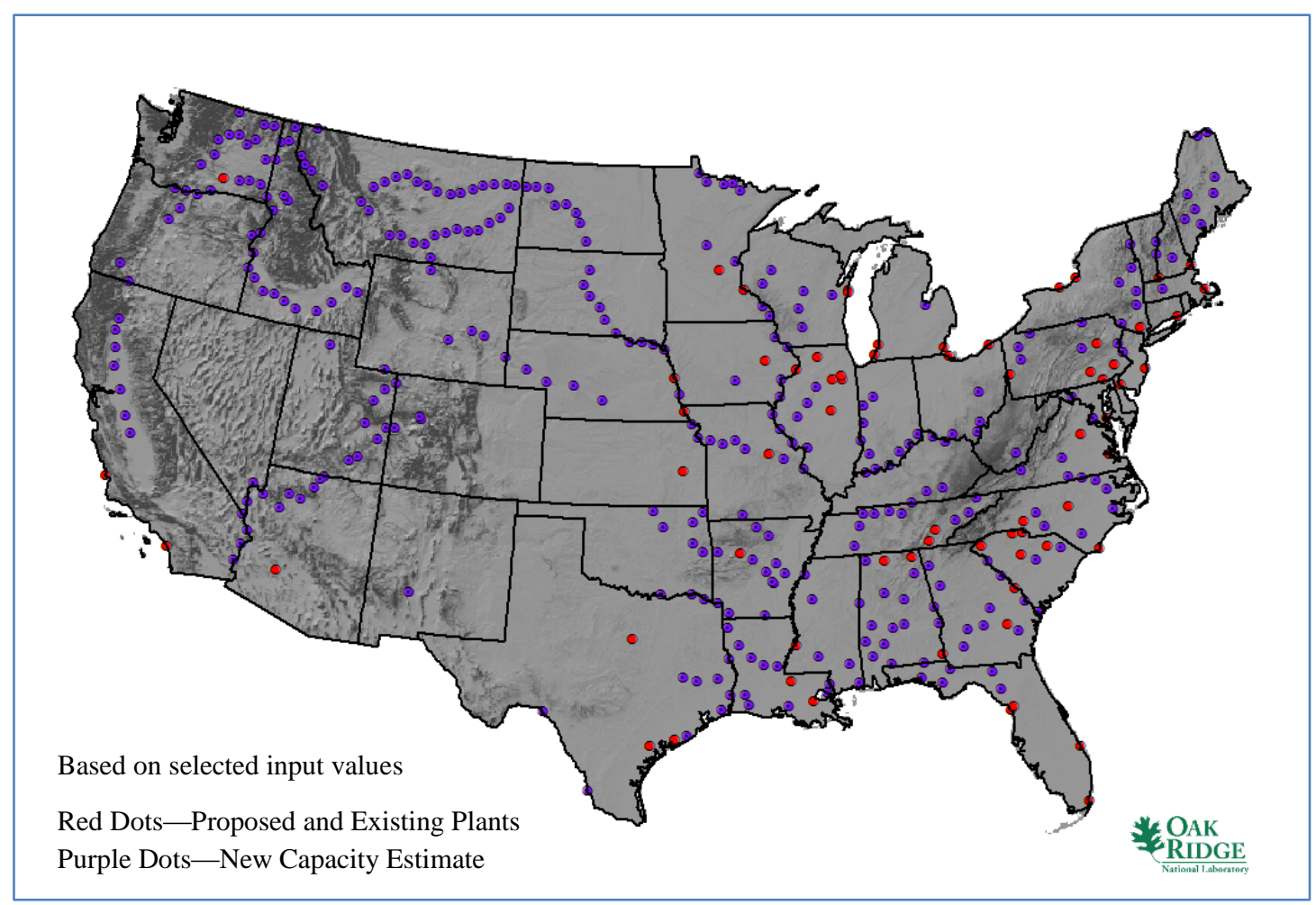

Fig. 38. Large reactor plant placement capacity estimate with state overlay. 


\subsubsection{Sensitivity Studies}

\subsubsection{1 $1100 \mathrm{MW}(\mathrm{e})$ results}

The AP1000 generating capacity falls between very large EPR-type reactors and small reactors that were used to constrain the study results. A sensitivity study was performed to indicate the siting availability for reactors of this size. The cooling water makeup requirements were adjusted from 200,000 gpm in the large reactor case to $135,000 \mathrm{gpm}$ for the AP1000 case to account for a gross generating capacity of $1100 \mathrm{MW}(\mathrm{e})$. Note that this reflects the rule of thumb that an individual plant will take no more than $10 \%$ of the available freshwater from the stream flow. ${ }^{1}$ Figure 39 reflects the AP1000 minimum stream flow SSEC layer substituted for the large reactor minimum stream flow SSEC layer shown in Fig. 30.

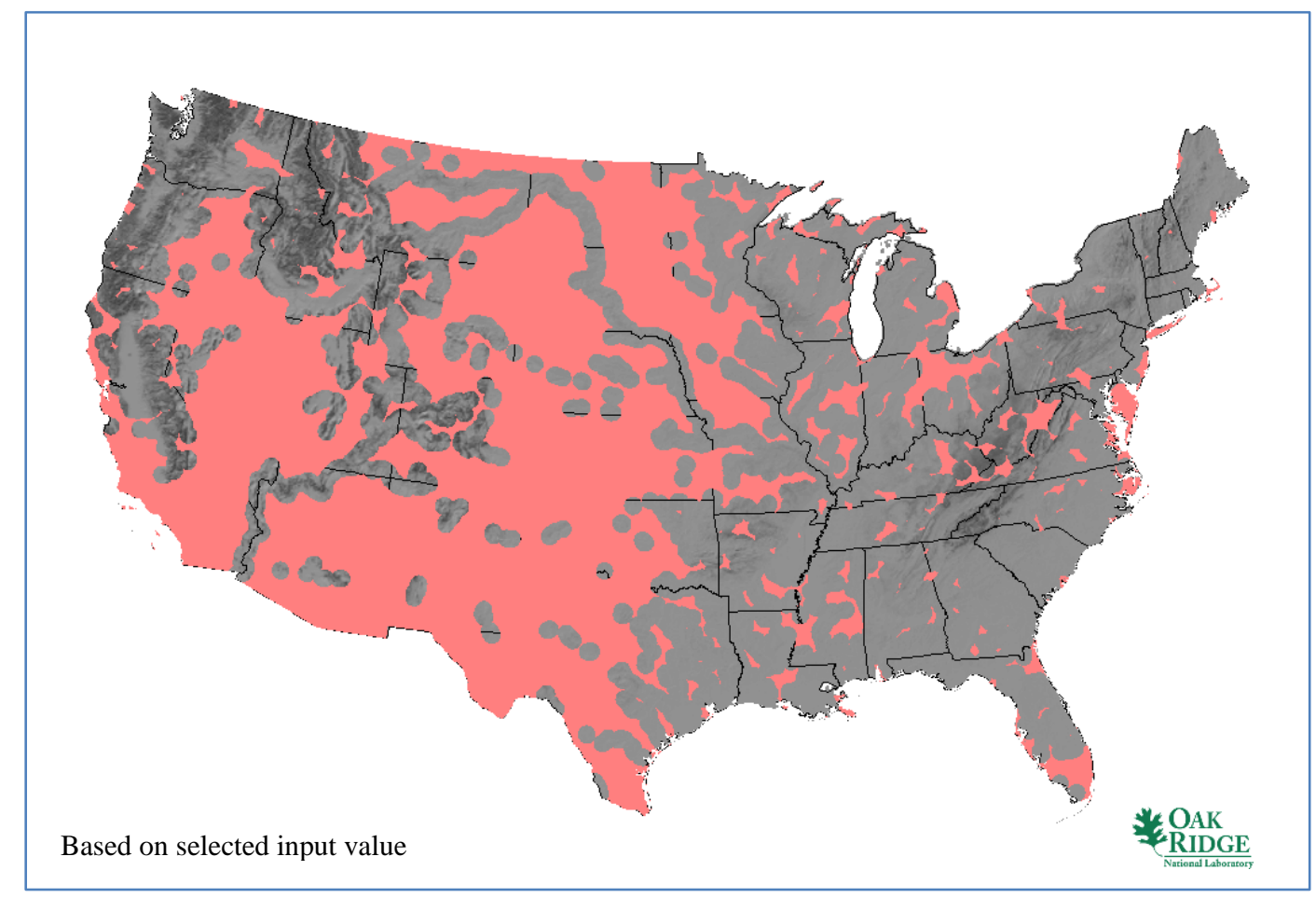

Fig. 39. AP1000 minimum low stream flow SSEC layer.

Figure 40 shows the resulting aggregated land (90\%) map when the cooling water flow requirement is decreased to $135,000 \mathrm{gpm}$. The passive AP1000 reactor plant has a smaller footprint than the nominal large reactor. Therefore, the AP1000 footprint was also reduced from 500 acres to 250 acres as part of the sensitivity study to reflect the reduced need for aggregated land that meets all SSEC requirements, which is also reflected in Fig. 40. Reducing the cooling water requirement increases the aggregated land available from $13.2 \%$ (Fig. 36) of the contiguous United States in the large reactor base case to $18.2 \%$ in the AP1000 sensitivity case. This represents a 38\% increase in available aggregated land with no siting challenges, or an additional 86 million acres. A linear comparison with the number of large reactor sites projected by the OR-SAGE capacity algorithm (322) yields an increase of 122 additional sites for a total of $488 \mathrm{GW}(\mathrm{e})$ in new AP1000 capacity. However, this projection assumes the large reactor parameters in the base case, in which the water region must restore itself to 200,000 gpm flow before allowing a subsequent large reactor plant placement. Since the AP1000 only requires 135,000 gpm flow to be restored and the capacity estimate analysis is separate from the base map generation methodology, this implies that the AP1000 capacity estimate is probably undervalued. Overall, cooling water requirements and projected plant footprint make a significant difference in the estimated results for nuclear generation. 
The typical dual-unit configuration for the AP1000 is easily accommodated by the modeling. Because the nominal footprint assumed for the AP1000 would accommodate one or two reactors, the capacity estimate comes down to tracking water availability. Since two plants use double the makeup water, essentially the same estimated capacity [488 GW(e)] would be available using half as many potential sites.

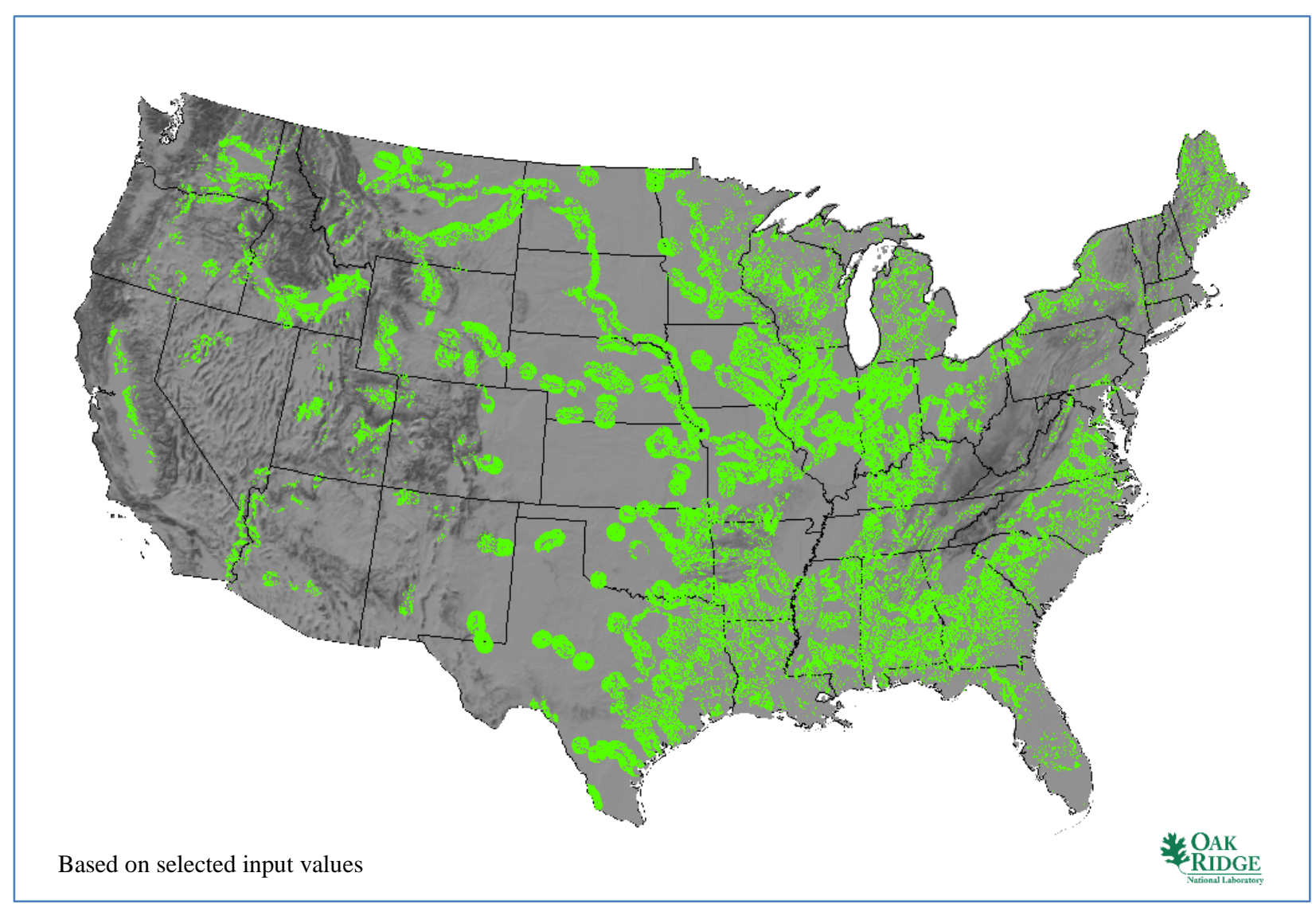

Fig. 40. AP1000 base map aggregated for 250-acre sites.

\subsubsection{Gray water}

If a reactor could use an alternate source of cooling, this would obviously open more available area and additional sites, especially in the Midwest and Southwest. An example of alternate cooling is the use of gray water; specifically, processed municipal wastewater.

To provide sufficient wastewater, a nuclear plant would require a sufficiently large population density nearby. However, high population density creates an exclusion that prevents nuclear plant siting. Therefore, a nuclear plant using wastewater for cooling must be close to a city to have available water, but also far enough from high-population areas to meet emergency planning requirements.

The 3-unit plant at Palo Verde, AZ, is a current example of the use of municipal wastewater to meet plant cooling needs. Palo Verde uses wastewater transported approximately 40 miles from Phoenix to supply its cooling needs, and the outer edge of the Phoenix buffered population zone boundary can be readily identified.

Figure 41 shows the Palo Verde plant location as a blue star and the buffered population zone boundary in red. There is a smaller population exclusion area in the Buckeye/Valencia area between Phoenix and Palo Verde, but this area is insufficient to supply cooling water. 


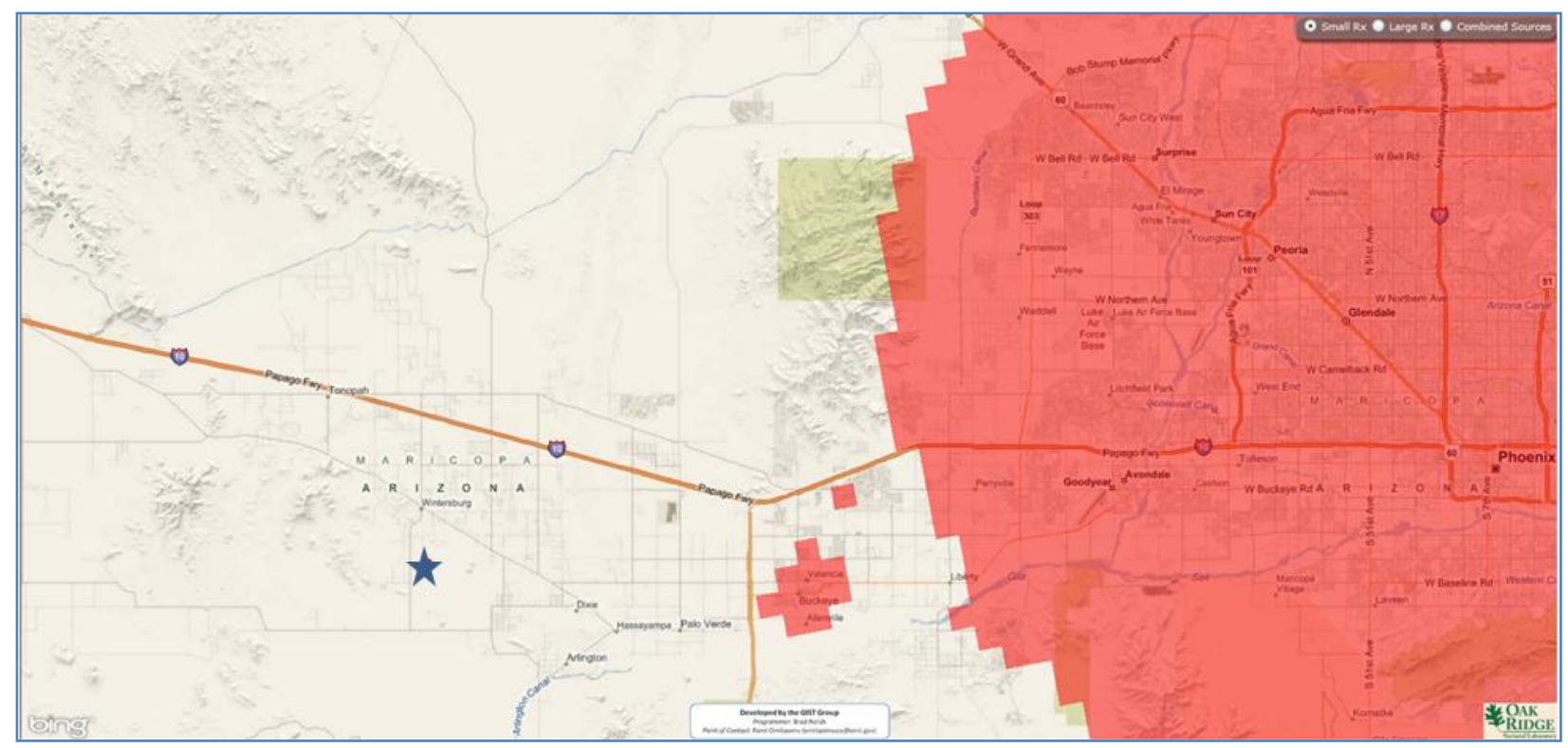

Fig. 41. Palo Verde and Phoenix buffered population zone boundary.

Using GIS data, Palo Verde is approximately 20 miles from the outer edge of the Phoenix buffered population zone boundary. The Palo Verde site passes all SSEC for a large reactor placement with the exception of adequate stream flow.

For a more general application of gray water usage, Palo Verde provides an acceptable reference case. The Palo Verde site has three large reactors, and the population of Phoenix is approximately 1.5 million. ${ }^{15}$ Therefore, as a rule of thumb, a city of at least 500,000 could support a single large reactor, or a city of 125,000 could support a single small reactor, within 20 miles of the buffered population zone boundary using processed municipal wastewater (gray water). For example, the desert city of Albuquerque, NM, has a population of approximately 500,000, ${ }^{16}$ and the main SSEC exclusions for the immediate vicinity are population, fault lines, protected lands, and insufficient stream flow.

Figure 42 shows two potential sites for siting a large reactor within 20 miles of the buffered population zone surrounding Albuquerque (shown in red). The only exclusion at the two flagged sites is insufficient stream flow. Based on the bounding conditions of the Phoenix application, it is reasonable to pump gray water over this distance.

${ }^{15}$ http://quickfacts.census.gov/qfd/states/04/0455000.html.

${ }^{16}$ http://quickfacts.census.gov/qfd/states/35/3502000.html. 


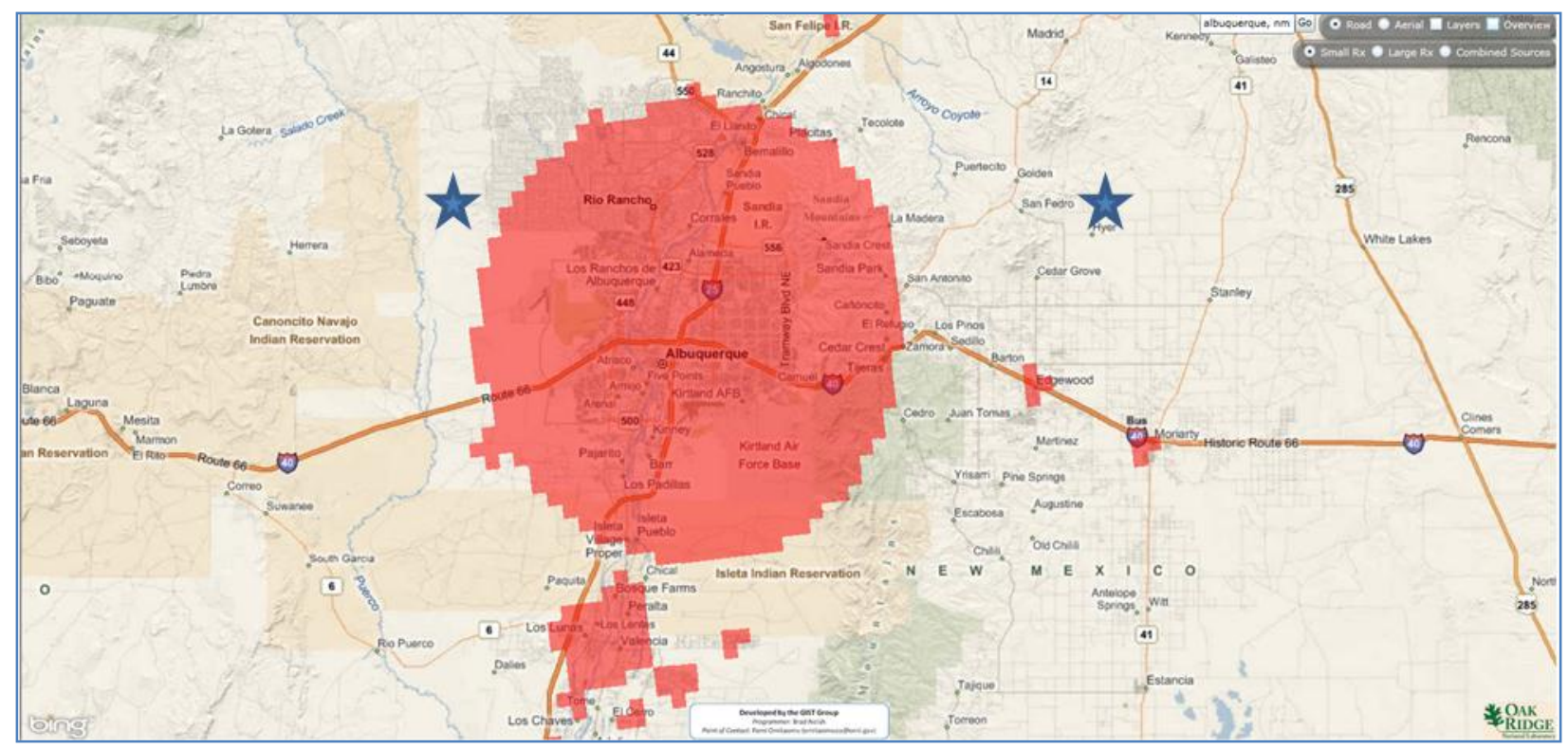

Fig. 42. Albuquerque, NM, with example potential nuclear sites using gray water.

By scaling to the large reactor plant example, a city of approximately 125,000 people could support a small reactor installation. West Valley City, UT, has a population of approximately $120,000^{17}$ and has a limited number of sites that meet all SSEC criteria except insufficient stream flow. One such site within 20 miles of the buffered population zone boundary is depicted in Fig. 43. This represents an example for a potential small reactor installation cooled by gray water. ${ }^{18}$ Note that gray water usage is not limited to dry or arid regions of the country. For example, proposed new reactors at the Turkey Point nuclear plant in south Florida currently plan to use gray water from Dade county (Miami).

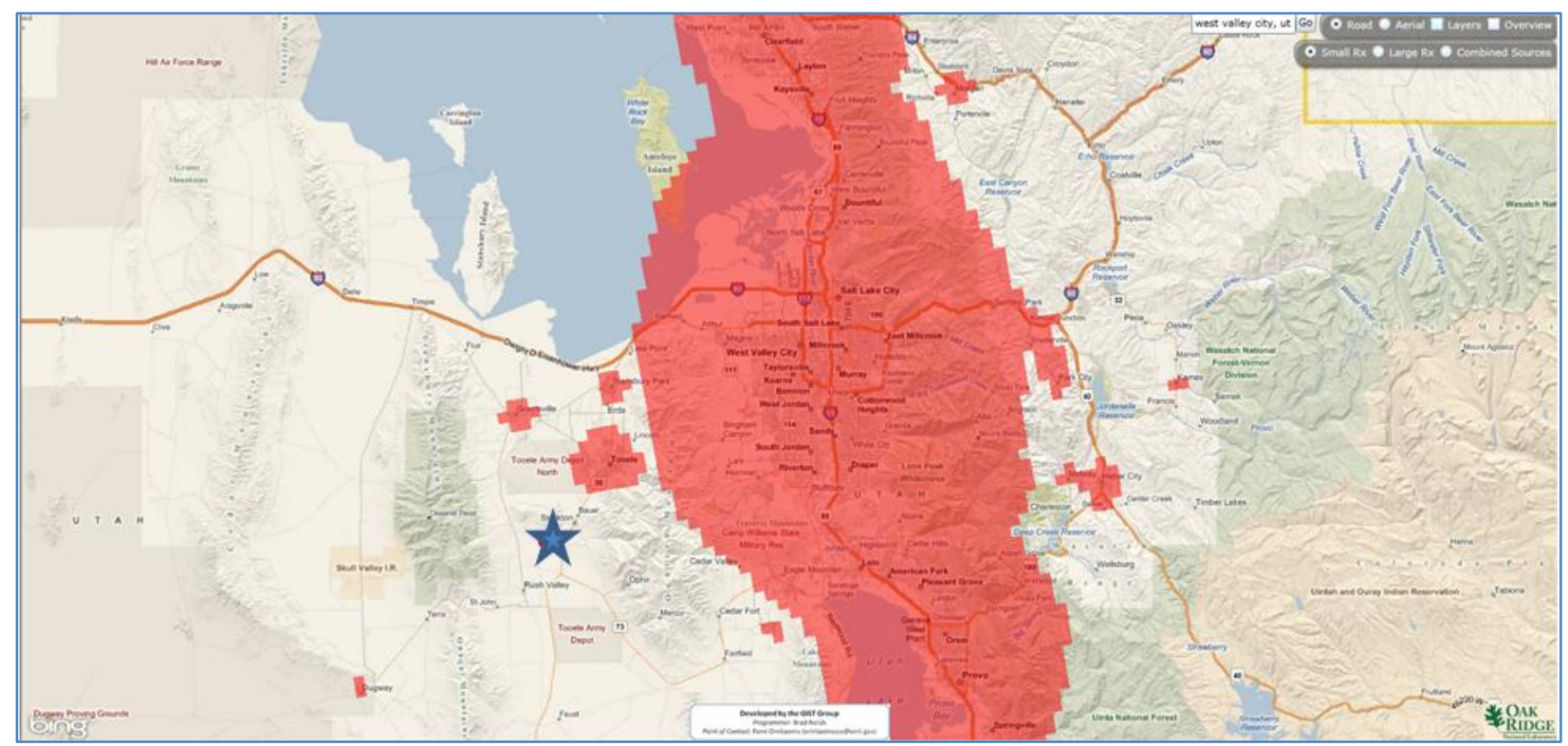

Fig. 43. West Valley City, UT, with an example potential nuclear site using gray water.

\footnotetext{
${ }^{17}$ http://quickfacts.census.gov/qfd/states/49/4983470.html.

${ }^{18}$ The Albuquerque and West Valley cases are examples and do not reflect a recommendation for a specific plant siting based on this study.
} 


\subsubsection{Ocean or Great Lakes cooling}

A sensitivity study on alternate cooling directly from the ocean or Great Lakes indicated a slight increase in available land for siting large or small reactors. Figure 44 shows the coastal cooling SSEC layer used for this sensitivity analysis. The gold regions depict a 20-mile band near the coast where cooling water can be drawn from the ocean or the Great Lakes. While all future thermoelectric power plants are expected to use $\mathrm{CCC}$, problems with brine concentrating in a saltwater CCC system would make oncethrough cooling more attractive in saltwater applications. However, CCC is assumed in this sensitivity study, though water makeup rates were not adjusted to account for increased brine blowdown.

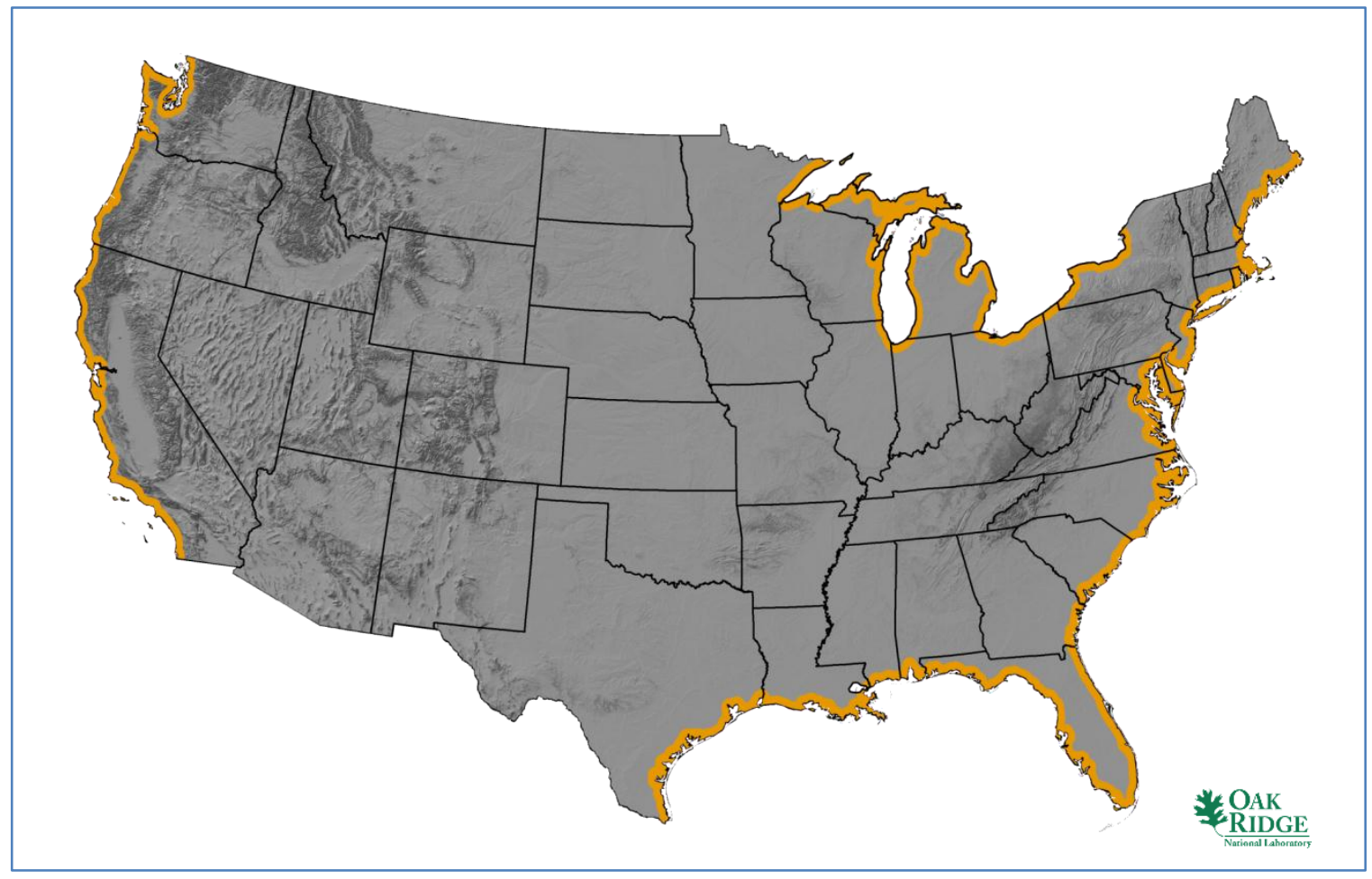

Fig. 44. Coastal cooling SSEC layer.

Figure 45 shows the generic reactor base map after the entire set of reactor SSEC is applied, substituting the ocean cooling SSEC layer for the stream flow cooling SSEC layer. In this sensitivity case, $1.8 \%$ of the contiguous land passes all SSEC limits and is available for cooling from the coast. Since stream flow was the differentiating factor between large and small reactor siting, this base map is applicable to large and small reactors. This depiction of land has not been aggregated for the reactor plant footprint size.

The additional available land for large and small reactor siting based solely on ocean cooling is shown in Fig. 46. This represents $0.23 \%$ of the contiguous United States that was not previously considered by the stream flow cooling case. The aggregated land for the large reactor footprint is $0.05 \%$ of the contiguous United States. The aggregated land for the small reactor footprint is $0.11 \%$ of the contiguous United States. This is not a significant increase, but it does represent approximately 850 thousand additional acres in the large reactor case and 1.9 million acres in the small reactor case. In addition, there is increased availability for plant placement based on land with the option of stream flow cooling or ocean cooling as depicted in Fig. 47. Figure 47 shows areas where ocean cooling is an alternative to stream cooling. Areas in black and purple depict additional siting areas that could be coastal cooled only (black-large or small reactor; purple - small reactors only). Areas in blue depict areas where plants could be stream cooled or coastal cooled. These areas can be further evaluated for additional siting capacity. 


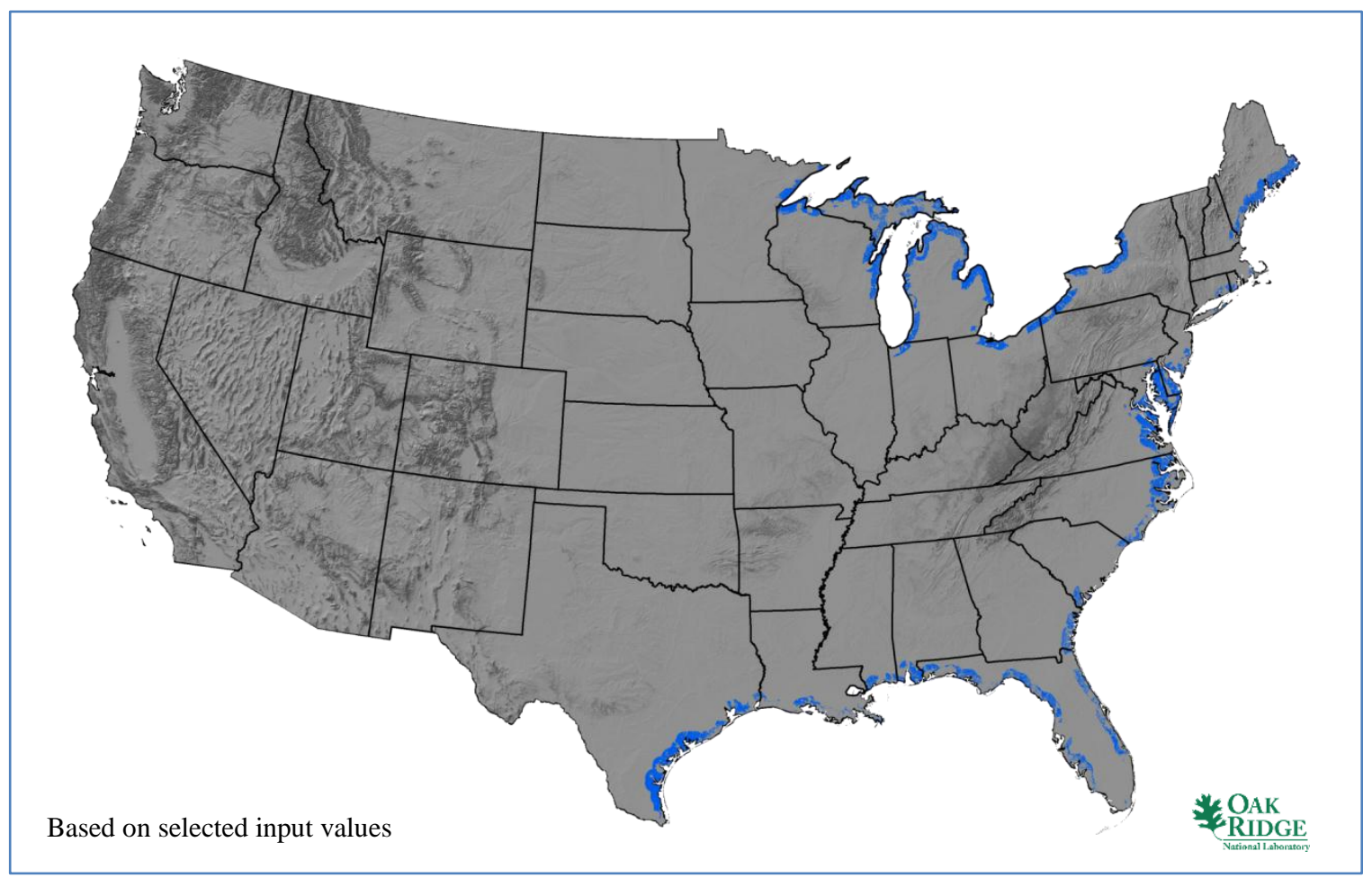

Fig. 45. Large reactor base map after applying coastal SSEC layer.

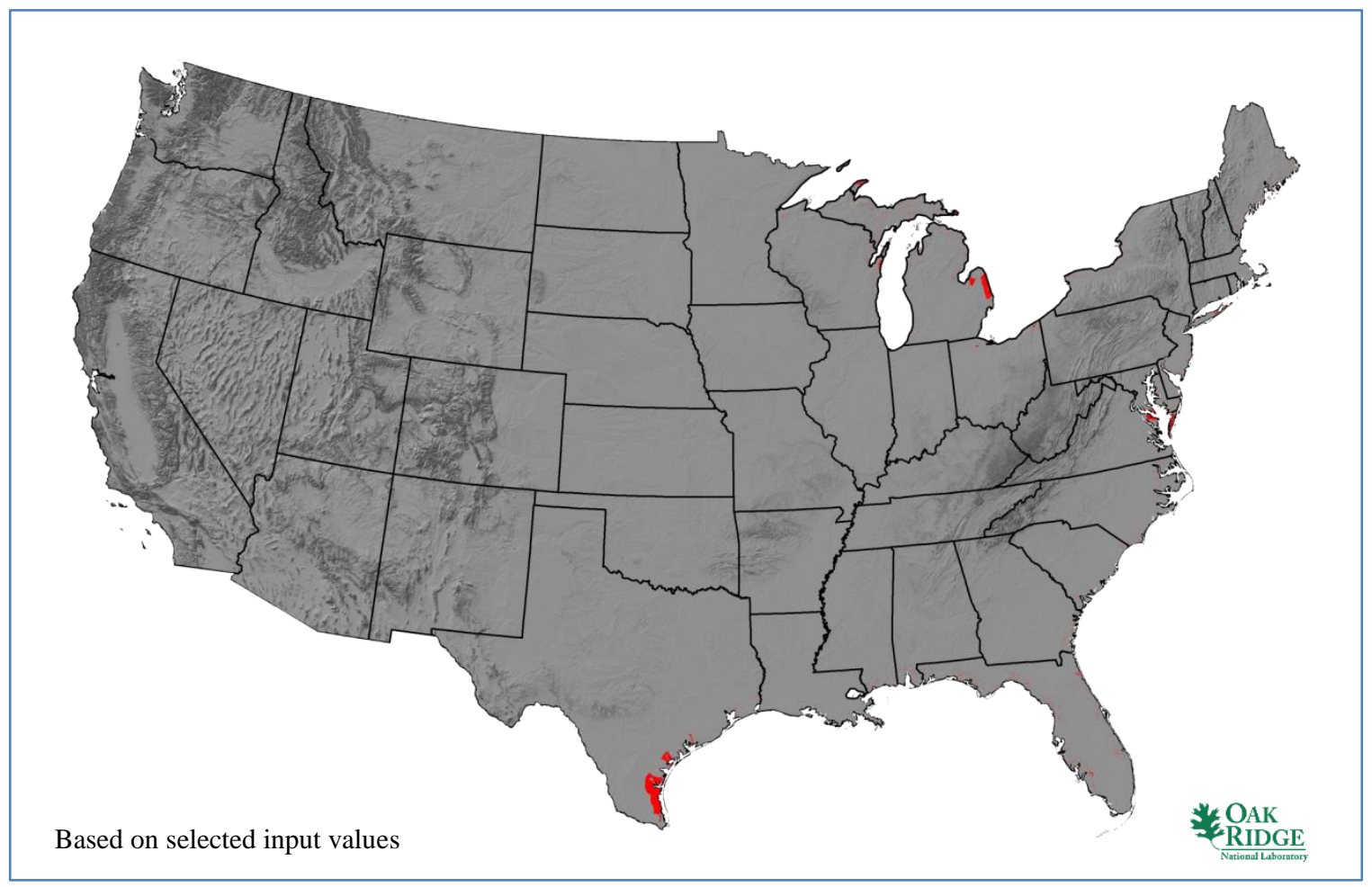

Fig. 46. Additional land for reactor siting based exclusively on coastal cooling. 


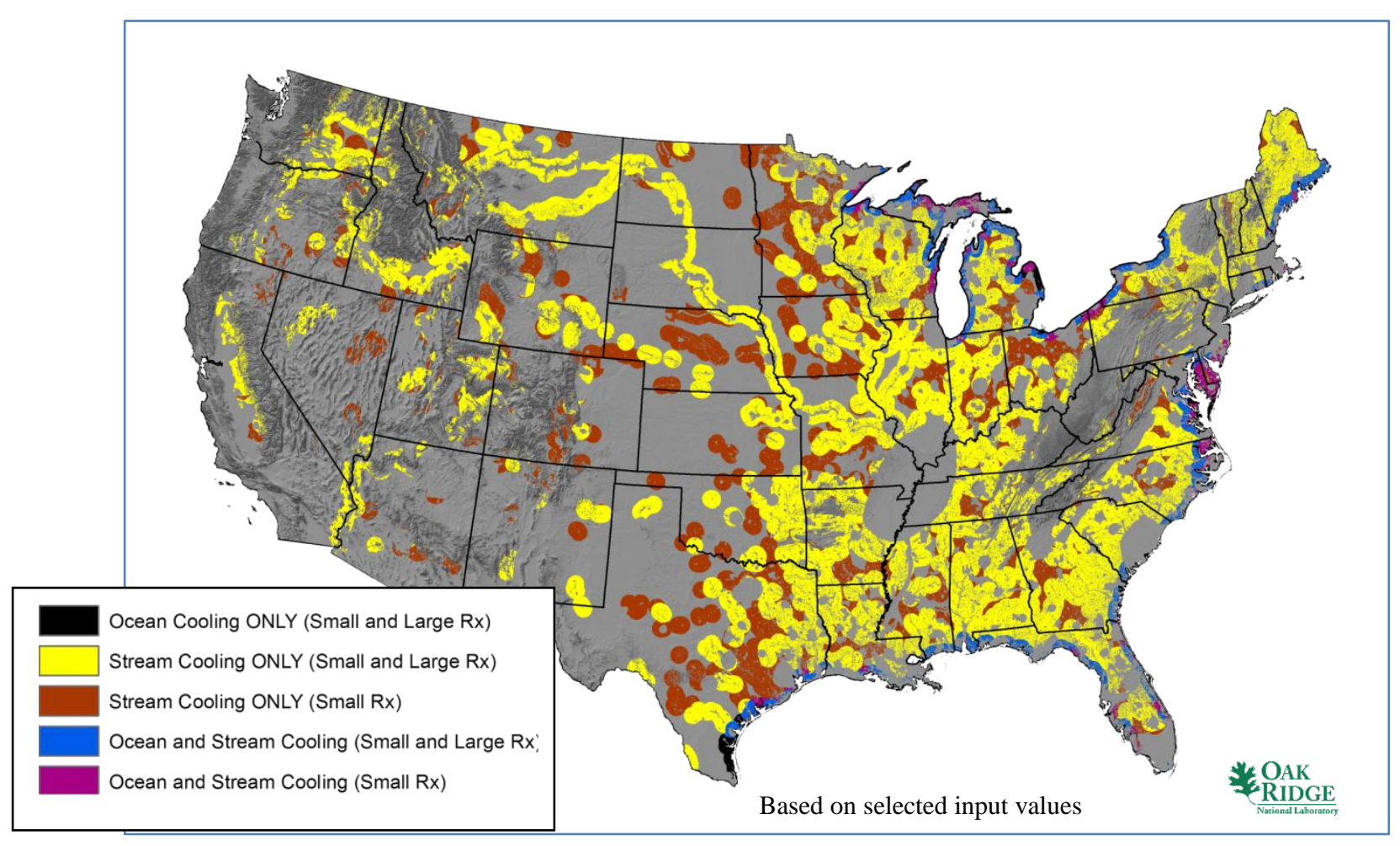

Fig. 47. Large and small reactor siting opportunities including coastal cooling.

\subsubsection{2035 Projections}

Over time, the siting options change depending on a wealth of factors, including load growth, population shifts, increased demand for fresh water, technology improvements, changed regulatory environment, climate shifts, and others. In addition, new power generation requires planning, financing, permitting, and construction. For nuclear power, this process can take more than a decade. GIS projections are only as good as the underlying data and trends, and uncertainty increases with the length of time projected. For these reasons, as discussed in the section "2035 Assumptions," a projection 25 years in the future was prepared for large nuclear power generation, based on population data and trends available to ORNL in its LandScan USA dataset and on a revised rule of thumb for fresh water availability to power generation.

Figure 48 depicts the projected 2035 population SSEC layer for nuclear power plants. As discussed previously, a population density of greater than 500 people per square mile begins to transition into an urban setting; so new nuclear plants in these areas, shown in red, continue to be excluded using the 2035 population projection. Figure 49 provides the comparable population SSEC layer for 2010.

Likewise, Fig. 49 shows the areas excluded in red based on a reduced availability of fresh water for CCC makeup in the future. To approximate the increased demand on water supplies in the future, it was decided that the simple rule of thumb to apply to the 2035 case would be that a given power source should not take more than $5 \%$ of the available stream flow at a given "new plant" location as opposed to $10 \%$ in the 2010 timeframe. Table 5 shows the resulting effect on stream flow: 400,000 gpm available within 20 miles in the case of large nuclear plants. Figure 30 provides the comparable stream flow SSEC layer for 2010 based on 200,000 gpm available within 20 miles. 


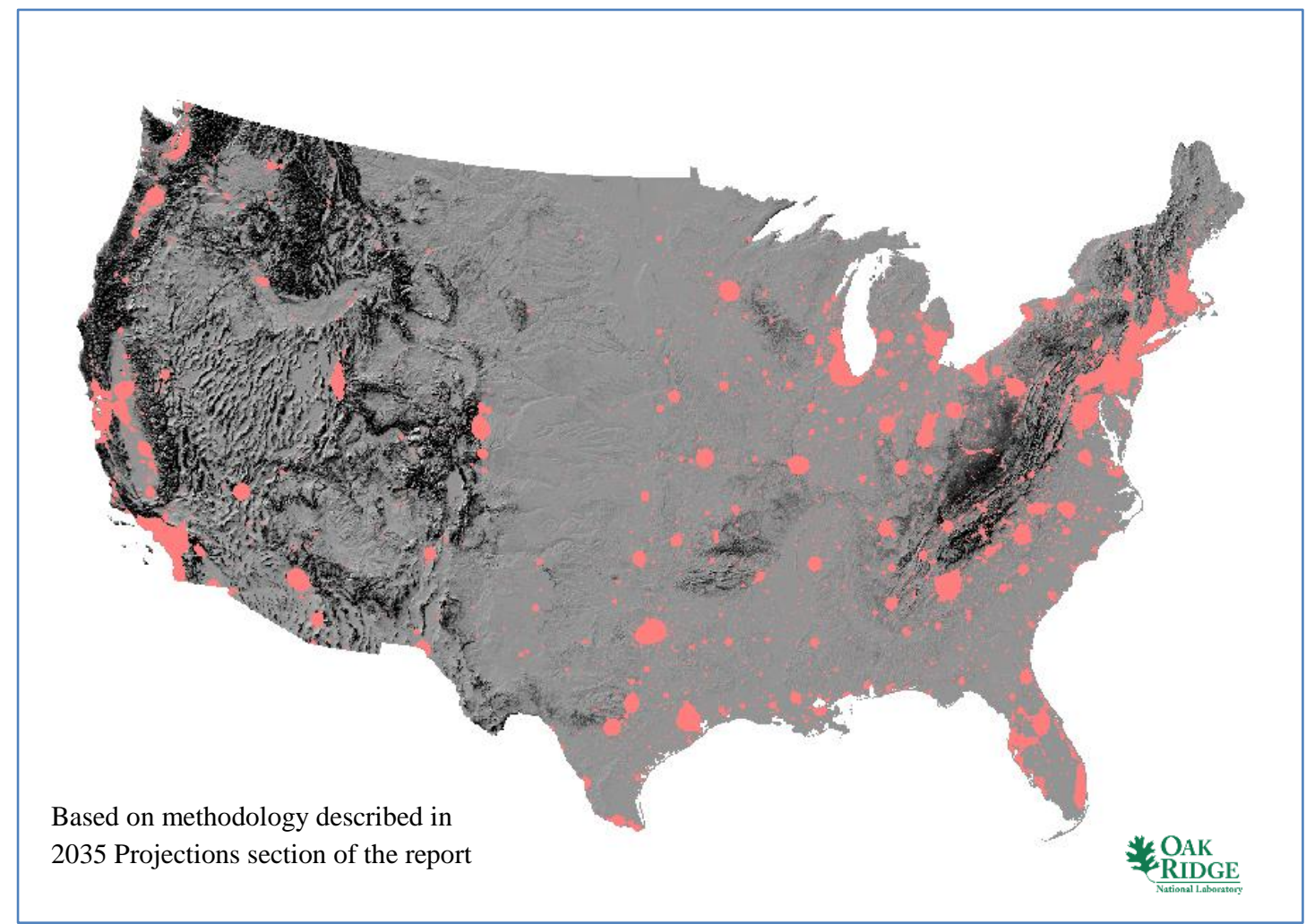

Fig. 48. Nuclear plant 2035 high population SSEC layer including 20-mile buffer.

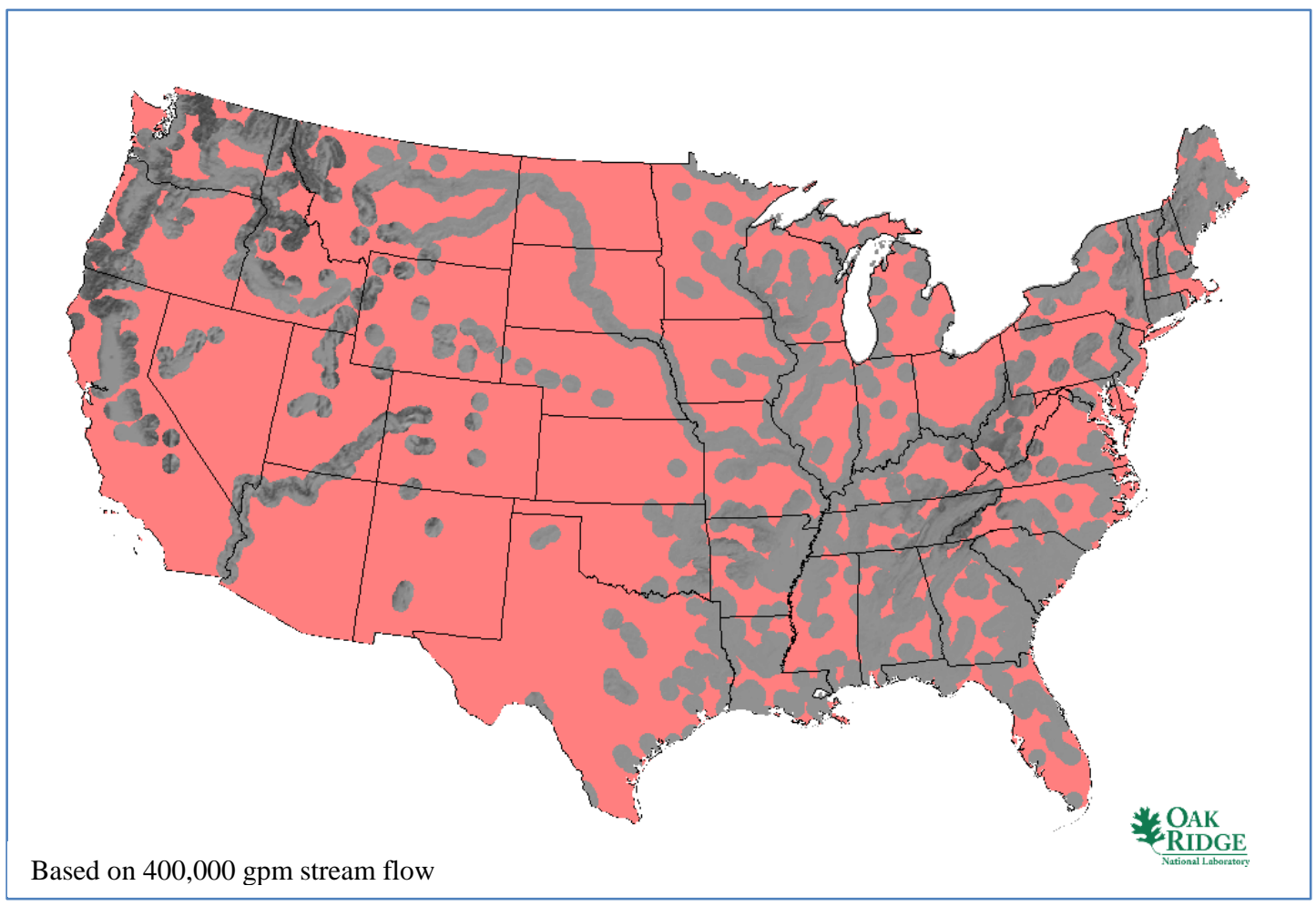

Fig. 49. Large nuclear plant 2035 low stream flow SSEC layer. 
As a result of substituting the 2035 projected SSEC layers shown in Figs. 48 and 49, the available land for siting a large reactor plant is diminished for 2035. Based on these projections and the previously selected values for the large reactor plant siting, Fig. 50 depicts the 2035 large reactor base map indicating 16\% of the contiguous United States is available, or 274 million acres. Compare this with the 2010 large reactor base map shown in Fig. 35, where 22\% of the contiguous United States is available, or 377 million acres. The 2035 projection for large reactor plants indicates a reduction in available land equivalent to 6\% of the contiguous United States, or a reduction of 103 million acres, before consideration of land aggregation to meet the nominal plant footprint size.

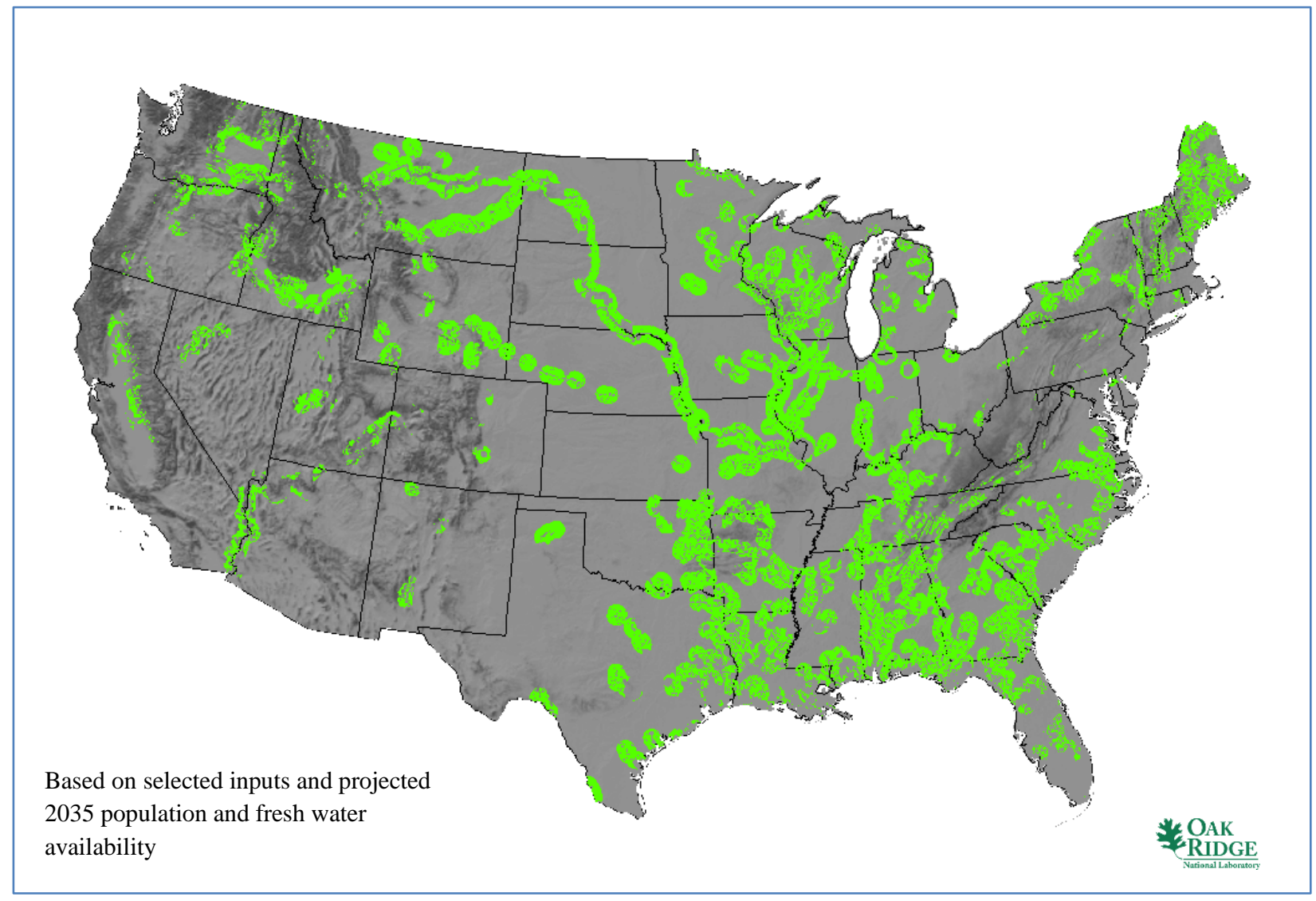

Fig. 50. Large nuclear plant 2035 base map.

The results of aggregating the projected available land from the base case as shown in Fig. 50 are depicted in green in Fig. 51. Land aggregation for a nominal 500-acre large reactor facility reduces the available land from $16 \%$ of the contiguous United States in the 2035 base case to $10 \%$ or 171 million acres. This is an actual reduction of $3 \%$ of the contiguous United States or 51 million acres compared with the aggregated land calculation for 2010 shown in Fig. 36, or a relative decrease of $23 \%$.

Figure 52 provides a visual comparison of the aggregated land available for large reactor plant siting, based on selected SSEC input parameters, for the 2010 and 2035 scenarios. Figure 52 shows that much of the land lost in the 2035 projection occurs in the isolated areas near presently available cooling water; these areas appear as individual circles. The population effects are less widespread; Census data projects that most population growth will occur in urban areas that already have high population densities, and population loss will occur in rural areas that already have low population densities. 
A rough comparison with the plant placement algorithm calculated for the 2010 large reactor plant base case would suggest that available new large reactor plant gross capacity would be decreased from $515 \mathrm{GW}(\mathrm{e})$ to approximately $396 \mathrm{GW}(\mathrm{e})$ by delaying installed new large reactor plant capacity to 2035 .

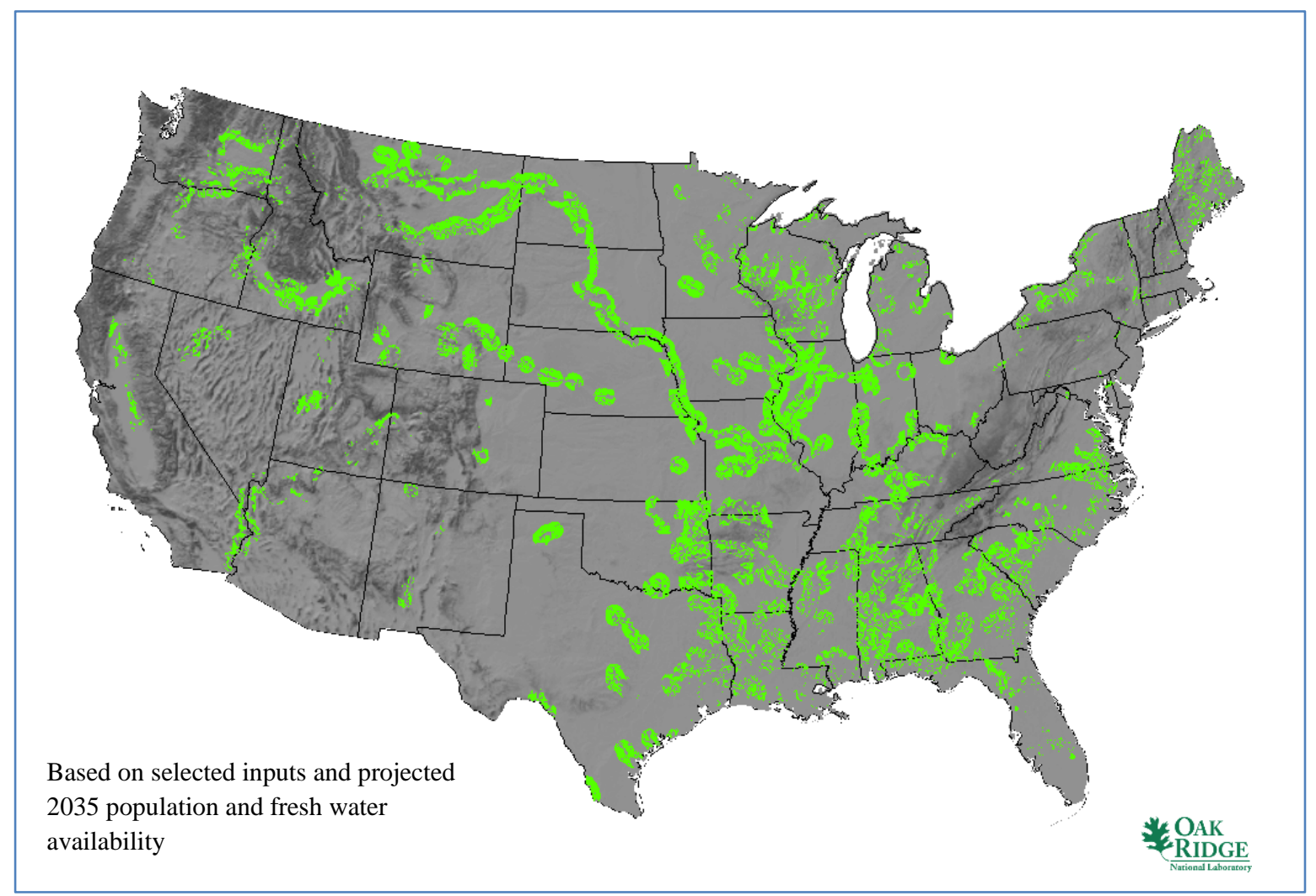

Fig. 51. Large reactor plant 2035 siting aggregated at $90 \%$ for 500 acre facility. 


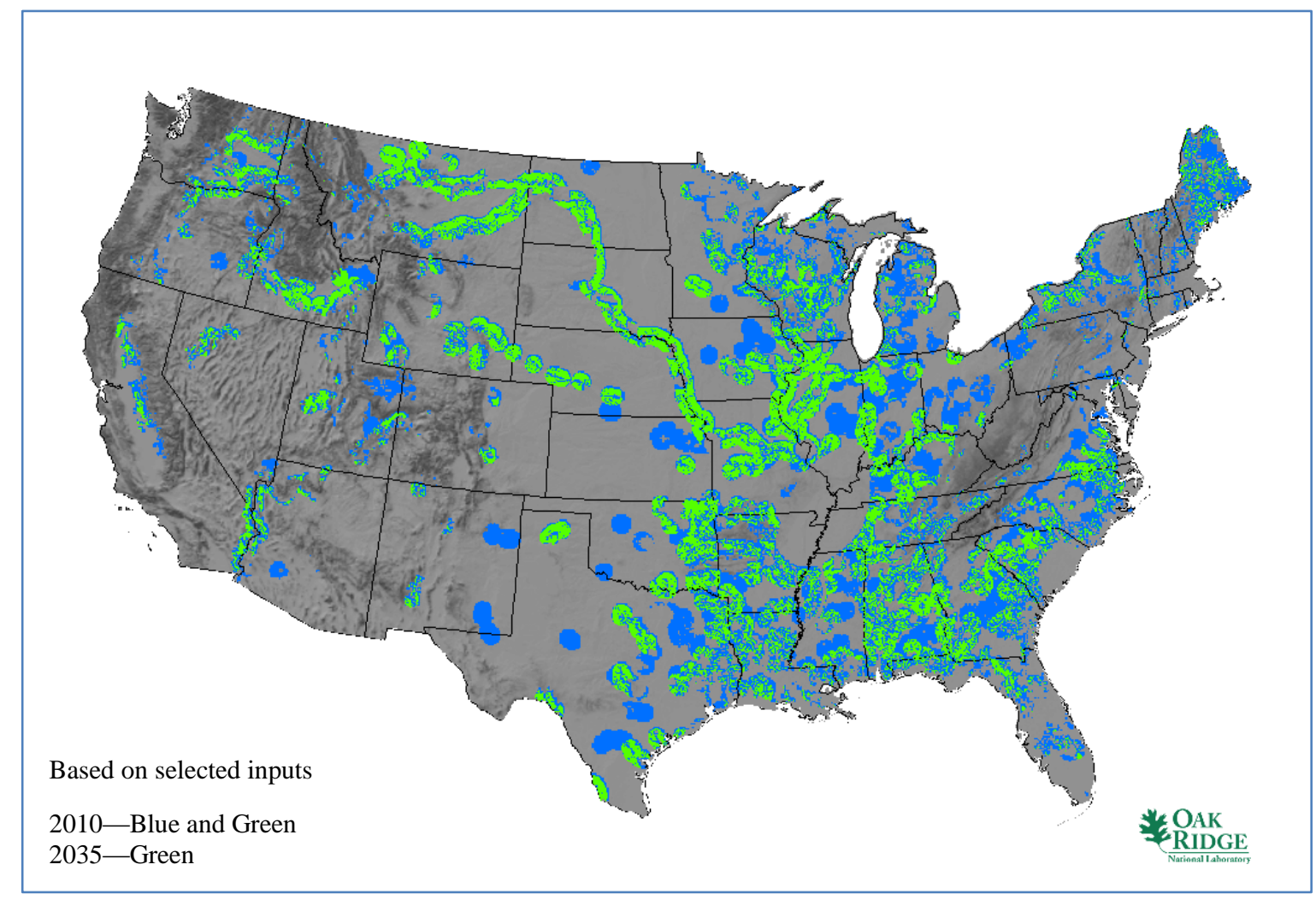

Fig. 52. Large reactor plant visual comparison of 2010 and 2035 aggregated land results.

\subsubsection{Tabular Results}

Table 6 shows the large reactor plant estimated results by state. An entry of 0.00 indicates a value greater than zero that does not show at two significant digits, while a blank entry implies a zero response. Note that the tabular results are not intended to show a "final" result. These results are based on a selected set of input values and a capacity projection algorithm. The relative values between states are the more significant table information. It should be further noted that Table 6 details only the results of aggregated land cells that had no siting challenges. Engineered solutions for land with one or more siting challenges would impact the entries included in Table 6.

Table 6 supports the fact that the Southeast has strong potential for large nuclear plant capacity. In addition, the northwestern states of Washington, Idaho, and Montana have extremely strong capacity based on plentiful cooling water. However, the projected demand in these northwestern states does not warrant the estimated capacity for large reactors based on the OR-SAGE capacity estimate algorithm. 
Table 6. Large nuclear plant results by state (no siting challenges, selected SSEC values)

\begin{tabular}{|c|c|c|c|}
\hline State $^{a}$ & $\begin{array}{c}\text { Portion of state } \\
\text { available to support } \\
500 \text { acre sites } \\
(\%)^{b}\end{array}$ & $\begin{array}{c}\text { Portion of contiguous } \\
\text { US available to } \\
\text { support } 500 \text { acre sites } \\
(\%)\end{array}$ & $\begin{array}{c}\text { Estimated capacity } \\
{[\mathrm{MW}(\mathrm{e})]^{c}}\end{array}$ \\
\hline Alabama & 39.47 & 0.69 & 22,400 \\
\hline Arizona & 2.78 & 0.11 & 14,400 \\
\hline Arkansas & 22.47 & 0.40 & 17,600 \\
\hline California & 2.99 & 0.16 & 14,400 \\
\hline Colorado & 1.86 & 0.06 & 6,400 \\
\hline Connecticut & 2.03 & 0.00 & \\
\hline Delaware & 2.21 & 0.00 & \\
\hline \multicolumn{4}{|c|}{ District of Columbia } \\
\hline Florida & 9.52 & 0.18 & 8,000 \\
\hline Georgia & 25.57 & 0.50 & 16,000 \\
\hline Idaho & 12.93 & 0.36 & 30,400 \\
\hline Illinois & 41.01 & 0.76 & 16,000 \\
\hline Indiana & 42.59 & 0.51 & 12,800 \\
\hline Iowa & 26.94 & 0.50 & 6,400 \\
\hline Kansas & 9.82 & 0.27 & 1,600 \\
\hline Kentucky & 23.59 & 0.31 & 12,800 \\
\hline Louisiana & 17.41 & 0.27 & 16,000 \\
\hline Maine & 18.12 & 0.19 & 12,800 \\
\hline Maryland & 6.02 & 0.02 & 1,600 \\
\hline Massachusetts & 1.70 & 0.00 & 1,600 \\
\hline Michigan & 13.72 & 0.26 & 1,600 \\
\hline Minnesota & 10.39 & 0.29 & 14,400 \\
\hline Mississippi & 23.77 & 0.38 & 9,600 \\
\hline Missouri & 25.02 & 0.58 & 11,200 \\
\hline Montana & 15.52 & 0.76 & 54,400 \\
\hline Nebraska & 13.29 & 0.34 & 12,800 \\
\hline Nevada & 2.09 & 0.08 & 3,200 \\
\hline New Hampshire & 3.36 & 0.01 & 3,200 \\
\hline New Jersey & 1.74 & 0.00 & 1,600 \\
\hline New Mexico & 5.26 & 0.21 & 1,600 \\
\hline New York & 10.78 & 0.17 & 8,000 \\
\hline North Carolina & 15.09 & 0.25 & 11,200 \\
\hline North Dakota & 10.41 & 0.25 & 12,800 \\
\hline Ohio & 16.81 & 0.23 & 6,400 \\
\hline Oklahoma & 24.05 & 0.56 & 14,400 \\
\hline Oregon & 4.88 & 0.16 & 12,800 \\
\hline Pennsylvania & 4.96 & 0.07 & 9,600 \\
\hline Rhode Island & 1.13 & 0.00 & \\
\hline
\end{tabular}


Table 6 (continued)

\begin{tabular}{|c|c|c|c|}
\hline State $^{a}$ & $\begin{array}{l}\text { Portion of state } \\
\text { available to support } \\
500 \text { acre sites } \\
\quad(\%)^{b}\end{array}$ & $\begin{array}{l}\text { Portion of contiguous } \\
\text { US available to } \\
\text { support } 500 \text { acre sites } \\
\qquad(\%)\end{array}$ & $\begin{array}{c}\text { Estimated capacity } \\
{[\mathrm{MW}(\mathrm{e})]^{c}}\end{array}$ \\
\hline South Carolina & 22.91 & 0.24 & 6,400 \\
\hline South Dakota & 9.48 & 0.24 & 11,200 \\
\hline Tennessee & 15.55 & 0.22 & 14,400 \\
\hline Texas & 13.00 & 1.17 & 14,400 \\
\hline Utah & 6.47 & 0.18 & 12,800 \\
\hline Vermont & 2.13 & 0.01 & 3,200 \\
\hline Virginia & 15.66 & 0.21 & 4,800 \\
\hline Washington & 9.89 & 0.22 & 25,600 \\
\hline West Virginia & 0.79 & 0.01 & 3,200 \\
\hline Wisconsin & 22.28 & 0.41 & 11,200 \\
\hline Wyoming & 10.45 & 0.34 & 8,000 \\
\hline Total & - & 13.15 & 515,200 \\
\hline \multicolumn{4}{|c|}{$\begin{array}{l}{ }^{a} \text { Generation capacity estimate is discussed in "Plant Placement Algorithm for Water-Dependent Power Sources." } \\
{ }^{b} \text { Land for sites is aggregated at } 90 \% \text { as discussed in "Methodology for Aggregating Land for the Typical Plant } \\
\text { Size." }\end{array}$} \\
\hline
\end{tabular}

Table 7 shows the large reactor plant estimated results by water region. Individual states may be wholly contained within a single water region or they may be part of multiple water regions. Figure 20 shows a US state map with the 18 water regions as an overlay. Note that the tabular results are not intended to show a "final" result. These results are based on a selected set of input values and a capacity projection algorithm. The relative values between regions are the more significant table information. It should be further noted that Table 7 details only the results of aggregated land cells that had no siting challenges. Engineered solutions for land with one or more siting challenges would impact the entries included in Table 7.

Table 7. Large reactor plant results by region (no siting challenges, selected SSEC values)

\begin{tabular}{|c|c|c|c|}
\hline Region $^{a}$ & $\begin{array}{c}\text { Portion of region } \\
\text { available to support } \\
500 \text { acre sites } \\
(\%)^{b}\end{array}$ & $\begin{array}{c}\text { Portion of contiguous } \\
\text { US available to } \\
\text { support } 500 \text { acre sites } \\
(\%)\end{array}$ & $\begin{array}{l}\text { Estimated capacity } \\
{[\mathrm{MW}(\mathrm{e})]^{c}}\end{array}$ \\
\hline 1. New England & 10.81 & 0.22 & 19,200 \\
\hline 2. Mid Atlantic & 5.33 & 0.18 & 20,800 \\
\hline 3. South Atlantic-Gulf & 23.37 & 2.11 & 70,400 \\
\hline 4. Great Lakes & 15.11 & 0.59 & 3,200 \\
\hline 5. Ohio & 22.22 & 1.20 & 46,400 \\
\hline 6. Tennessee & 14.88 & 0.20 & 9,600 \\
\hline 7. Upper Mississippi & 28.66 & 1.80 & 36,800 \\
\hline
\end{tabular}


Table 7. (continued)

\begin{tabular}{lccr}
\hline \multicolumn{1}{c}{ Region $^{a}$} & $\begin{array}{c}\text { Portion of region } \\
\text { available to support } \\
\mathbf{5 0 0} \text { acre sites } \\
(\mathbf{\%})^{\mathbf{b}}\end{array}$ & $\begin{array}{c}\text { Portion of contiguous } \\
\text { US available to } \\
\text { support 500 acre sites } \\
\mathbf{( \% )}\end{array}$ & $\begin{array}{c}\text { Estimated capacity } \\
{[\mathbf{M W}(\mathbf{e})]^{c}}\end{array}$ \\
\hline 8. Lower Mississippi & 15.75 & 0.53 & 19,200 \\
9. Souris-Red-Rainy & 2.67 & 0.05 & 8,000 \\
10. Missouri & 14.84 & 2.51 & 102,400 \\
11. Arkansas-White-Red & 15.62 & 1.29 & 33,600 \\
12. Texas-Gulf & 14.14 & 0.86 & 11,200 \\
13. Rio Grande & 5.09 & 0.23 & 4,800 \\
14. Upper Colorado & 5.96 & 0.22 & 22,400 \\
15. Lower Colorado & 3.59 & 0.17 & 17,600 \\
16. Great Basin & 2.80 & 0.13 & 1,600 \\
17. Pacific Northwest & 8.12 & 0.74 & 75,200 \\
18. California & 2.28 & 0.12 & 12,800 \\
\hline Total & - & $\mathbf{1 3 . 1 5}$ & $\mathbf{5 1 5 , 2 0 0}$ \\
\hline${ }^{a}$ Generation capacity estimate is discussed in "Plant Placement Algorithm for Water-Dependent Power Sources." \\
${ }^{b}$ Land for sites is aggregated at $90 \%$ as discussed in "Methodology for Aggregating Land for the Typical Plant Size." \\
${ }^{c}$ Plant placement/capacity estimate is completely unbiased. Shifting the initial plant placement upstream or downstream \\
will affect all subsequent proposed plant placements and could affect the regional capacity. \\
\hline
\end{tabular}

\subsection{Small Reactor}

This analysis characterizes suitable areas for "small" reactors. For the purposes of this study, a small reactor is a light water reactor with a nominal output of $350 \mathrm{MW}(\mathrm{e})$, representative of a single small modular reactor (SMR) or a cluster of small reactors. The Department of Energy defines an $\mathrm{SMR}^{19}$ as a reactor with an electrical output of approximately $300 \mathrm{MW}(\mathrm{e})$ or less. Therefore, $350 \mathrm{MW}(\mathrm{e})$ was considered a reasonable bounding estimate of an initial SMR installation. As with the large reactor, the power output is used to determine the necessary stream flow to supply makeup water for cooling, which is subsequently reflected in the SSEC modeling application. Plant cooling in all cases is provided by a closed-cycle mechanical-draft cooling tower with makeup water required for evaporation and blowdown.

\subsubsection{Site Selection and Evaluation Criteria}

The current SSEC for small reactors differs from large reactors only in required cooling flow. The following SSEC were selected for small nuclear power plants:

- Land with a population density greater than 500 people per square mile (including a 20mile buffer) is excluded.

- Land with safe shutdown earthquake peak ground acceleration (2\% chance in a 50-year return period) of greater than $0.3 \mathrm{~g}$ is excluded.

- Land too close to identified fault lines (length determines standoff distance) is excluded.

\footnotetext{
${ }^{19}$ Warren F. Miller, Jr., Assistant Secretary for Nuclear Energy, U.S. DOE, Statement before the Senate Committee on Energy and Natural Resources, December 15, 2009.
} 
- $\quad$ Protected lands (e.g., national parks, historic areas, wildlife refuges) are excluded.

- Land with a slope greater than $12 \%\left(\sim 7^{\circ}\right)$ is excluded.

- Land with a moderate or high landslide hazard susceptibility is excluded.

- Wetlands and open water are excluded.

- Land that lies within a 100-year floodplain is excluded.

- Land areas that are greater than 20 miles from cooling water makeup sources with at least $50,000 \mathrm{gpm}$ are excluded for small reactor plant applications.

- Land located in proximity to hazardous facilities is avoided.

Based on preliminary design information and expert judgment, it is assumed that an SMR single or multimodule site can easily be accommodated on a 50-acre footprint.

Except in Fig. 53, regarding cooling water, the individual SSEC layers for the nominal small reactor plant are the same as for the nominal large reactor plant. As for the large reactor, SMR cooling water requirements are based on rules of thumb for cooling water required per megawatt of generation. ${ }^{9}$ Additionally, it was assumed that cooling water makeup should be limited to taking no more than $10 \%$ of the available stream flow. ${ }^{1}$ This limited the siting of reactor plants to the vicinity of streams with sufficient flow volumes. Twenty miles was considered to be within reasonable proximity to a cooling water source, allowing for pumping. ${ }^{1}$

Areas shown in red are excluded based on the selected input parameter value. Excluded areas in each individual layer can be modified based on different assumptions or requirements for the SSEC.

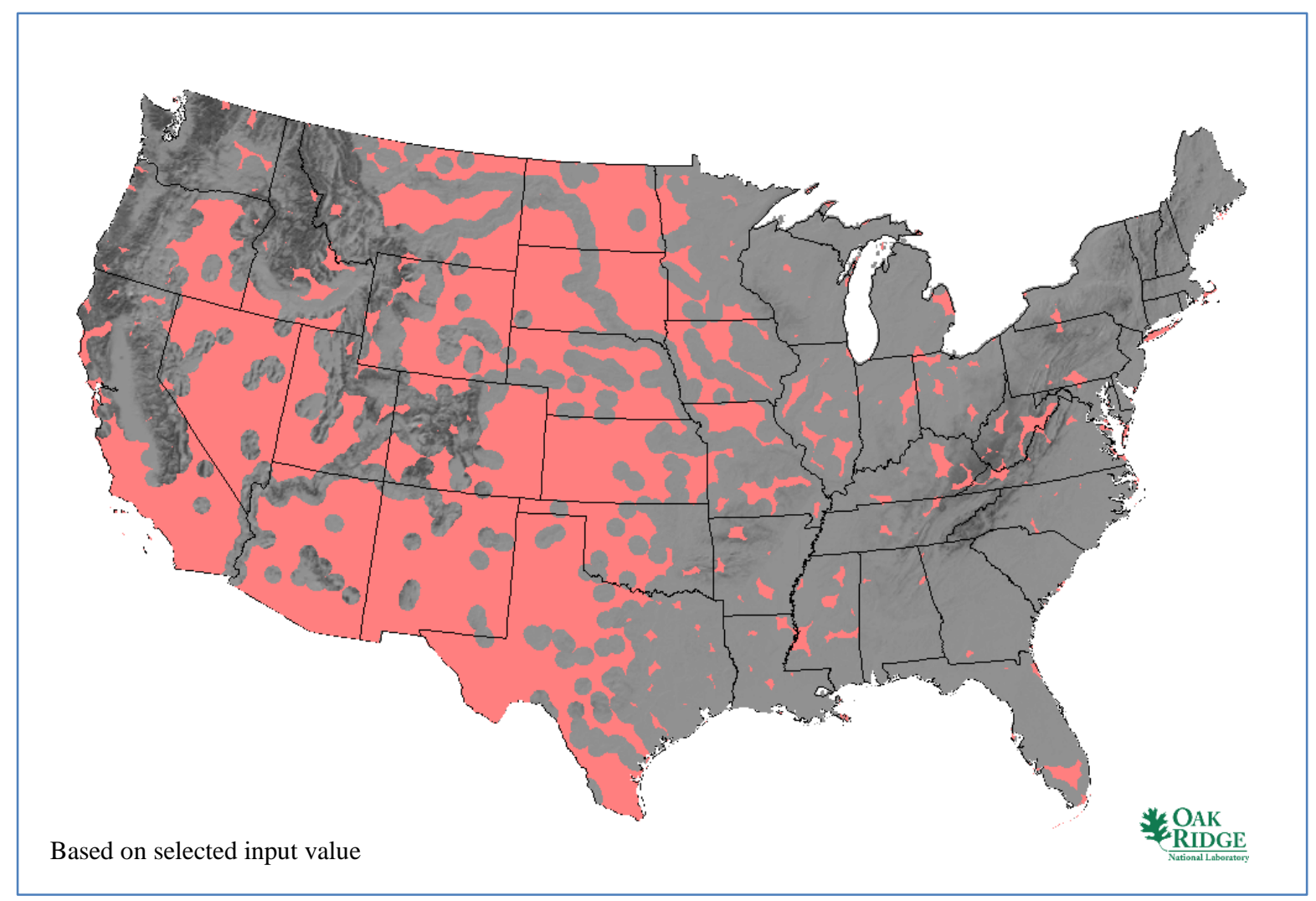

Fig. 53. Small reactor low stream flow SSEC layer ${ }^{20}$.

\footnotetext{
${ }^{20}$ Large reactor minimum low stream flow SSEC layer is shown in Fig. 30 on page 31.
} 
The successive application of each small reactor SSEC layer to the overall available land in the contiguous United States can be captured as a step-down histogram as shown in Fig. 54. Since the SSEC layers are independent, the shape of the cumulative histogram is strictly determined by the order in which the SSEC layers (steps) are applied. However, the end result at step 10 is the same no matter the SSEC layer application order.

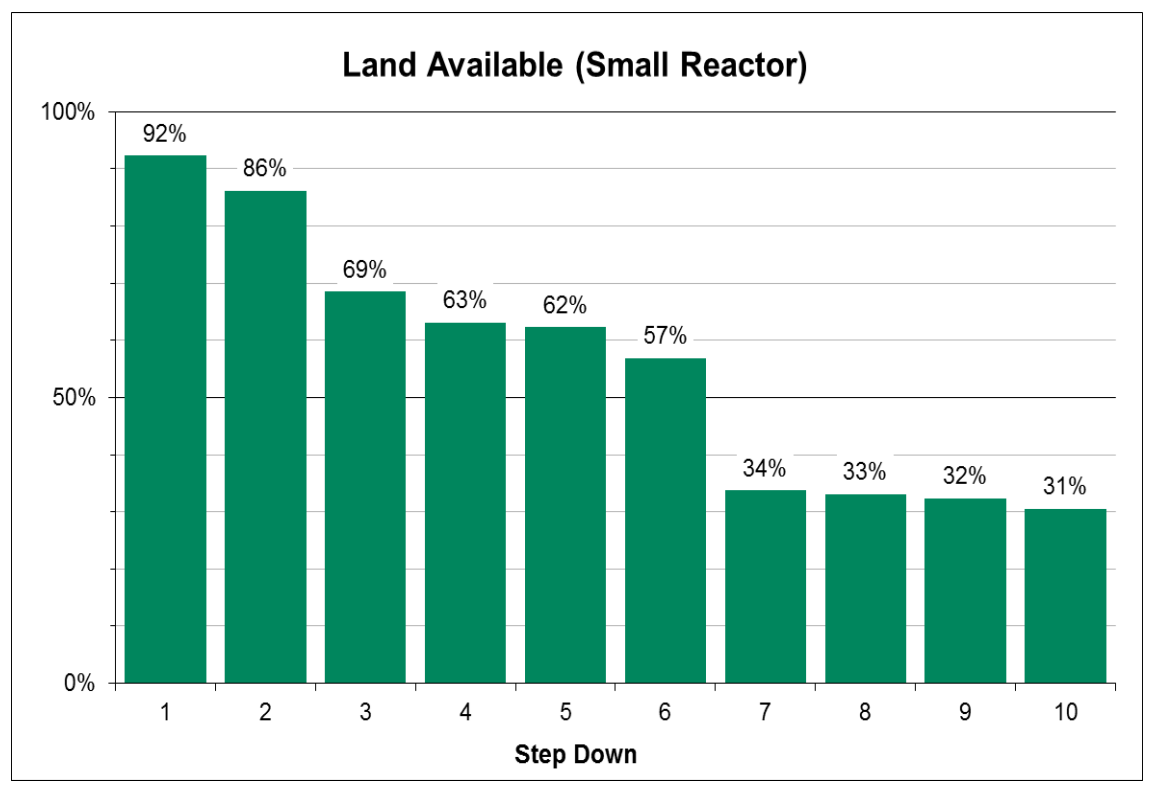

\author{
Order of SSEC Layers \\ 1. Population \\ 2. Wetlands/open \\ water \\ 3. Protected lands \\ 4. Landslide hazard \\ 5. 100-year floodplain \\ 6. Slope \\ 7. Stream-flow \\ 8. Fault lines \\ 9. Hazardous facilities \\ 10. Safe shutdown \\ earthquake
}

Fig. 54. Small reactor step-down histogram.

As with the large reactor case, stream flow is the most significant factor affecting the SMR available land estimate. Future air-cooled SMR designs will have a great impact on the available siting area.

OR-SAGE tracks the parameters for each individual 100 by $100 \mathrm{~m}$ cell. As a result, not only can the cells that are clear of all the SSEC layer exclusions be displayed visually, but also cells that are tripped by one, two, or three or more exclusions can be tracked and displayed. This is known as the small reactor composite map and is shown in Fig. 55. This is a powerful aspect to OR-SAGE, because it allows areas with a limited number of siting challenges to also be identified. Engineering solutions may be available for areas with limited siting challenges. The areas in green in Fig. 55 have no siting challenges based on the selected values for the small reactor SSEC layers. However, the areas in yellow also include a significant land area and have just a single siting challenge. An examination of the individual layers indicates that inadequate stream flow is the most common siting challenge in the mid-section of the contiguous United States. This can lead to consideration of alternative methods of cooling, other than stream flow. There are proposed small reactor designs that are examining an air-cooled option. This would effectively remove the stream flow SSEC layer for such small reactors, greatly expanding the land area with no siting challenges. 


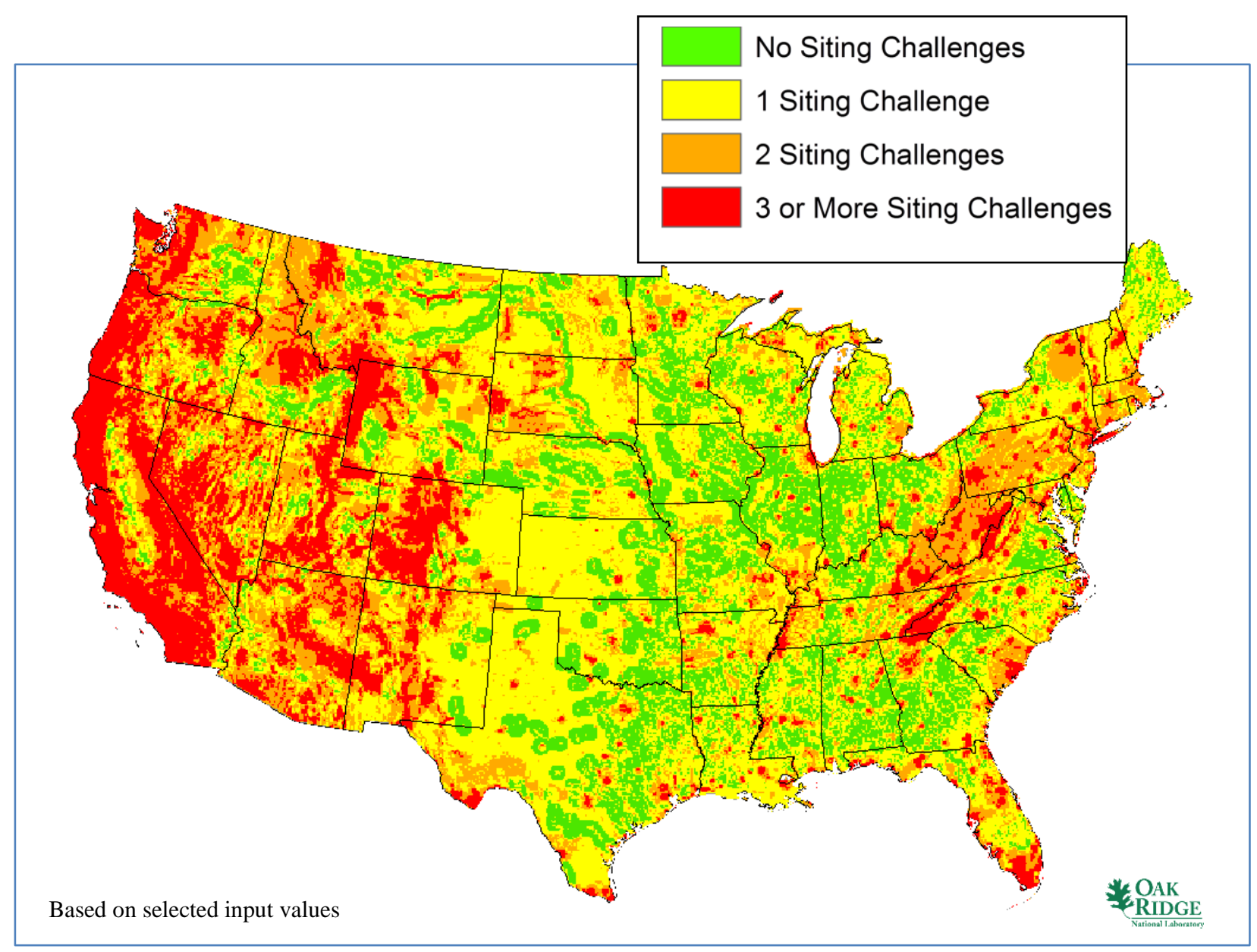

Fig. 55. Small reactor composite map detailing siting challenges.

\subsubsection{Base Map}

The "Approach and Methodology" (Sect. 1.3) section describes the process of developing a base map, which is created to reflect one set of values based on the stated assumptions and nuclear plant SSEC. The base map shows where all SSEC criteria are met. The areas depicted in green from the small reactor composite map shown in Fig. 55 are used to develop the small reactor base map.

The small reactor base map showing only the areas with no siting challenges based on the selected input values for the small reactor SSEC is shown in Fig. 56. The area in green shows areas with no siting challenges and represents $31 \%$ of the contiguous United States. This area has not been aggregated for 50 -acre small reactor sites. 


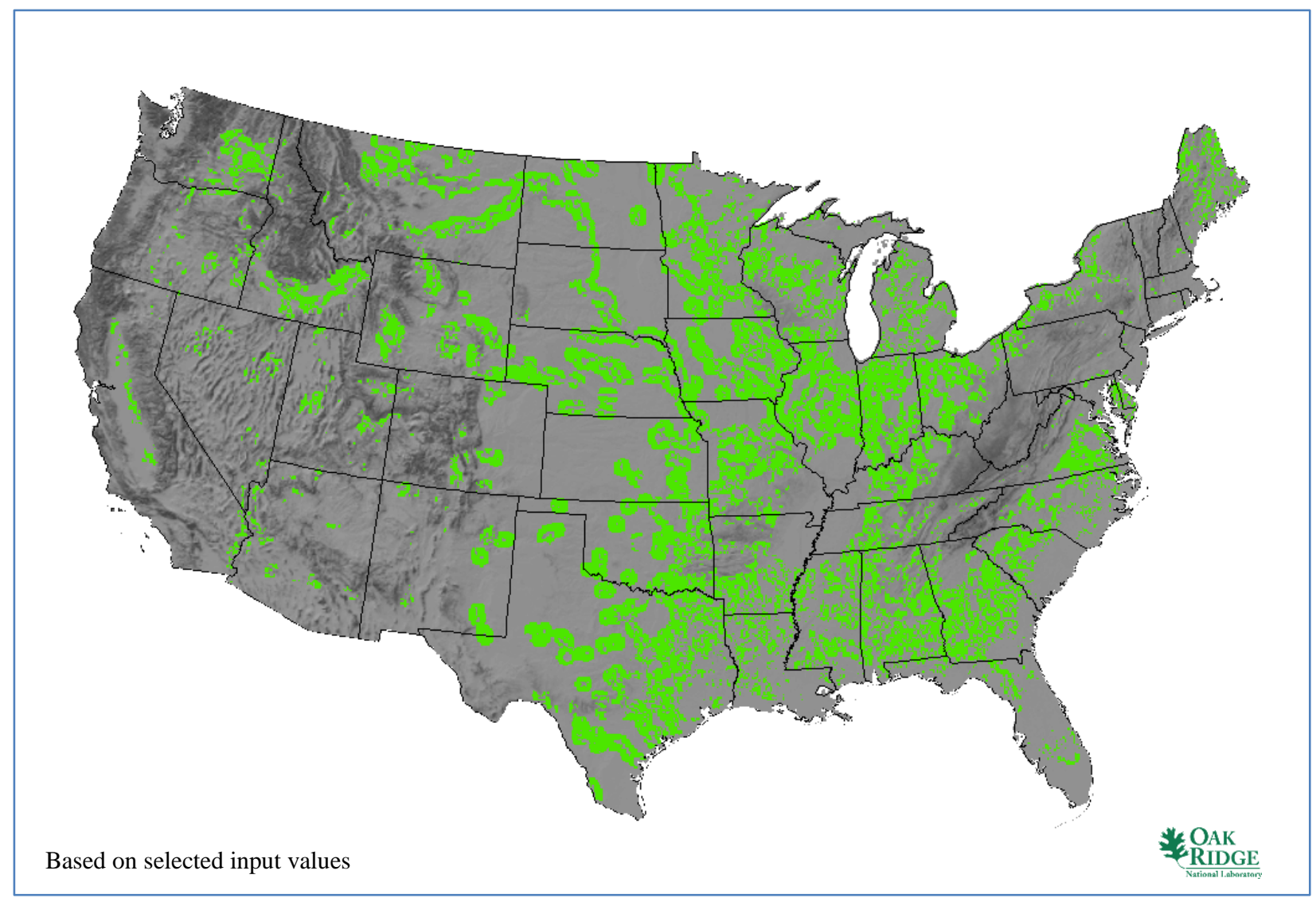

Fig. 56. Small reactor base map.

Figure 57 shows the effect of aggregating the available land from the small reactor base map at a $90 \%$ aggregation rate. The available aggregated land with no siting challenges for small reactor facilities is $24.3 \%$ ( 416 million acres) of the contiguous United States based on the stated assumptions and nuclear plant SSEC.

Figure 57 shows that the green cells follow rivers in the Northwest and the Great Plains states, while the Southeast, Great Lakes, and New England states have sufficient cooling water to have more widespread potential siting areas. The Appalachian and Rocky Mountain ranges, as well as the arid desert regions, generate obvious exclusions. 


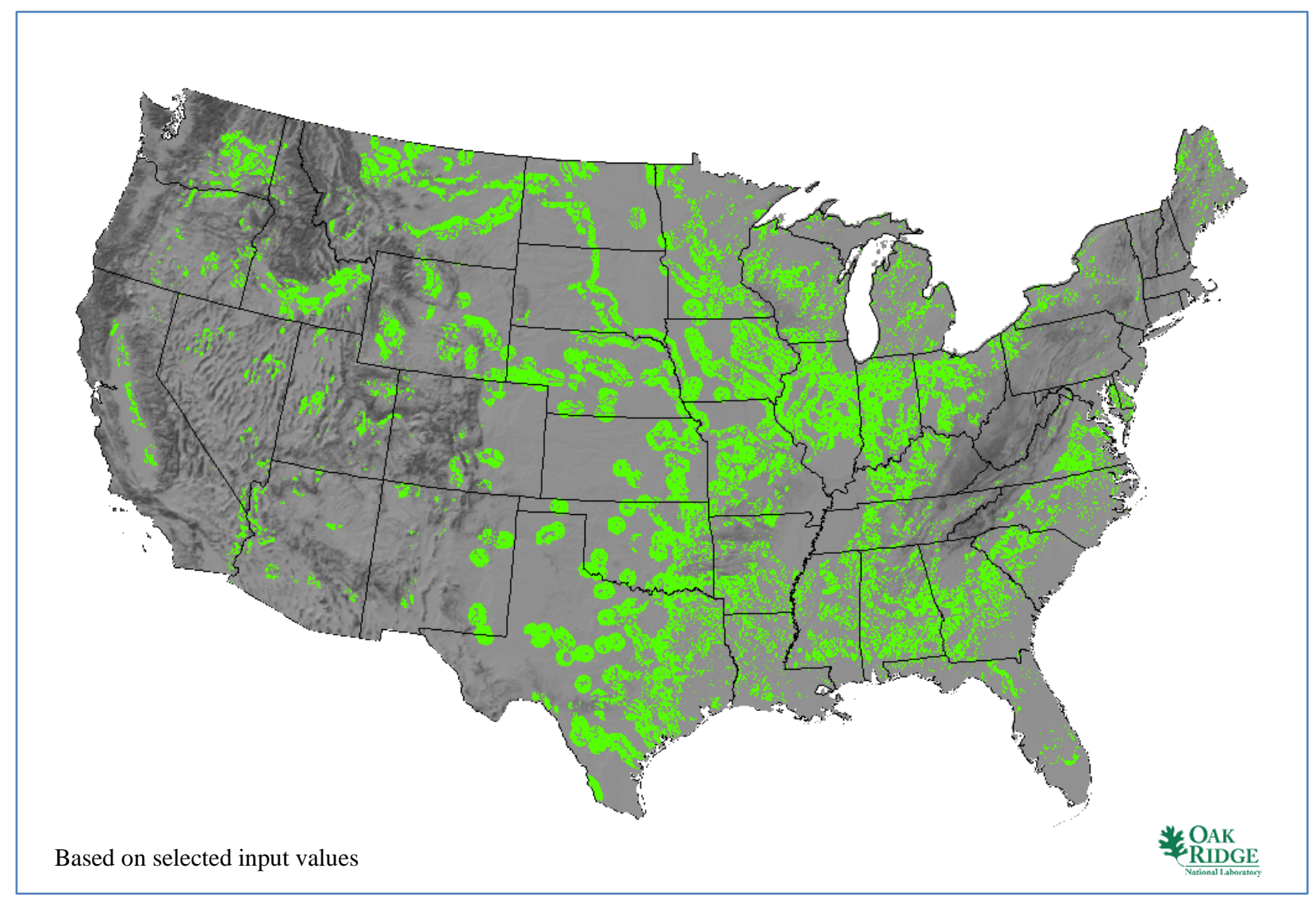

Fig. 57. Small reactor base map aggregated for 50 -acre sites.

\subsubsection{Plant Placement Results}

A calculation of small reactor capacity was estimated using the plant placement methodology. The predictions are based on a nominal $350 \mathrm{MW}(\mathrm{e})$ plant installation positioned on 50 acres of land. This estimate is independent of other thermal plant installation predictions and is not tied directly to current estimates of power demand.

Figure 58 displays the result of the plant placement algorithm for small reactor plants. The plants are projected based on individual water basins. Using this methodology, space and stream flow cooling are available to support placement of at least $201 \mathrm{GW}(\mathrm{e})$ in small reactor plants. Blue dots represent a new single small reactor plant placement and red dots show existing reactor plants of varying sizes. The goal of the plant placement exercise is to predict small reactor plant capacity and not to predict actual plant sites.

The small reactor capacity estimate of $201 \mathrm{GW}(\mathrm{e})$ is a minimum value based on the constraints of the plant placement algorithm. For a more direct comparison with the large reactor case, with an estimated capacity of $515 \mathrm{GW}(\mathrm{e})$, the difference in cooling water demand should be considered. In terms of cooling water demand, a single large site could hold four small sites. Even though the representative small reactor [350 MW(e)] is assumed to use $25 \%$ of the cooling water that a large $1600 \mathrm{MW}(\mathrm{e})$ plant requires, the small reactor generates approximately $22 \%$ as much power. Direct replacement of a single large reactor projected site with four small reactor sites would use the same amount of water and use only 200 of the 500 acres aggregated for the large reactor. This substitution would cause the former large reactor projected sites to generate only $1400 \mathrm{MW}$ instead of $1600 \mathrm{MW}$. However, when this capacity is multiplied over the 322 estimate large reactor sites, the small reactor case would generate $451 \mathrm{GW}(\mathrm{e})$ 
total, or more than double the original calculation at $201 \mathrm{GW}(\mathrm{e})$. Therefore, the small reactor capacity estimate at $201 \mathrm{GW}(\mathrm{e})$ is considered a minimum capacity value.

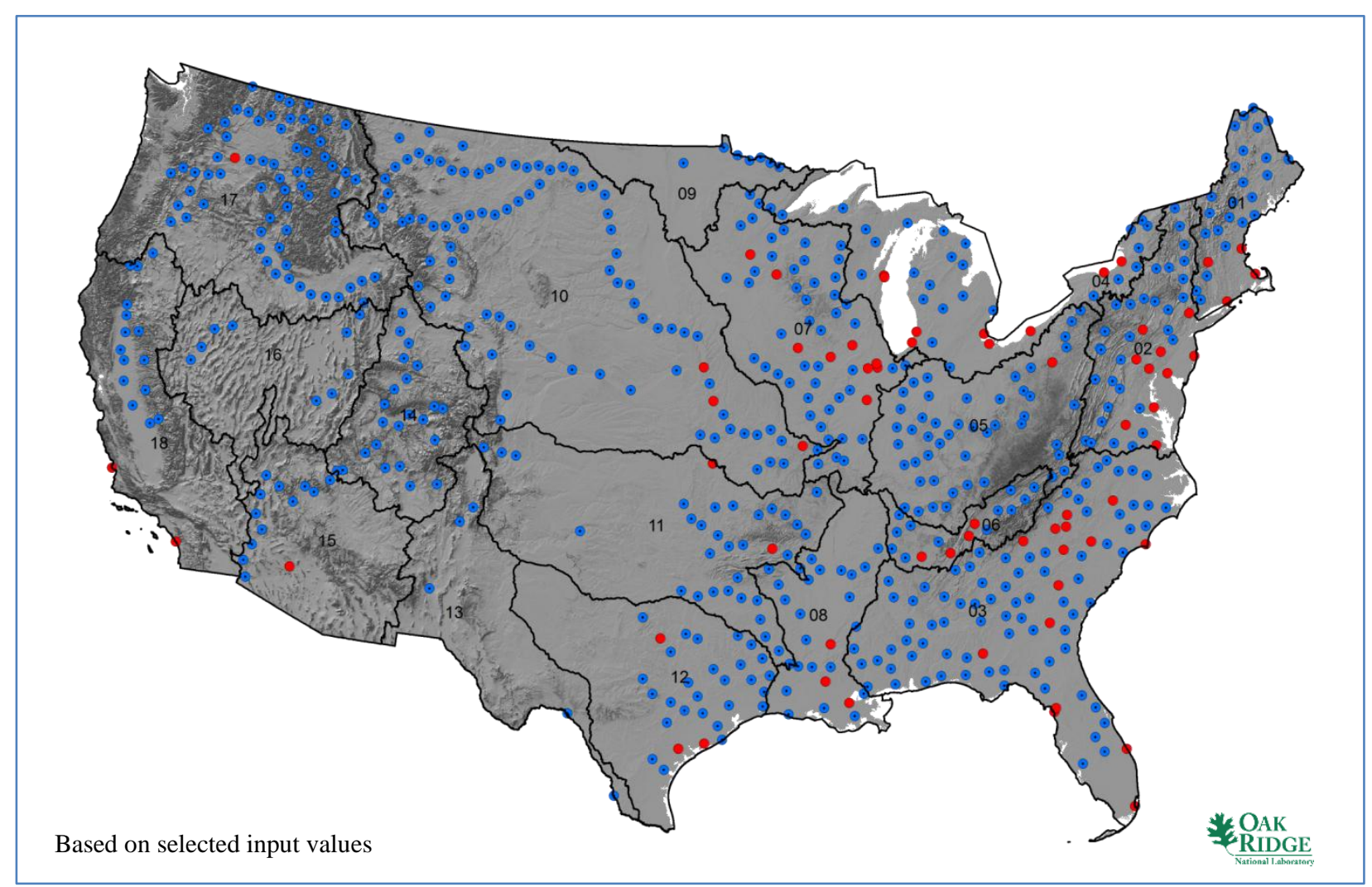

Fig. 58. Small reactor plant placement capacity estimate.

The capacity estimate is shown in Fig. 59 with a state map overlay. State-by-state results can be affected by the unbiased nature of the initial plant placement in any given water basin, the use of single plant sites, and the arbitrary limit of 20 miles between unit projections. The plant capacity estimate indicates that states in a significant portion of the country can support siting at least $3 \mathrm{GW}(\mathrm{e})$ in small reactor facilities with no siting challenges. 


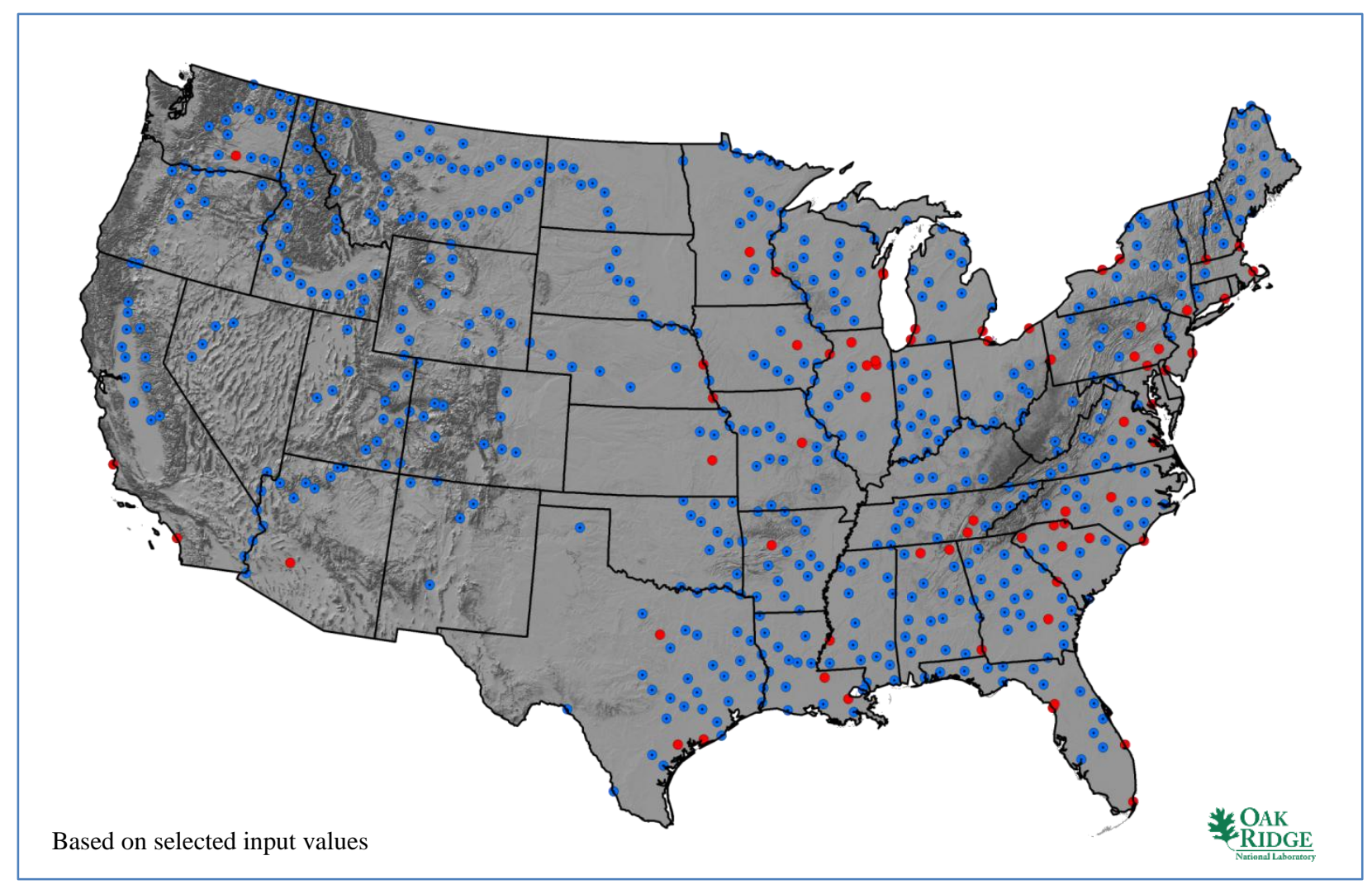

Fig. 59. Small reactor plant placement capacity estimate with state overlay.

Table 8 shows the comparison of large and small reactor siting with no siting challenges based on the selected SSEC and implementing the key siting assumptions. The large reactor and small reactor results are independent of each other.

Table 8. Comparison of independent large reactor and small reactor siting results

\begin{tabular}{lcc}
\hline & Large reactor [1600 MW(e)] & Small reactor [350 MW(e)] \\
\hline Base map (no challenges) & $22 \%$ contiguous US & $31 \%$ contiguous US \\
Land aggregation for reactor footprint & $13 \%$ contiguous US & $24 \%$ contiguous US \\
Number of plants estimated & 322 & 574 \\
Estimate capacity & $515 \mathrm{GW}(\mathrm{e})$ & $201 \mathrm{GW}(\mathrm{e})$ \\
\hline
\end{tabular}

\subsubsection{Sensitivity Studies}

\subsubsection{2035 Projections}

Over time, the siting options change depending on a wealth of factors, including load growth, population shifts, increased demand for fresh water, technology improvements, changed regulatory environment, climate shifts, and others. In addition, new power generation requires planning, financing, permitting, and construction. For nuclear power, this process can take more than a decade. GIS projectionss are only as good as the underlying data and trends, and uncertainty increases with the length of time projected. For these reasons, as discussed in the section "2035 Assumptions," a projection 25 years in the future was 
prepared for small nuclear power generation, based on population data and trends available to ORNL in its LandScan USA dataset and a revised rule of thumb for fresh water availability to power generation.

Figure 48 depicts the projected 2035 population SSEC layer for nuclear power plants. As discussed previously, a population density of more than 500 people per square mile begins to transition into an urban setting; so new nuclear plants in these areas, shown in red, continue to be excluded using the 2035 population projection. Figure 49 provides the comparable population SSEC layer for 2010.

Likewise, Fig. 60 shows the areas excluded in red, based on a reduced availability of fresh water for CCC makeup in the future. To approximate the increased demand on water supplies in the future, it was decided that the simple rule of thumb to apply to the 2035 case would be that a given power source should not take more than $5 \%$ of the available stream flow at a given "new plant" location, as opposed to $10 \%$ in the 2010 timeframe. Table 5 shows the resulting effect on stream flow: 100,000 gpm available within 20 miles in the case of small nuclear plants. Figure 53 provides the comparable stream flow SSEC layer for 2010 based on 50,000 gpm available within 20 miles.

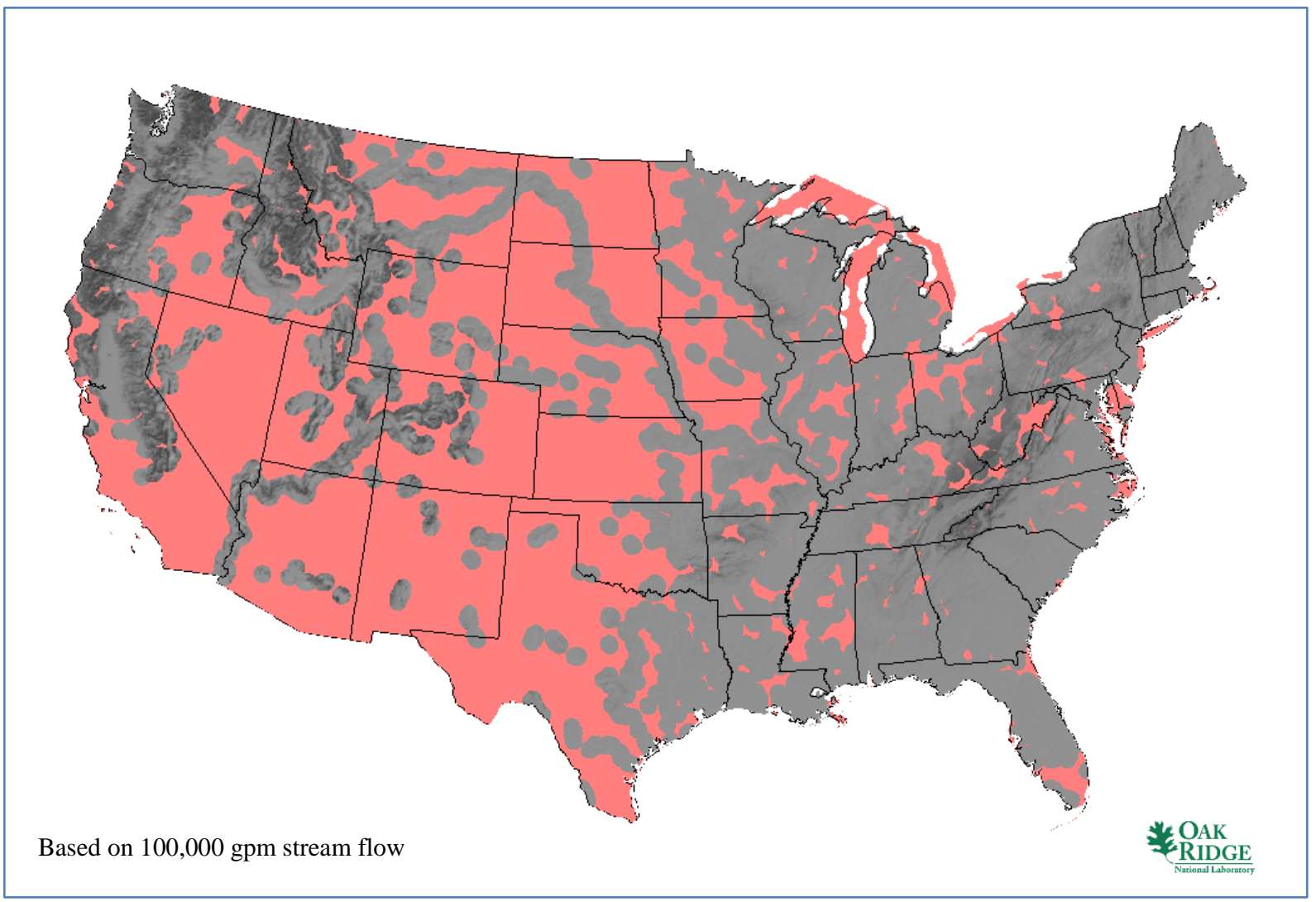

Fig. 60. Small nuclear plant 2035 low stream flow SSEC layer.

As a result of substituting the 2035 projected SSEC layers shown in Figs. 48 and 60, the available land for siting a small reactor plant is diminished for 2035. Based on these projections and the previously selected values for the small reactor plant siting, Fig. 61 depicts the 2035 small reactor base map indicating 26\% of the contiguous United States is available, or 445 million acres. Compare this with the 2010 small reactor base map shown in Fig. 56 on which $31 \%$ of the contiguous United States is available, or 531 million acres. The 2035 projection for small reactor plants indicates a reduction in available land equivalent to $5 \%$ of the contiguous United States or a reduction of 86 million acres before consideration of land aggregation to meet the nominal plant footprint size. 


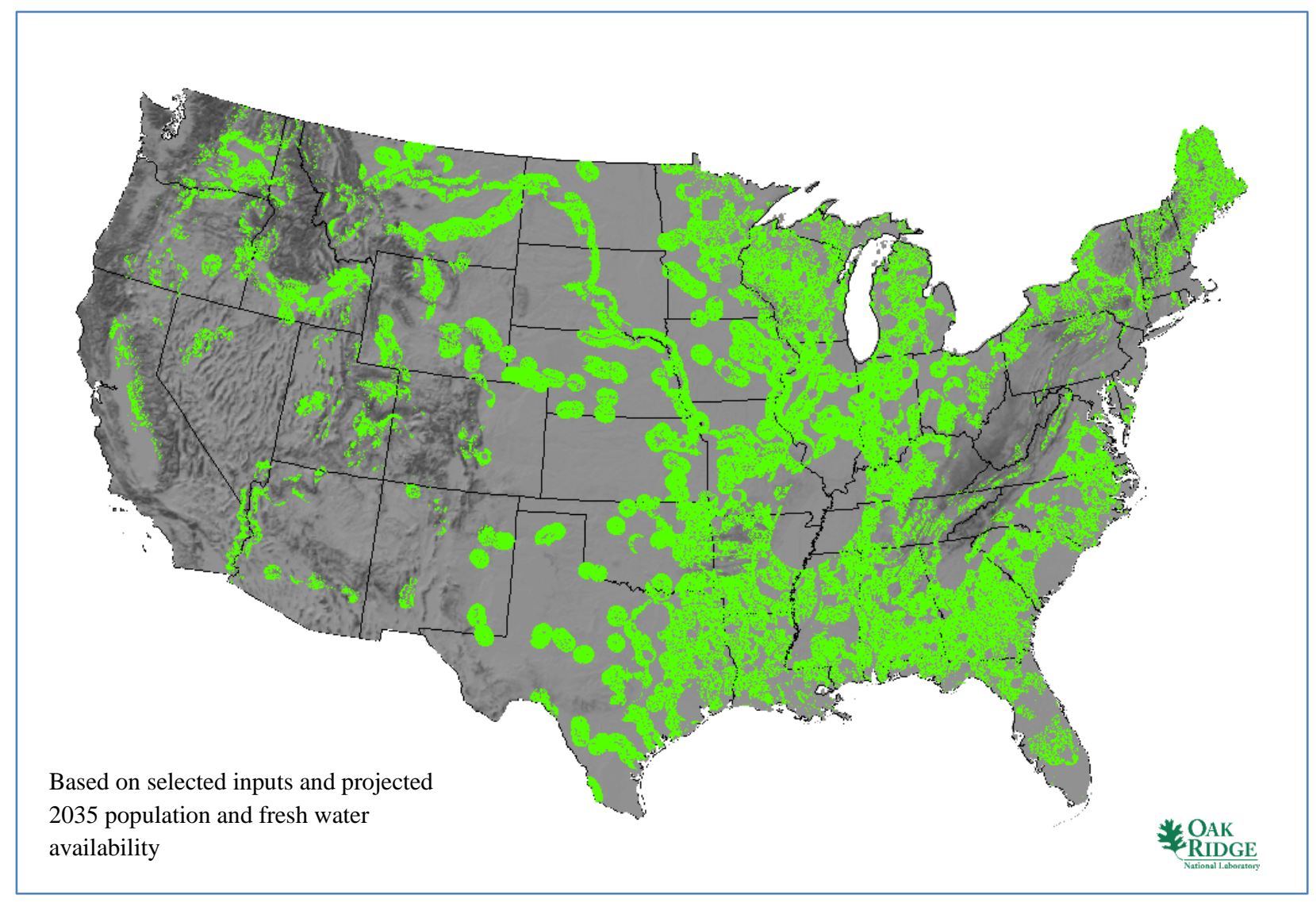

Fig. 61. Small nuclear plant 2035 base map.

The results of aggregating the projected available land from the base case, as shown in Fig. 61, are depicted in green in Fig. 62. Land aggregation for a nominal 50-acre small reactor facility reduces the available land from $26 \%$ of the contiguous United States in the 2035 base case to $20 \%$ or 103 million acres. This is an actual reduction of $4 \%$ of the contiguous United States or 68 million acres compared with the aggregated land calculation for 2010 shown in Fig. 57, or a relative decrease of $17 \%$. The introduction of an air-cooled small reactor would significantly affect this result.

Figure 63 provides a visual comparison of the aggregated land available for small reactor plant siting, based on selected SSEC input parameters, for the 2010 and 2035 scenarios. Figure 63 shows that much of the land lost in the 2035 projection occurs in the isolated areas near presently-available cooling water; these areas appear as individual circles. The population effects are less widespread; Census data project that most population growth will occur in urban areas that already have high population densities, and population loss will occur in rural areas that already have low population densities. 


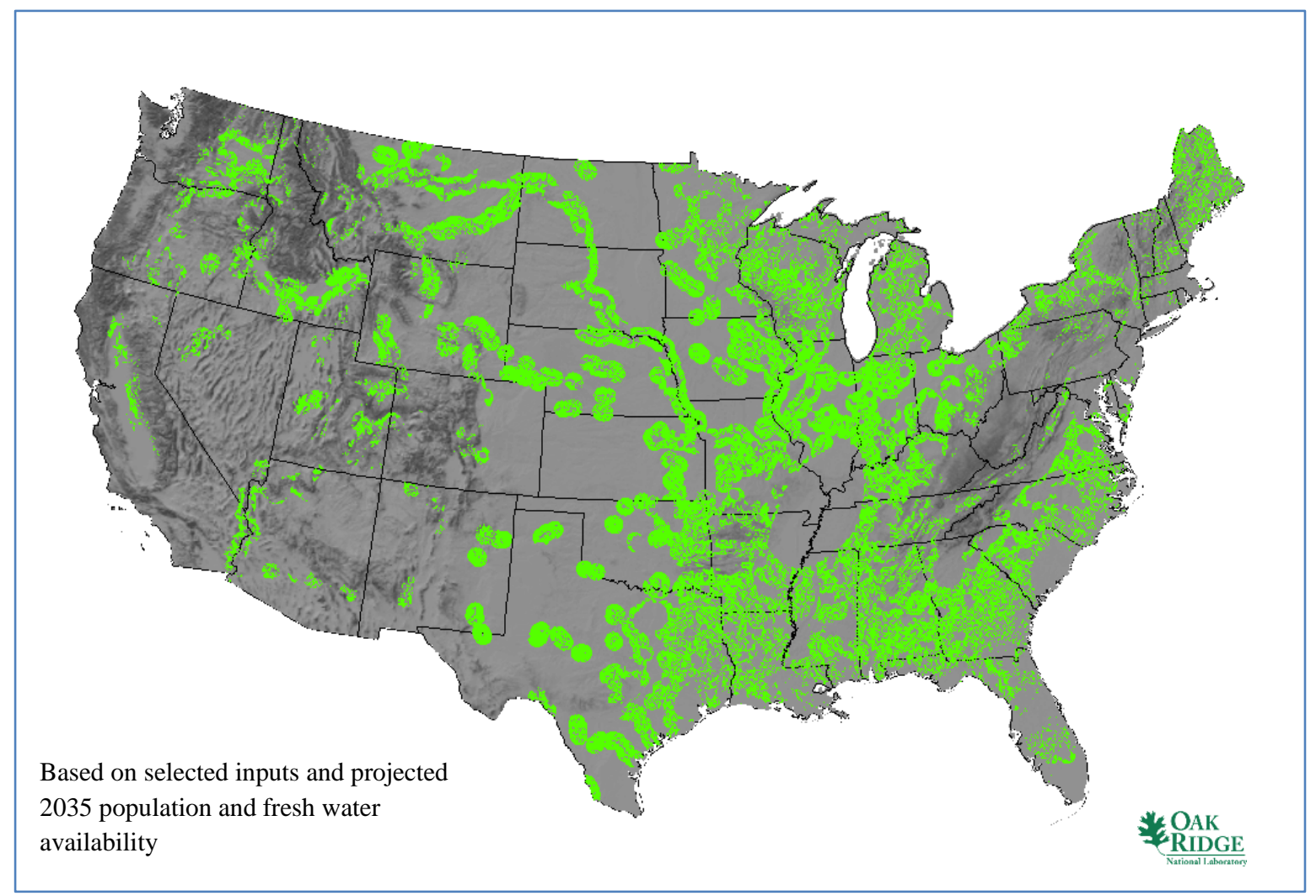

Fig. 62. Small reactor plant 2035 siting aggregated at $90 \%$ for 50 acre facility.

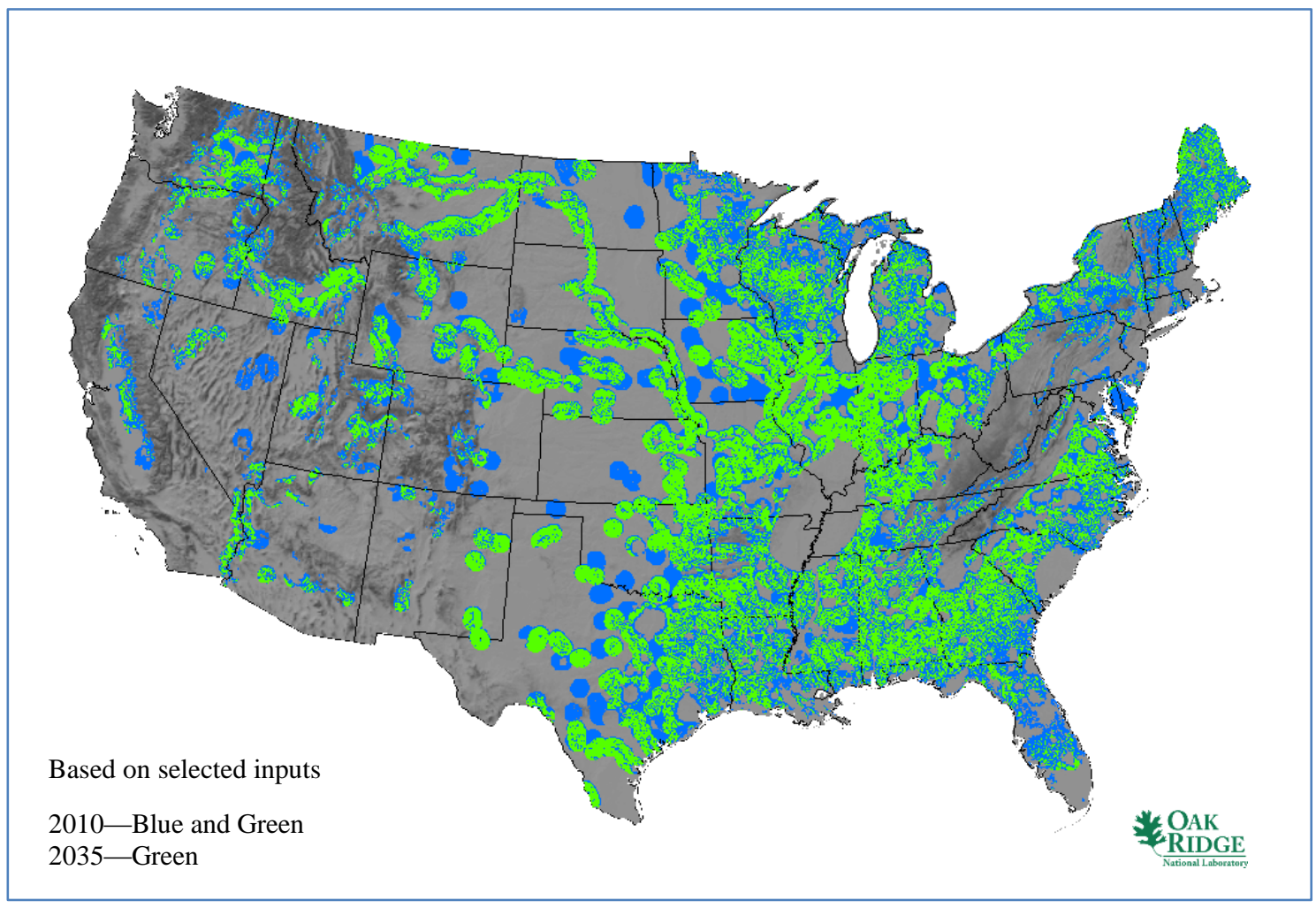

Fig. 63. Small reactor plant visual comparison of 2010 and 2035 aggregated land results. 
A rough comparison with the plant placement algorithm calculated for the 2010 small reactor plant base case would suggest that available new small reactor plant gross capacity would be decreased from 201 $\mathrm{GW}(\mathrm{e})$ to approximately $167 \mathrm{GW}(\mathrm{e})$ by delaying installed new small reactor plant capacity to 2035 .

\subsubsection{Tabular Results}

Table 9 shows the small reactor plant estimated results by state. An entry of 0.00 indicates a value greater than zero that does not show at two significant digits, while a blank entry implies a zero response. Note that the tabular results are not intended to show a "final" result. These results are based on a selected set of input values and a capacity projection algorithm. The relative values between states are the more significant table information. It should be further noted that Table 9 details the results only of aggregated land cells that had no siting challenges. Engineered solutions for land with one or more siting challenges would impact the entries included in Table 9.

Table 9. Small reactor plant results by state (no siting challenges, selected SSEC values)

\begin{tabular}{|c|c|c|c|}
\hline State $^{a}$ & $\begin{array}{c}\text { Portion of state } \\
\text { available to support } \\
50 \text { acre sites } \\
(\%)^{b}\end{array}$ & $\begin{array}{c}\text { Portion of contiguous } \\
\text { US available to } \\
\text { support } 50 \text { acre sites } \\
(\%)\end{array}$ & $\begin{array}{c}\text { Estimated capacity } \\
{[M W(e)]^{c}}\end{array}$ \\
\hline Alabama & 54.44 & 0.95 & 5,600 \\
\hline Arizona & 5.86 & 0.22 & 3,500 \\
\hline Arkansas & 35.16 & 0.62 & 4,900 \\
\hline California & 4.92 & 0.26 & 5,600 \\
\hline Colorado & 9.12 & 0.31 & 4,200 \\
\hline Connecticut & 8.67 & 0.01 & 700 \\
\hline Delaware & 39.06 & 0.03 & \\
\hline \multicolumn{4}{|c|}{ District of Columbia } \\
\hline Florida & 19.65 & 0.38 & 4,550 \\
\hline Georgia & 43.20 & 0.85 & 7,000 \\
\hline Idaho & 17.69 & 0.49 & 9,450 \\
\hline Illinois & 52.82 & 0.98 & 4,200 \\
\hline Indiana & 62.36 & 0.75 & 5,250 \\
\hline Iowa & 54.89 & 1.02 & 3,850 \\
\hline Kansas & 20.76 & 0.56 & 1,050 \\
\hline Kentucky & 30.64 & 0.41 & 4,200 \\
\hline Louisiana & 32.43 & 0.50 & 5,250 \\
\hline Maine & 39.48 & 0.42 & 5,600 \\
\hline Maryland & 24.12 & 0.08 & 700 \\
\hline Massachusetts & 7.89 & 0.02 & 350 \\
\hline Michigan & 30.87 & 0.59 & 4,900 \\
\hline Minnesota & 36.45 & 1.03 & 5,950 \\
\hline Mississippi & 41.56 & 0.67 & 4,900 \\
\hline Missouri & 39.55 & 0.91 & 4,550 \\
\hline Montana & 21.68 & 1.06 & 15,400 \\
\hline
\end{tabular}


Table 9. (continued)

\begin{tabular}{|c|c|c|c|}
\hline State $^{a}$ & $\begin{array}{c}\text { Portion of state } \\
\text { available to support } \\
50 \text { acre sites } \\
(\%)^{b}\end{array}$ & $\begin{array}{c}\text { Portion of contiguous } \\
\text { US available to } \\
\text { support } 50 \text { acre sites } \\
(\%)\end{array}$ & $\begin{array}{c}\text { Estimated capacity } \\
{[\mathrm{MW}(\mathrm{e})]^{c}}\end{array}$ \\
\hline Nebraska & 36.90 & 0.94 & 3,150 \\
\hline Nevada & 6.09 & 0.22 & 1,750 \\
\hline New Hampshire & 15.83 & 0.05 & 700 \\
\hline New Jersey & 7.46 & 0.02 & 700 \\
\hline New Mexico & 8.73 & 0.36 & 1,750 \\
\hline New York & 21.56 & 0.35 & 6,300 \\
\hline North Carolina & 28.49 & 0.46 & 4,550 \\
\hline North Dakota & 19.97 & 0.47 & 3,150 \\
\hline Ohio & 41.86 & 0.57 & 2,800 \\
\hline Oklahoma & 42.40 & 0.99 & 4,550 \\
\hline Oregon & 9.97 & 0.32 & 5,600 \\
\hline Pennsylvania & 10.72 & 0.16 & 3,500 \\
\hline Rhode Island & 5.03 & 0.00 & \\
\hline South Carolina & 30.63 & 0.32 & 2,450 \\
\hline South Dakota & 11.94 & 0.31 & 2,100 \\
\hline Tennessee & 25.38 & 0.36 & 5,600 \\
\hline Texas & 30.31 & 2.72 & 10,500 \\
\hline Utah & 11.03 & 0.31 & 4,550 \\
\hline Vermont & 10.03 & 0.03 & 1,750 \\
\hline Virginia & 25.62 & 0.34 & 4,550 \\
\hline Washington & 16.19 & 0.36 & 5,950 \\
\hline West Virginia & 1.60 & 0.01 & 1,400 \\
\hline Wisconsin & 43.40 & 0.81 & 5,950 \\
\hline Wyoming & 21.22 & 0.69 & 5,950 \\
\hline Total & - & 24.28 & 200,900 \\
\hline \multicolumn{4}{|c|}{$\begin{array}{l}{ }^{a} \text { Generation capacity estimate is discussed in "Plant Placement Algorithm for Water-Dependent Power Sources." } \\
{ }^{b} \text { Land for sites is aggregated at } 90 \% \text { as discussed in "Methodology for Aggregating Land for the Typical Plant } \\
\text { Size." } \\
\text { " Plant placement/capacity estimate is completely arbitrary and unbiased. Shifting the initial plant placement } \\
\text { upstream or downstream will affect all subsequent proposed plant placements and could affect the state capacity. }\end{array}$} \\
\hline
\end{tabular}

Table 10 shows the small reactor plant estimate results by water region. Individual states may be wholly contained within a single water region or they may be part of multiple water regions. Figure 20 shows a US state map with the 18 water regions as an overlay. Note that the tabular results are not intended to show a "final" result. These results are based on a selected set of input values and a capacity projection algorithm. The relative values between regions are the more significant table information. It should be further noted that Table 10 details the results only of aggregated land cells that had no siting challenges. Engineered solutions for land with one or more siting challenges would impact the entries included in Table 10 . 
Table 10. Small reactor plant results by region (no siting challenges, selected SSEC values)

\begin{tabular}{|c|c|c|c|}
\hline Region $^{a}$ & $\begin{array}{l}\text { Portion of region } \\
\text { available to support } \\
500 \text { acre sites } \\
\quad(\%)^{b}\end{array}$ & $\begin{array}{l}\text { Portion of contiguous } \\
\text { US available to } \\
\text { support } 500 \text { acre sites } \\
\quad(\%)\end{array}$ & $\begin{array}{c}\text { Estimate capacity } \\
{[M W(e)]^{c}}\end{array}$ \\
\hline 1. New England & 26.36 & 0.52 & 8,400 \\
\hline 2. Mid Atlantic & 14.63 & 0.51 & 10,850 \\
\hline 3. South Atlantic - Gulf & 37.47 & 3.38 & 28,000 \\
\hline 4. Great Lakes & 34.43 & 1.34 & 9,100 \\
\hline 5. Ohio & 33.32 & 1.79 & 16,450 \\
\hline 6. Tennessee & 25.17 & 0.34 & 4,200 \\
\hline 7. Upper Mississippi & 51.02 & 3.20 & 16,800 \\
\hline 8. Lower Mississippi & 28.61 & 0.97 & 7,700 \\
\hline 9. Souris-Red-Rainy & 21.67 & 0.43 & 2,450 \\
\hline 10. Missouri & 25.06 & 4.24 & 30,450 \\
\hline 11. Arkansas-White-Red & 29.64 & 2.44 & 11,200 \\
\hline 12. Texas-Gulf & 36.74 & 2.24 & 9,450 \\
\hline 13. Rio Grande & 8.67 & 0.39 & 1,750 \\
\hline 14. Upper Colorado & 11.94 & 0.45 & 8,400 \\
\hline 15. Lower Colorado & 6.55 & 0.31 & 4,200 \\
\hline 16. Great Basin & 6.62 & 0.31 & 3,150 \\
\hline 17. Pacific Northwest & 13.15 & 1.20 & 23,100 \\
\hline 18. California & 4.33 & 0.23 & 5,250 \\
\hline Total & - & 24.29 & 200,900 \\
\hline \multicolumn{4}{|c|}{$\begin{array}{l}{ }^{a} \text { Generation capacity estimate is discussed in "Plant Placement Algorithm for Water-Dependent Power Sources." } \\
{ }^{b} \text { Land for sites is aggregated at } 90 \% \text { as discussed in "Methodology for Aggregating Land for the Typical Plant Size." } \\
{ }^{c} \text { Plant placement/capacity estimate is completely unbiased. Shifting the initial plant placement upstream or downstream } \\
\text { will affect all subsequent proposed plant placements and could affect the regional capacity. }\end{array}$} \\
\hline
\end{tabular}




\section{ADVANCED COAL RESULTS}

A pulverized coal oxycombustion power plant uses oxygen in the combustion process. This produces a flue gas stream of $\mathrm{CO}_{2}$ and water. The water can be removed, leaving a nearly pure stream of $\mathrm{CO}_{2}$. The $\mathrm{CO}_{2}$ is compressed to 2215 psia and transported via a pipeline to a saline geological formation where it is stored.

\subsection{Site Selection and Evaluation Criteria}

Siting of advanced coal plants is not held to the same regulatory rigor as nuclear power plant siting. However, the nuclear plant siting SSEC were considered to be a reasonable starting point to establish the advanced coal SSEC. Nuclear plants must consider seismic restrictions and earthquake faults as a public safety issue. Seismic and earthquake fault restrictions for advanced coal plants become an investment protection issue. Therefore, it is assumed that there are no seismic or earthquake fault issues for advanced coal plant siting, beyond local building codes. Likewise, proximity to hazardous facilities (nuclear plant SSEC) is not considered applicable to advanced coal plant placement as a public safety precaution; rather, proximity to hazardous facilities would be expected to be governed by local zoning restrictions.

Population density of greater than 500 people per square mile begins to transition into an urban setting, so new advanced coal plants in these areas are excluded based on anticipated available space and zoning restrictions. However, there is no need to include a buffer for public safety. Engineering judgment indicated that other nuclear SSEC such as wetlands and open water, protected lands, slope, landslide hazards, and floodplains should continue to be excluded for new advanced coal plant candidate area siting.

A Department of Energy (DOE)/National Energy Technology Laboratory (NETL) report, Water Requirements for Existing and Emerging Thermoelectric Plant Technologies, ${ }^{9}$ provided water consumption factors for integrated gasification combined cycle, supercritical pulverized coal, and subcritical pulverized coal plants using carbon capture technology. The subcritical pulverized coal plant had the highest water consumption factor, including carbon capture technology, so this plant type was conservatively used to establish the water requirements for advanced coal. Nominal advanced coal plant parameters were provided in a DOE/NETL report, Pulverized Coal Oxycombustion Power Plants. ${ }^{21}$ This report indicated that the nominal advanced coal plant is situated on 300 acres and that the gross output is $750 \mathrm{MW}(\mathrm{e})$, which was factored into the advanced coal plant water requirement calculation. This report also indicated that reasonable access to coal delivery was a necessary requirement.

The report Pulverized Coal Oxycombustion Power Plants also indicated that carbon could be piped up to 50 miles to a saline aquifer formation. ORNL expertise indicated that this distance could be pushed to a higher value with certain provisions, such as avoiding high slopes, faults, and crossing of protected lands. Consultations with Carnegie Melon University researchers in December 2010 confirmed this assumption.

Saline formations assessed for storage are restricted to those where the following basic criteria for the storage are met: (1) pressure and temperature conditions in the saline formation are adequate to keep the carbon dioxide in dense phase (supercritical) or liquid phase, (2) a suitable seal is present to limit vertical flow of the carbon dioxide to the surface, and (3) salinity in the saline formation is $>10,000 \mathrm{ppm}$ total

\footnotetext{
${ }^{21}$ National Energy Technology Laboratory, Pulverized Coal Oxycombustion Power Plants, DOE/NETL-2007/1291, prepared for the US Department of Energy, August 2008.
} 
dissolved solids. For this capacity estimate, a depth of $2500 \mathrm{ft}$ below surface is accepted as a reasonable proxy for these criteria to be met. ${ }^{22}$

EPA nonattainment data are available on air pollution. It was assumed that permits for new advanced coal plants may be more difficult in areas that do not currently meet the EPA air pollution standards. Therefore, these data were used as an SSEC for the advanced coal plant case.

Geological storage capacity and carbon injection rates are noted as issues for the use of advanced coal (clean coal) technology. However, no publicly available GIS data are currently available to permit the inclusion of these issues as additional advanced coal SSEC.

The SSEC for the nominal 750 MW(e) advanced coal plant positioned on 300 acres of land are

- Land with a population density greater than 500 people per square mile (with no buffer) is excluded.

- Wetlands and open water are excluded.

- Protected lands (e.g., national parks, historic areas, wildlife refuges) are excluded.

- Land with a slope greater than $12 \%\left(\sim 7^{\circ}\right)$ is excluded.

- Land with a moderate or high landslide hazard susceptibility is excluded.

- Land that lies within a 100-year floodplain is excluded.

- Land areas that are more than 20 miles from cooling water makeup sources with at least 125,000 gpm are excluded.

- Land that is more than 20 miles from rail access or more than 1 mile from barge access is avoided.

- Land that does not meet the EPA air pollution standards based on nonattainment data is avoided.

- Land that is more than 150 miles from a saline aquifer geologic formation is avoided.

- Carbon pipelines should avoid crossing fault lines, slopes greater than $12 \%$, and crossing protected lands.

Figures 64-74 show the individual SSEC layers for the nominal advanced coal plant based on the values provided in this list. Areas shown in red are excluded based on the selected input parameter value. Excluded areas in each individual layer can be modified based on different assumptions or requirements for the SSEC.

\footnotetext{
${ }^{22}$ National Energy Technology Laboratory, Geologic Storage Formation Classificaiton, DOE/NETL-2010/1420, prepared for the U.S. Department of Energy, September 2010.
} 


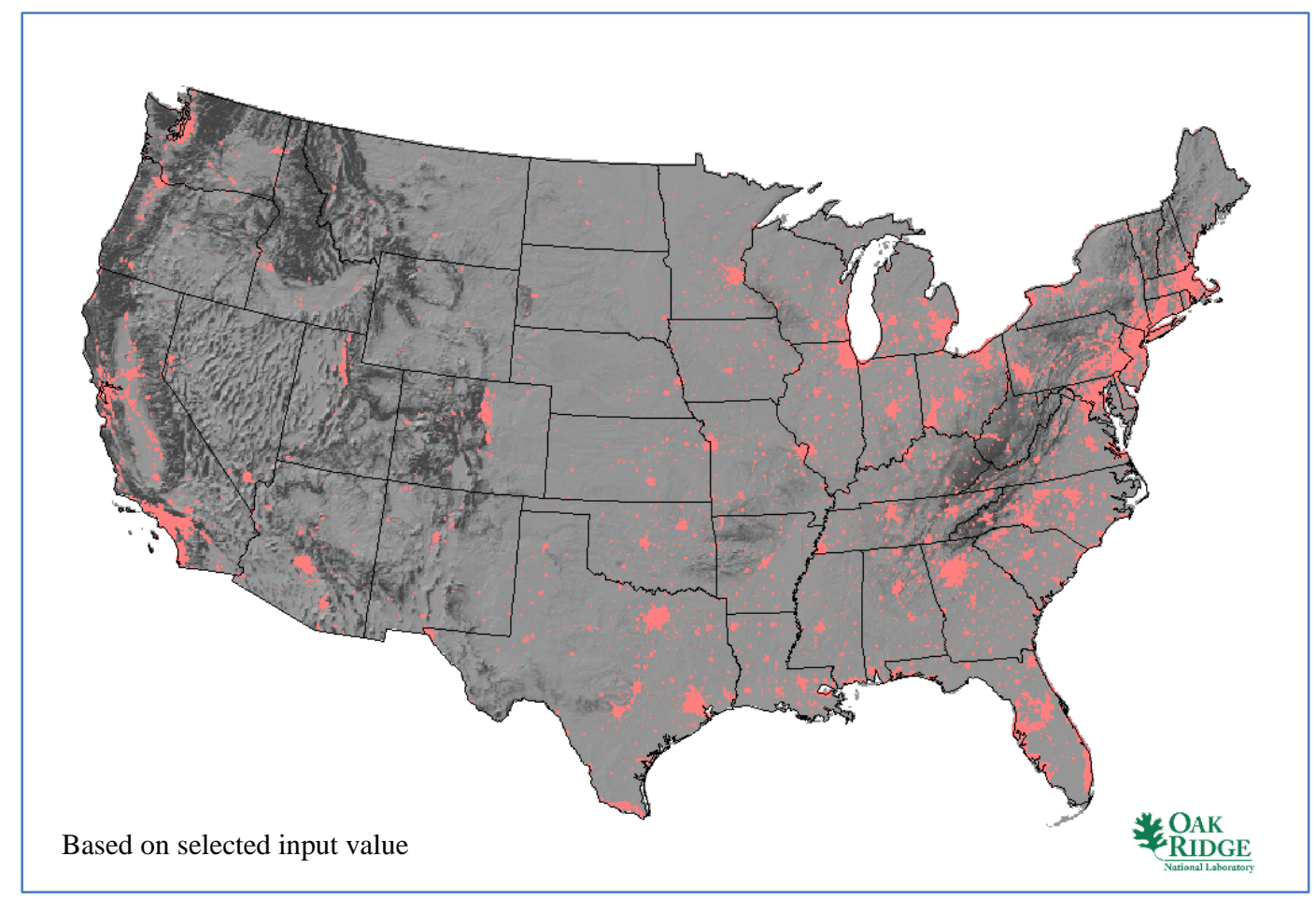

Fig. 64. Advanced coal high population SSEC layer.

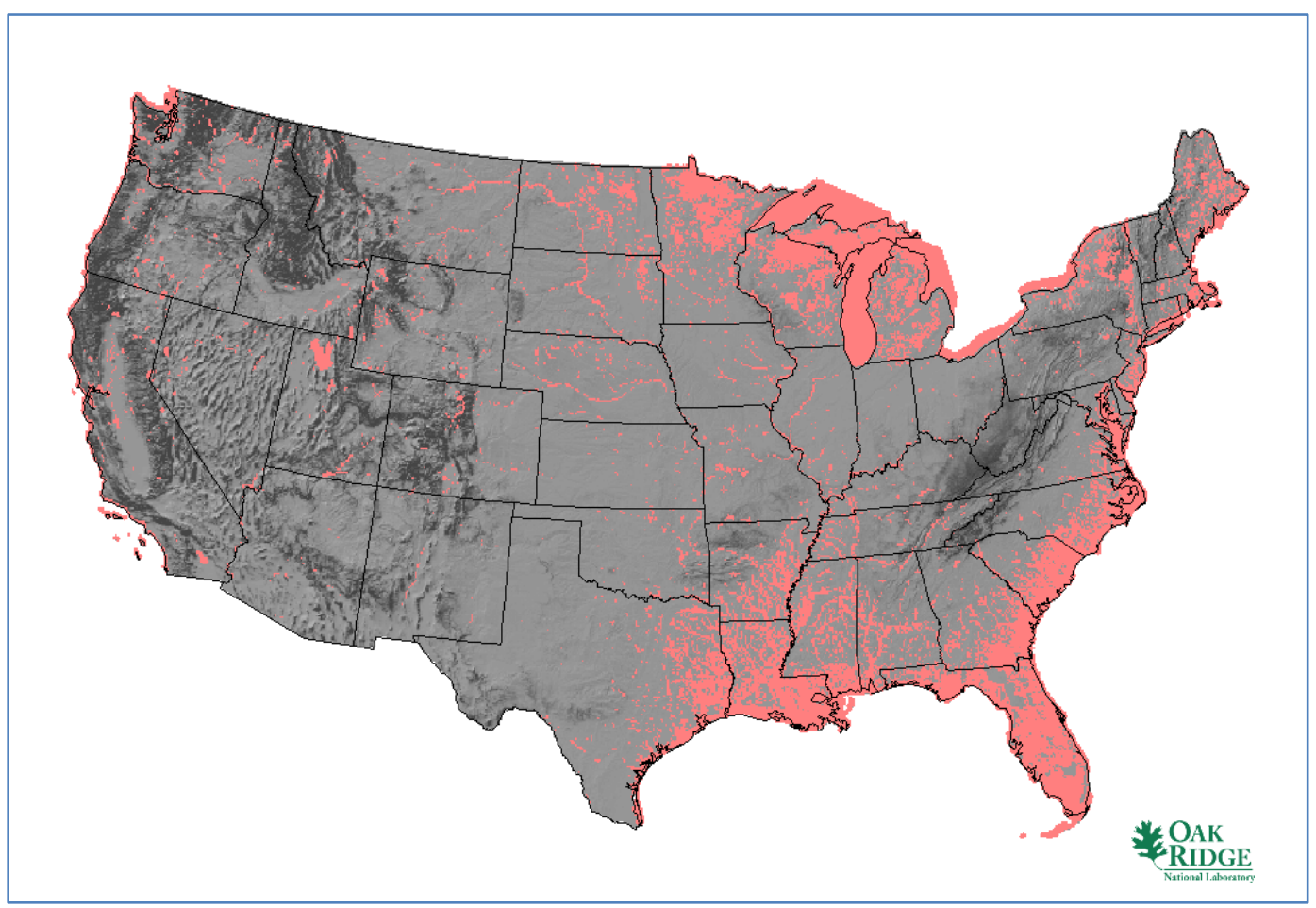

Fig. 65. Advanced coal wetlands and open water SSEC layer. 


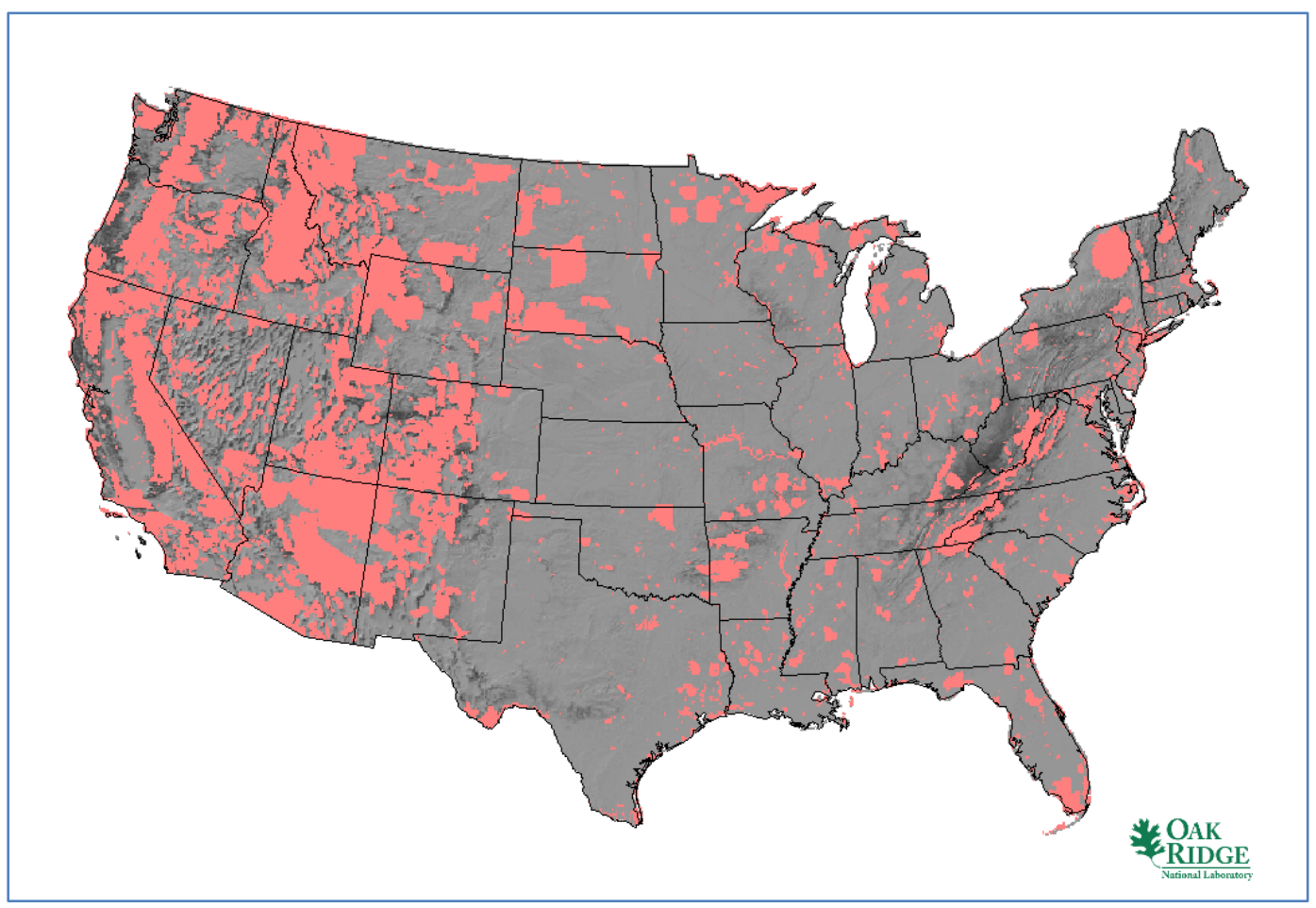

Fig. 66. Advanced coal protected lands SSEC layer.

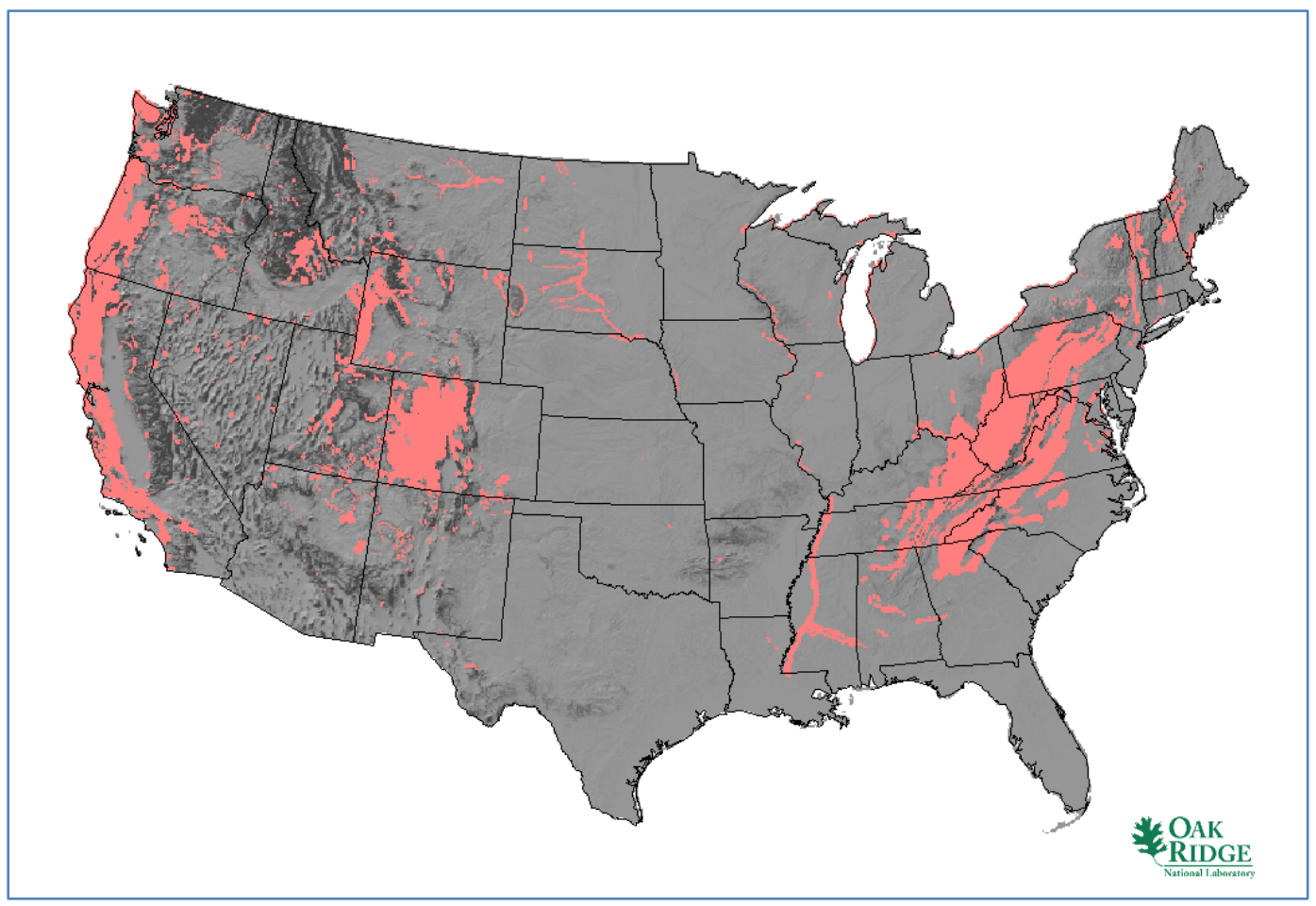

Fig. 67. Advanced coal landslide hazards SSEC layer. 


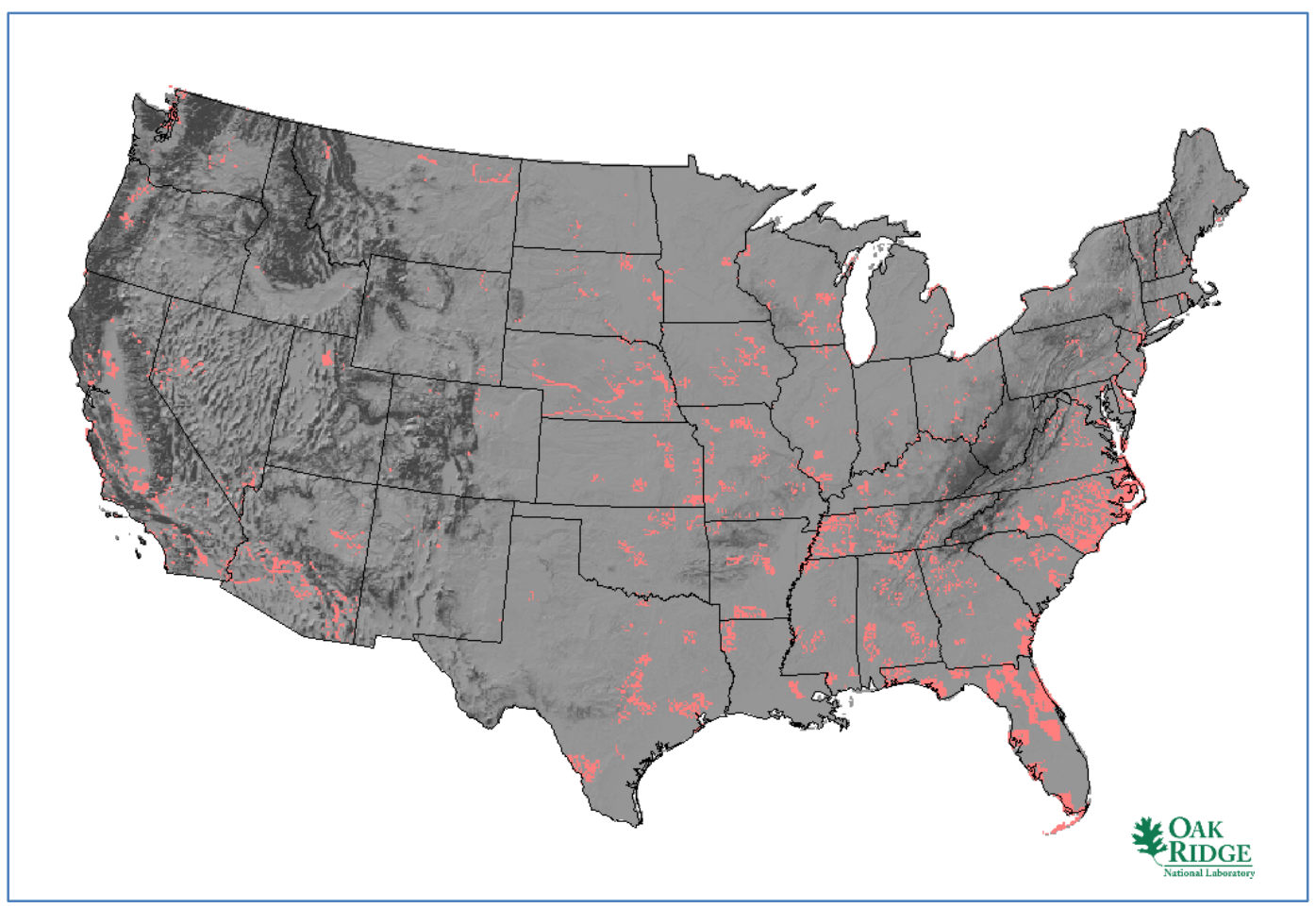

Fig. 68. Advanced coal 100-year floodplain SSEC layer.

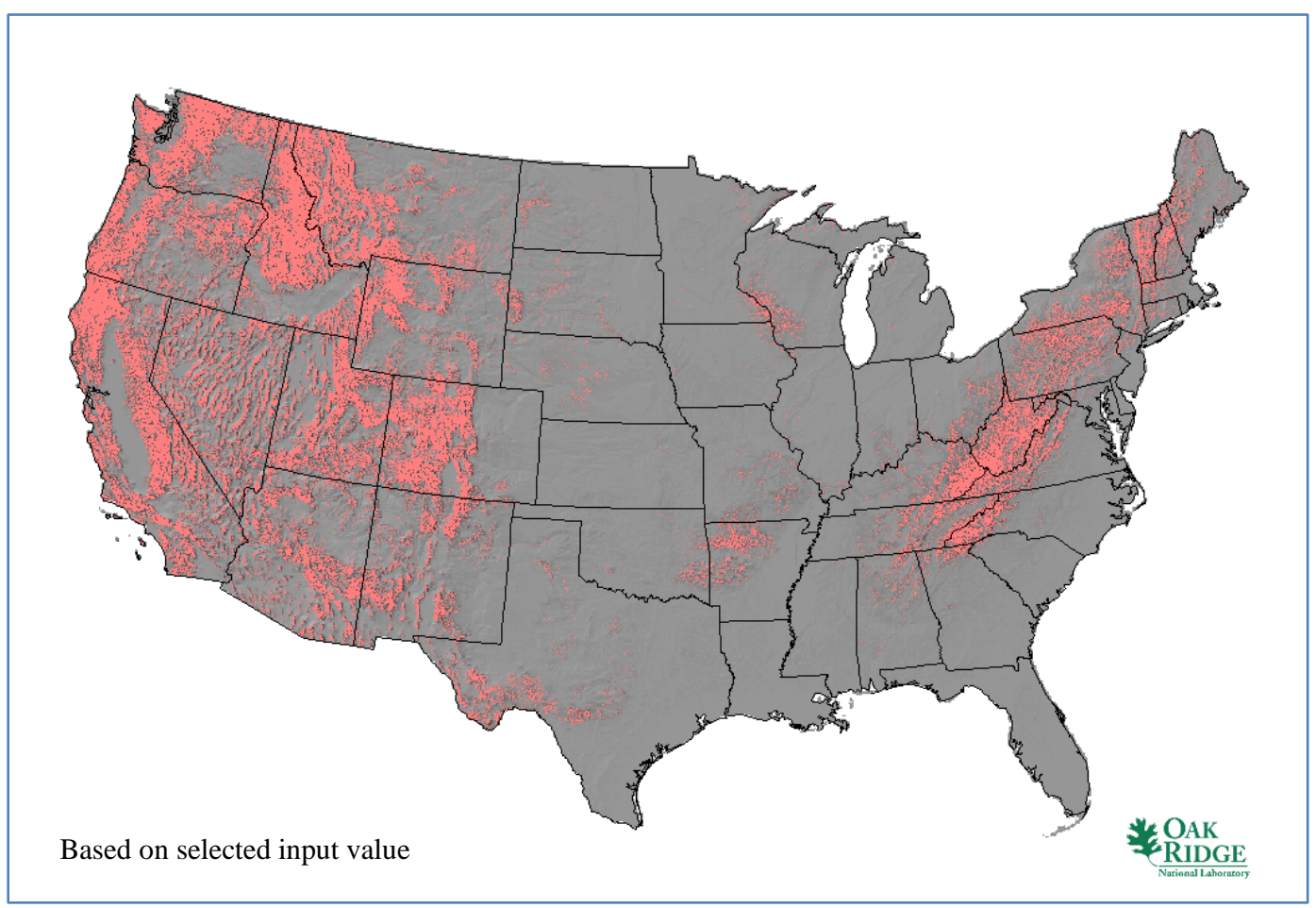

Fig. 69. Advanced coal high slope SSEC layer. 


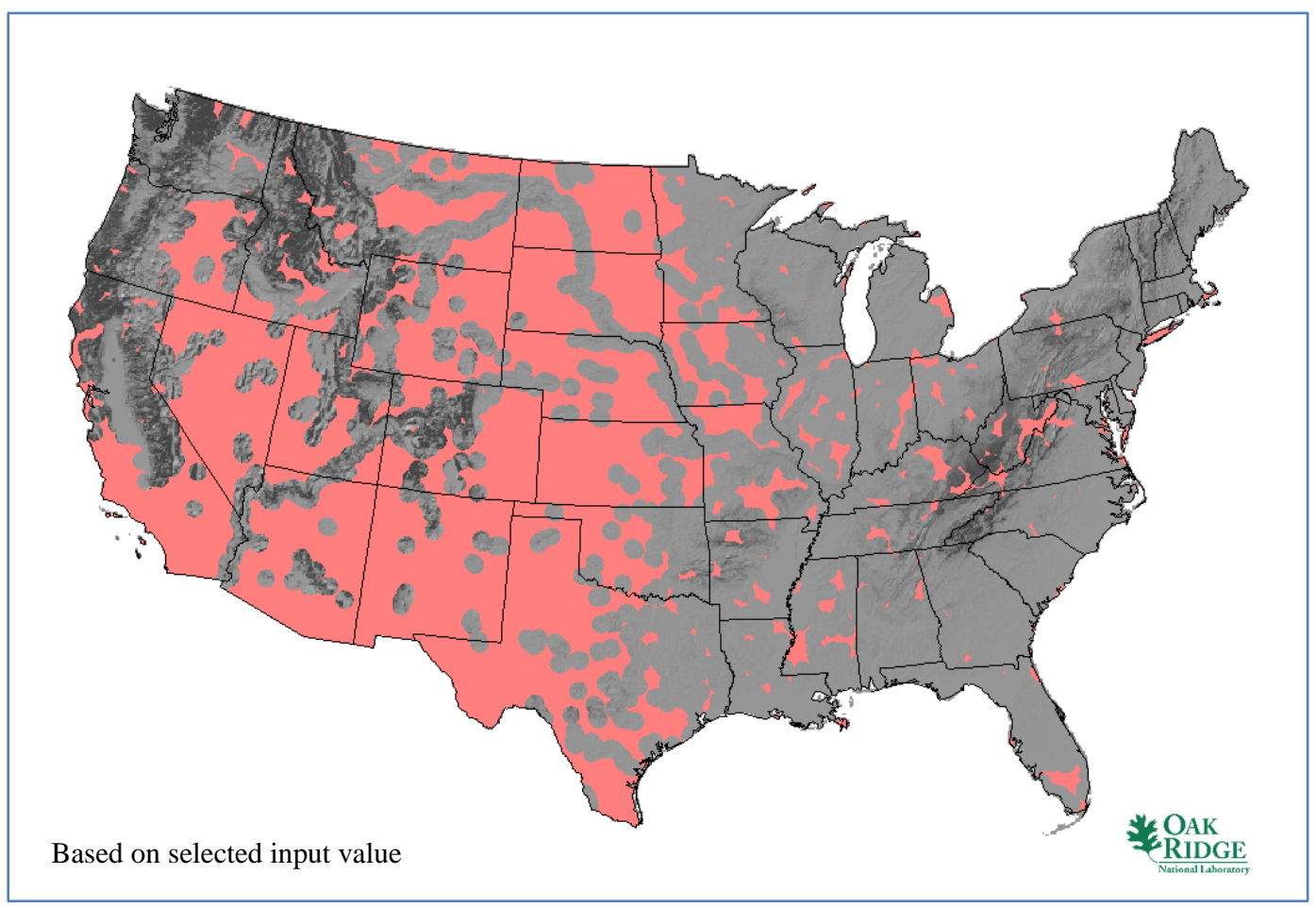

Fig. 70. Advanced coal low stream flow SSEC layer.

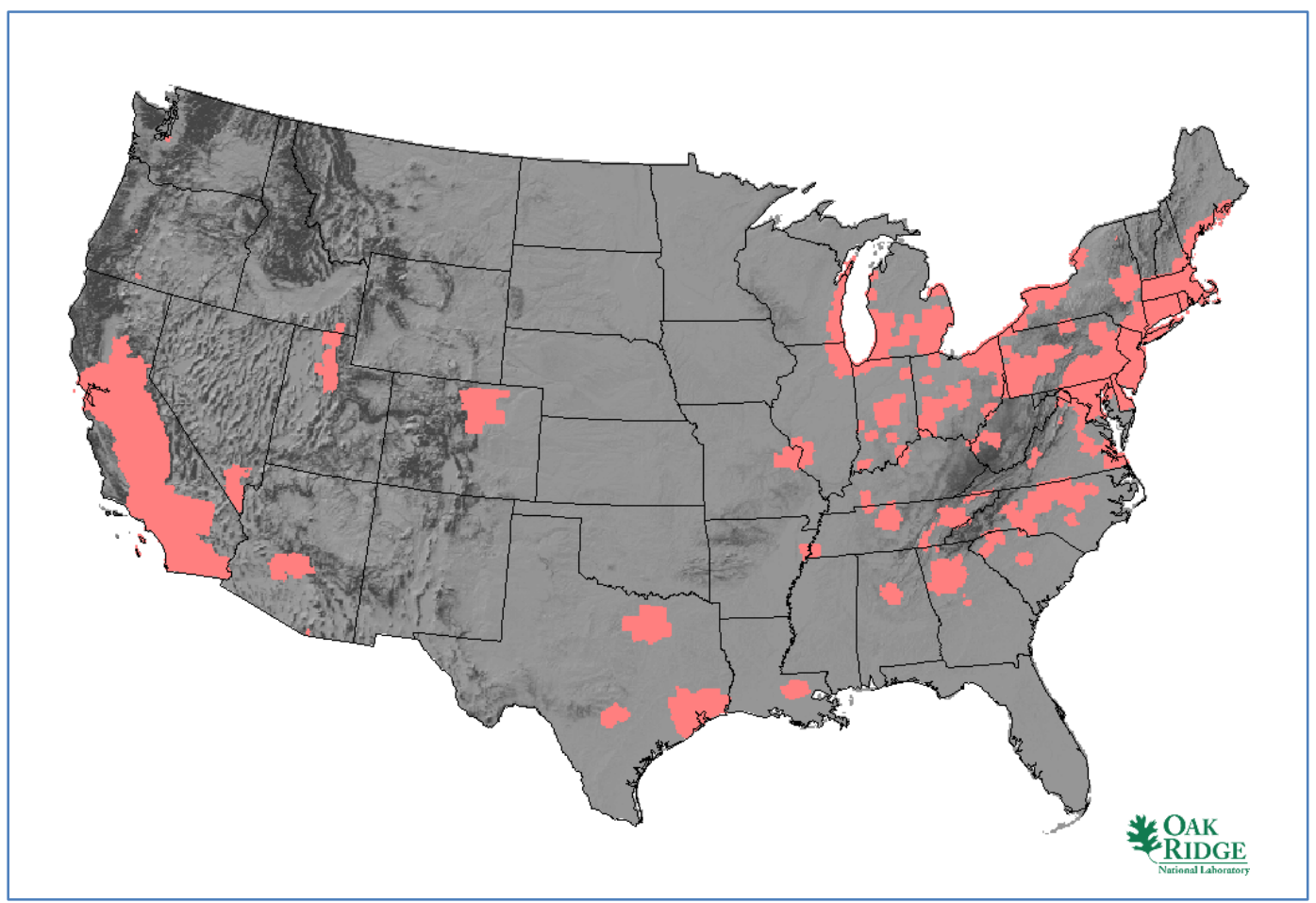

Fig. 71. Advanced coal EPA nonattainment SSEC layer. 


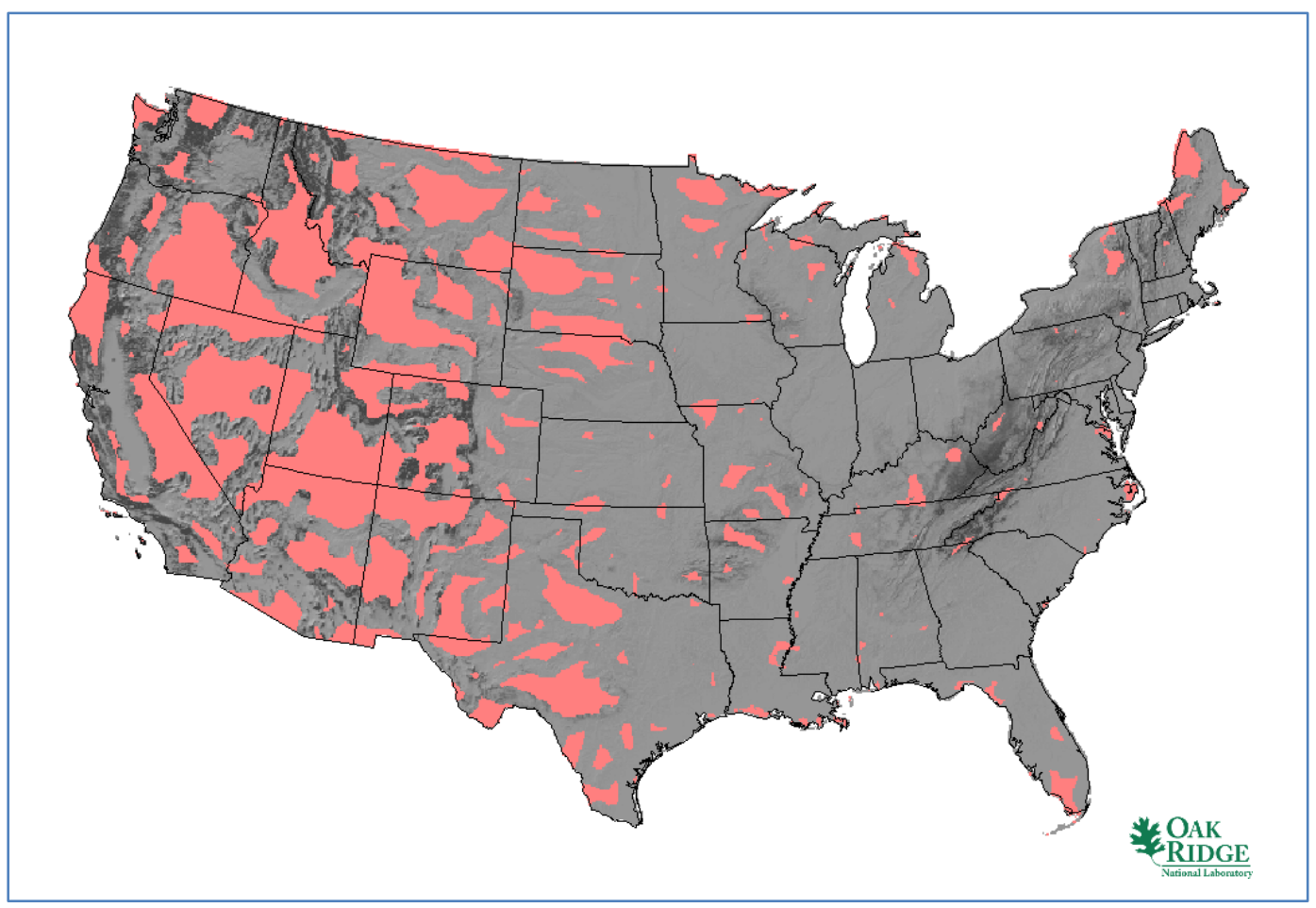

Fig. 72. Advanced coal lack of transport SSEC layer.

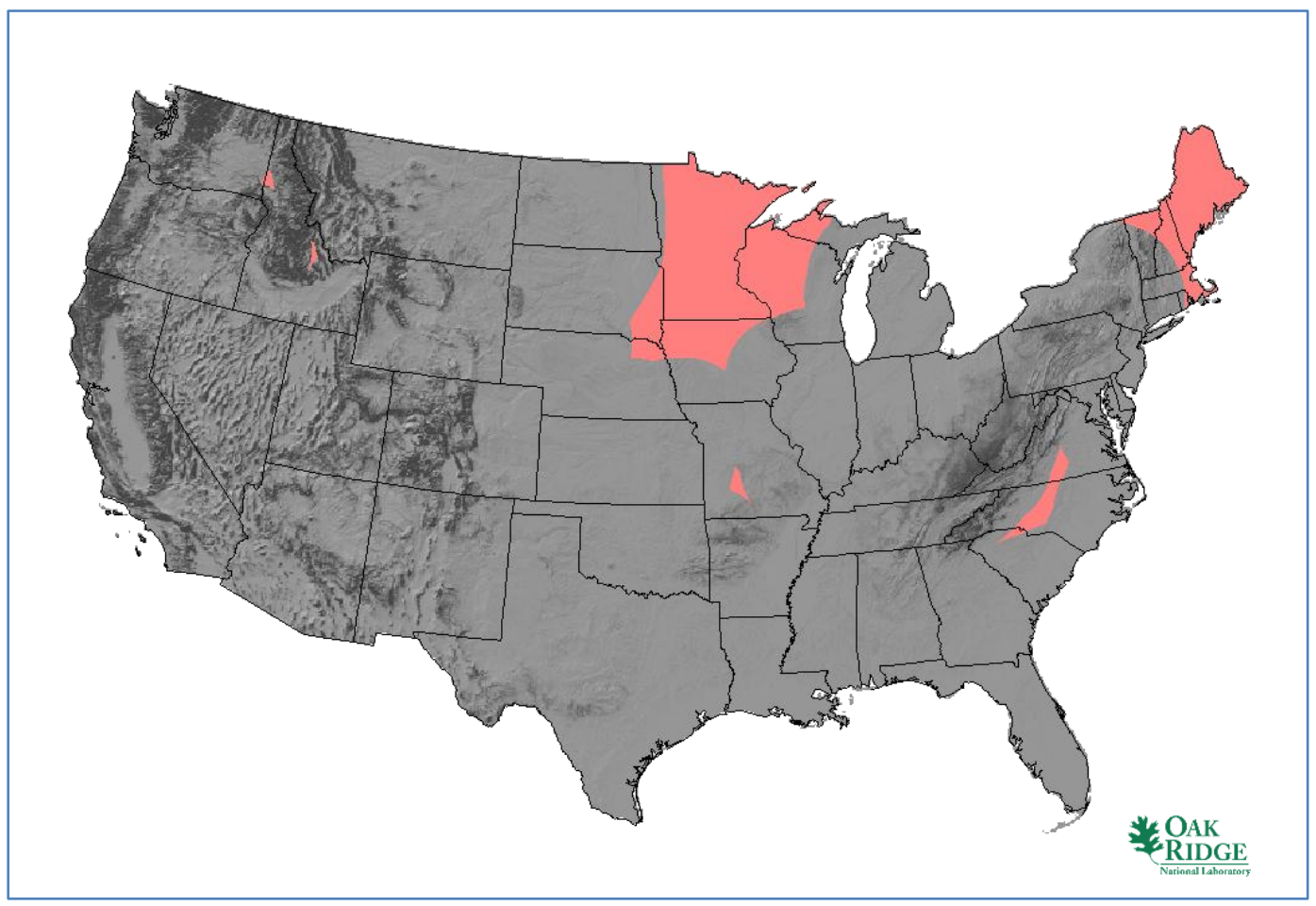

Fig. 73. Advanced coal lack of access to saline formations SSEC layer. 


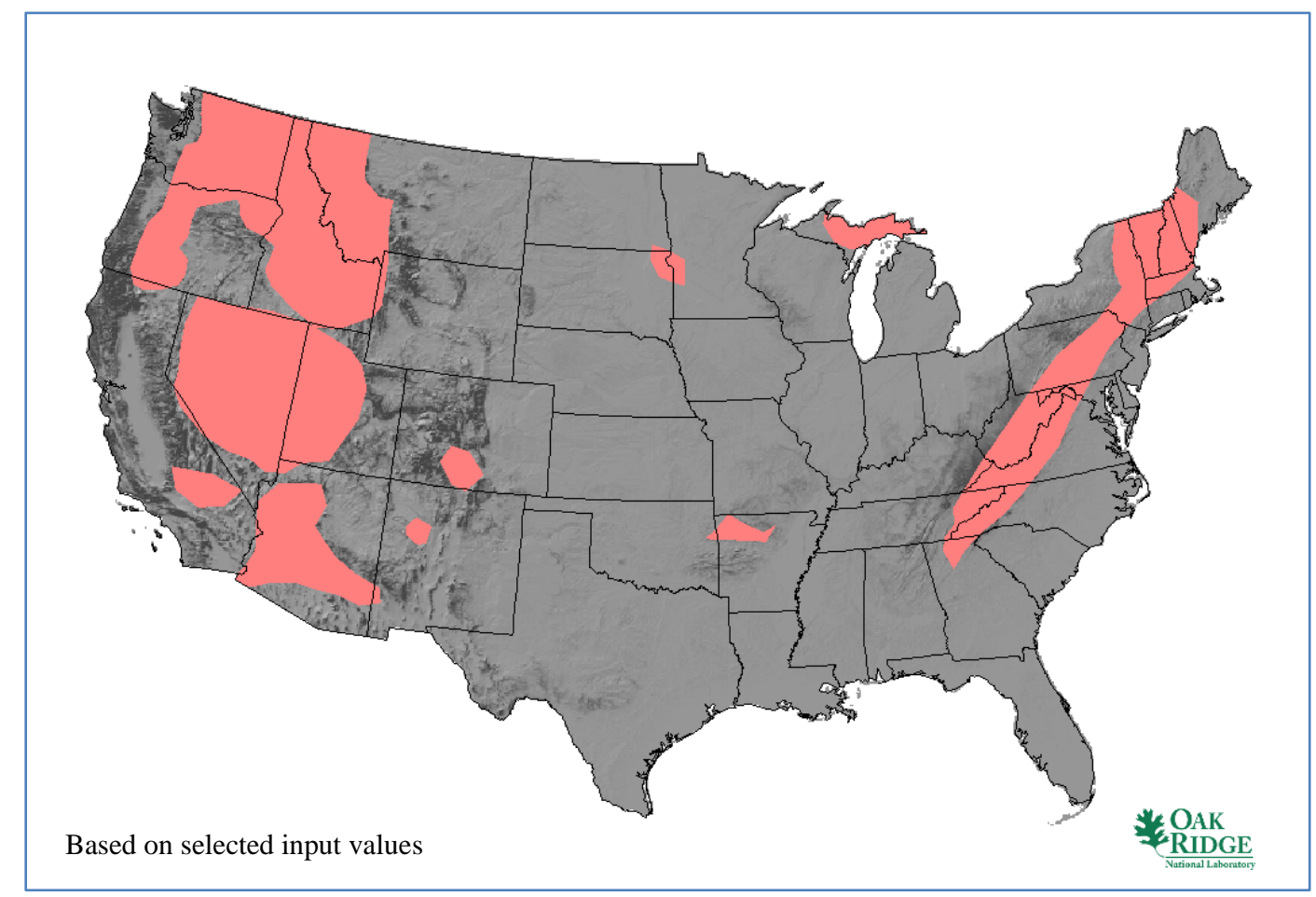

Fig. 74. Advanced coal carbon pipeline restrictions SSEC layer.

The successive application of each advanced coal SSEC layer to the overall available land in the contiguous United States can be captured as a step-down histogram as shown in Fig. 75. The SSEC layers are independent. Therefore, the shape of the cumulative histogram is strictly determined by the order in which the SSEC layers (steps) are applied. However, the end result at step 11 is the same no matter what the SSEC layer application order.

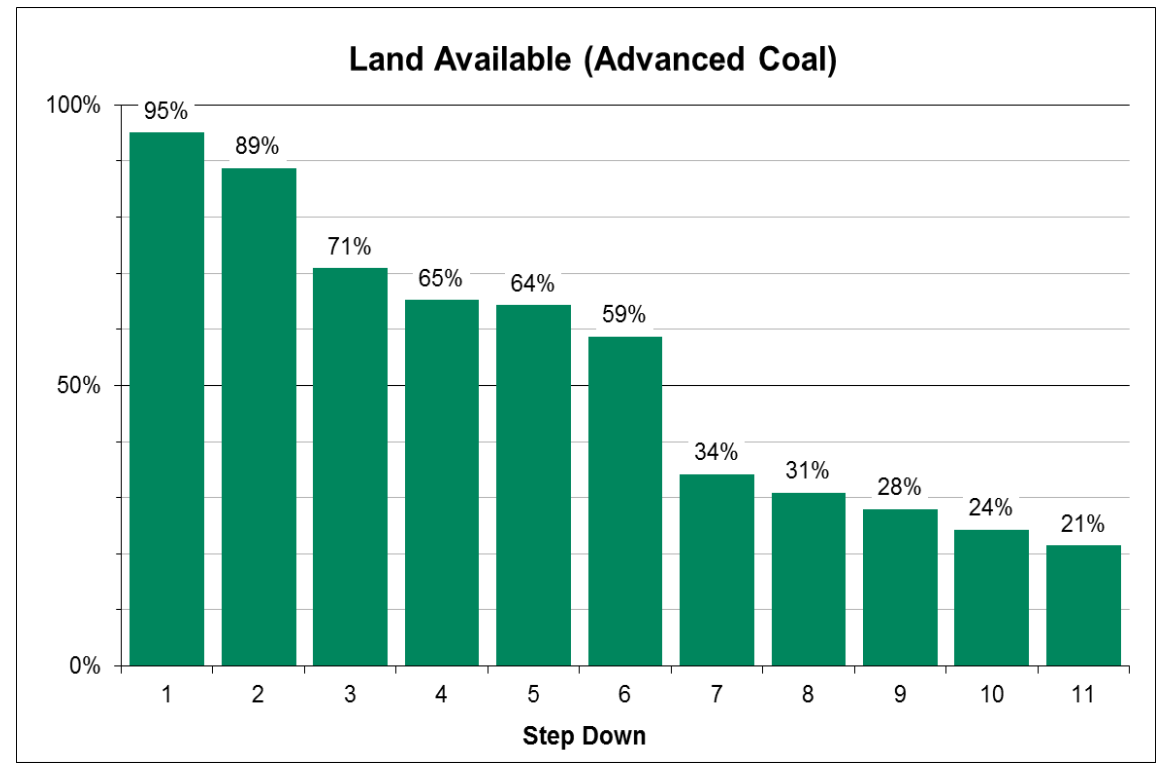

\section{Order of SSEC Layers}

1. Population

2. Wetlands/open water

3. Protected lands

4. Landslide hazard

5. 100-year floodplain

6. Slope

7. Stream flow

8. EPA nonattainment

9. Access to coal

10. Saline formation

11. Carbon pipeline

Fig. 75. Advanced coal step-down histogram. 
A review of the individual SSEC layers and the histogram provides the following insights:

- Protected lands, transportation, and slope are significant factors in the West.

- Pipeline restrictions are significant factors in the West and along the Appalachian chain all the way into New England.

- Distance to a saline storage formation precludes most of Minnesota and Maine.

- Cooling water is a significant factor in the West and central portion of the United States.

OR-SAGE tracks the parameters for each individual 100 by $100 \mathrm{~m}$ cell. As a result, not only can the cells that are clear of all the SSEC layer exclusions be displayed visually, but also cells that are tripped by one, two, or three or more exclusions can be tracked and displayed. This is known as the advanced coal composite map, shown in Fig. 76. This is a powerful aspect of OR-SAGE, because it allows areas with a limited number of siting challenges to also be identified. Engineering solutions for areas with limited siting challenges may be available. The areas in green in Fig. 76 have no siting challenges based on the selected values for the advanced coal SSEC layers. However, the areas in yellow also include a significant land area and have just a single siting challenge. An examination of the individual layers indicates that inadequate stream flow is the most common siting challenge in the midsection of the contiguous United States. This can lead to consideration of alternative methods of cooling. Note that the areas in black do not sit above a saline formation and are not within 150 miles of an acceptable geologic formation (the selected piping parameter value used in this study).

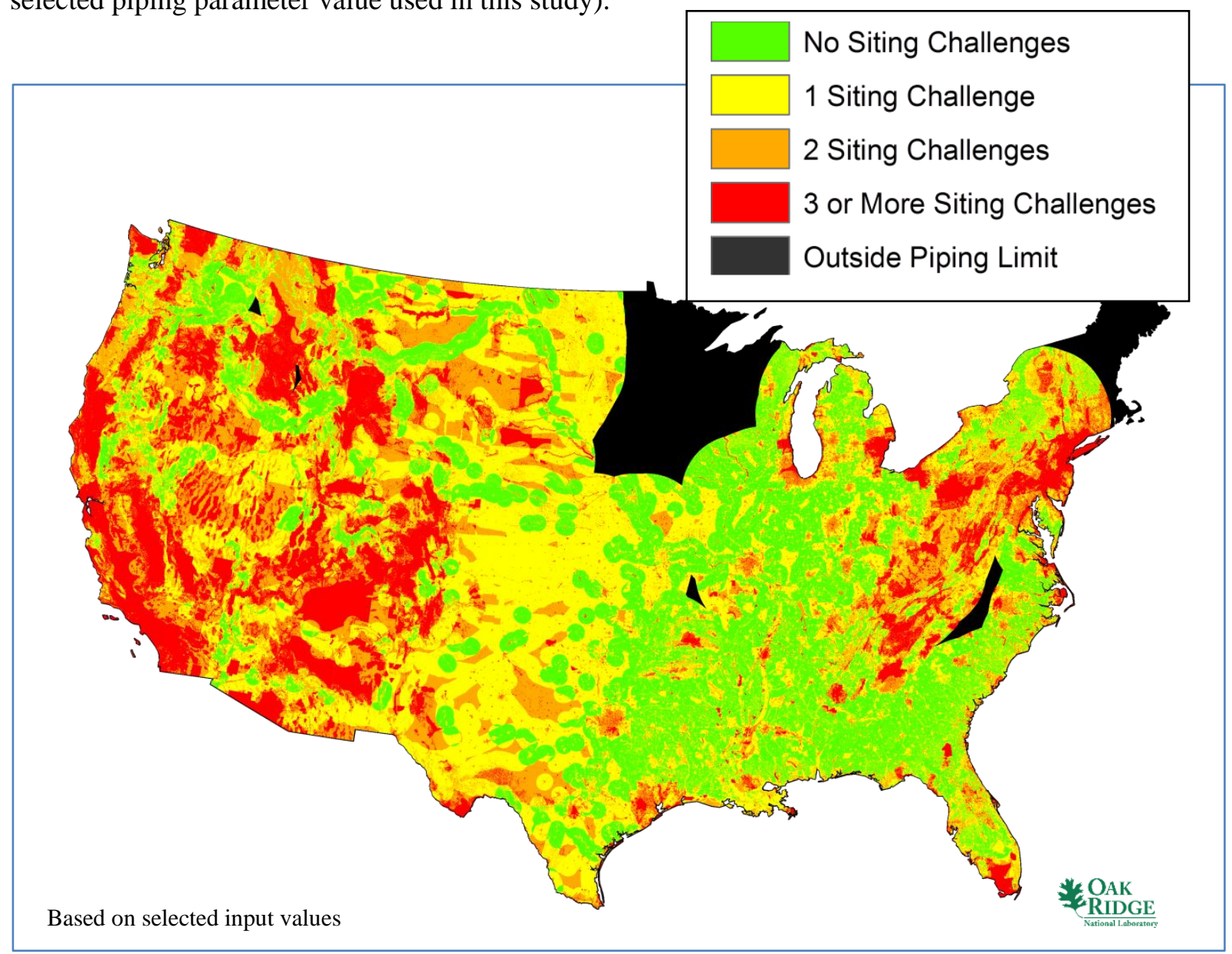

Fig. 76. Advanced coal composite map detailing siting challenges. 


\subsection{Key Assumptions}

In addition to the assumptions detailed in the section "Critical Assumptions" section (Sect. 2) of this report regarding stream flow, land aggregation, plant placement projections, and 2035 estimates, there are several key assumptions that bound the advanced coal plant results:

1. The parasitic house loads for a clean coal plant using available scrubber technology and underground carbon capture are estimated to be $200 \mathrm{MW}(\mathrm{e}) .^{19}$

2. The distance for piping compressed carbon to a suitable underground storage location is limited only by economics and geography.

3. Public opinion would make it more difficult to site an advanced coal plant in an area that did not currently meet the EPA air pollution standards based on nonattainment data.

4. Stream flow is based on a composite of 7Q10 data from the USGS and existing lake and reservoir data. This is intended to reflect potential drought conditions in site availability.

5. Aggregation of GIS land cells into 300 acre parcels requires only that $90 \%$ or more of the individual cells pass SSEC. This allows for small imperfections in a parcel without requiring that the parcel be discarded from consideration.

\subsection{Base Map}

The "Approach and Methodology" section (Sect. 1.3) describes the process of developing a base map. The base maps depicted in this section reflect one set of values based on the stated assumptions and selected SSEC. The areas depicted in green from the advanced coal composite map shown in Fig. 76 are used to develop the advanced coal base map.

The advanced coal base map was developed in two parts. Locations that sit over an acceptable geological formation for carbon storage do not have to consider carbon pipelines and the associated pipeline restrictions. Locations that sit within a 150-mile band around an acceptable geological formation for carbon storage (but not on a formation) had to be further evaluated for carbon pipeline limitations.

Figure 77 depicts the available saline formations that support carbon storage. These include offshore formations. However, cross-border availability into Canada or Mexico is not depicted.

Land that sits directly over an acceptable geological formation and meets all other advanced coal SSEC is shown in Fig. 78. The green areas are acceptable for advanced coal placement based on the selected values for the advanced coal SSEC. They represent $9.7 \%$ of the contiguous United States.

The next step is to evaluate the land that is within a 150-mile buffer around each geological formation. This is depicted as the blue band around the gold geological formation for a single geological area in Fig. 79. The advanced coal SSEC are then applied to the blue carbon piping buffer regions for all generated piping buffer zones. This process is shown in Fig. 80, where the land in green supports placement of an advanced coal plant without consideration of piping and the red areas are excluded for various reasons as a result of applying the advanced coal SSEC layers. 


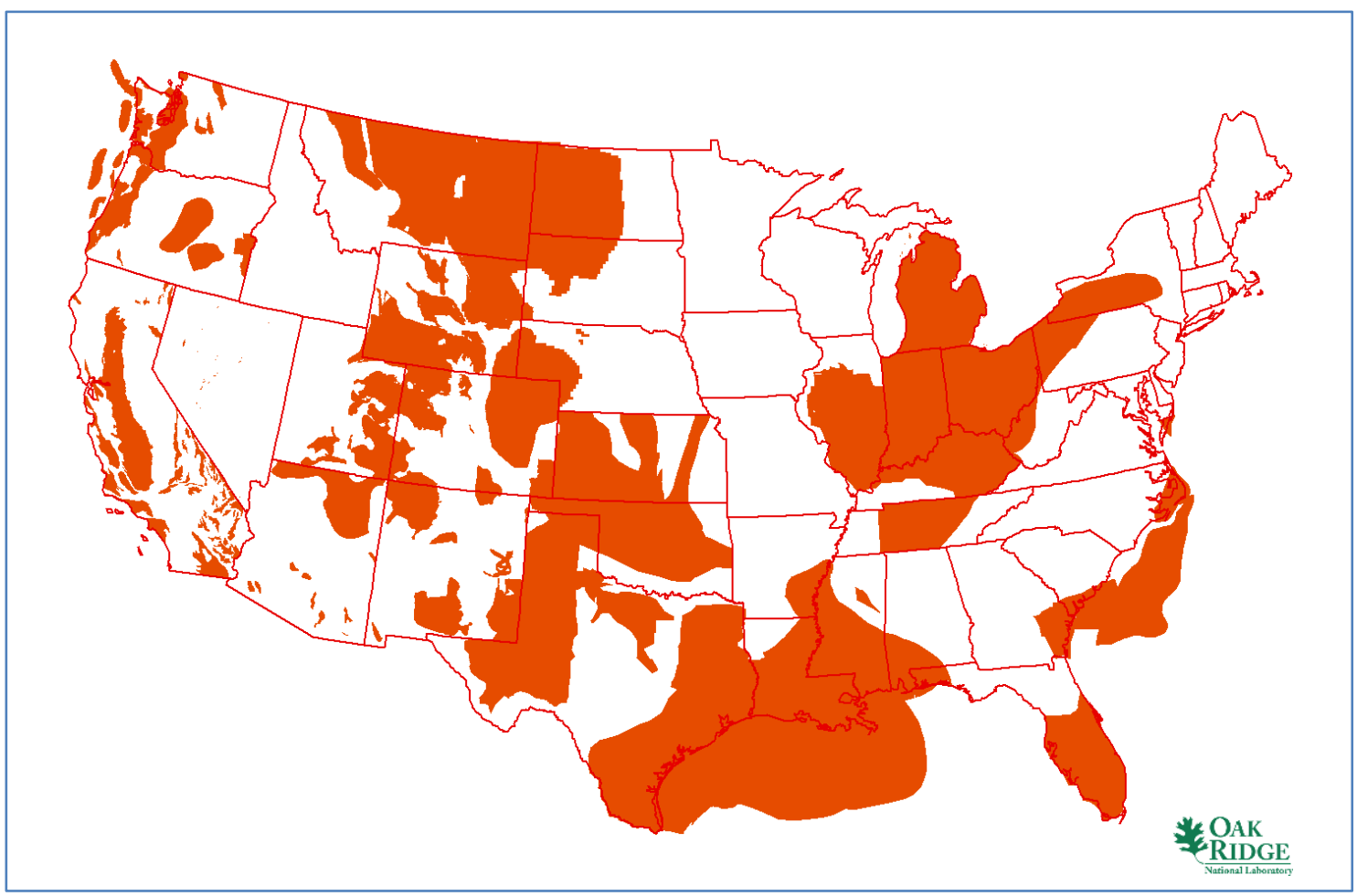

Fig. 77. Geological formations amenable to carbon storage.

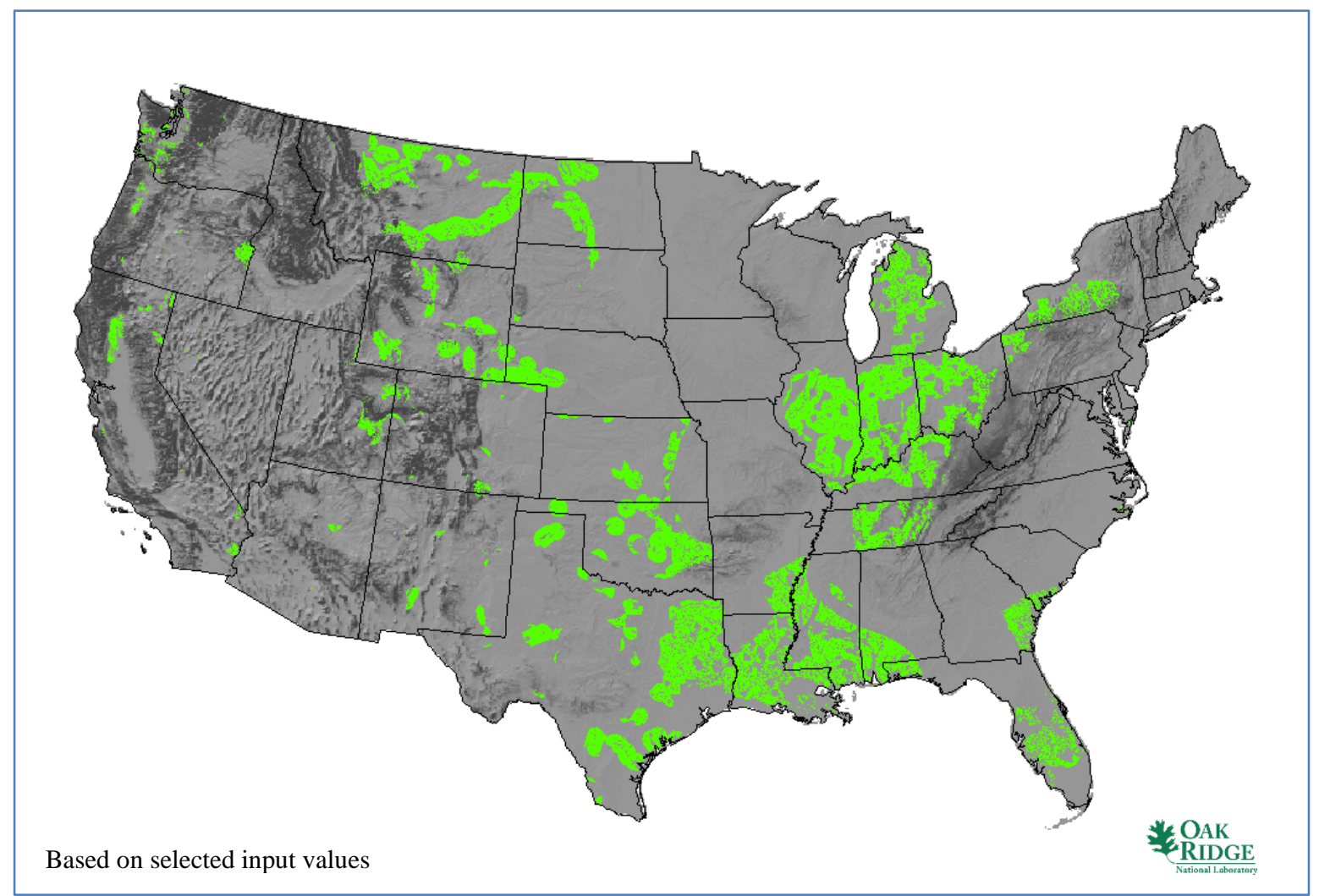

Fig. 78. Advanced coal sites that sit directly over a geological formation (no aggregation for plant size). 


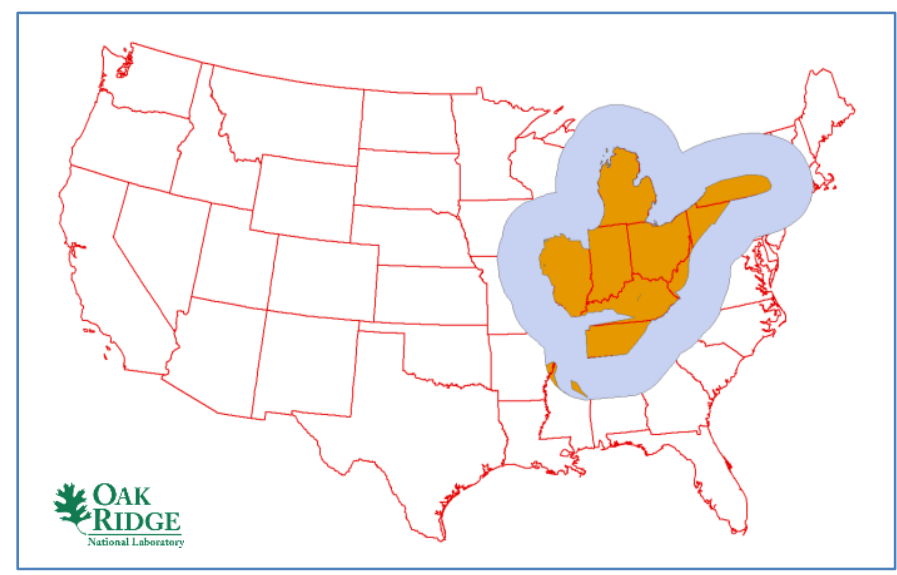

Fig. 79. Identification of the carbon piping regions.

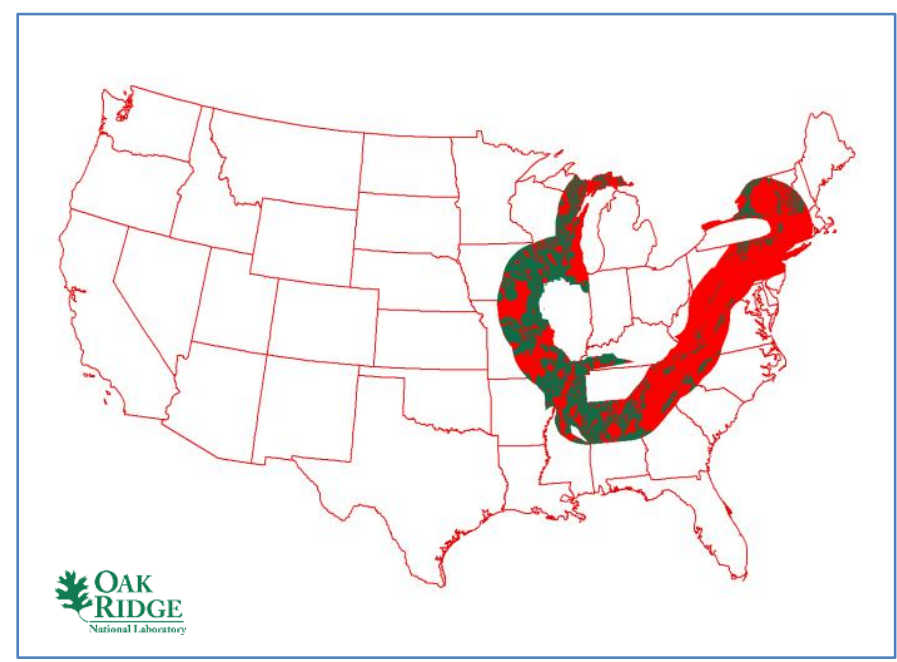

Fig. 80. Evaluation of the carbon piping regions.

Finally, the areas in green in Fig. 80 must be evaluated to determine if a pipe run is feasible to the geological formation. For example, there are numerous green areas in the Appalachian region that are completely surrounded by red excluded land. Further evaluation indicates that these green areas are surrounded by high slope, protected lands, or fault lines. Therefore, these green areas must be removed from further consideration because carbon piping to a geological formation is not considered to be feasible. This process is repeated for all areas acceptable to advanced coal plant siting that fall within a 150-mile buffer zone.

Figure 81 shows the advanced coal base map after discarding acceptable sites within the 150-mile piping buffer zones that do not support the actual pipe run to a geological formation. All acceptable areas are shown in green. The combined available land is $21.5 \%$ of the continguous United States, an increase of $11.8 \%$ over the sites that were directly above a geological formation (shown in Fig. 78). About $3 \%$ of the formerly acceptable sites within the piping buffer zones were discarded based on piping limitations. As shown in Fig. 82, aggregating the available land from the advanced coal base map for the nominal 300 -acre $750 \mathrm{MW}(\mathrm{e})$ advanced coal plant provides for $15.5 \%$ of the contiguous United States or 265 million acres based on the selected SSEC criteria. 


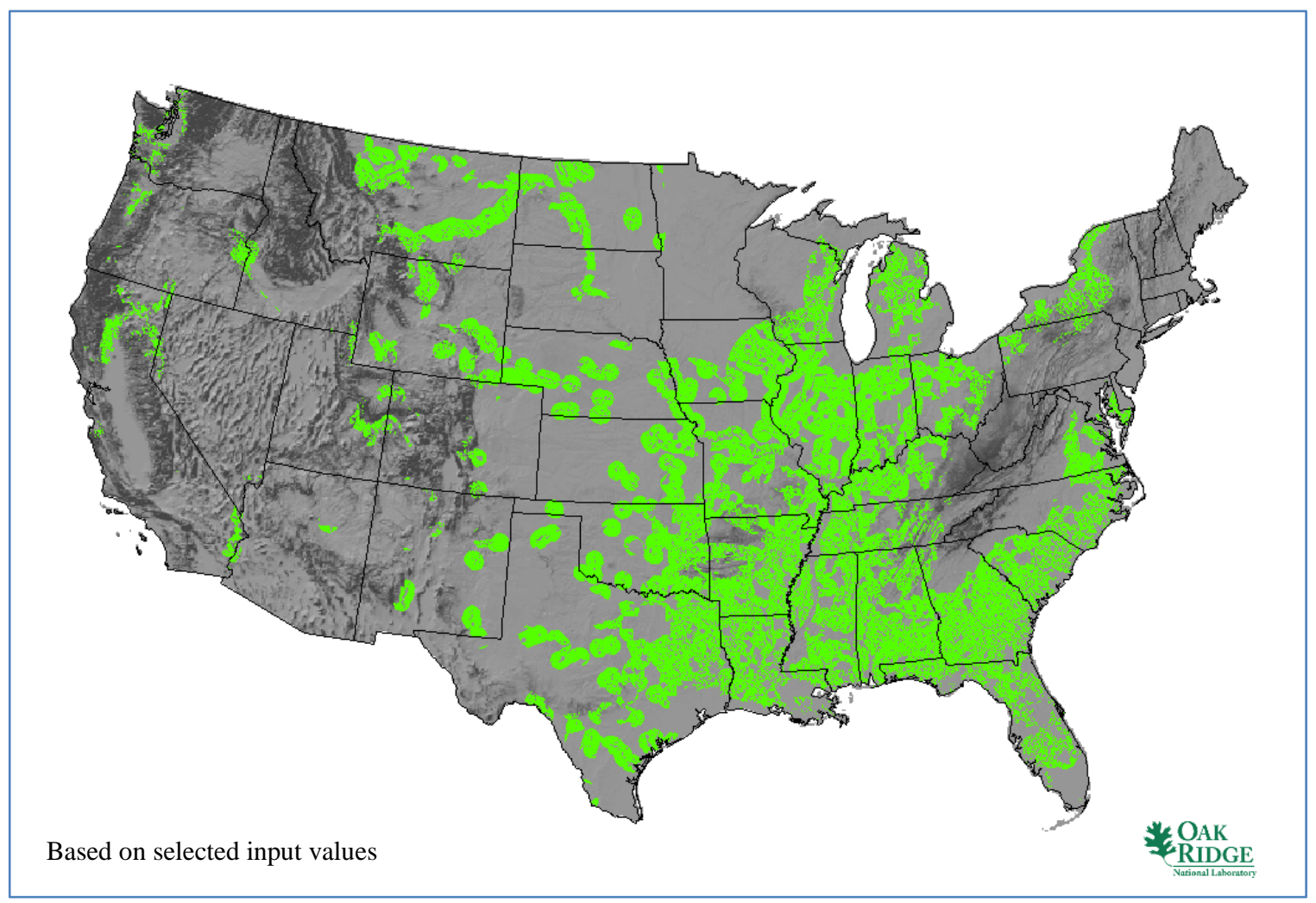

Fig. 81. Combined advanced coal base map after applying carbon piping limitations.

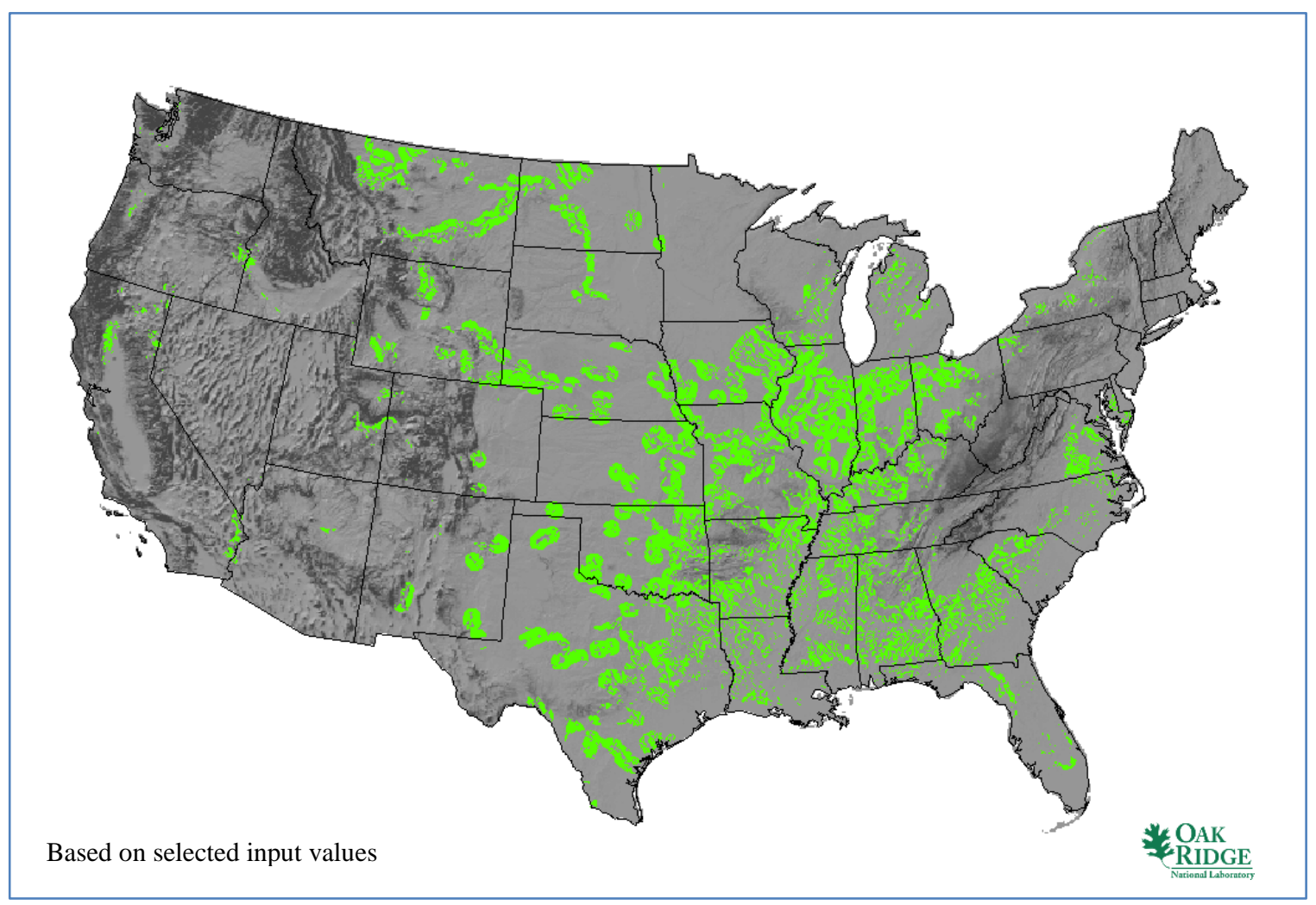

Fig. 82. Advanced coal plant siting aggregated at $90 \%$ for 300 acre facility. 


\subsection{Plant Placement Results}

A calculation of advanced coal plant capacity was performed using the methodology described in the section "Plant Placement Algorithm for Water-Dependent Power Sources." The predictions are based on a nominal $750 \mathrm{MW}(\mathrm{e})$ (gross) advanced coal plant installation positioned on 300 acres of land. This estimate is independent of other thermal plant installation predictions and is not tied directly to current estimates of power demand.

Figure 83 displays the result of the plant placement algorithm overlaid by the 18 water regions. The plants are projected based on individual water regions in locations where stream flow is at or above $125,000 \mathrm{gpm}$. The green dots are projected sites that are located directly above saline formations that can be used for carbon sequestration. The red dots are projected sites that require the carbon to be compressed and piped up to 150 miles to a saline formation for storage. No consideration is made for the lifetime storage capacity of any given geological formation. Both colored dots are projected sites for the purposes of calculating advanced coal capacity. No dot represents an actual plant placement recommendation. The estimated capacity is approximately split, with $99 \mathrm{GW}(\mathrm{e})$ of capacity above the saline formations and an additional $117 \mathrm{MW}(\mathrm{e})$ of capacity requiring piping transport to a saline formation. The plants are projected based on individual water basins. The plant placement algorithm is designed to project plant placements while tracking available water flow in the basin.

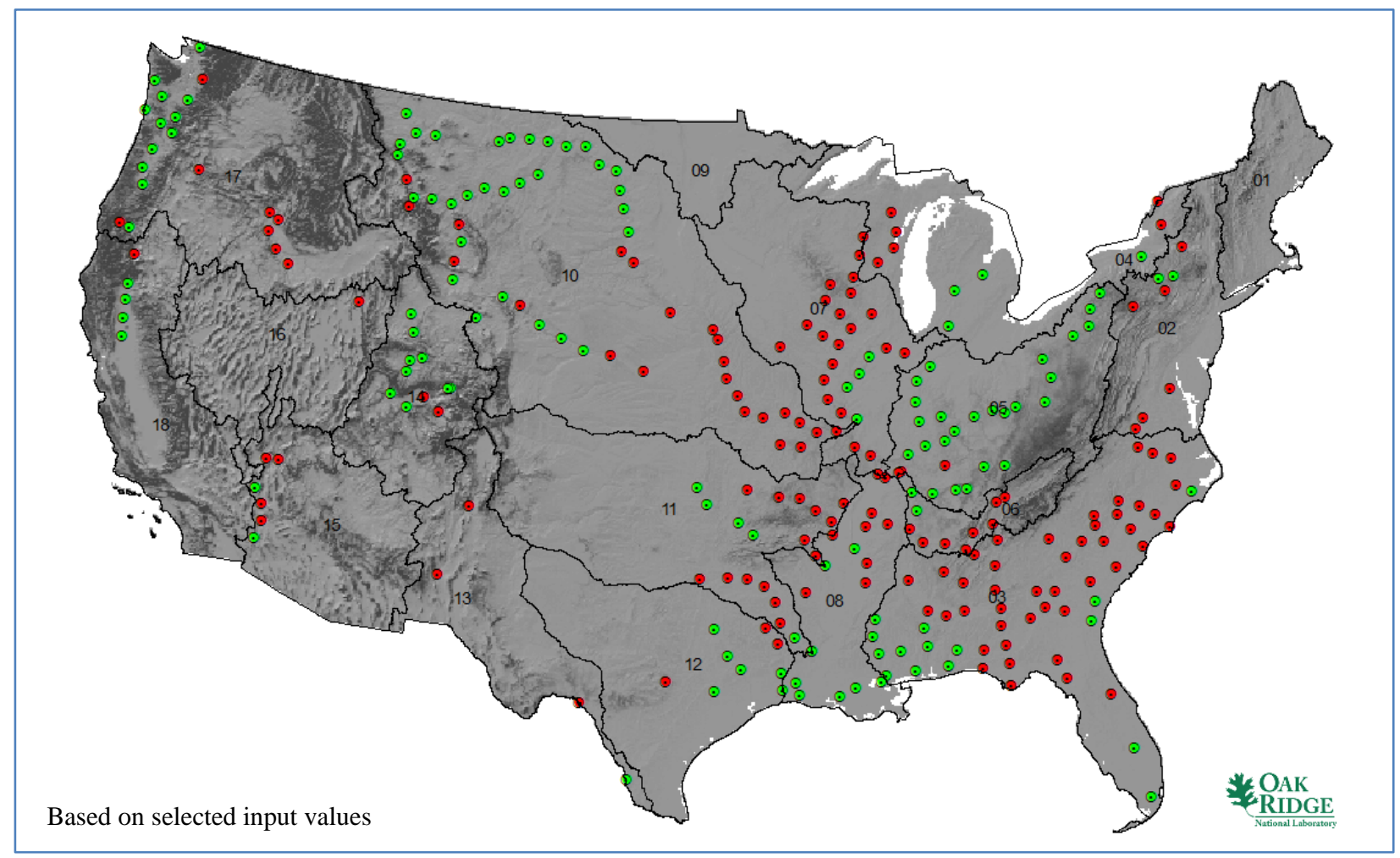

Fig. 83. Advanced coal plant placement results by water region.

The display in Fig. 84 shows the projected plant placements with a state map overlay. Here, all projected plant placements are shown in green. State-by-state results can be affected by the unbiased nature of the initial plant placement in any given water basin and the arbitrary limit of 20 miles between unit projections as discussed in the section "Plant Placement Algorithm for Water-Dependent Power Sources." 


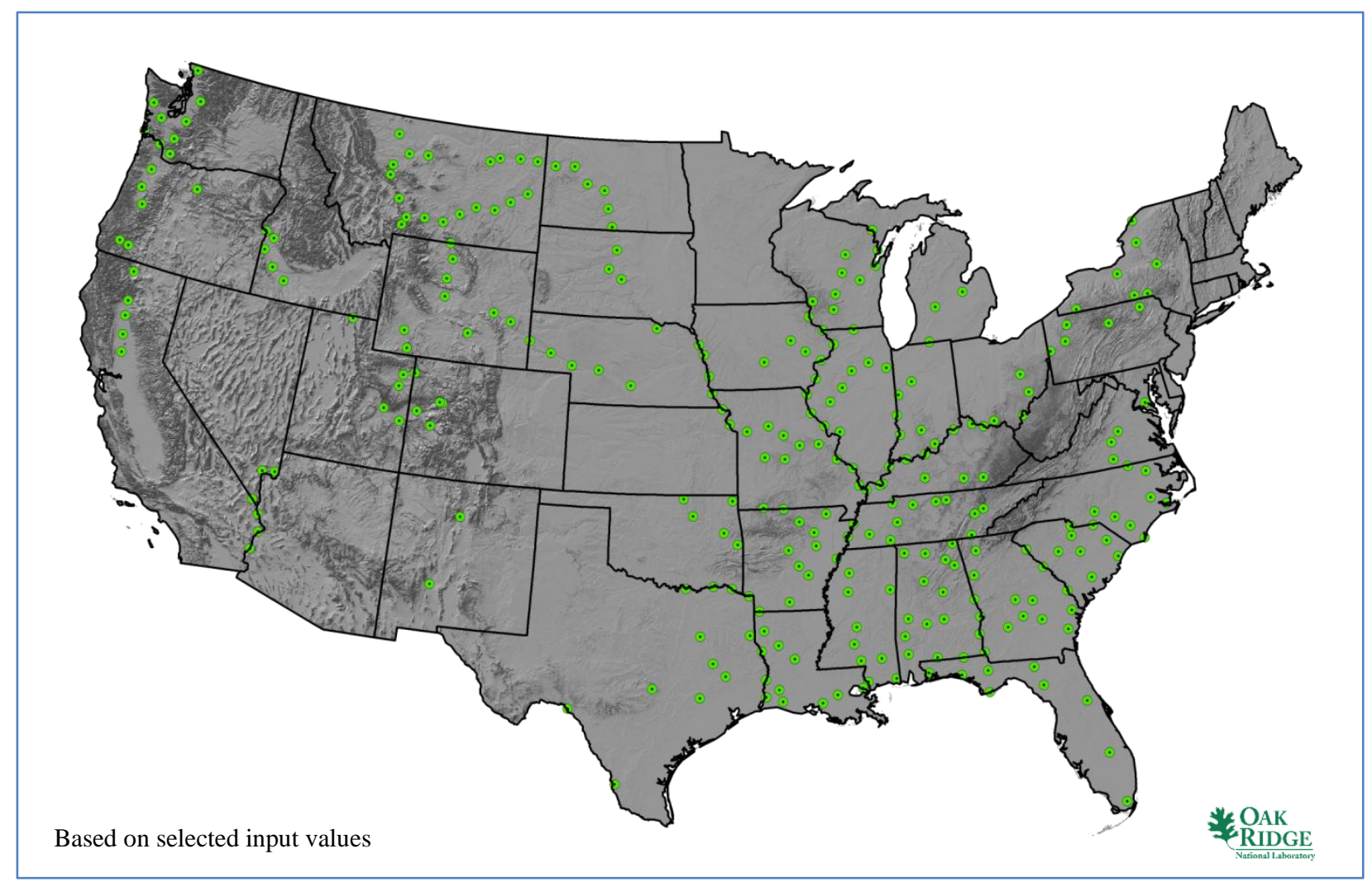

Fig. 84. Advanced coal plant placement results by state.

The placement algorithm projects the placement of 288 advanced coal plants for a gross capacity of $216 \mathrm{GW}(\mathrm{e})$. Assuming a parasitic load for scrubbing and carbon capture, this represents a net capacity of approximately $158.4 \mathrm{GW}(\mathrm{e})$. The states with the strongest projection for advanced coal plant installations and capacity (10 or more sites each) are Montana, Illinois, Missouri, Arkansas, Texas, Louisiana, Tennessee, Alabama, and Georgia. The placement algorithm estimated approximately $99 \mathrm{GW}(\mathrm{e})$ of gross capacity directly over saline geological formations and $117 \mathrm{GW}(\mathrm{e})$ of gross capacity within 150 miles of a saline geological formation for carbon storage.

\subsection{Consideration of Advanced Coal and Nuclear Plant Combined Placement}

The advanced coal plant results are similar to the large nuclear plant results, based on similar cooling water requirements and plant size. The major difference is the lack of seismic restrictions for siting an advanced coal plant. That difference generates pockets of area that are more favorable for advanced coal plant siting. Likewise, the requirement to pipe and store the carbon create pockets of area that are more favorable for nuclear plant siting. However, nuclear-based thermoelectric plants and advanced coal plants will be competing for the same cooling water resources. Therefore, an algorithm was developed to do the following:

1. In any given state, identify the following three siting combinations:

a. Areas where a representative advanced coal plant will pass all exclusions and a large nuclear plant fails on at least one criterion;

b. Areas where a representative large reactor plant will pass all exclusions and an advanced coal plant fails on at least one criterion; and

c. Areas where both a representative advanced coal plant and a large nuclear plant will pass all exclusions. 
2. Preferentially populate the water basins in a given state for advanced coal plants per the information from step 1a above.

3. Using the remaining available water, preferentially populate the water basins in a given state for large nuclear plants per the information from step $1 \mathrm{~b}$ above.

4. Use the remaining available water to populate the water basins in a given state for large nuclear plants per the information from step 1c above. The assumption here is that an advanced coal plant will fit anywhere a large nuclear plant will fit, so the large reactor plant is bounding. We assume a one-for-one tradeoff between large reactors and coal plants for simplicity, though in reality more than one typical advanced coal plant could replace one typical large nuclear plant.

This selection hierarchy was set up to reflect the economics and lead time of nuclear construction versus coal plant construction. A combined base map was developed for this sensitivity study, as shown in Fig. 85 .

The OR-SAGE capacity estimate algorithm was applied using the preference hierarchy outlined above. Fig. 86 shows the results of the capacity estimate. The red dots represent estimated advanced coal plant placements, and the blue dots represent large nuclear plant placements for the purpose of predicting capacity. No dot represents an actual plant placement recommendation. The placement hierarchy was biased toward advanced coal plant placement. Therefore, 252 advanced coal facilities but just 76 large nuclear facilities are estimated. Overall, $311 \mathrm{GW}(\mathrm{e})$ of gross capacity is estimated in this scenario. This compares with $216 \mathrm{GW}$ (e) of gross capacity using only independent advanced coal results and $515 \mathrm{GW}$ (e) of gross capacity using only independent large nuclear plant results.

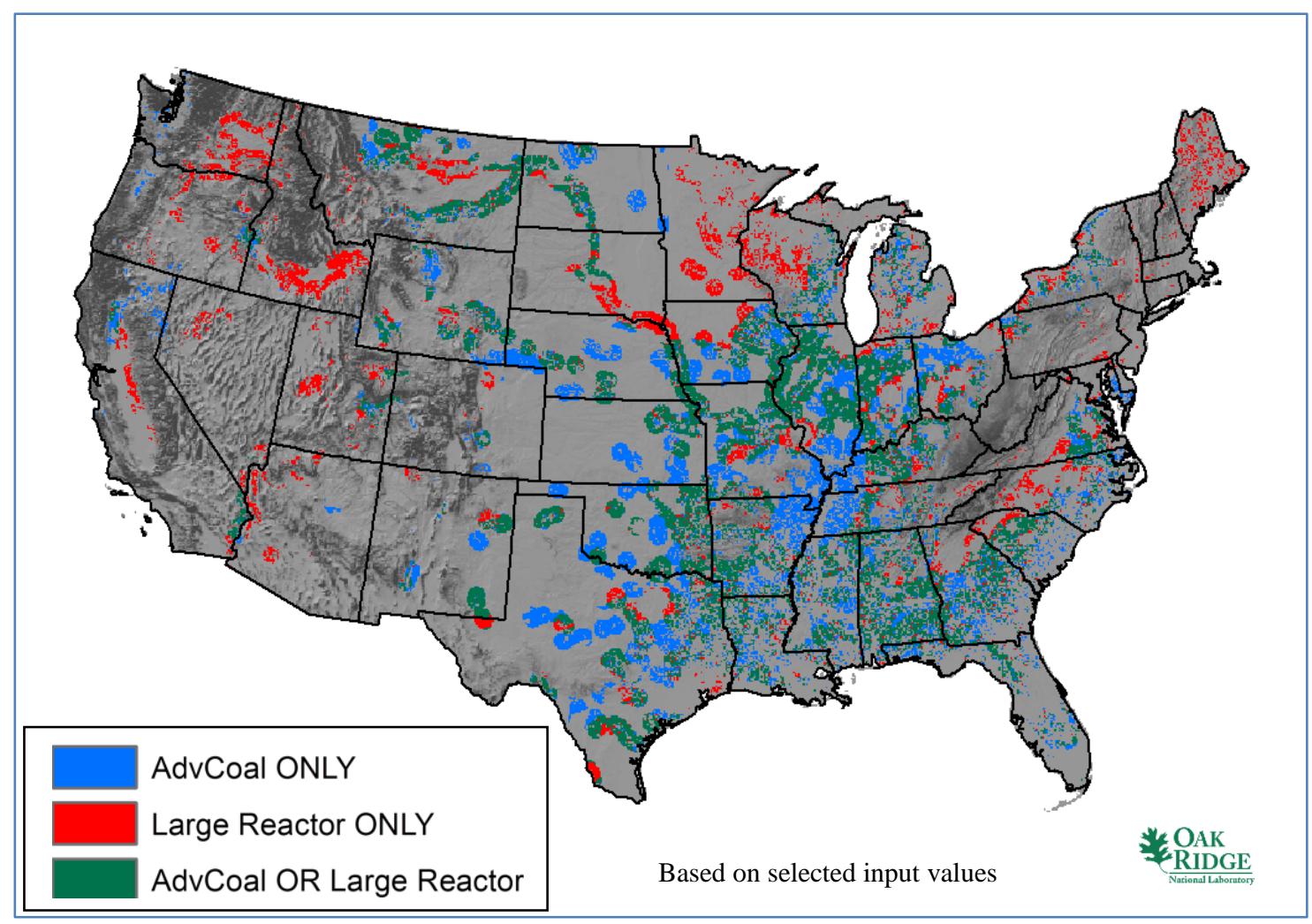

Fig. 85. Combined aggregated land for advanced coal and large nuclear plants. 


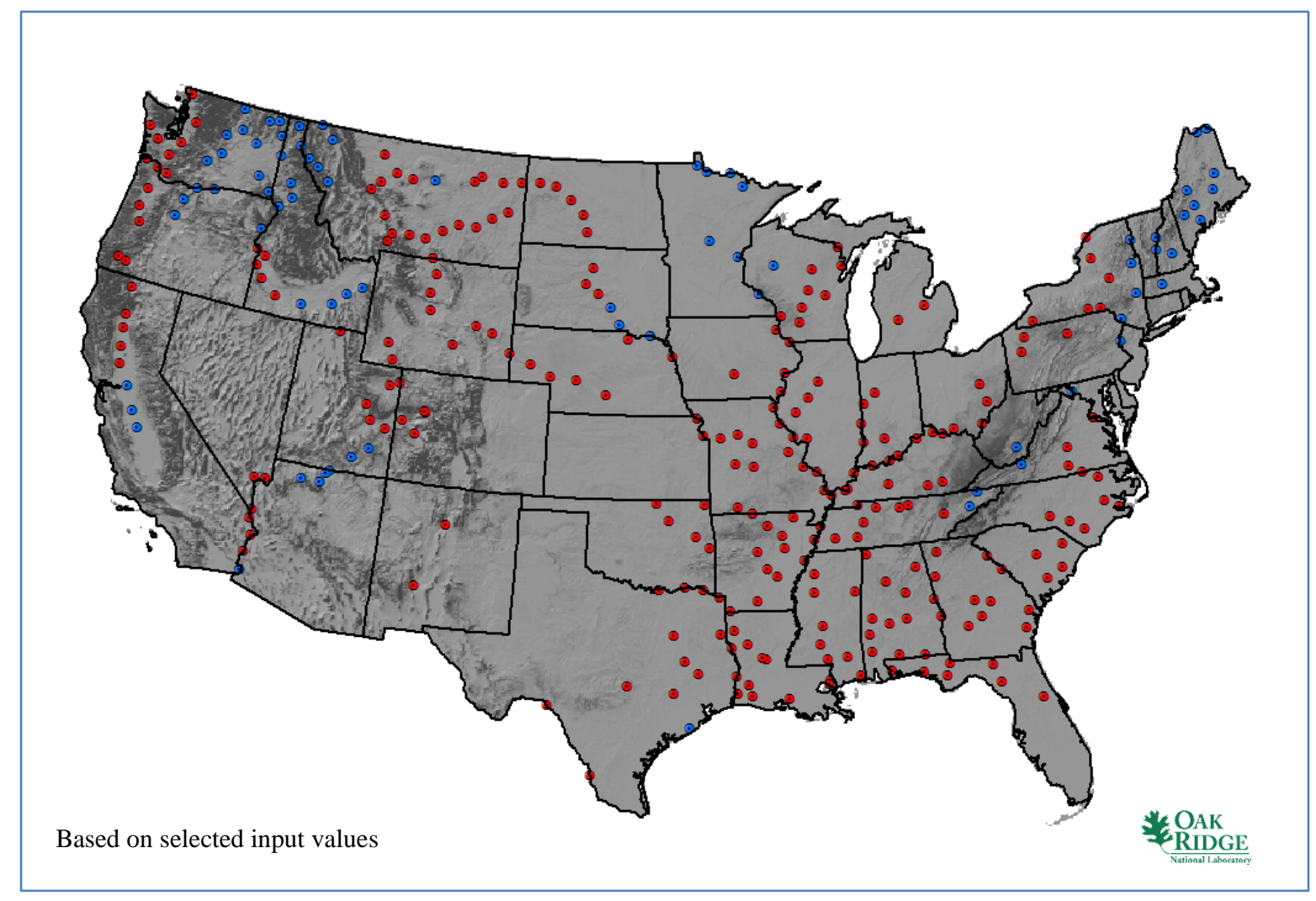

Fig. 86. Combined advance coal and nuclear plant placement results.

\subsection{Sensitivity Studies}

\subsubsection{Distance Carbon is Piped to a Geological Formation}

Piping carbon to a geological formation can represent a sizable capital and operational expense.

Sensitivity studies were performed for piping lengths of 0 miles, 25 miles, and 200 miles. Figure 87 shows the geological formations amenable to carbon storage with a 25-mile buffer zone applied to allow for carbon piping. Sites that pass the remaining SSEC selected for advanced coal plants will have to fit within this footprint. Figure 88 shows the results of this sensitivity study with $10.2 \%$ of the contiguous United States, aggregated for 300-acre advanced coal plants, available for site selection.

Likewise, the geological formations amenable to carbon storage with a 200-mile buffer zone applied to allow for carbon piping are shown in Fig. 89. Sites that pass the remaining SSEC selected for advanced coal plants will have to fit within this footprint. At this distance value, this GIS layer is not highly discriminating. In effect, this layer removes only Minnesota and Maine from further consideration for advanced coal siting. Figure 90 shows the results of this sensitivity study with $16.4 \%$ of the contiguous United States, aggregated for 300-acre advanced coal plants, available for site selection. Essentially, this result approximates the upper bound on land area available for advanced coal plant siting assuming an unlimited piping distance. 


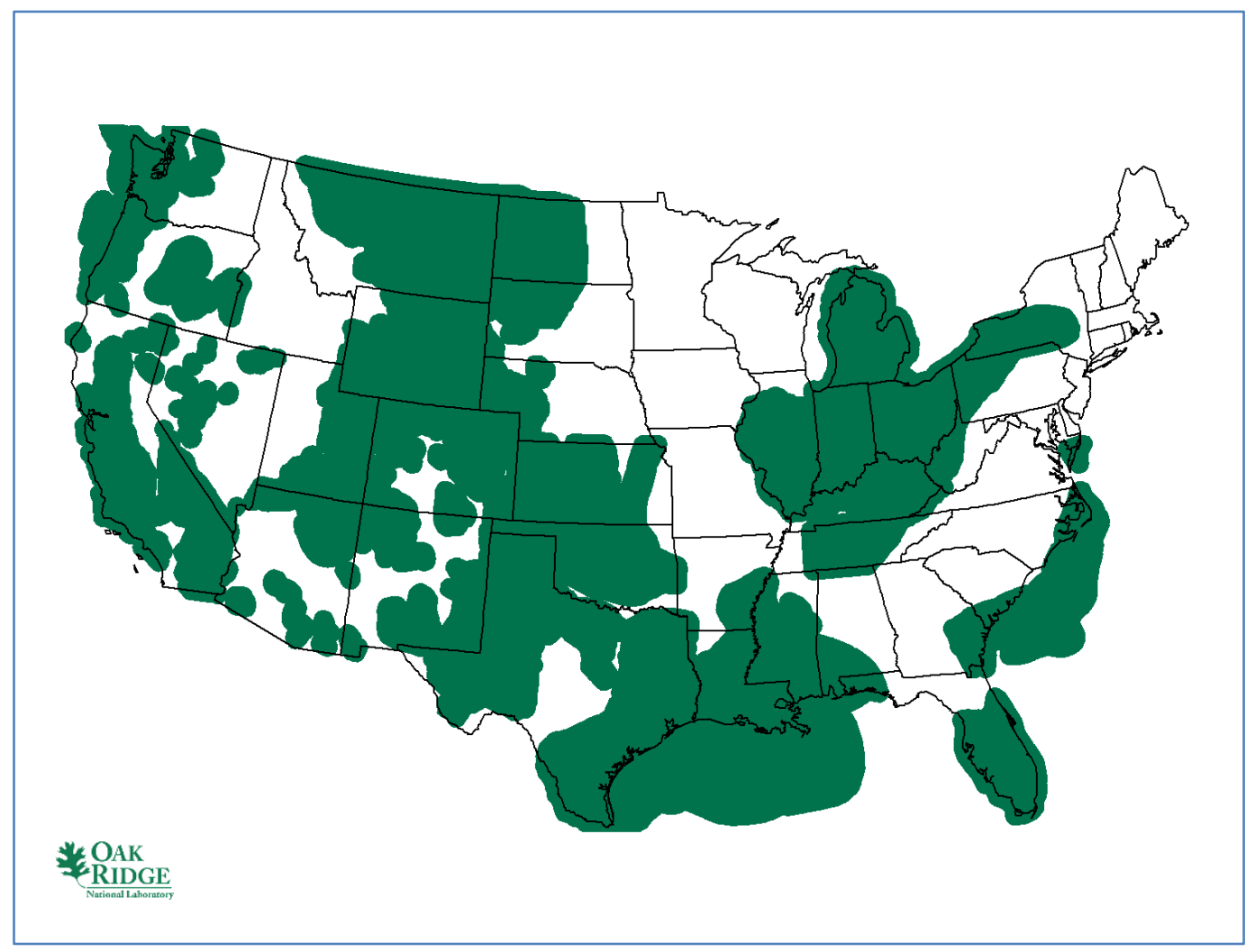

Fig. 87. Advanced coal plant saline formations with a 25-mile piping buffer zone.

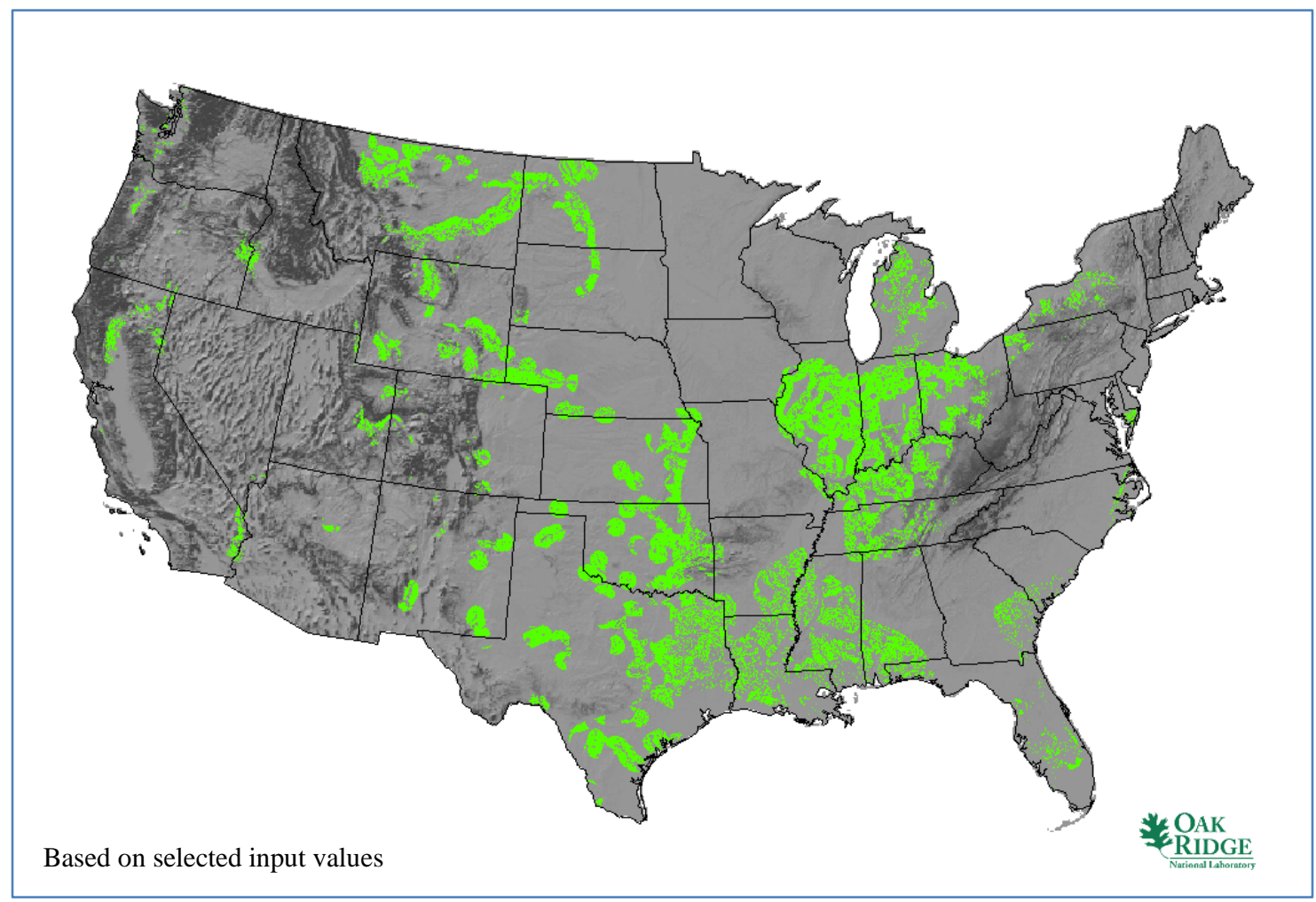

Fig. 88. Advanced coal plant siting options with 25-mile carbon piping limit. 


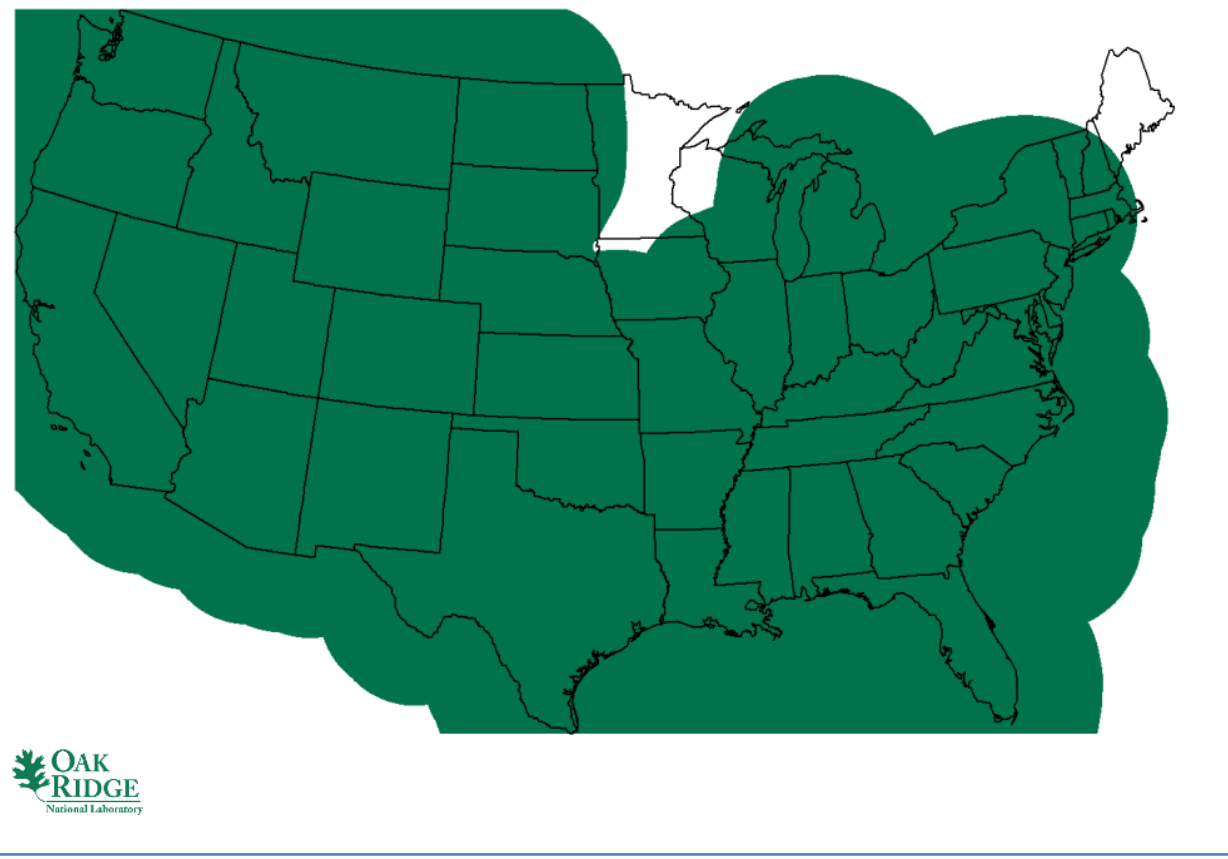

Fig. 89. Advanced coal plant saline formations with a 200-mile piping buffer zone.

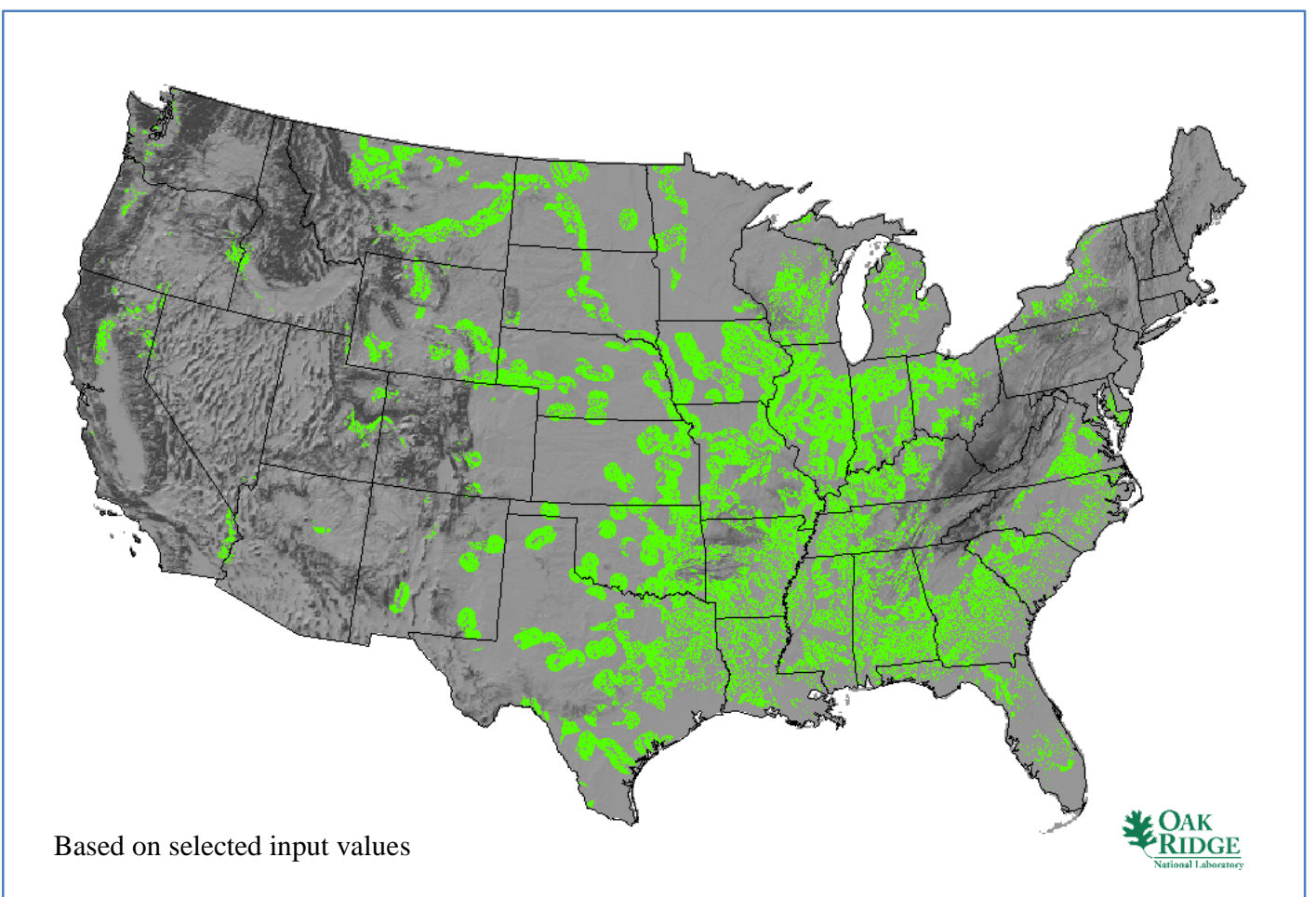

Fig. 90. Advanced coal plant siting options with 200-mile carbon piping limit.

Table 11 compiles the results of the carbon piping distance sensitivity study. The difference between a piping distance of 0 miles and a piping distance of 150 miles is consistent with the previous plant 
placement algorithm results. Allowing a carbon piping distance of 150 miles provides a little more than double the available area for advanced carbon plant siting, and the plant siting algorithm estimate just under half of the advanced coal plants on top of a geological formation for storage (the 0 mile piping option).

Table 11. Available percentage of contiguous US in carbon piping distance sensitivity study

\begin{tabular}{lc}
\hline \multicolumn{1}{c}{ Aggregated land (90\%) when: } & Contiguous US \\
\hline Carbon piping limited to 0 miles & $6.9 \%$ \\
Carbon piping limited to 25 miles & $10.2 \%$ \\
Carbon piping limited to 150 miles & $15.5 \%$ \\
Carbon piping limited to 200 miles & $16.4 \%$ \\
\hline
\end{tabular}

The previous advanced coal plant placement algorithm results can be extended to the sensitivity study results for the 25-mile case and the 200-mile case. A rough comparison with the plant placement algorithm calculated for the 25 -mile carbon piping case would suggest that available advanced coal plant gross capacity would be reduced to approximately $142 \mathrm{GW}(\mathrm{e})$. Conversely, available advanced coal plant gross capacity for the 200-mile carbon piping case would be increased to approximately $229 \mathrm{GW}(\mathrm{e})$.

\subsubsection{Removal of the EPA Nonattainment Data SSEC Layer}

It can be argued that proven clean coal technology would be accepted in regions that do not currently meet EPA air pollution standards based on nonattainment data. Therefore, a sensitivity study was performed by simply removing the EPA nonattainment data SSEC layer (Fig. 71) from the results.

Figure 91 shows the results of removing the EPA nonattainment data layer from the selected SSEC criteria. The available land aggregated for plant size is increased to $17.1 \%$ of the contiguous United States or 293 million acres. This compares with $15.5 \%$ of the contiguous United States ( 265 million acres) in the base case (Fig. 82). A rough comparison with the plant placement algorithm calculated for the advanced coal plant base case would suggest that available advanced coal plant gross capacity would be increased from $216 \mathrm{GW}(\mathrm{e})$ to approximately $238 \mathrm{GW}(\mathrm{e})$ by not applying the EPA nonattainment data SSEC layer.

\subsubsection{Median Carbon Piping Distance}

Piping carbon to a geological formation for storage incurs an additional cost related to distance. Figure 92 segments the proposed advanced coal plant placement results by the distance to the edge of the nearest geological formation. 


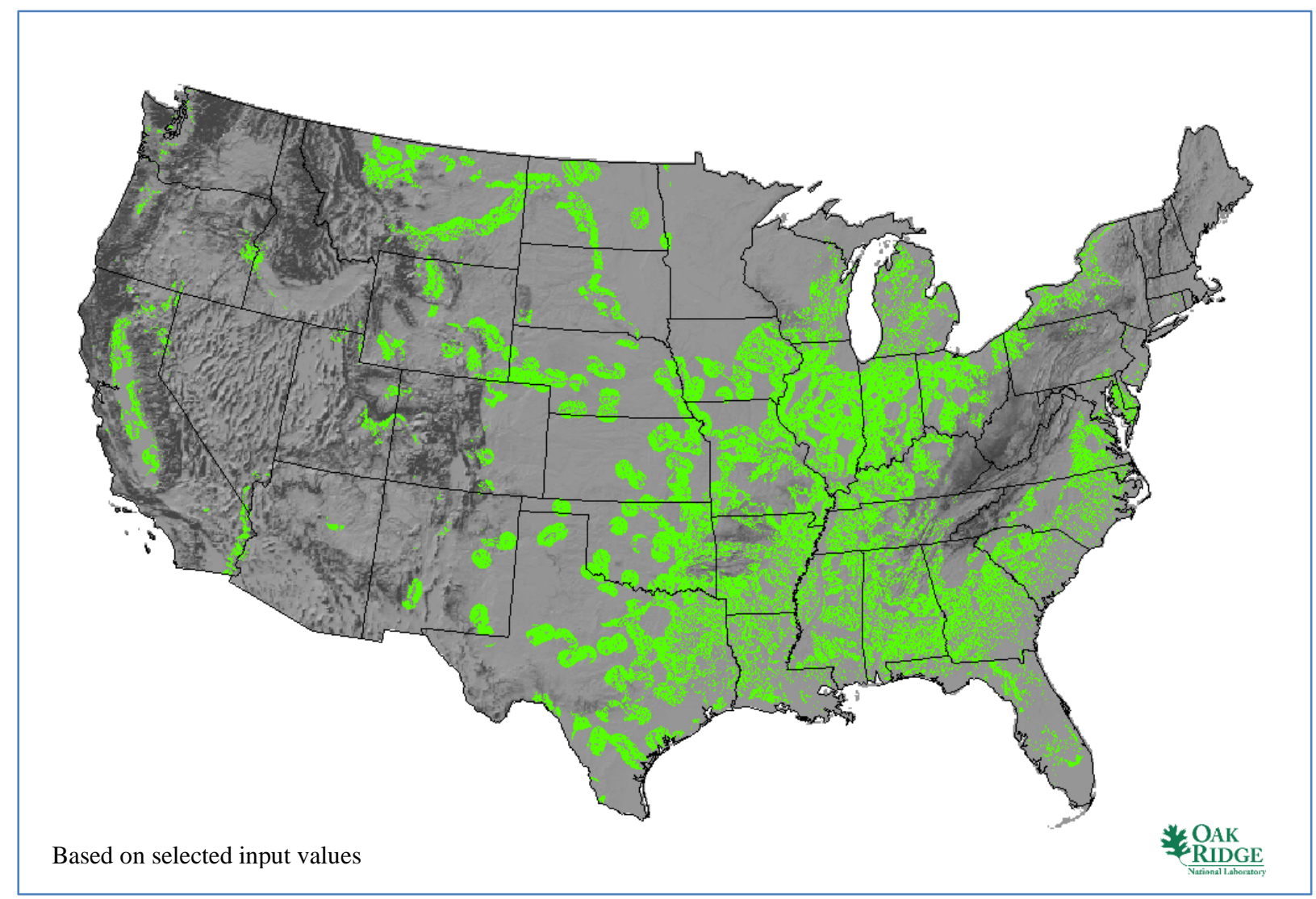

Fig. 91. Advanced coal plant siting options without EPA SSEC layer.

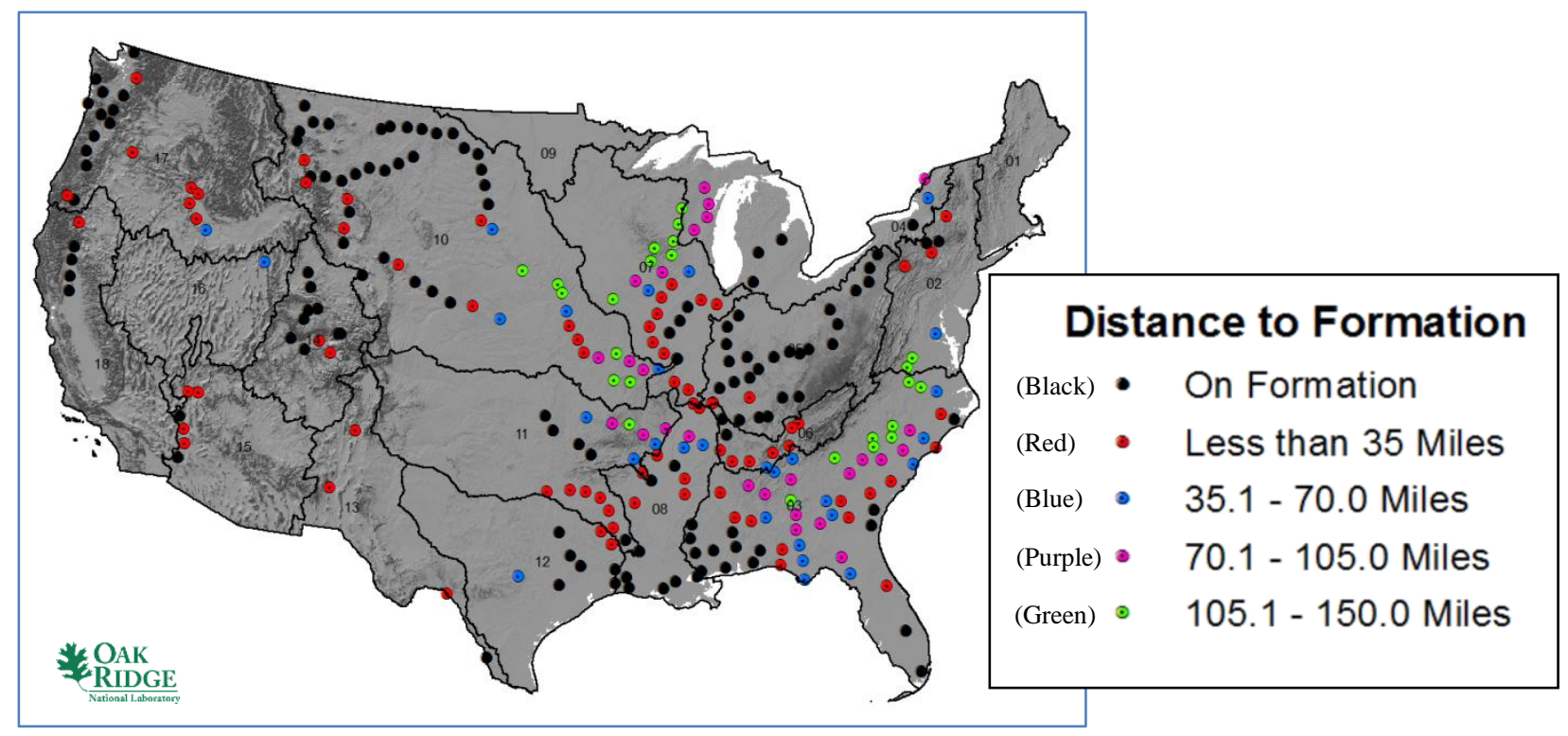

Fig. 92. Carbon piping distance to geological storage formation. 


\subsubsection{Projections}

Over time, the siting options change depending on a wealth of factors, including load growth, population shifts, increased demand for fresh water, changed regulatory environment, climate shifts, and others. In addition, new power generation requires planning, financing, permitting, and construction. For advanced coal, this process typically takes several years. GIS projections are only as good as the underlying data and trends, and uncertainty increases with the length of time projected. Based on this, as discussed in the section "2035 Assumptions," a projection 25 years in the future was prepared for advanced coal power generation, based on population data and trends available to ORNL in its LandScan USA dataset and a revised rule of thumb for freshwater availability to power generation.

Figure 93 depicts the projected 2035 population SSEC layer for advanced coal. As discussed previously, a population density of greater than 500 people per square mile begins to transition into an urban setting, so new advanced coal plants in these areas, shown in red, continue to be excluded using the 2035 population projection. There is no need to include a buffer for public safety. Figure 64 provides the comparable population SSEC layer for 2010.

Likewise, Fig. 94 shows the areas excluded in red, based on a reduced availability of fresh water for CCC makeup in the future. To approximate the increased demand on water supplies in the future, it was decided that the simple rule of thumb to apply to the 2035 case would be that a given power source should not take more than $5 \%$ of the available stream flow at a given "new plant" location, as opposed to $10 \%$ in the 2010 timeframe. Table 5 shows the resulting effect on stream flow: 250,000 gpm available within 20 miles in the case of advanced coal. Figure 70 provides the comparable stream flow SSEC layer for 2010 based on 125,000 gpm available within 20 miles. It should be noted that this study does not consider the retirement of older coal plants, which would release the current obligation of fresh cooling water, already accounted for in the GIS data, to be applied to newer power generation applications.

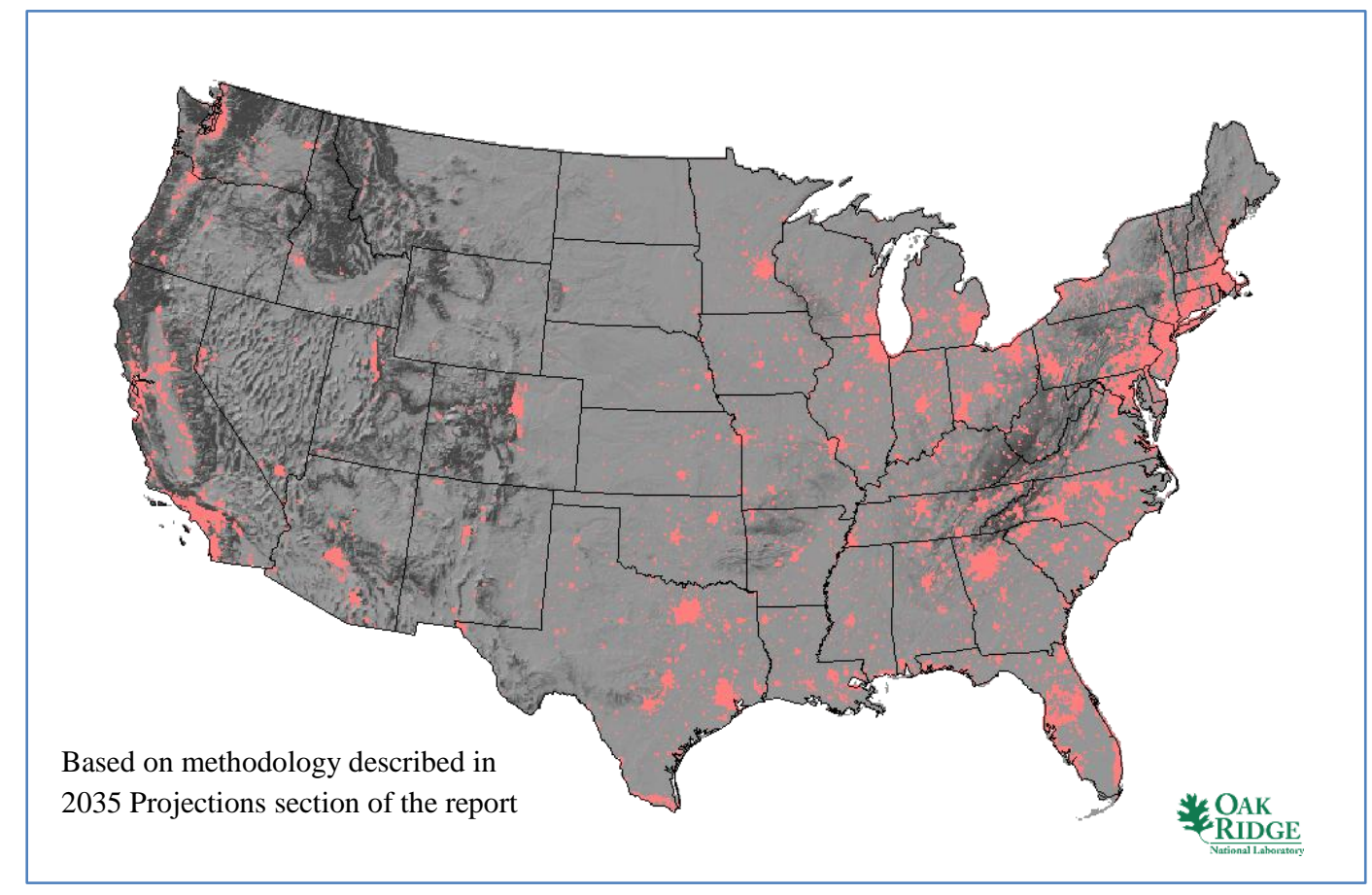

Fig. 93. Advanced coal 2035 high population SSEC layer. 


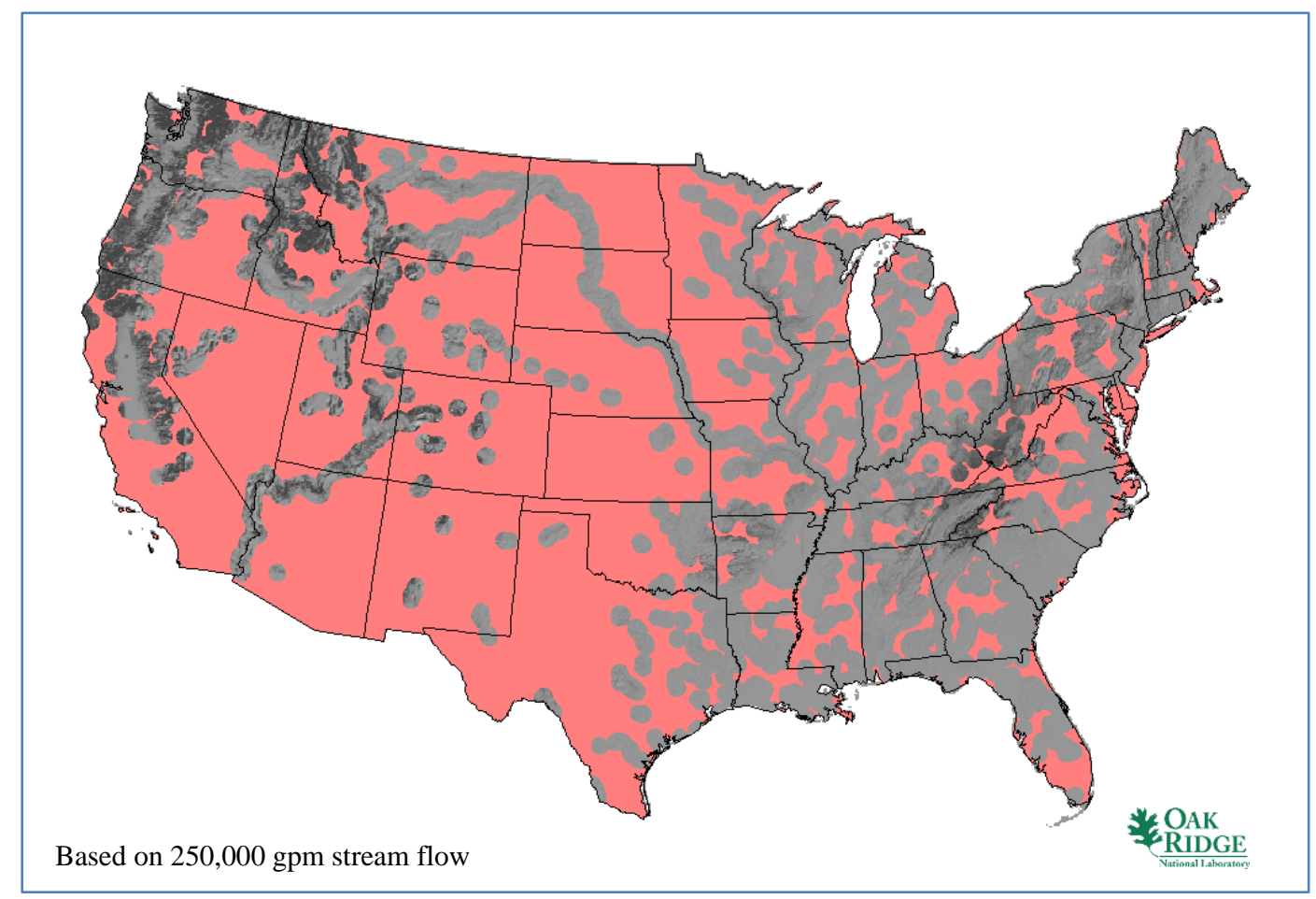

Fig. 94. Advanced coal 2035 low stream flow SSEC layer.

As a result of substituting the 2035 projected SSEC layers shown in Figs. 93 and 94, the available land for siting an advanced coal plant is diminished for 2035. Based on these projections and the previously selected values for the advanced coal plant siting, Fig. 95 depicts the 2035 advanced coal base map indicating $17.3 \%$ of the contiguous United States is available, or 296 million acres. Compare this with the 2010 advanced coal base map shown in Fig. 81 on which $21.5 \%$ of the contiguous United States is available, or 368 million acres. The 2035 projection for advanced coal indicates a reduction in available land equivalent to $4.2 \%$ of the contiguous United States, or a reduction of 72 million acres, before consideration of land aggregation to meet the nominal plant footprint size. 


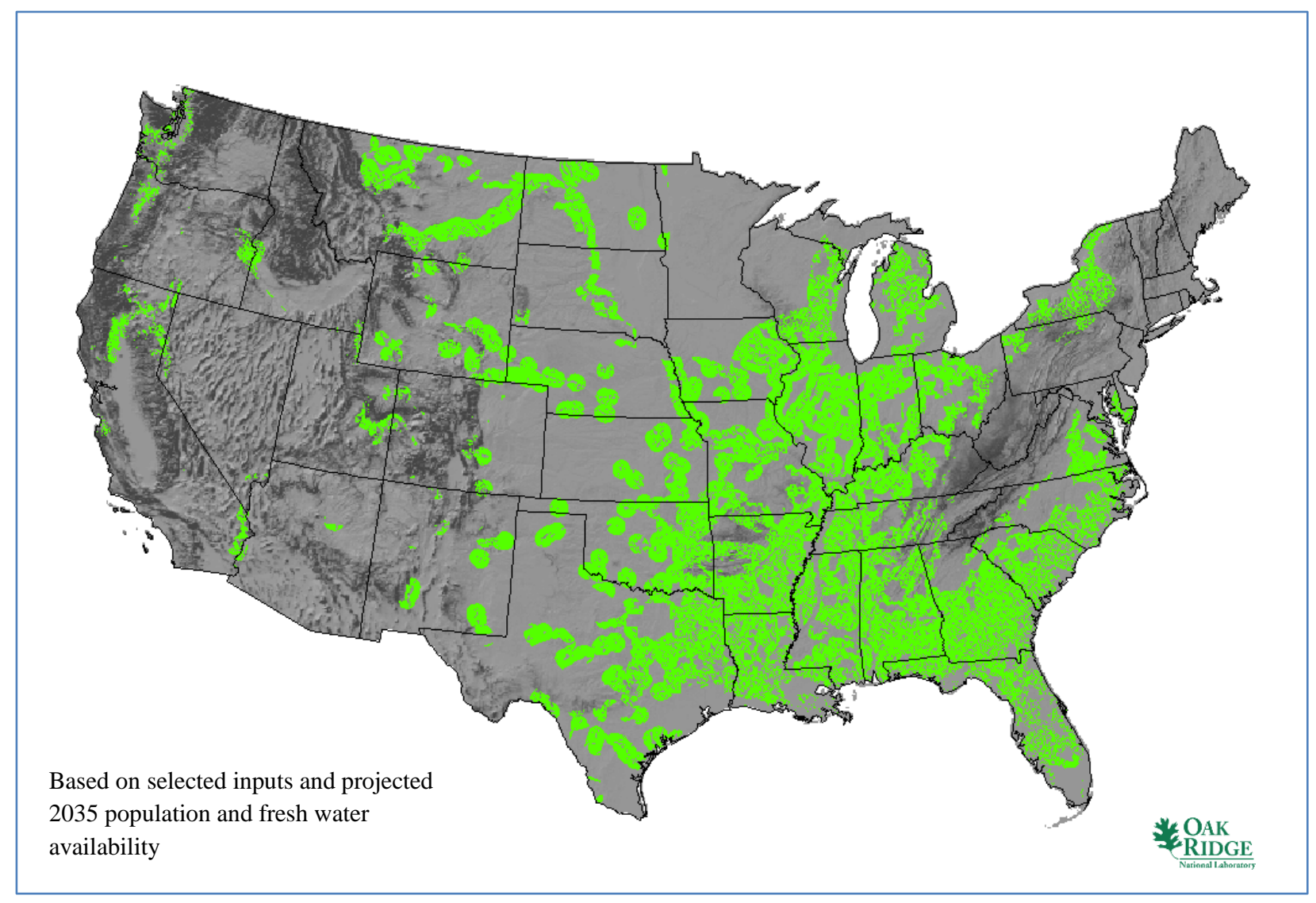

Fig. 95. Advanced coal 2035 base map.

The results of aggregating the projected available land from the base case shown in Fig. 95 are depicted in green in Fig. 96. Land aggregation for a nominal 300-acre advanced coal facility reduces the available land from $17.3 \%$ of the contiguous United States in the 2035 base case to $11.9 \%$ or 204 million acres. This is an actual reduction of $3.6 \%$ of the contiguous United States, or 62 million acres, compared with the aggregated land calculation for 2010 shown in Fig. 82, or a relative decrease of $23 \%$.

Figure 97 provides a visual comparison of the aggregated land available for advanced coal plant siting, based on selected SSEC input parameters, for the 2010 and 2035 scenarios. A rough comparison with the plant placement algorithm calculated for the 2010 advanced coal plant base case would suggest that available new advanced coal plant gross capacity would be decreased from $216 \mathrm{GW}$ (e) to approximately $166 \mathrm{GW}(\mathrm{e})$ by delaying installed new advanced coal capacity to 2035 . 


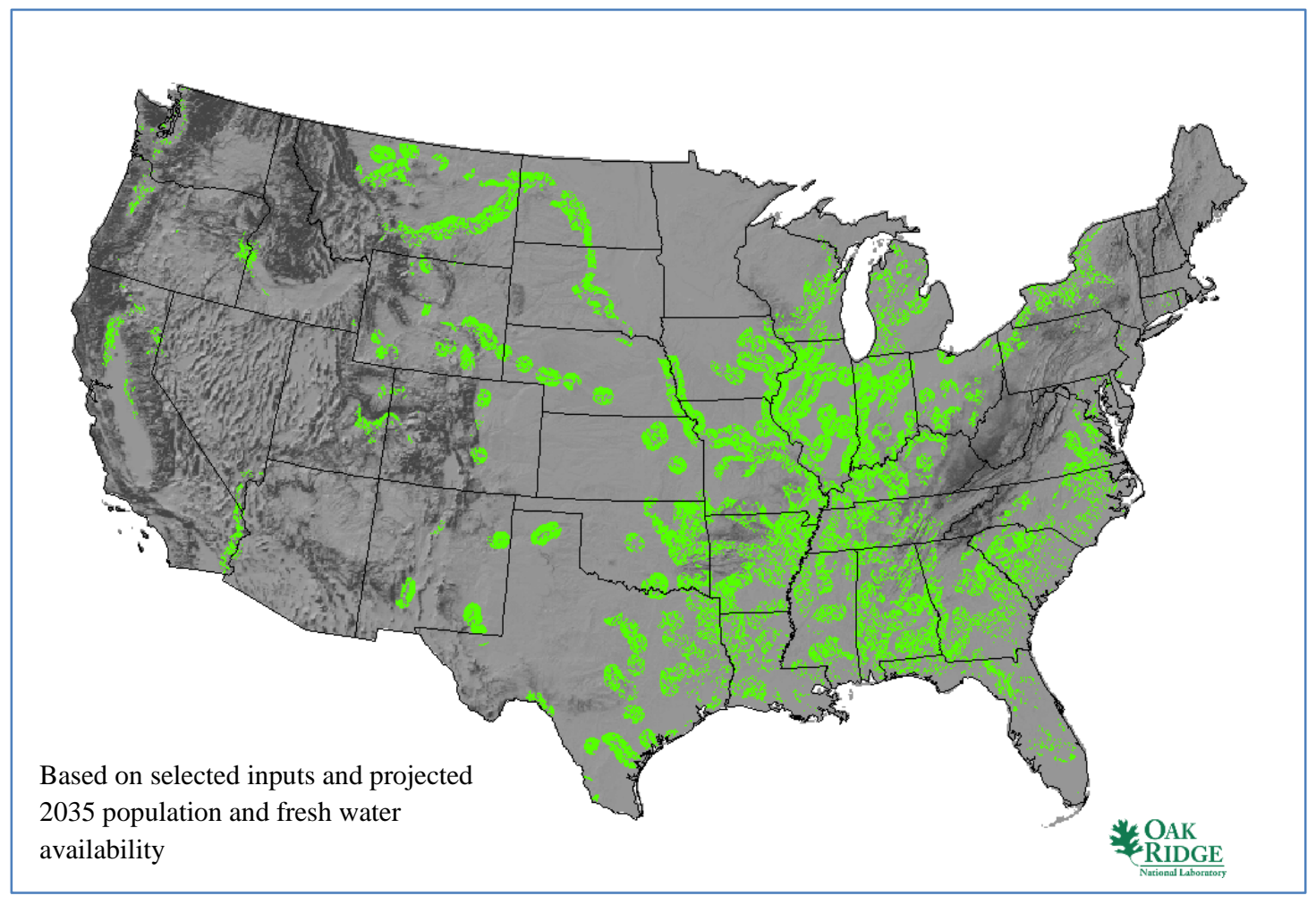

Fig. 96. Advanced coal plant 2035 siting aggregated at $90 \%$ for 300 acre facility.

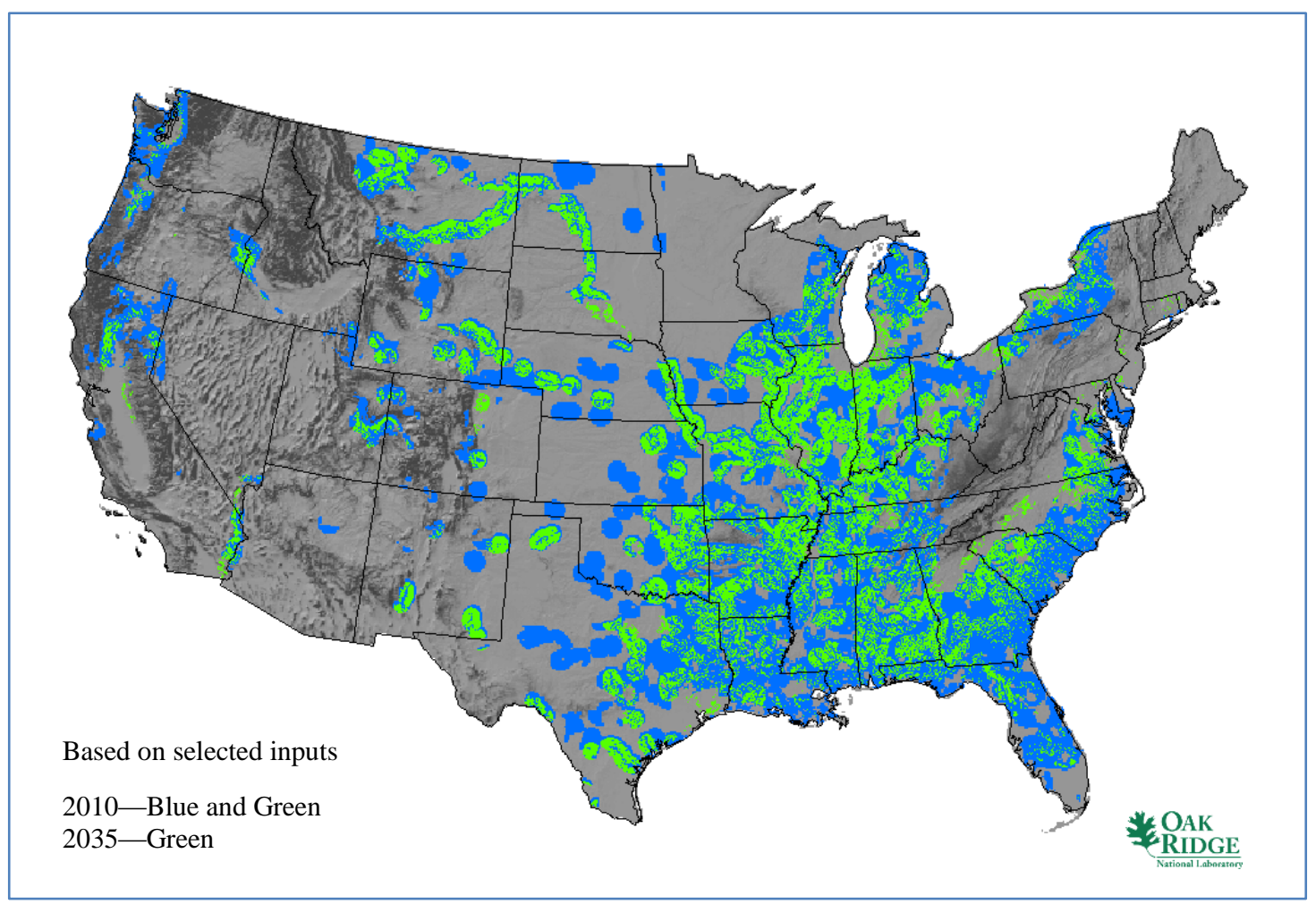

Fig. 97. Advanced coal plant visual comparison of 2010 and 2035 aggregated land results. 


\subsection{Tabular Results}

Table 12 shows the advanced coal plant estimate results by state. An entry of 0.00 indicates a value greater than zero that does not show at two significant digits, while a blank entry implies a zero response. Note that the tabular results are not intended to show a "final" result. These results are based on a selected set of input values and a capacity projection algorithm. The relative values between states are the more significant table information. It should be further noted that Table 12 details only the results for aggregated land cells that had no siting challenges. Engineered solutions for land with one or more siting challenges would impact the entries included in Table 12.

A review of the portion of the contiguous United States available to support advanced coal tabulated in the third column of Table 12 indicates that Texas, Illinois, Oklahoma, Missouri, and Alabama should provide the greatest capacity estimate for new advanced coal plant installations. The OR-SAGE capacity estimate algorithm results tabulated in the right column of Table 12 indicate that Montana, Alabama, Missouri, Illinois, and Arkansas should provide the greatest advanced coal capacity. This highlights the role that adequate cooling water plays in the OR-SAGE capacity algorithm. Montana has an abundance of cooling water which allows siting to be maximized in that state, irrespective of actual demand.

Conversely, Texas and Oklahoma have more restricted water availability, which forces many otherwise acceptable sites to be discarded after a plant placement by the estimation algorithm while waiting for sufficient water to be replenished within the water region to allow for a subsequent advanced coal plant placement.

Table 12. Advanced coal results by state (no siting challenges, selected SSEC values)

\begin{tabular}{lccr}
\hline \multicolumn{1}{c}{ State $^{\boldsymbol{a}}$} & $\begin{array}{c}\text { Portion of state } \\
\text { available to support } \\
\mathbf{3 0 0} \text { acre sites } \\
(\mathbf{( \% )})^{\boldsymbol{b}}\end{array}$ & $\begin{array}{c}\text { Portion of contiguous } \\
\text { US available to } \\
\text { support 300 acre sites } \\
\mathbf{( \% )}\end{array}$ & $\begin{array}{c}\text { Estimated capacity } \\
{[\mathbf{M W ( e )}]^{\boldsymbol{c}}}\end{array}$ \\
\hline Alabama & 47.35 & 0.82 & 12,750 \\
Arizona & 0.62 & 0.02 & 10,500 \\
Arkansas & 41.78 & 0.74 & 6,750 \\
California & 3.33 & 0.17 & 3,750 \\
Colorado & 3.66 & 0.13 & \\
Connecticut & & & \\
Delaware & 0.09 & 0.00 & 6,750 \\
District of Columbia & & & 9,750 \\
Florida & 14.85 & 0.29 & 3,750 \\
Georgia & 34.21 & 0.68 & 11,250 \\
Idaho & 1.13 & 0.03 & 4,500 \\
Illinois & 56.38 & 1.05 & 6,000 \\
Indiana & 48.14 & 0.58 & 750 \\
Iowa & 34.92 & 0.65 & 6,000 \\
Kansas & 19.23 & 0.52 & 8,250 \\
Kentucky & 32.45 & 0.43 & \\
Louisiana & 25.71 & 0.40 & \\
\hline
\end{tabular}


Table 12. (continued)

\begin{tabular}{|c|c|c|c|}
\hline State $^{a}$ & $\begin{array}{l}\text { Portion of state } \\
\text { available to support } \\
300 \text { acre sites } \\
(\%)^{b}\end{array}$ & $\begin{array}{l}\text { Portion of contiguous } \\
\text { US available to } \\
\text { support } 300 \text { acre sites } \\
(\%)\end{array}$ & $\begin{array}{c}\text { Estimated capacity } \\
{[\mathrm{MW}(\mathrm{e})]^{c}}\end{array}$ \\
\hline \multicolumn{4}{|l|}{ Maine } \\
\hline Maryland & 11.12 & 0.04 & 750 \\
\hline \multicolumn{4}{|l|}{ Massachusetts } \\
\hline Michigan & 12.98 & 0.25 & 3,000 \\
\hline Minnesota & 0.72 & 0.02 & \\
\hline Mississippi & 35.47 & 0.57 & 6,750 \\
\hline Missouri & 37.40 & 0.86 & 12,000 \\
\hline Montana & 14.85 & 0.73 & 14,250 \\
\hline Nebraska & 22.90 & 0.58 & 4,500 \\
\hline Nevada & 0.29 & 0.01 & 1,500 \\
\hline \multicolumn{4}{|l|}{ New Hampshire } \\
\hline \multicolumn{4}{|l|}{ New Jersey } \\
\hline New Mexico & 6.80 & 0.28 & 1,500 \\
\hline New York & 8.35 & 0.13 & 5,250 \\
\hline North Carolina & 12.82 & 0.21 & 6,000 \\
\hline North Dakota & 16.25 & 0.38 & 4,500 \\
\hline Ohio & 28.07 & 0.38 & 2,250 \\
\hline Oklahoma & 39.56 & 0.92 & 4,500 \\
\hline Oregon & 1.90 & 0.06 & 5,250 \\
\hline Pennsylvania & 3.65 & 0.05 & 3,750 \\
\hline \multicolumn{4}{|l|}{ Rhode Island } \\
\hline South Carolina & 24.32 & 0.25 & 6,000 \\
\hline South Dakota & 3.63 & 0.09 & 2,250 \\
\hline Tennessee & 25.11 & 0.35 & 7,500 \\
\hline Texas & 20.44 & 1.83 & 8,250 \\
\hline Utah & 2.91 & 0.08 & 3,750 \\
\hline \multicolumn{4}{|l|}{ Vermont } \\
\hline Virginia & 15.08 & 0.20 & 2,250 \\
\hline Washington & 1.12 & 0.03 & 6,000 \\
\hline West Virginia & 0.07 & 0.00 & 750 \\
\hline Wisconsin & 13.47 & 0.25 & 6,000 \\
\hline Wyoming & 13.12 & 0.42 & 6,750 \\
\hline Total & - & 21.49 & 216,000 \\
\hline \multicolumn{4}{|c|}{$\begin{array}{l}{ }^{a} \text { Generation capacity estimate is discussed in "Plant Placement Algorithm for Water-Dependent Power Sources." } \\
{ }^{b} \text { Land for sites is aggregated at } 90 \% \text { as discussed in "Methodology for Aggregating Land for the Typical Plant } \\
\text { Size." }\end{array}$} \\
\hline
\end{tabular}


Table 14 shows the results of the combined advanced coal plant and large reactor plant placement evaluation. This evaluation was biased to place coal plants first in areas that supported only coal plant placement. The remaining water was allocated to large nuclear plants in areas that supported only large nuclear plants or could support either large nuclear plants or advanced coal plants.

Table 14. Combined advanced coal and large nuclear plant evaluation (no siting challenges, selected SSEC values)

\begin{tabular}{|c|c|c|}
\hline State & $\begin{array}{c}\text { Estimated large } \\
\text { reactor capacity } \\
{[\mathrm{MW}(\mathrm{e})]}\end{array}$ & $\begin{array}{c}\text { Estimated advanced } \\
\text { coal plant capacity } \\
{[\mathrm{MW}(\mathrm{e})]}\end{array}$ \\
\hline Alabama & & 9,750 \\
\hline Arizona & 6,400 & 1,500 \\
\hline Arkansas & & 9,750 \\
\hline California & 6,400 & 5,250 \\
\hline Colorado & & 3,750 \\
\hline \multicolumn{3}{|l|}{ Connecticut } \\
\hline \multicolumn{3}{|l|}{ Delaware } \\
\hline \multicolumn{3}{|c|}{ District of Columbia } \\
\hline Florida & & 5,250 \\
\hline Georgia & & 7,500 \\
\hline Idaho & 16,000 & 3,000 \\
\hline Illinois & & 6,000 \\
\hline Indiana & & 3,750 \\
\hline Iowa & & 3,750 \\
\hline \multicolumn{3}{|l|}{ Kansas } \\
\hline Kentucky & & 6,750 \\
\hline Louisiana & & 8,250 \\
\hline Maine & 12,800 & \\
\hline \multicolumn{3}{|l|}{ Maryland } \\
\hline Massachusetts & 1,600 & \\
\hline Michigan & & 2,250 \\
\hline Minnesota & 11,200 & \\
\hline Mississippi & & 6,000 \\
\hline Missouri & & 12,000 \\
\hline Montana & 9,600 & 14,250 \\
\hline Nebraska & 1,600 & 4,500 \\
\hline Nevada & & 1,500 \\
\hline New Hampshire & 3,200 & \\
\hline New Jersey & 1,600 & \\
\hline New Mexico & & 1,500 \\
\hline New York & 4,800 & 4,500 \\
\hline North Carolina & & 5,250 \\
\hline North Dakota & & 3,750 \\
\hline
\end{tabular}


Table 14. (continued)

\begin{tabular}{lrr}
\hline \multicolumn{1}{c}{ State } & $\begin{array}{c}\text { Estimated large } \\
\text { reactor capacity } \\
\text { [MW(e)] }\end{array}$ & $\begin{array}{c}\text { Estimated advanced } \\
\text { coal plant capacity } \\
\text { [MW(e)] }\end{array}$ \\
\hline Ohio & & 2,250 \\
Oklahoma & 8,000 & 4,500 \\
Oregon & & 6,000 \\
Pennsylvania & & 2,250 \\
Rhode Island & & \\
South Carolina & 3,200 & 3,000 \\
South Dakota & 3,200 & 2,250 \\
Tennessee & 1,600 & 5,250 \\
Texas & 3,200 & 9,000 \\
Utah & 3,200 & 3,750 \\
Vermont & 1,600 & \\
Virginia & 17,600 & 2,250 \\
Washington & 3,200 & 5,250 \\
West Virginia & 1,600 & 750 \\
Wisconsin & & 6,000 \\
Wyoming & $\mathbf{1 2 1 , 6 0 0}$ & 6,750 \\
\hline Total & & $\mathbf{1 8 9 , 0 0 0}$ \\
\hline
\end{tabular}




\section{SOLAR POWER RESULTS}

Water-cooled or thermal concentrated solar plants (CSPs) typically employ arrays of ground-based mirrors that focus energy on a heat transfer medium in a pipe. The heat transfer medium may be oil, a salt slurry, or water. The heat transfer medium is pumped to a heat exchanger where steam is generated to run a turbine. The steam is condensed in a condenser, where heat is rejected to an ultimate heat sink. The ultimate heat sink (typically a cooling tower) requires makeup water to replace water lost to evaporation. Some water is also required to clean the mirrors.

Dry-cooled CSPs can employ parabolic mirrors that focus solar energy onto a Stirling engine that requires no cooling water or a more typical thermoelectric plant rejecting waste heat to the air. A limited amount of water is required to keep the mirrors clean. Photovoltaic (PV) cells can also be considered a form of dry solar power (not concentrated). Commercial-scale PV plants were not considered for this study because they are not prominent in available literature. Private and small-scale PV installations are used nation-wide and are not amenable to much discrimination using GIS techniques.

\subsection{Site Selection and Evaluation Criteria}

Siting of CSPs has as much to do with sufficient solar radiation and the technology chosen as with regulatory rigor. However, a selection of nuclear plant siting SSEC was considered to be a reasonable starting point to exclude certain areas. Nuclear plants must consider seismic restrictions and earthquake faults as a public safety issue. As with the advanced coal plants, seismic and earthquake fault restrictions are an investment protection issue. Therefore, it is assumed that there are no seismic or earthquake fault issues for solar plant siting, beyond local building codes. Likewise, proximity to hazardous facilities is not considered applicable to solar plant placement as a public safety precaution.

Commercial-scale solar installations require a fair amount of unshaded space. Since population densities of greater than 500 people per square mile begin to transition into an urban setting, commercial solar plants are excluded in these areas. However, no buffer for public safety is required. Engineering judgment indicated that other nuclear SSEC such as wetlands and open water, protected lands, landslide hazards, and floodplains should continue to be excluded for new commercial solar plant candidate area siting. Government support of renewable energy implies that some protected lands such as Bureau of Land Management (BLM) areas that are not of critical environmental concern and National Forestry land, except inventoried roadless areas, may be open to solar power plant sites. Therefore, the protected land definition applied to solar plant siting is relaxed versus the array of protected lands excluded from nuclear power plant siting.

A DOE report to Congress, Reducing Water Consumption of CSP Electricity Generation, ${ }^{23}$ and a Congressional Research Service document ${ }^{24}$ provide water consumption factors for commercial watercooled and dry-cooled CSPs. These documents indicate that a CSP uses approximately 800 gallons of water per megawatt-hour. This was factored into the minimum stream flow SSEC on a gallon per minute basis.

Generation of power at commercial-scale CSPs requires a reasonable quantity of relatively flat land that receives enough direct normal solar irradiation to make the return on investment worthwhile. A US Department of the Interior, BLM document ${ }^{25}$ recommends that a potential CSP site receive at least

\footnotetext{
${ }^{23}$ U.S. DOE, Concentrating Solar Power Commercial Application Study: Reducing Water Consumption of CSP Electricity Generation, Report to Congress, 2009.

${ }^{24}$ Congressional Research Service, Water Issues of Concentrating Solar Power (CSP) Electricity in the U.S. Southwest, June 200 9.

${ }^{25}$ U.S. Department of the Interior, Bureau of Land Management, Assessing the Potential for Renewable Energy on Public Lands, February 2003.
} 
$5 \mathrm{kWh} / \mathrm{m}^{2} /$ day of direct normal solar irradiation. The BLM document further recommends that the slope of the land be no greater than 5\% and ideally less than 1\%. An NREL study indicated that CSP plant cost could be optimized with plant outputs of between $88 \mathrm{MW}(\mathrm{e})$ and $220 \mathrm{MW}(\mathrm{e}) .{ }^{26}$ Based on this value, a representative plant size of $100 \mathrm{MW}(\mathrm{e})$ situated on 500 acres was selected for analysis.

The SSEC for the nominal $100 \mathrm{MW}$ (e) solar plant positioned on 500 acres of land are as follows:

- Land with a population density greater than 500 people per square mile (with no stand-off buffer) is excluded.

- Wetlands and open water are excluded.

- Protected lands (e.g., national parks, historic areas, wildlife refuges) are excluded.

- Land with a slope of greater than $5 \%\left(\sim 3^{\circ}\right)$ is excluded.

- Land with a moderate or high landslide hazard susceptibility is excluded.

- Land that lies within a 100-year floodplain is excluded.

- Land areas that are more than 20 miles from cooling water makeup sources with at least 15,000 gpm are excluded for thermoelectric plant applications.

- No cooling water restriction is imposed on dry-cooled plant applications.

- Land with direct normal solar irradiation of less than 5 kilowatt-hours $/ \mathrm{m}^{2}$ per day is avoided.

Figures 98-105 show the individual SSEC layers for the nominal commercial-scale CSP based on the values provided in the list above. Areas shown in red are excluded based on the selected input parameter value. Excluded areas in each individual layer can be modified based on different assumptions or requirements for the SSEC.

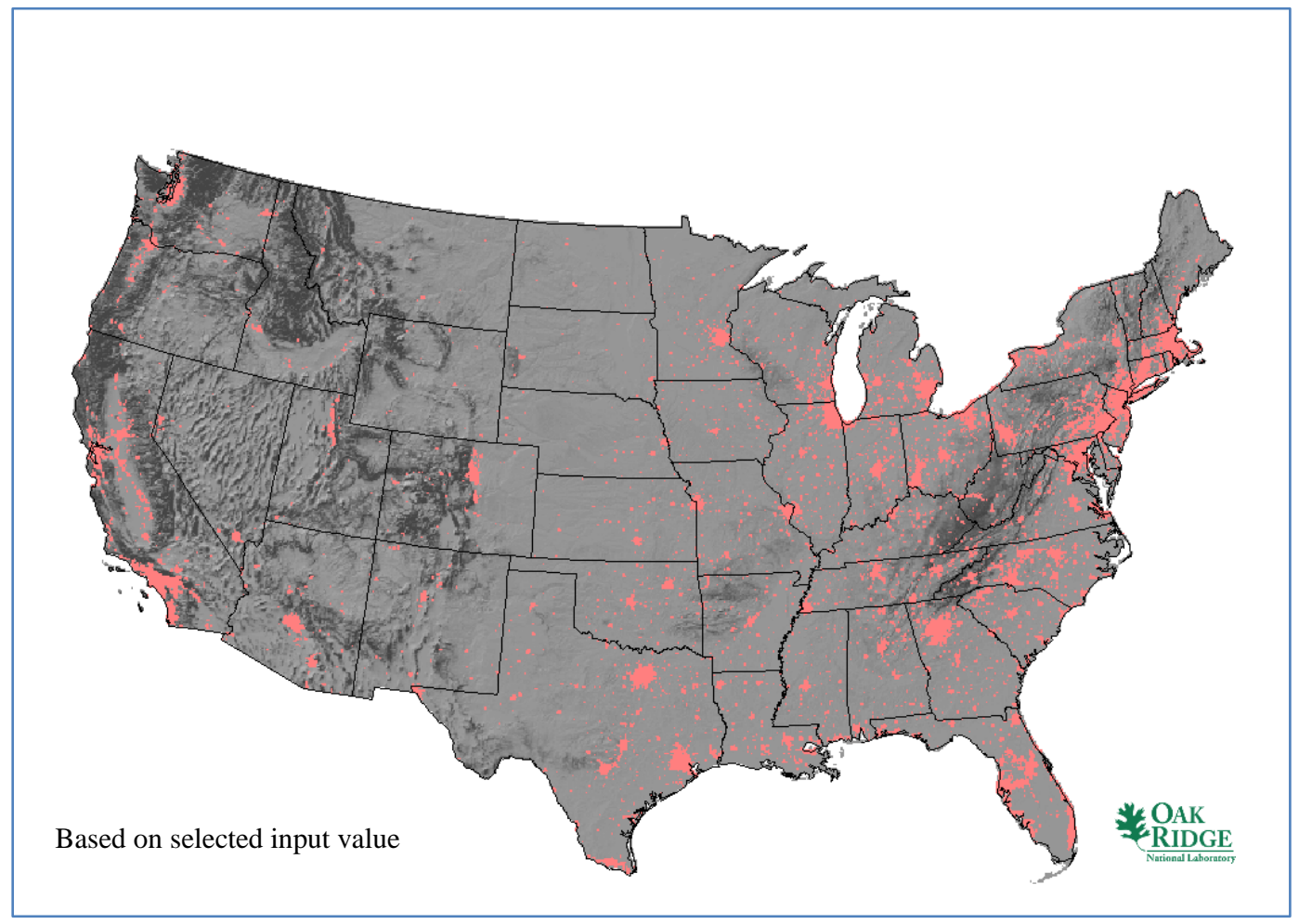

Fig. 98. Solar power high population SSEC layer.

\footnotetext{
${ }^{26}$ National Renewable Energy Laboratory, Nexant Parabolic Trough Solar Power Plant Systems Analysis, Nexant, Inc., July 2006.
} 


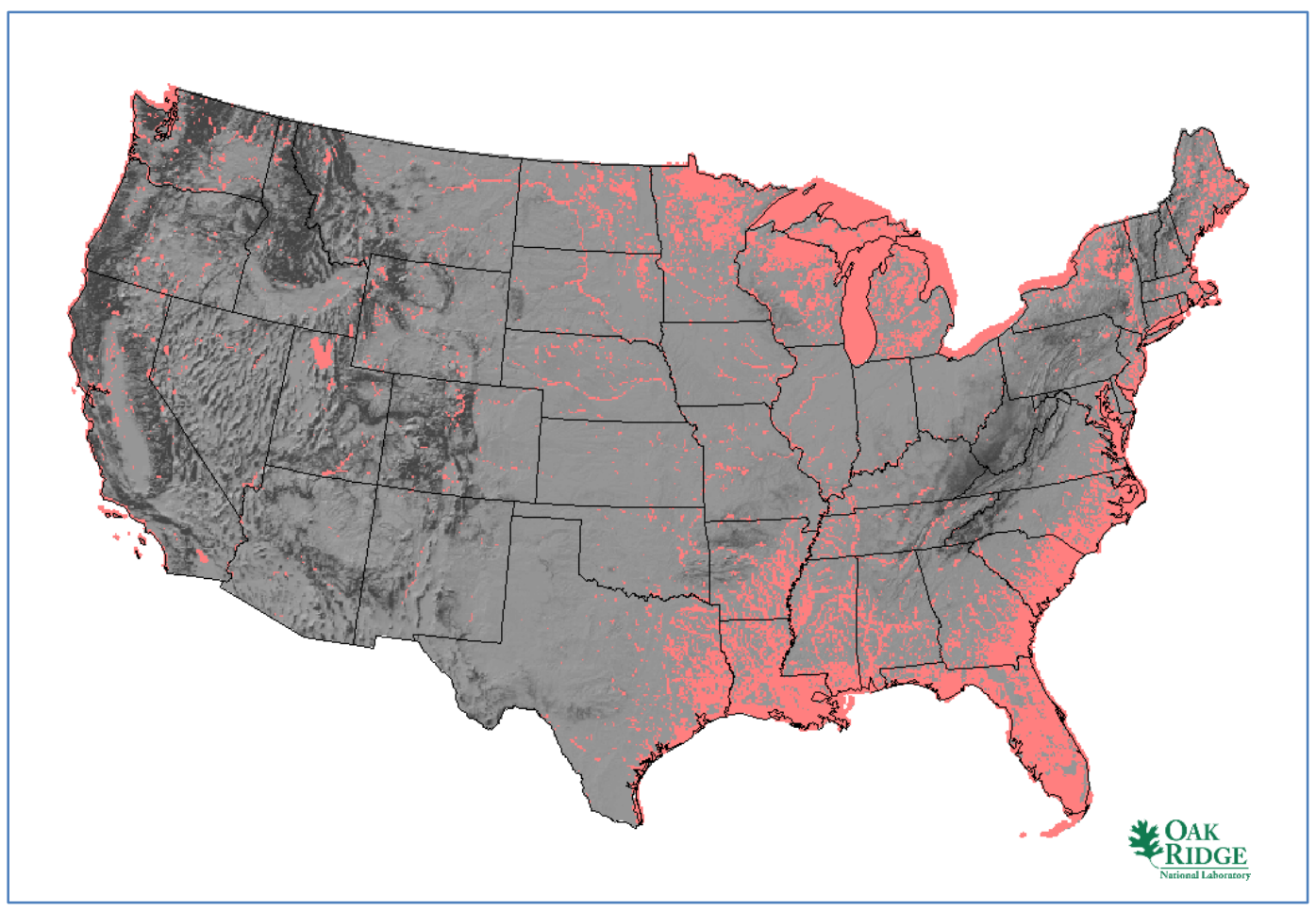

Fig. 99. Solar wetlands and open water SSEC layer.

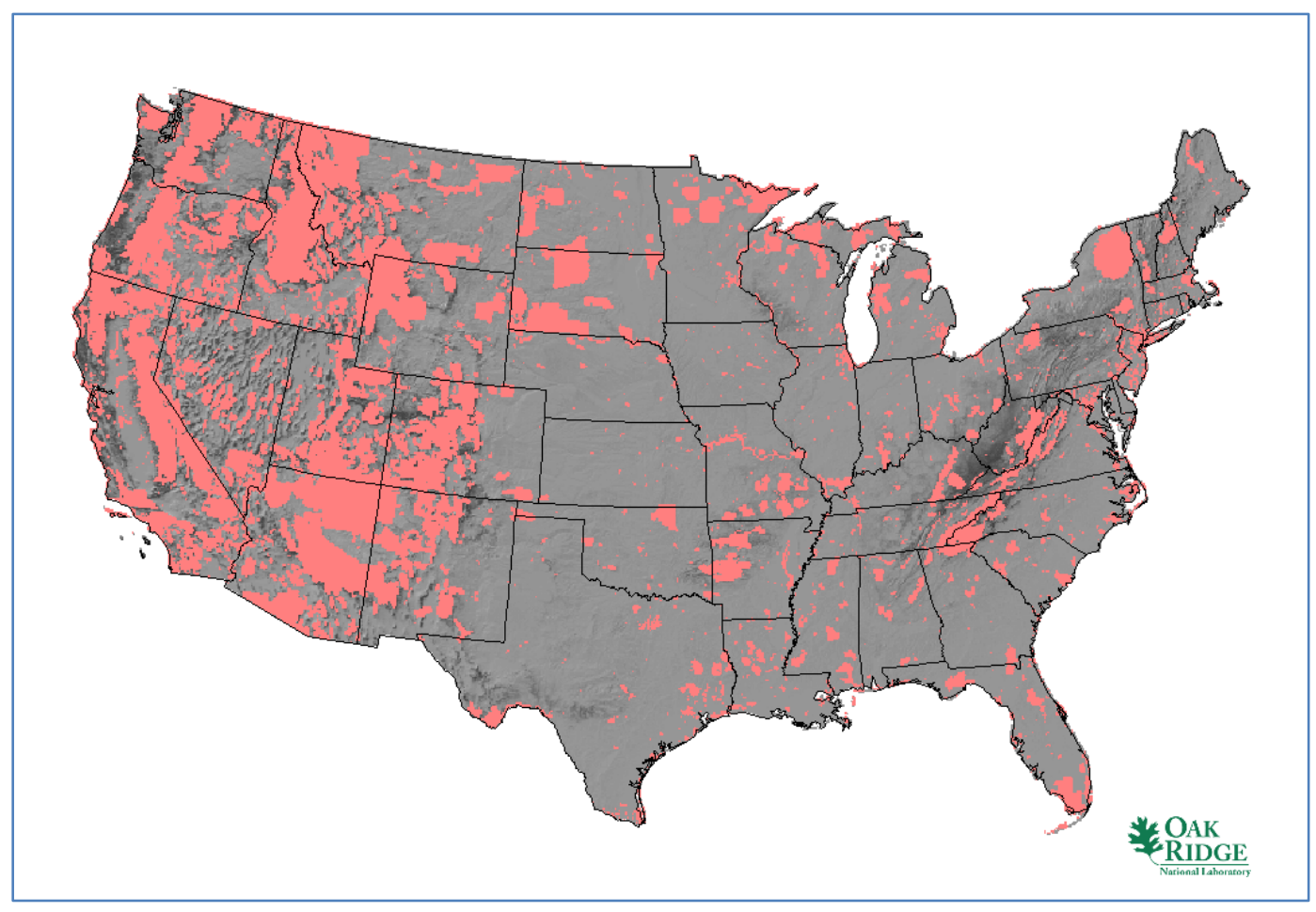

Fig. 100. Solar protected lands SSEC layer. 


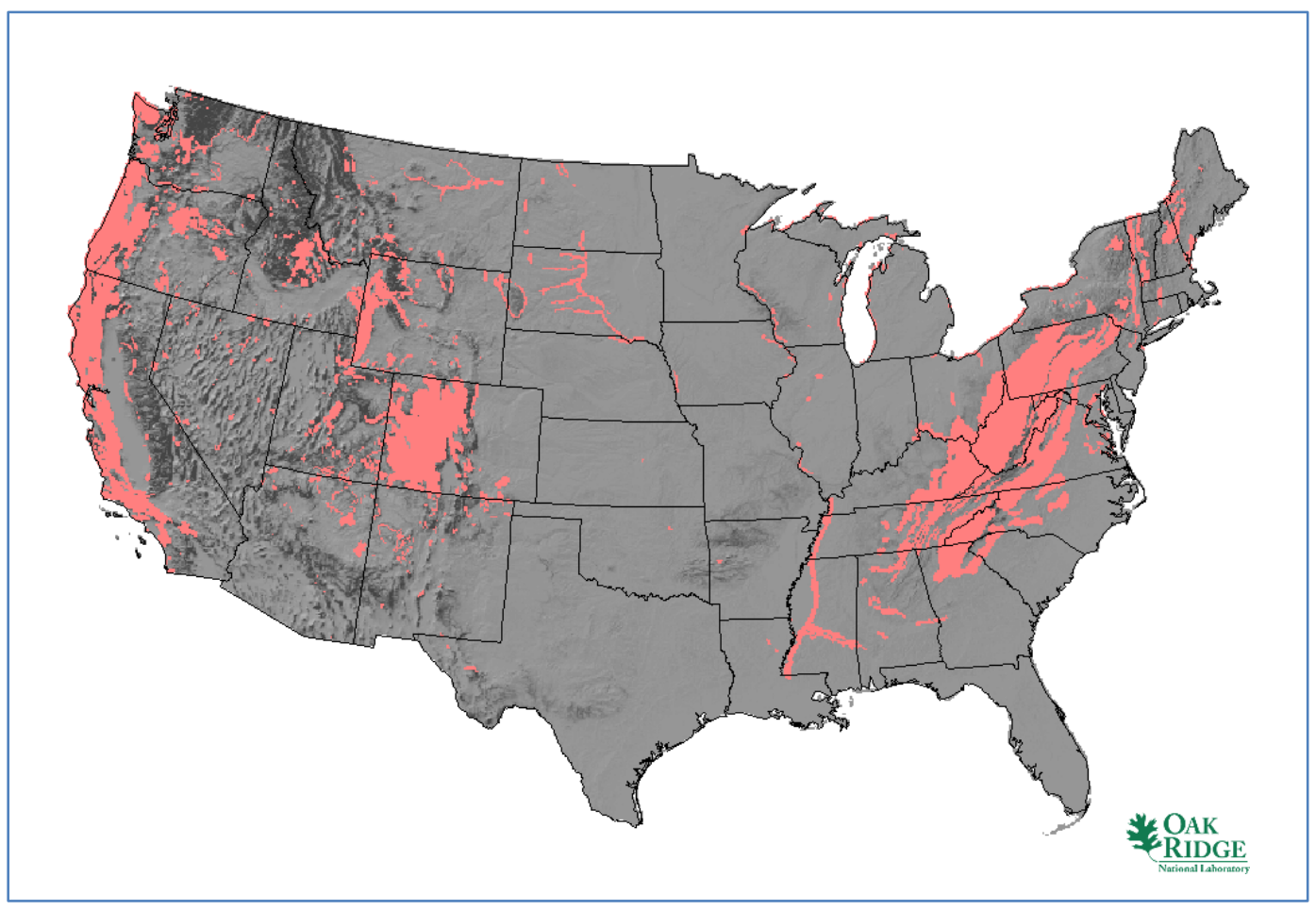

Fig. 101. Solar landslide hazards SSEC layer.

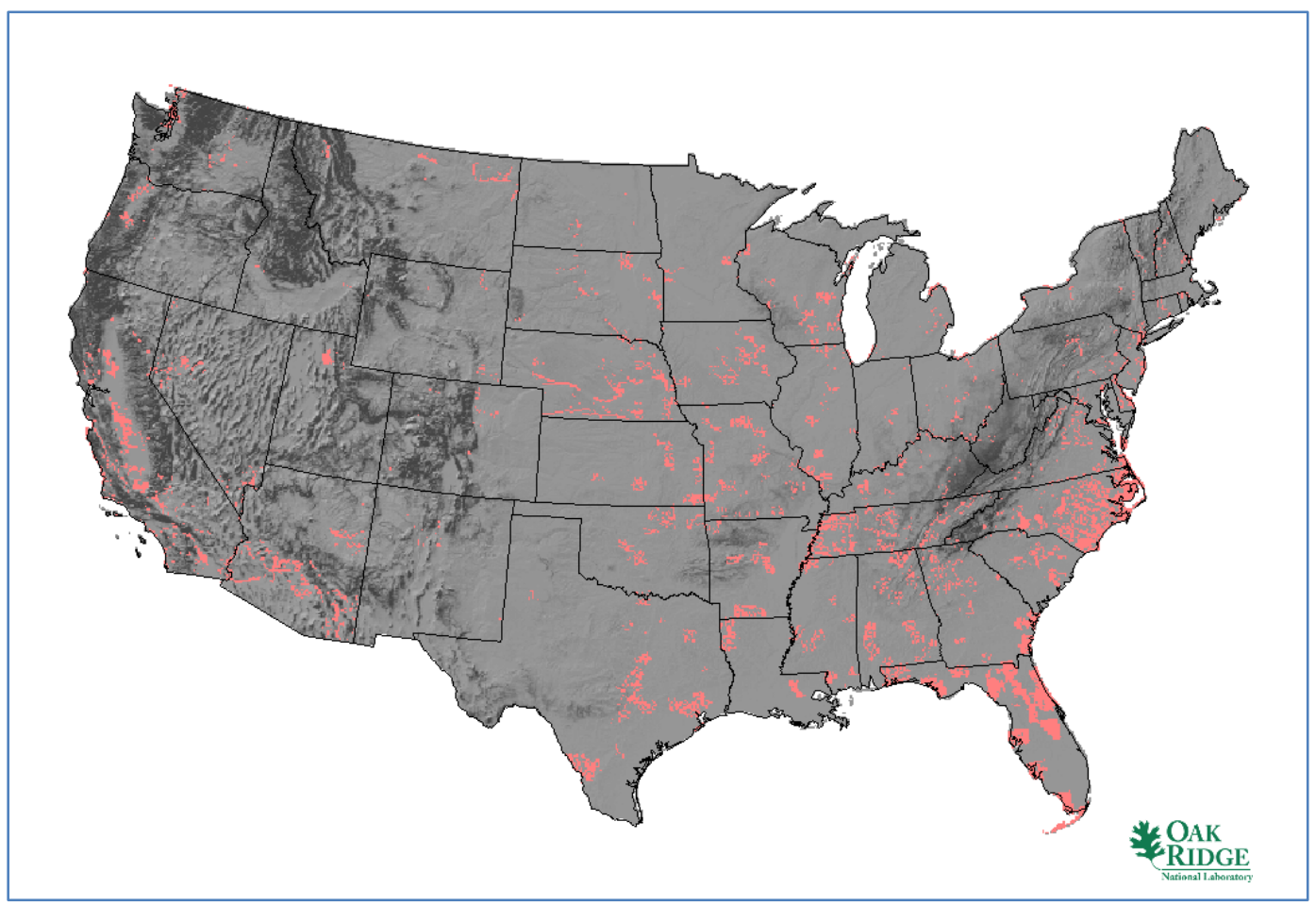

Fig. 102. Solar 100-year floodplain SSEC layer. 


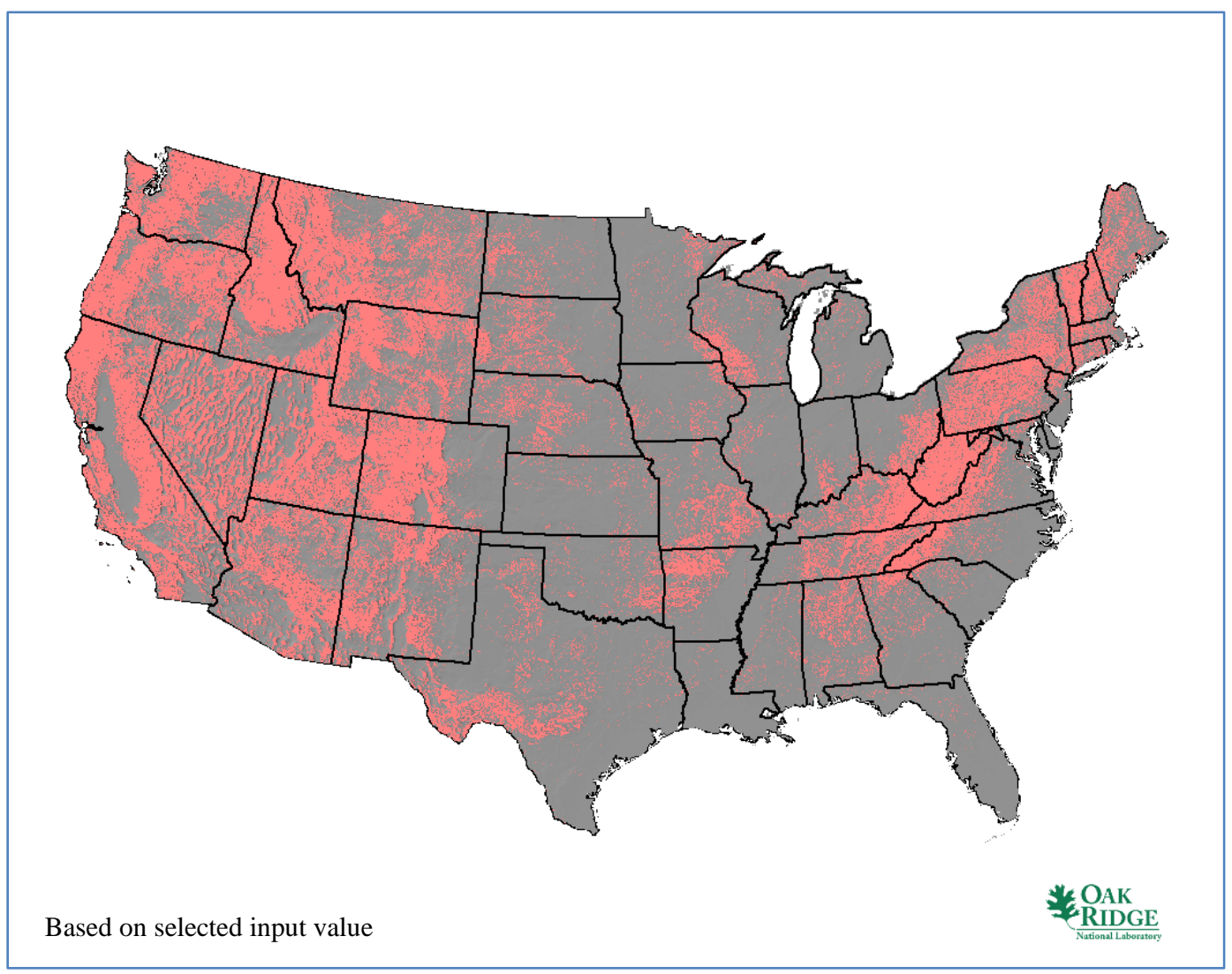

Fig. 103. Solar high slope SSEC layer (greater than 5\%).

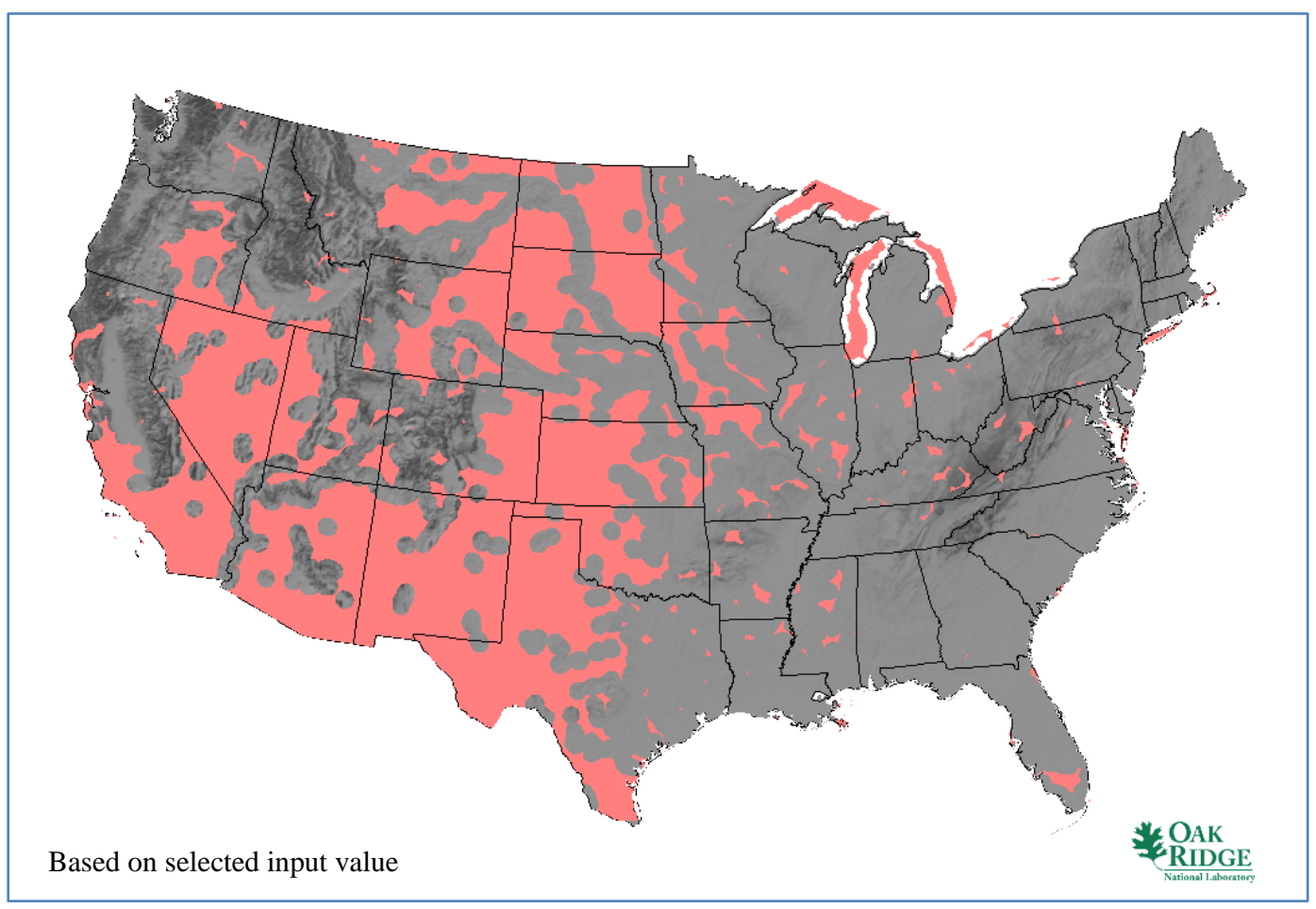

Fig. 104. Solar low stream flow cooling SSEC layer (water-cooled CSP only). 


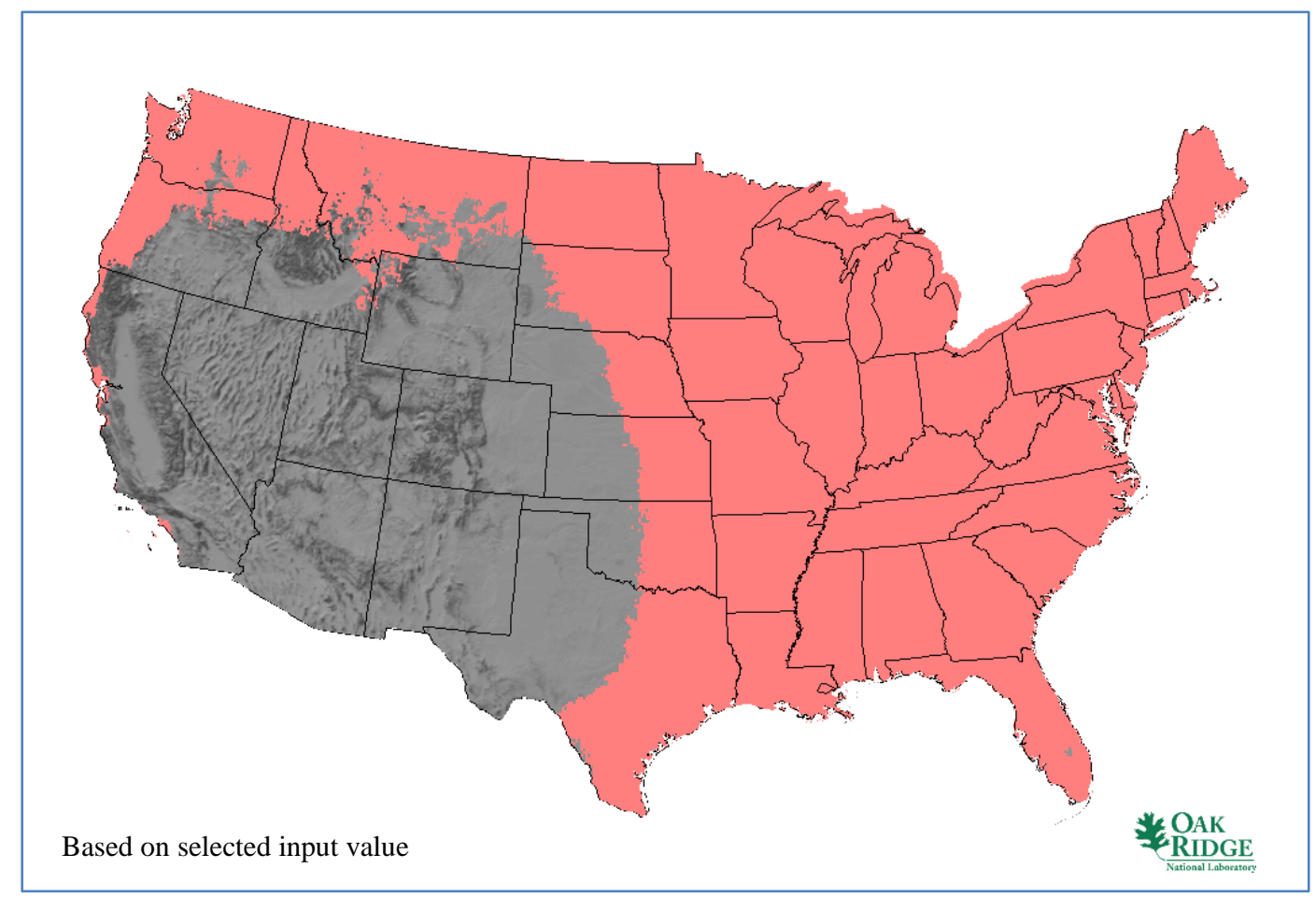

Fig. 105. Solar low direct normal solar irradiation SSEC layer. 
The successive application of each solar SSEC layer to the overall available land in the contiguous United States can be captured as a step-down histogram as shown in Fig. 106. Note that this figure depicts the land step-down for water-cooled CSPs. Dry-cooled CSPs would not include step 7. The SSEC layers are independent. Therefore, the shape of the cumulative histogram is strictly determined by the order in which the SSEC layers (steps) are applied. However, the end result at step 8 is the same no matter what the SSEC layer application order. A review of the individual SSEC layers and the histogram shows that protected lands, slope, cooling water, and direct normal solar irradiation are the most significant contributors to the end result.

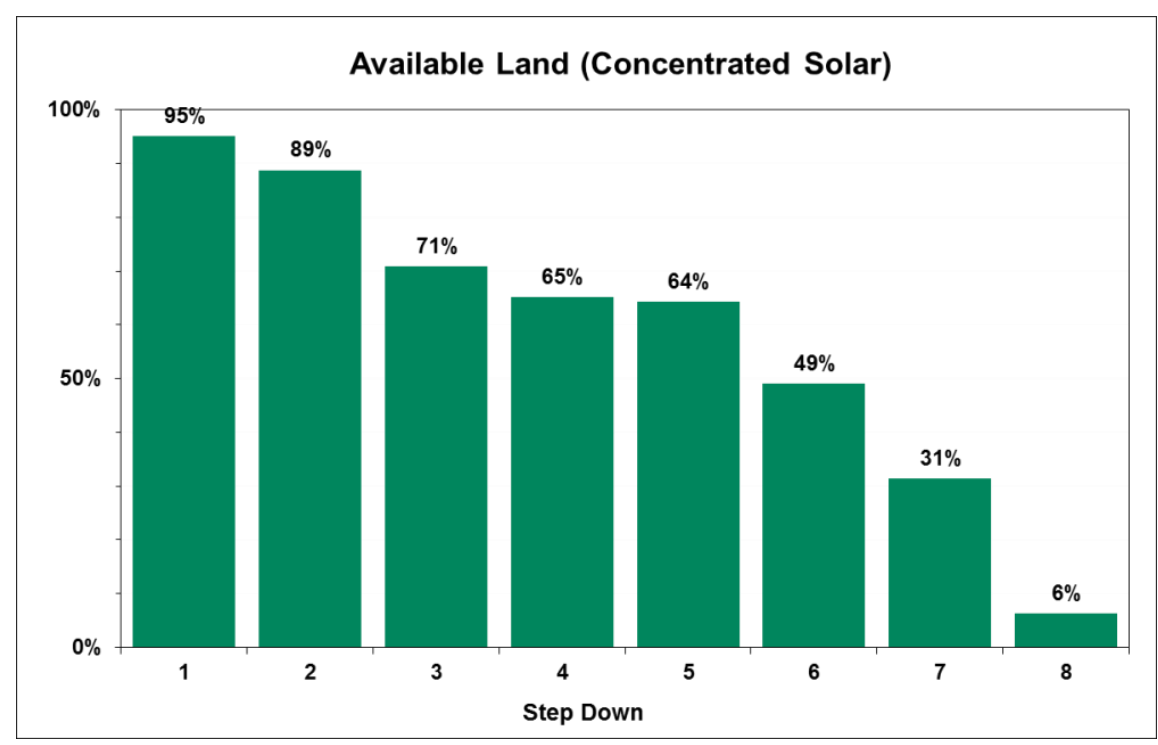

\author{
Order of SSEC Layers \\ 1. Population \\ 2. Wetlands/Open \\ Water \\ 3. Protected Lands \\ 4. Landslide Hazard \\ 5. 100yr Floodplain \\ 6. Slope \\ 7. Stream-flow \\ 8. Solar Radiation
}

Fig. 106. Water-cooled CSP step-down histogram.

Therefore, insights are available on how to best improve the prospects for solar power generation based on an evaluation of the initial GIS screening. Protected lands could possibly be made more open to renewable power generation at government and voter discretion. At the cost of more disruption to the environment, slope can be changed by more exhaustive and costly site preparation. Cooling water requirements and minimum direct normal solar irradiation requirements can possibly be improved by technology advances.

OR-SAGE tracks the parameters for each individual 100 by $100 \mathrm{~m}$ cell. As a result, not only can the cells that are clear of all the solar SSEC layer exclusions be displayed visually, but also cells that are tripped by one, two, or three or more exclusions can be tracked and displayed. This is known as the solar composite map, shown in Fig. 107 for the water-cooled CSP. This is a powerful aspect of OR-SAGE, because it allows areas with a limited number of siting challenges to also be identified. Engineering solutions for areas with limited siting challenges may be available. The areas in green in Fig. 107 have no siting challenges based on the selected values for the solar SSEC layers. However, the much more prominent areas in yellow have just a single siting challenge. An examination of the individual layers indicates that inadequate stream flow is the most common siting challenge in the Southwest. This can lead to consideration of alternative methods of cooling. In the case of solar generation, dry-cooled technology is available. 


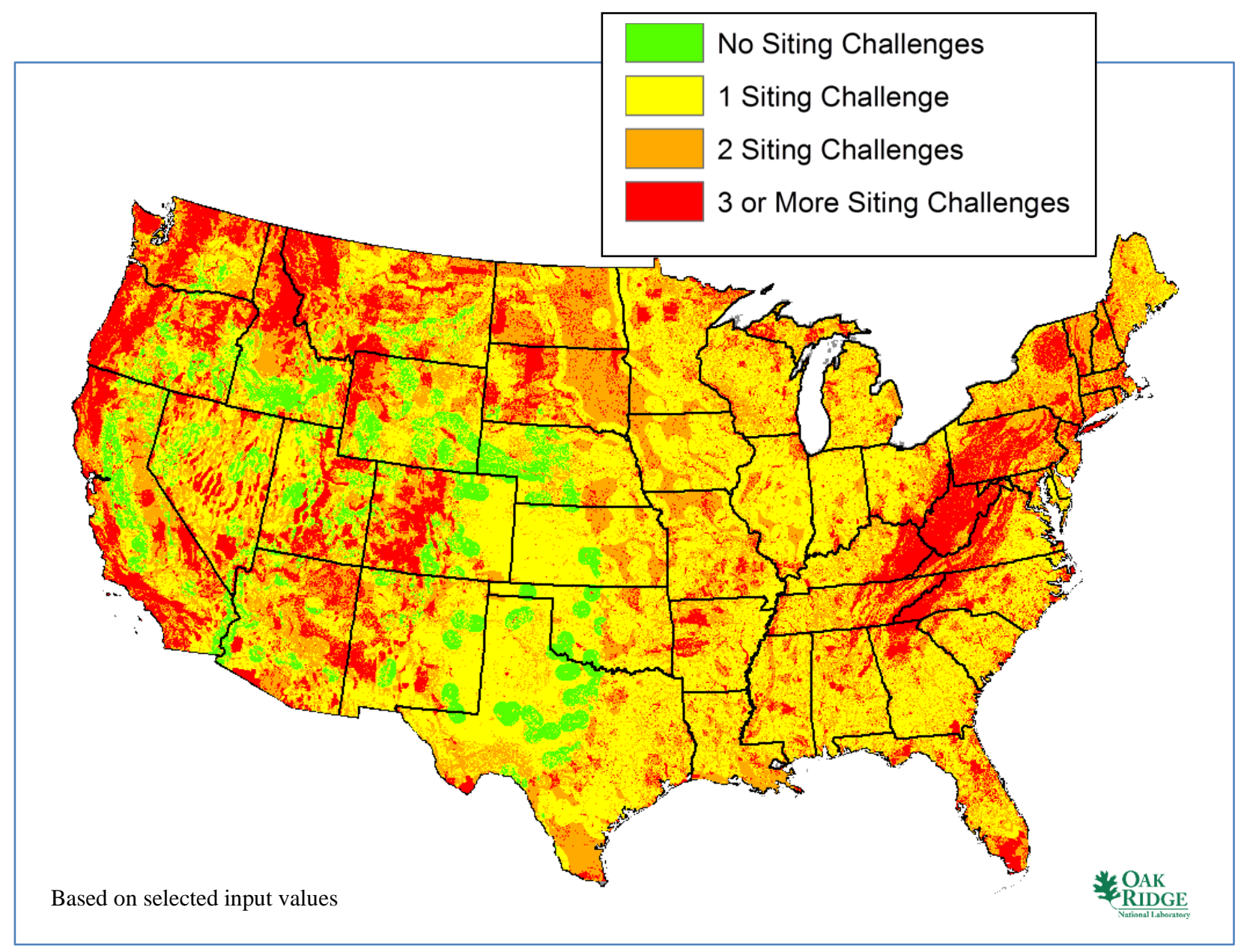

Fig. 107. Water-cooled CSP composite map detailing siting challenges.

\subsection{Key Assumptions}

In addition to the assumptions detailed in the "Critical Assumptions" section (Sect. 2) regarding stream flow, land aggregation, plant placement projections, and 2035 estimates, there are several key assumptions that bound the solar plant results:

1. A general rule of thumb for solar power is that it takes 5 acres of land to support $1 \mathrm{MW}(\mathrm{e})$ output. Therefore, for a nominal $100 \mathrm{MW}$ (e) solar facility, 500 acres will be required. This impacts the aggregation of land to support a given solar facility. In reality, the power ratings for solar plant installations are likely to be quite varied. More land will be available to construct solar facilities smaller than $100 \mathrm{MW}(\mathrm{e})$ because the process of aggregating land will be less limiting. Likewise, less land will be available for solar facilities larger than $100 \mathrm{MW}(\mathrm{e})$ because the process of aggregating land will be more limiting (see "Methodology for Aggregating Land for the Typical Plant Size").

2. Dry-cooled CSPs use roughly 5 to 20 gallons of water per megawatt-hour for mirror washing. ${ }^{23,24}$ It was assumed that this quantity of water needed for mirror washing could be trucked to the site or would not otherwise burden the local water supply infrastructure.

3. Stream flow demand based on CSP water consumption was not altered based on an expected CSP capacity factor in the range of 25 to $40 \%$, depending on technology and storage capability. ${ }^{24}$ It was assumed that stream flow limitations would be imposed on a real-time basis. If stream flow 
limitations are applied on a daily basis (or greater), then available land for water-cooled CSPs would increase. The net effect would be something less than the projected results for dry-cooled CSPs that are independent of stream flow.

4. Stream flow is based on a composite of 7Q10 data from the USGS and existing lake and reservoir data. This is intended to reflect potential drought conditions in site availability.

5. Aggregation of GIS land cells into 500 acre parcels requires only $90 \%$ or greater of the individual cells to pass the SSEC. This allows for small imperfections in a parcel without requiring that the parcel be discarded from consideration.

\subsection{Base Maps}

The "Approach and Methodology" section (Sect. 1.3) describes the process of developing a base map. The base maps depicted in this section reflect one set of values based on the stated assumptions and selected SSEC. The areas depicted in green from the solar composite map shown in Fig. 107 are used to develop the water-cooled solar base map.

The base maps show that power generation from CSPs is available only in the western part of the country. This is a direct function of the direct normal irradiation limitation. As solar technology improves, it is reasonable to expect that the direct normal solar irradiation SSEC limitation at $5 \mathrm{kilowatt-hours} / \mathrm{m}^{2}$ per day may be reduced, which subsequently opens up additional land appropriate for CSP application.

\subsubsection{Thermal Solar Plants}

The water-cooled CSP base map is shown in Fig. 108. This is the most prominent form of commercialscale solar power generation discussed in current literature. Initially, the current SSEC values limit watercooled CSP to $6.2 \%$ of the contiguous United States or approximately 106 million acres.

It is interesting to note that a swath of land in the central United States (West Texas and arcing to the northwest) has especially strong water-cooled CSP siting potential. The central valley of California and the California-Arizona border also show good water-cooled CSP siting potential. The spotty nature of available land is primarily a result of available water and slope. FigureFig. 109 shows the limited availability of cooling water that meets the minimum requirements for the representative water-cooled CSP in the Southwest, where water-cooled CSP is most available based on the availability of direct normal irradiation. Technology improvements could allow lower values of direct normal solar irradiation to be profitable, opening up some areas in the deep Southeast.

As shown in Fig. 110, aggregating the available land from the water-cooled CSP base map for the nominal 500-acre $100 \mathrm{MW}$ (e) water-cooled solar plant reduces the available land to $3.5 \%$ of the contiguous United States based on the selected SSEC. This represents approximately 60 million acres of land with no siting challenges, based on the selected input factors (SSEC), available for siting 500-acre water-cooled CSPs.

Though there is a 46 million acre decrease in available land from the base case map shown in Fig. 108 to the aggregated land case shown in Fig. 110, it is important to note that solar plant installations in particular are highly variable in size. Therefore, much of this land may be recoverable through plant installations that are smaller than the nominal plant size. However, total water-cooled CSP capacity is ultimately limited by the amount of available cooling water. 


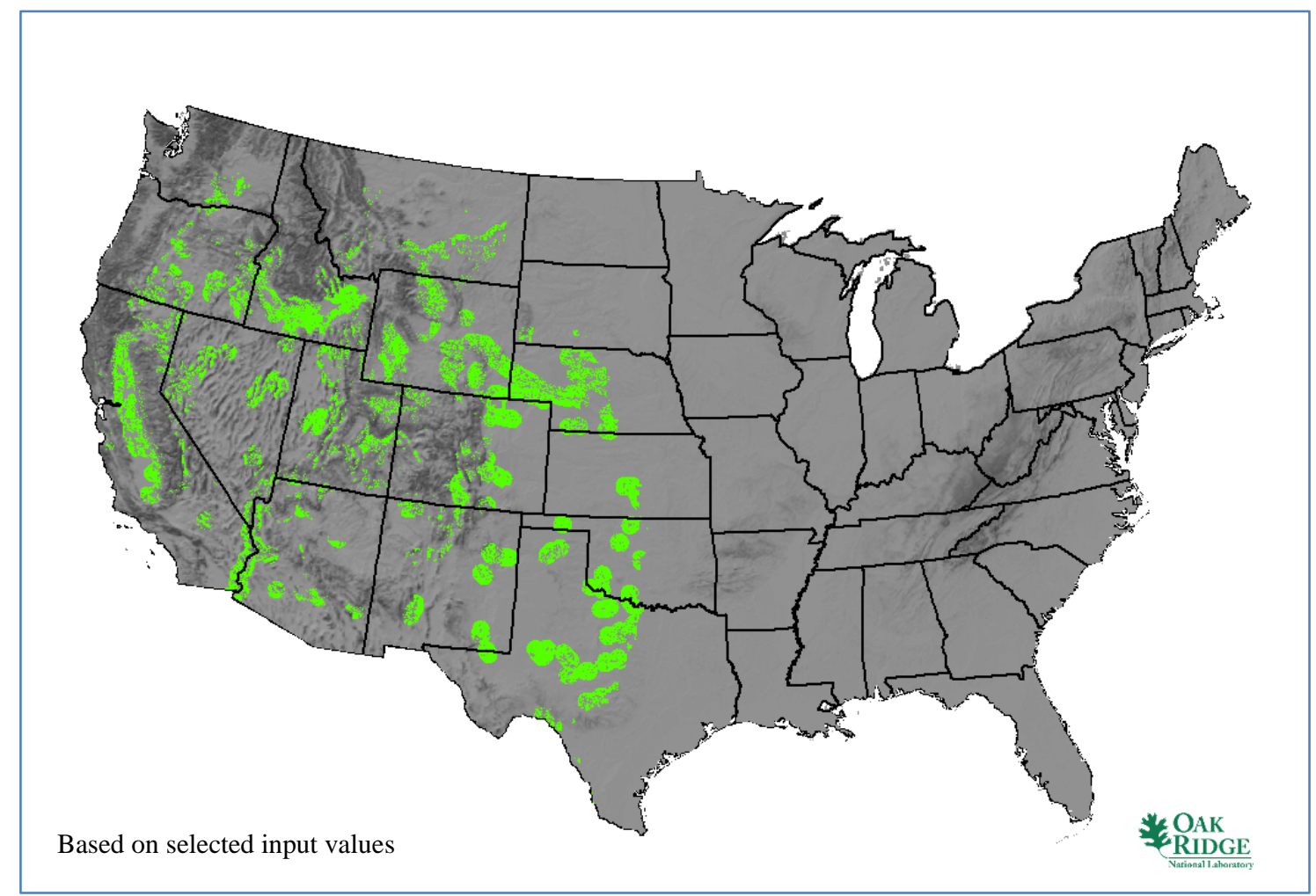

Fig. 108. Water-cooled CSP base map.

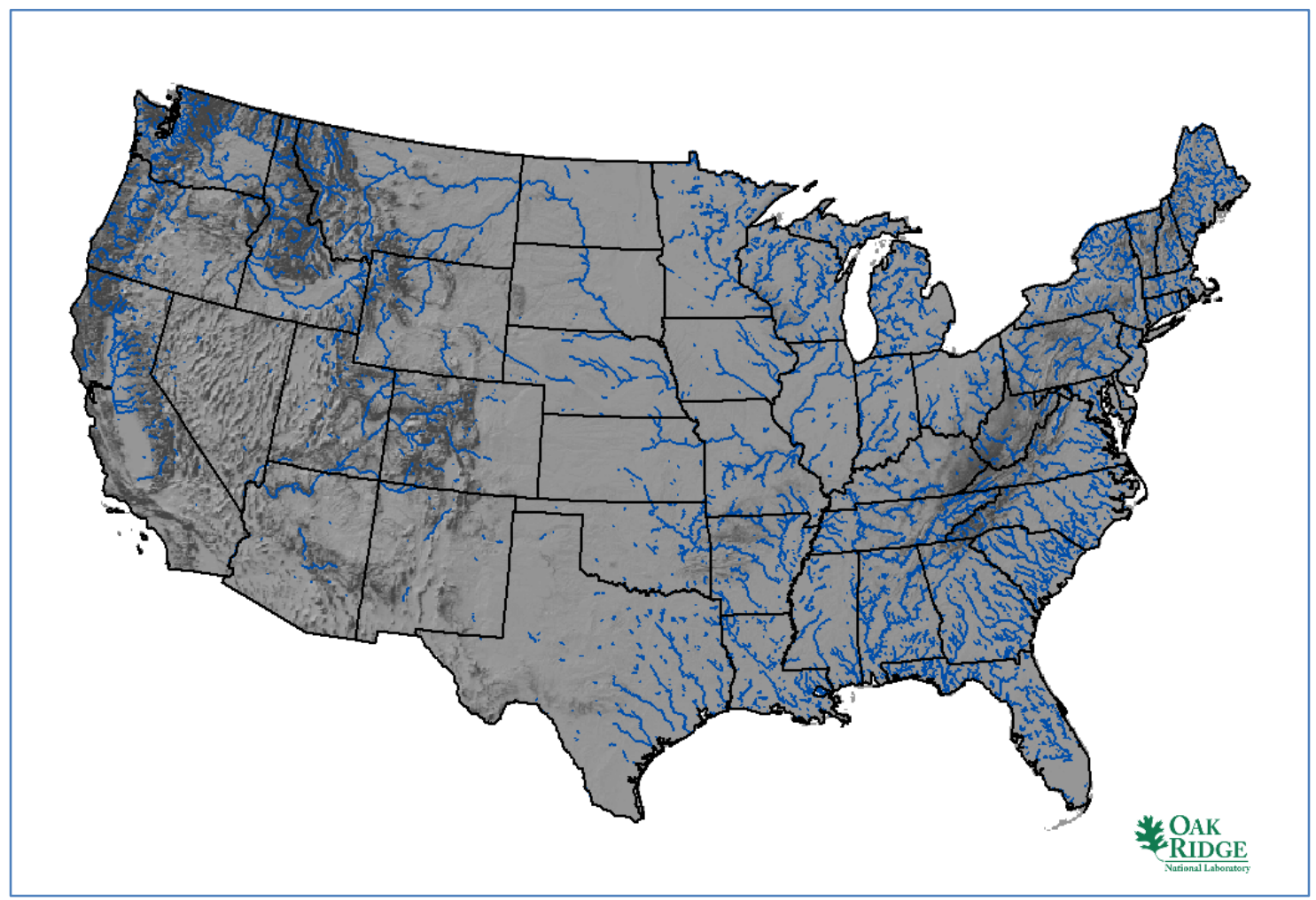

Fig. 109. Composite stream flow of at least 15,000 GPM. 


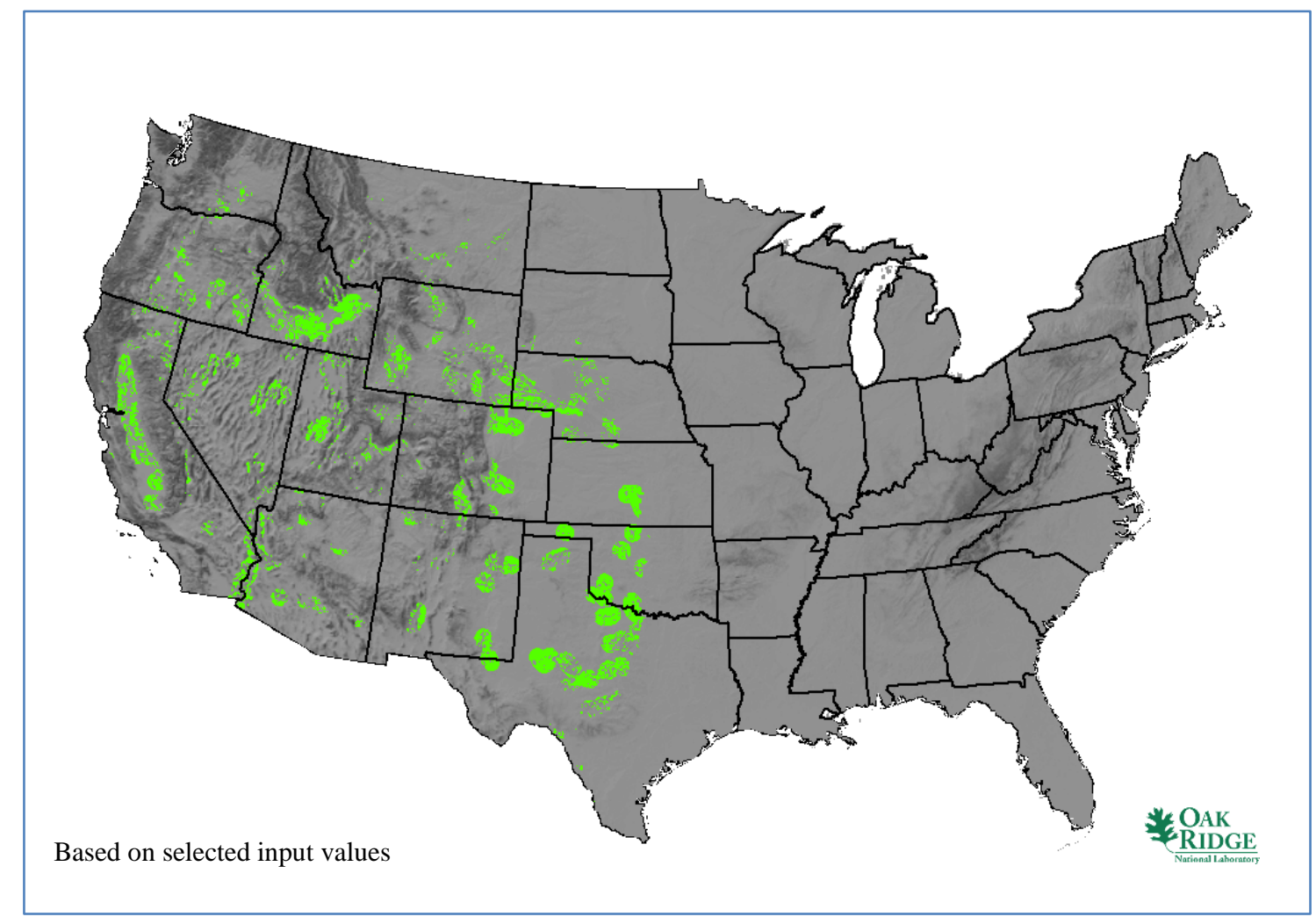

Fig. 110. Water-cooled CSP aggregated at $90 \%$ for 500 acre facility.

\subsubsection{Dry Solar Plants (Requiring Only Cleaning Water)}

Technology improvements could allow dry-cooled CSP plants to be more practical, eliminating the SSEC limitation on cooling water. Such a development would open up significantly more area in the Southwest for commercial-scale solar power generation. The dry-cooled CSP base map is shown in Fig. 111. Drycooled CSP technology increases the available contiguous US area with no siting challenges from $6.2 \%$ (106 million acres) in the water-cooled case to $18.2 \%$ or approximately 312 million acres. The central United States (West Texas and northward) would remain especially strong for dry-cooled CSP siting potential.

Since cooling water would no longer be a factor, the results in the dry-cooled CSP case would be influenced most by direct normal irradiation and slope. Aggregating the land for a 500-acre dry-cooled facility at a $90 \%$ aggregation rate reduces the available land to $12.0 \%$ of the contiguous United States or 205 million acres, as shown in Fig. 112. Still, this is a three-fold increase over available aggregated CSP land for the wet-cooled CSP case. However, dry-cooled CSP technology is not currently applied as frequently as the wet-cooled CSP case. 


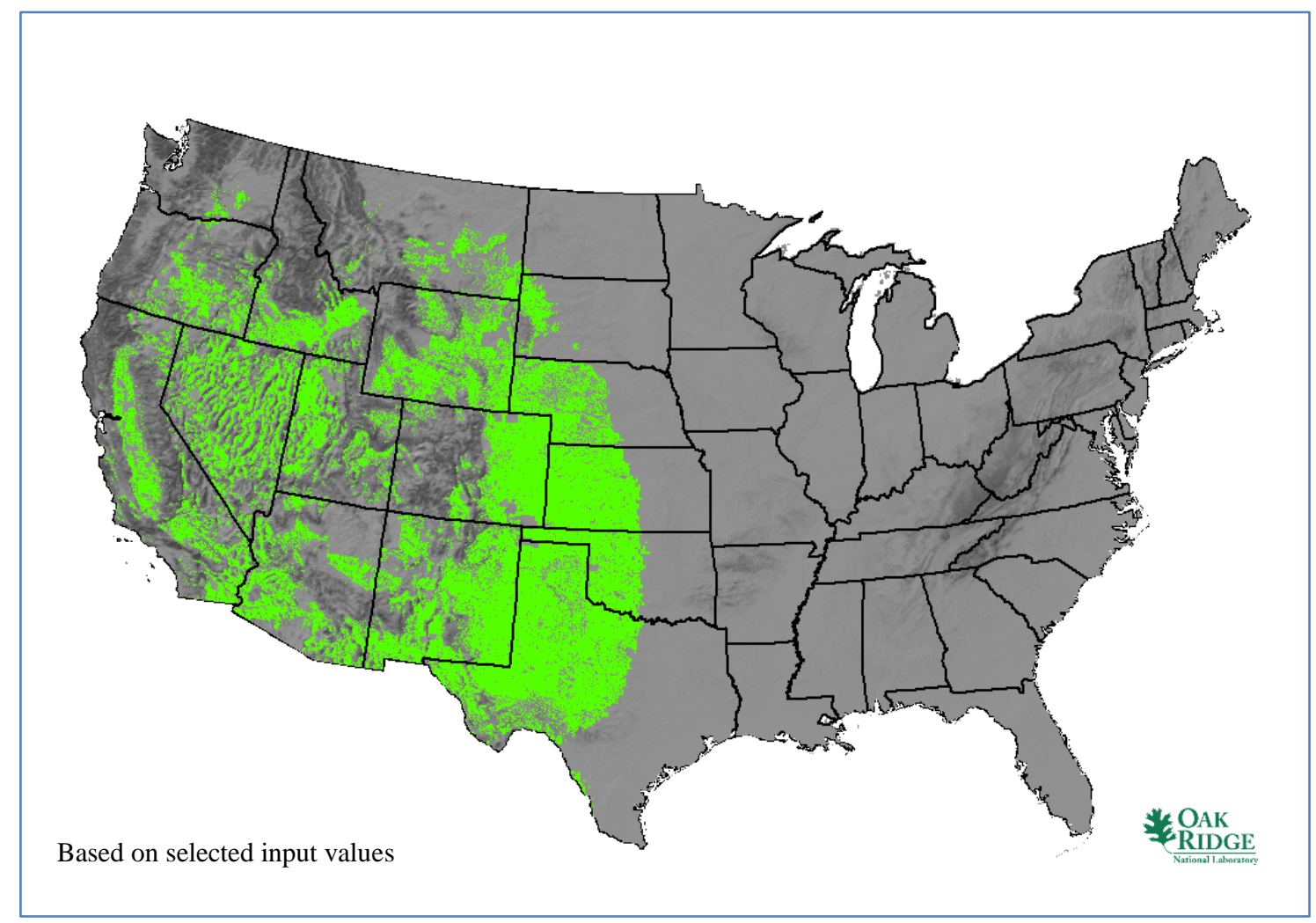

Fig. 111. Dry-cooled CSP base map.

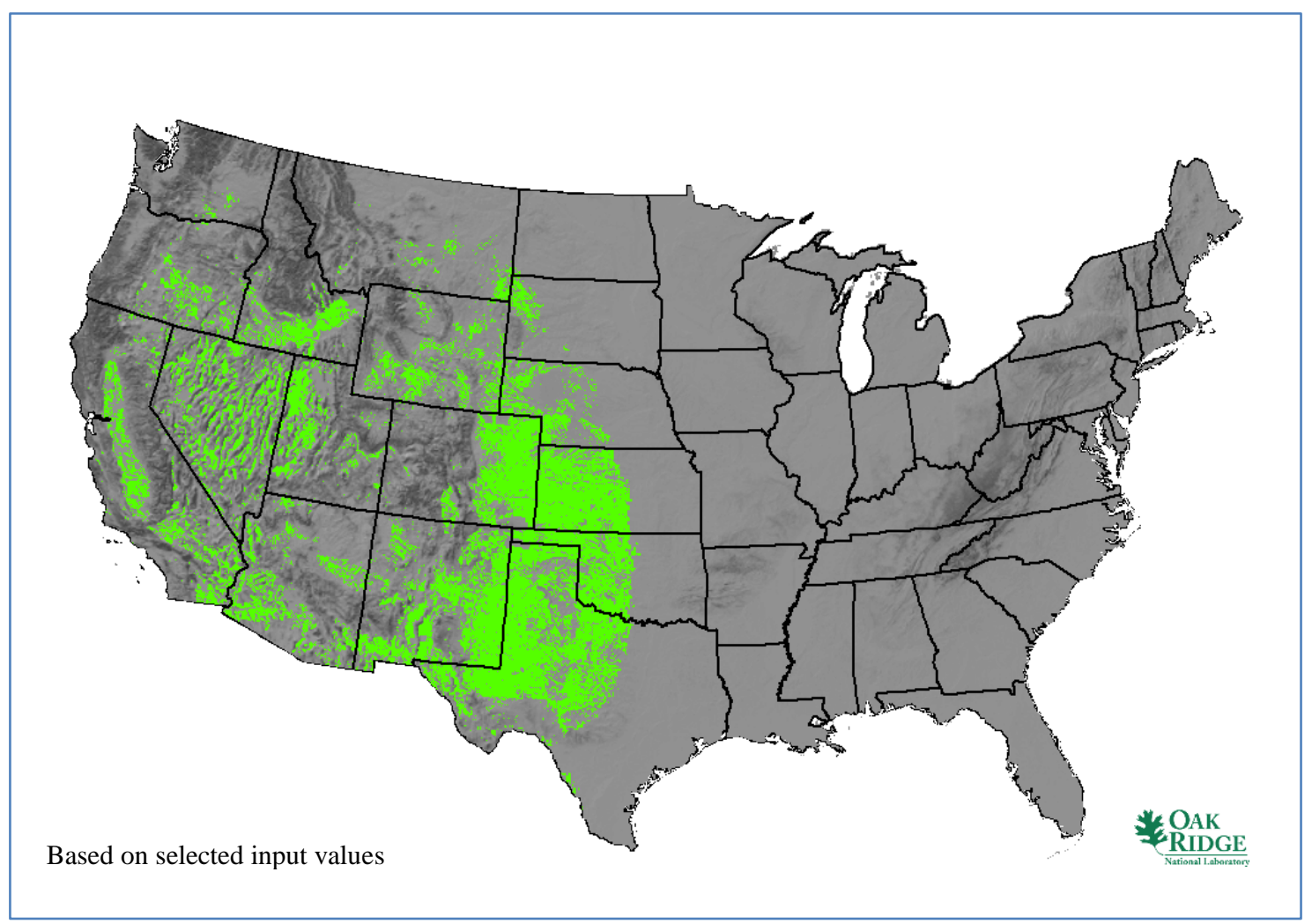

Fig. 112. Dry-cooled CSP aggregated at $90 \%$ for 500 acre facility. 


\subsection{Plant Placement Results}

A calculation of wet-cooled CSP capacity was performed using the methodology described in the section "Plant Placement Algorithm for Water-Dependent Power Sources." The predictions are based on a nominal $100 \mathrm{MW}$ (e) solar plant installation positioned on 500 acres of land. This estimate is independent of other thermal plant installation predictions and is not tied directly to current estimates of power demand.

Figure 113 displays the result of the plant placement algorithm overlaid by the 18 water regions. The plants are projected based on individual water basins in locations where stream flow is at or above $15,000 \mathrm{gpm}$. The green dots are projected sites for the purpose of calculating water-cooled CSP capacity. No dot represents an actual plant placement recommendation. The same results are depicted in Fig. 114 with a state map overlay. State-by-state results can be affected by the unbiased nature of the initial plant placement in any given water basin and the arbitrary limit of 20 miles between unit projections as discussed in the section "Plant Placement Algorithm for Water-Dependent Power Sources."

The plant placement algorithm is designed to project plant placements while tracking available water flow in the basin. Therefore, the placement estimate is not amenable to dry-cooled solar facilities. However, there is over three times the area available for dry-cooled CSP installation. So it is reasonable to assume that there would be at least three times the capacity for dry-cooled CSP as for water-cooled CSP capacity.

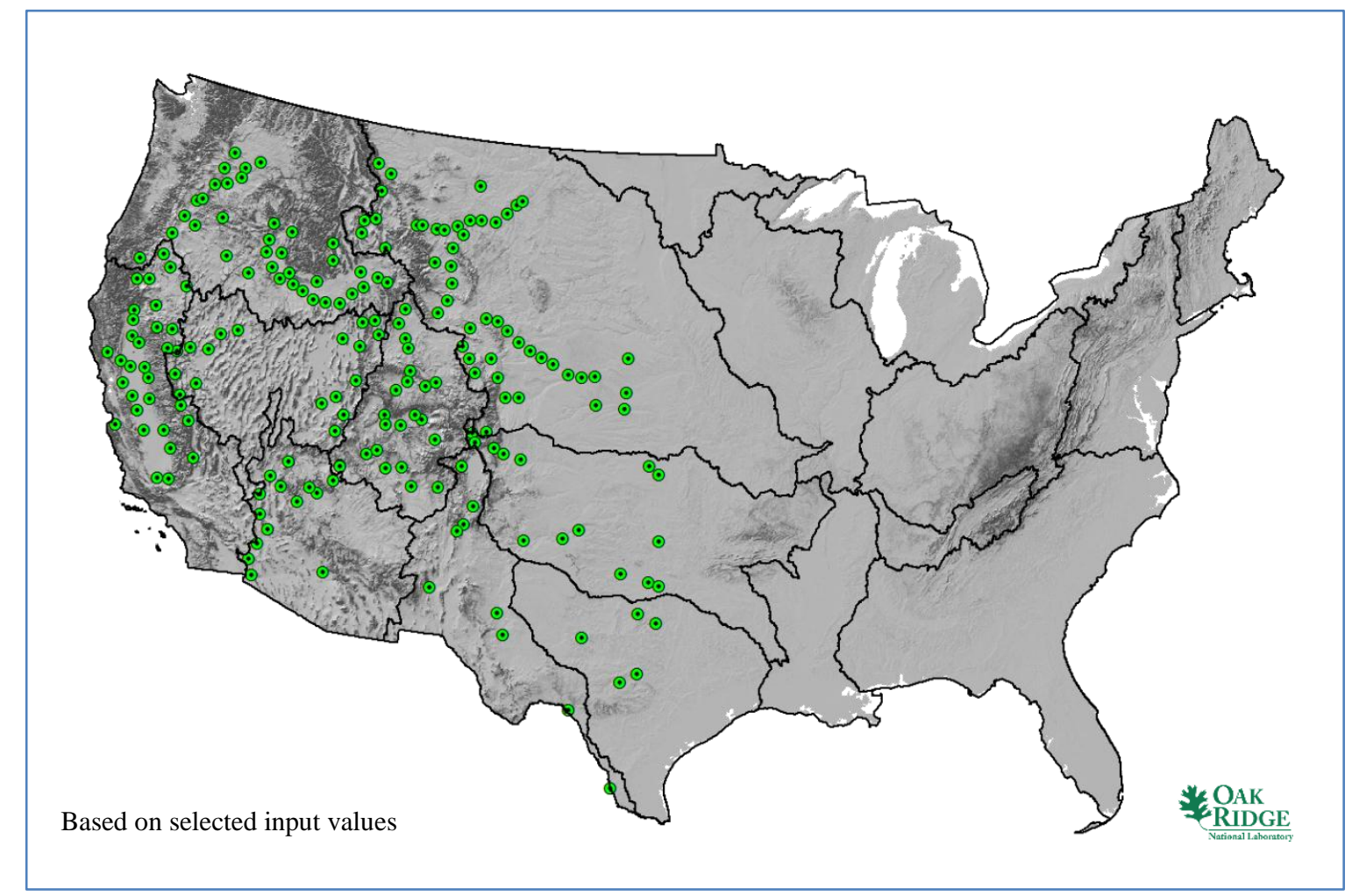

Fig. 113. Water-cooled CSP capacity calculation by water region. 


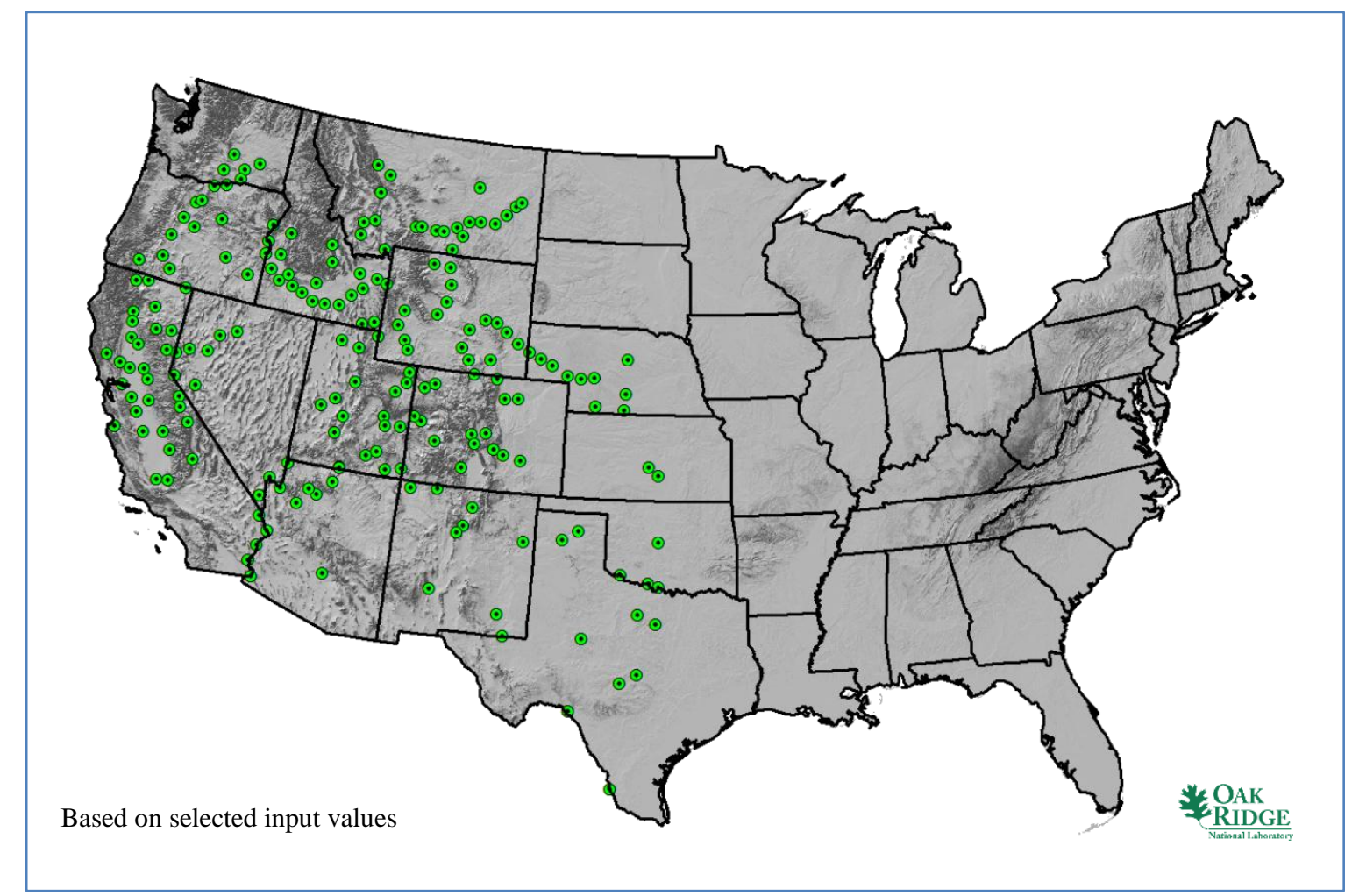

Fig. 114. Water-cooled CSP capacity calculation by state.

The placement algorithm projects the placement of 200 water-cooled $100 \mathrm{MW}(\mathrm{e})$ solar facilities for a total capacity of $20.0 \mathrm{GW}(\mathrm{e})$. This is the equivalent of more than twelve large nuclear power plants. Though a swath of land in the central United States (West Texas and northward) has especially strong water-cooled CSP siting potential, the available water flow in that area is quickly assigned to a limited number of solar facilities. The states with the strongest projection for plant installations and capacity (more than 15 sites each) are California, Idaho, Montana, Utah, Colorado, and Wyoming. States with good capacity (6 to 15 sites each) are Oregon, Nevada, Arizona, New Mexico, Nebraska, and Texas. Other states projected with limited water-cooled CSP capacity include Washington, Kansas, and Oklahoma. The nominal solar plant size assumed in this calculation is a major factor in the results. Solar plant installations vary widely in capacity. Also, rivers that makeup state borders can affect the results since the siting algorithm arbitrarily places a plant on either side of a river if both banks support a plant placement.

For a capacity estimate of dry-cooled CSP technology, an evaluation of available land is necessary. Aggregated land results for the dry-cooled CSP case represent $12.0 \%$ of the contiguous United States compared with $3.5 \%$ for the water-cooled CSP case. This represents an increase in available land for drycooled CSP installations by a factor of 3.4. Applying this factor to the water-cooled CSP capacity calculation provides one approach to predicting dry-cooled CSP capacity. This logic produces a drycooled CSP capacity estimate of $68.0 \mathrm{GW}(\mathrm{e})$. Because the OR-SAGE capacity estimate algorithm requires stream flow cooling to be reestablished above the minimum 15,000 gpm SSEC requirement after a plant placement, it is likely that many suitable water-cooled CSP sites are discarded. Therefore, it is also likely that a simple land comparison factor (3.4) probably undervalues the dry-cooled CSP capacity estimate. The ultimate upper limit on dry-cooled CSP capacity is available land. Therefore, another approach would be to assume that some percentage of the aggregated dry-cooled CSP land with no siting challenges (205 million acres) could be used for dry-cooled CSP installations. If it were assumed that $1 \%$ of the available aggregated land could be dedicated to dry-cooled CSP capacity, then the dry-cooled CSP 
capacity estimate would be $410 \mathrm{GW}(\mathrm{e})$ based on the selected solar SSEC layers and values. Therefore, a reasonable range for dry-cooled CSP capacity is probably 70 to $400 \mathrm{GW}(\mathrm{e})$. On the upper end [400 $\mathrm{GW}(\mathrm{e})]$, that would be the equivalent of 250 large nuclear power plants.

\subsection{Sensitivity Studies}

\subsubsection{Slope}

Relative to slope, land can be evaluated in a variety of ways. For example, land sloped by more than 5\% may be amenable to CSP sites if the slope faces south or southwest. However, this type of slope probably favors PV plants more than CSP. Lacking this kind of specific GIS data, it is assumed that flatter land more readily favors CSP siting while requiring less costly site preparation. A sensitivity study on slope revealed the decrease in available land for both the water-cooled and dry-cooled CSP cases as slope was first reduced to 3\% and then to 1\%. Figure 115 depicts the 3\% slope SSEC layer that was substituted for the initial 5\% slope case depicted in Fig. 103.

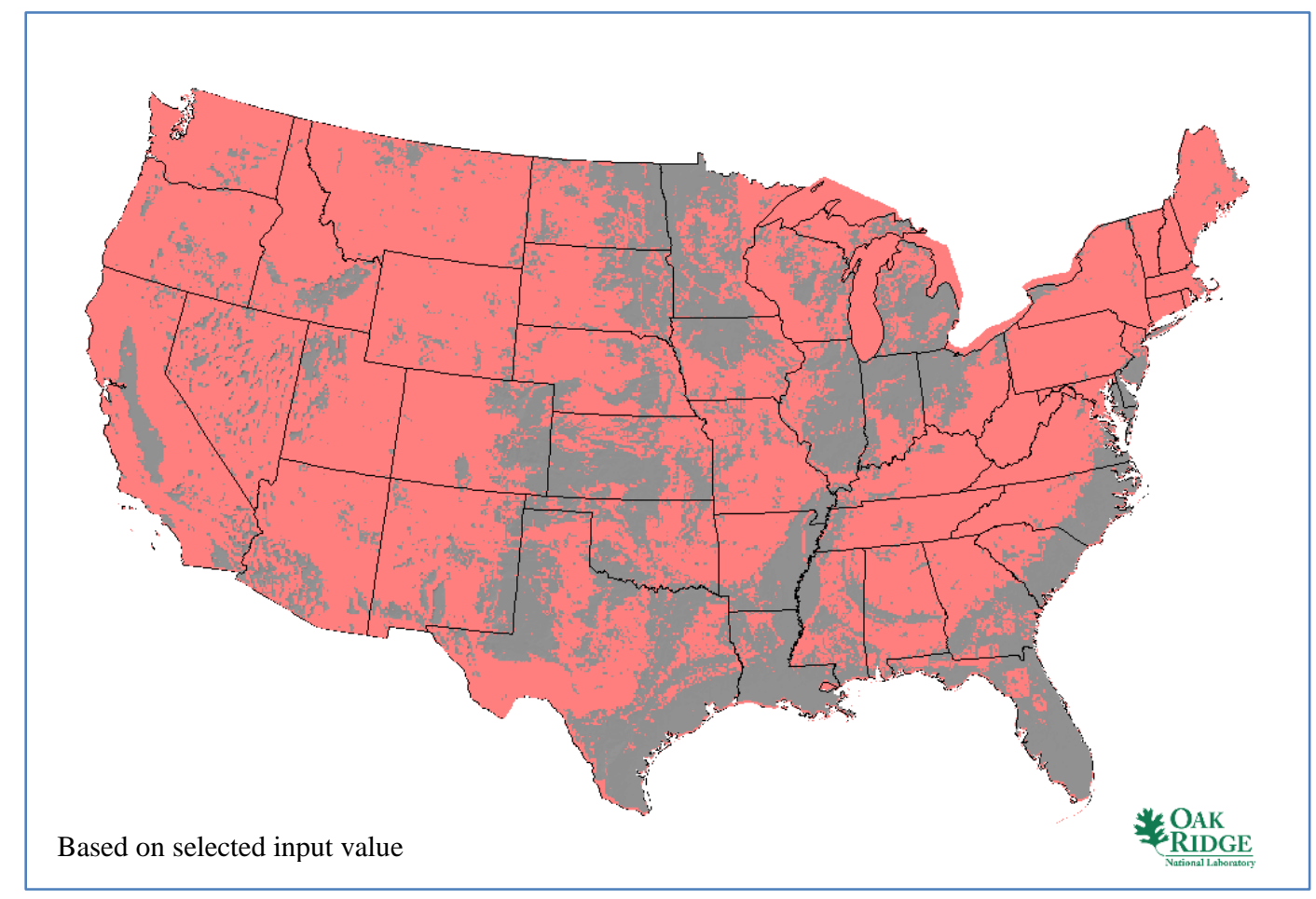

Fig. 115. Solar high slope SSEC layer (greater than 3\%).

Likewise, Fig. 116 depicts the 1\% slope SSEC layer that was substituted for the initial 5\% slope case (Fig. 103). 


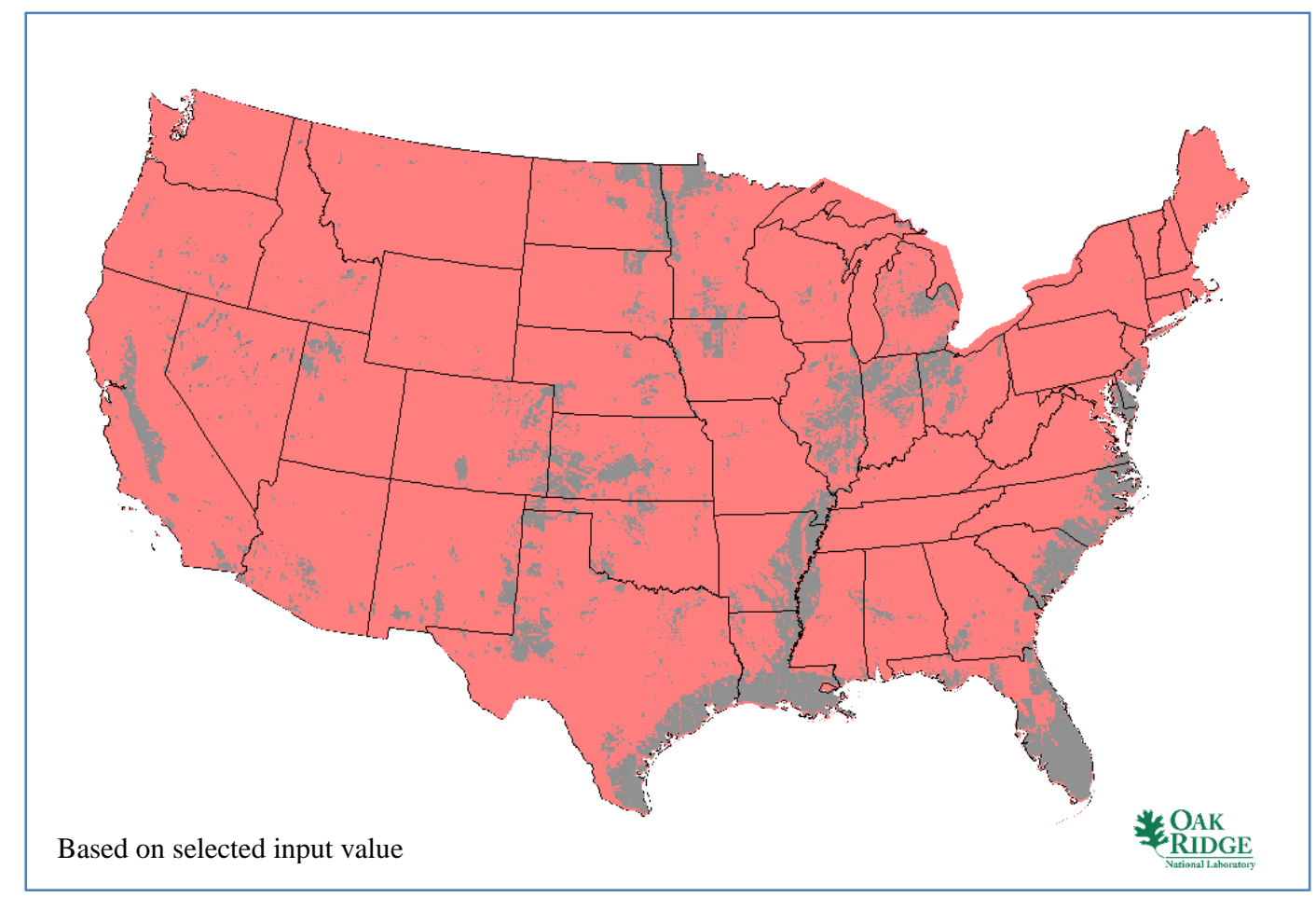

Fig. 116. Solar high slope SSEC layer (greater than 1\%).

As shown in Table 15, the sensitivity study results are quite sensitive to slope.

Table 15. Available percentage of contiguous US in slope sensitivity study

\begin{tabular}{lcc}
\hline \multicolumn{1}{c}{ Aggregated land (90\%) when: } & Water-cooled CSP & Dry-cooled CSP \\
\hline Slope limited to 5\% & $3.5 \%$ & $12.0 \%$ \\
Slope limited to 3\% & $2.2 \%$ & $7.8 \%$ \\
Slope limited to 1\% & $0.6 \%$ & $2.5 \%$ \\
\hline
\end{tabular}

When the slope limitation is decreased to $1 \%$, the available aggregated land for siting a CSP is reduced to about $1 / 5$ of the $5 \%$ slope case for water-cooled CSP and about $1 / 4$ of the $5 \%$ slope case for dry-cooled CSP placement.

A rough comparison with the plant placement algorithm calculated for the 5\% slope case would suggest that available water-cooled CSP capacity would be reduced to approximately $12.6 \mathrm{GW}(\mathrm{e})$ for the $3 \%$ slope case and to approximately $3.4 \mathrm{GW}(\mathrm{e})$ for the $1 \%$ slope case. Therefore, the greatest sensitivity is observed below 3\% slope. Dry-cooled CSP capacity is similarly affected.

\subsubsection{Stream Flow}

If stream flow limitations were applied on a cumulative daily basis instead of a real-time basis, and watercooled CSPs maintained a 40\% capacity factor (upper end value; range of $25 \%$ to $40 \%$ expected), then the minimum stream flow SSEC for water-cooled CSPs could be decreased from to 15,000 gpm to 6,000 gpm. With a lower minimum stream flow value, there would be a corresponding increase in available land. Figure 117 shows the stream flow cooling SSEC layer substituted for the base case ( 104). 


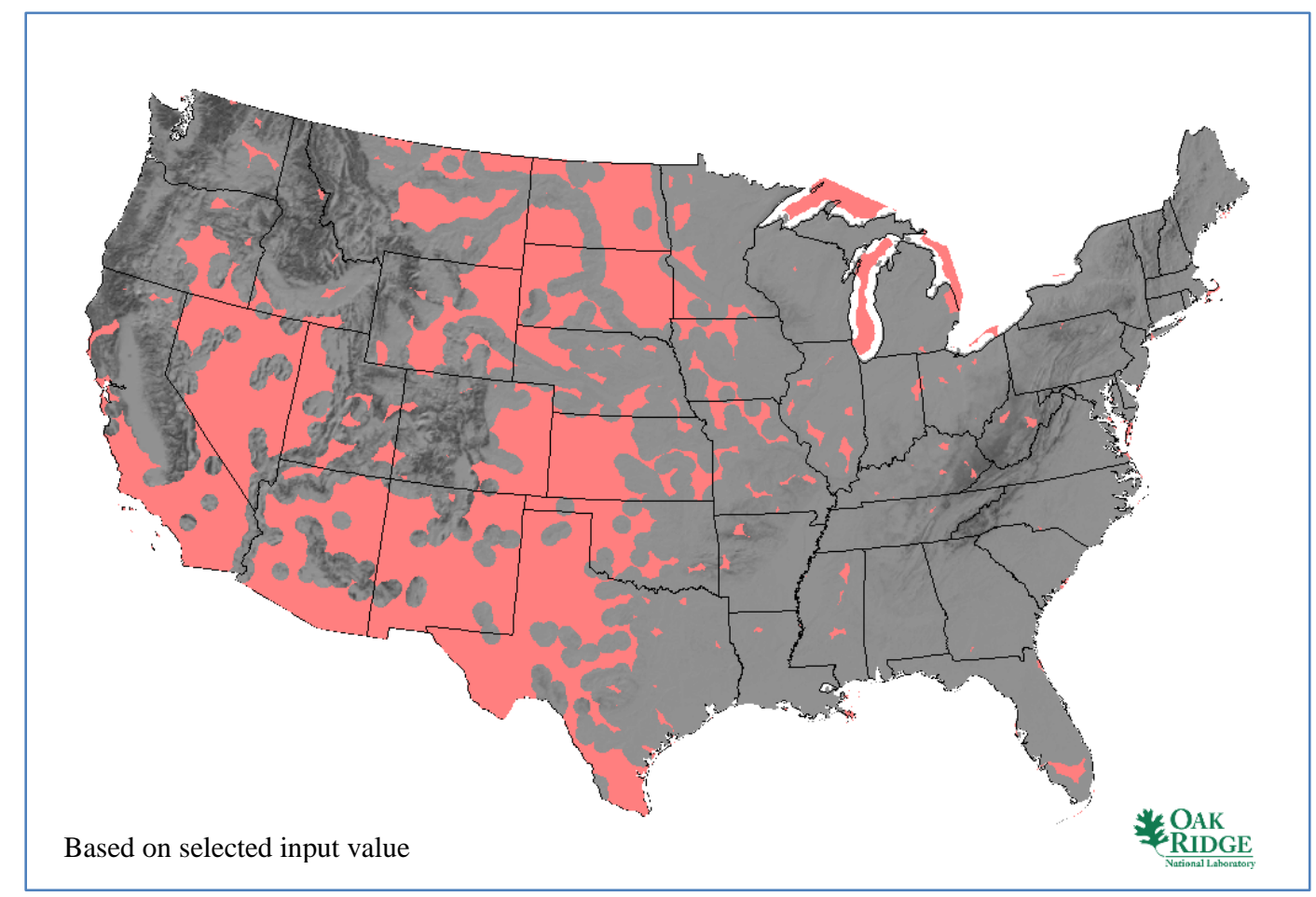

Fig. 117. Solar low stream flow SSEC layer (6,000 gpm within 20 miles) (water-cooled CSP only).

Figure 118 shows the resulting aggregated land (90\%) map based on the revised solar stream flow cooling SSEC layer at 6,000 gpm. Reducing the cooling water requirement increases the aggregated land available from $3.5 \%$ of the contiguous United States in the base case (Fig. 110) to $3.9 \%$ in the sensitivity case. Although the absolute value appears small, this represents a $11 \%$ increase in available land with no siting challenges, or an additional 6.8 million acres. A linear comparison with the base case capacity estimate $[20.0 \mathrm{GW}(\mathrm{e})]$ yields an increase of $2.3 \mathrm{GW}(\mathrm{e})$ for a total of $22.3 \mathrm{GW}(\mathrm{e})$ in new water-cooled CSP capacity. This additional capacity, based on 6,000 gpm stream flow cooling, is the equivalent of more than one additional large nuclear power plant $[1.6 \mathrm{GW}(\mathrm{e})]$ or the net output of four advanced coal plants [750 MW(e) gross and $550 \mathrm{MW}(\mathrm{e})$ net]. 


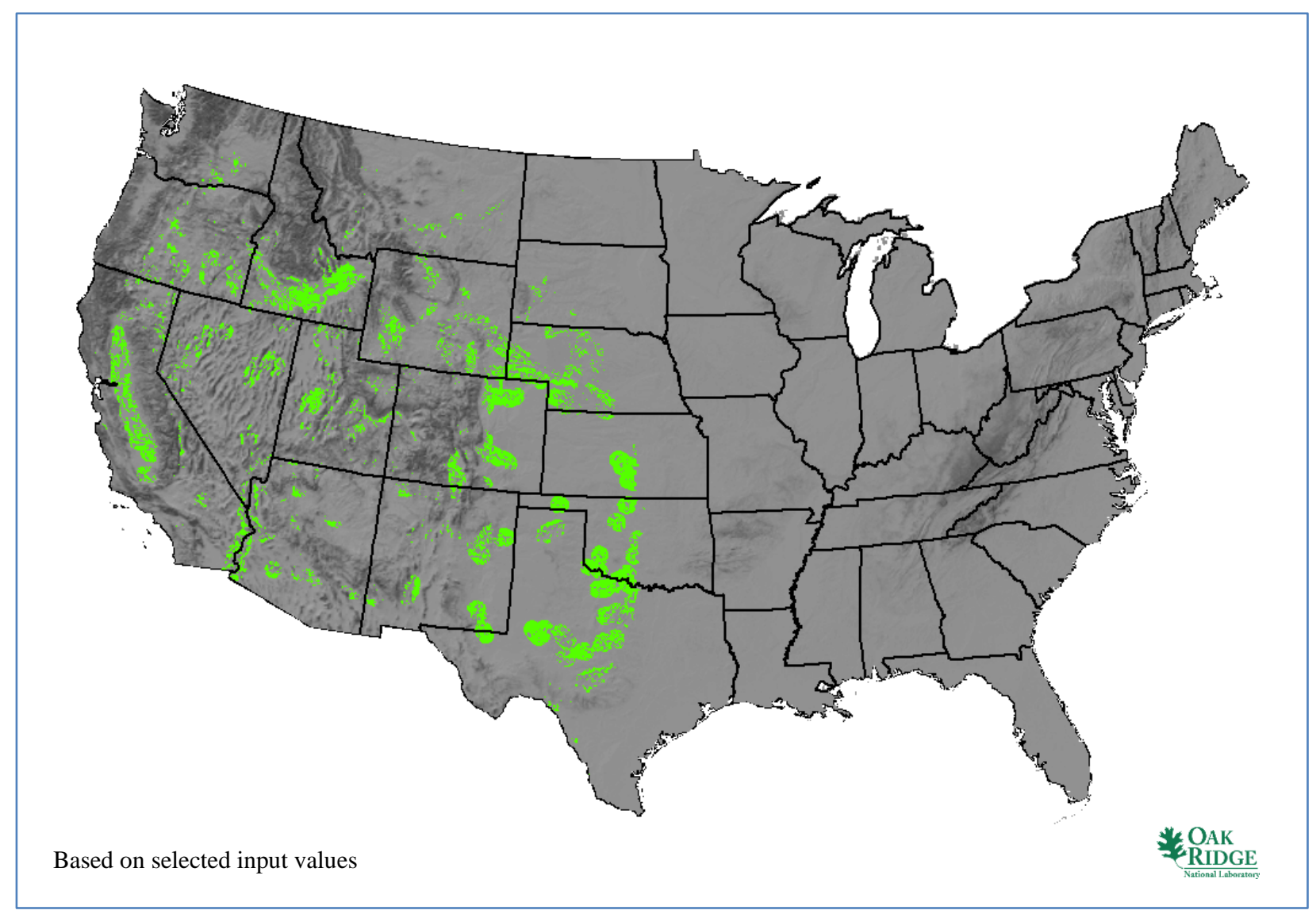

Fig. 118. Water-cooled CSP sensitivity considering $40 \%$ capacity factor (aggregated land result).

\subsubsection{Projections}

Over time, the siting options change depending on a wealth of factors, including load growth, population shifts, increased demand for fresh water (water-cooled CSP), improved technology, changed regulatory environment, climate shifts, and others. In addition, new power generation requires planning, financing, permitting, and construction. For CSP, this process typically takes several years, depending on the application. GIS projections are only as good as the underlying data and trends, and uncertainty increases with the length of time projected. For these reasons, as described in the section "2035 Assumptions," a projection 25 years in the future was prepared for CSP generation, based on population data and trends available to ORNL in its LandScan USA dataset and a revised rule of thumb for freshwater availability to water-cooled CSP power generation.

Figure 119 depicts the projected 2035 population SSEC layer for solar power applications. As discussed previously, a population density of more than 500 people per square mile begins to transition into an urban setting, so new CSPs in these areas, shown in red, continue to be excluded using the 2035 population projection. There is no need to include a buffer for public safety. Figure 98 provides the comparable population SSEC layer for 2010. 


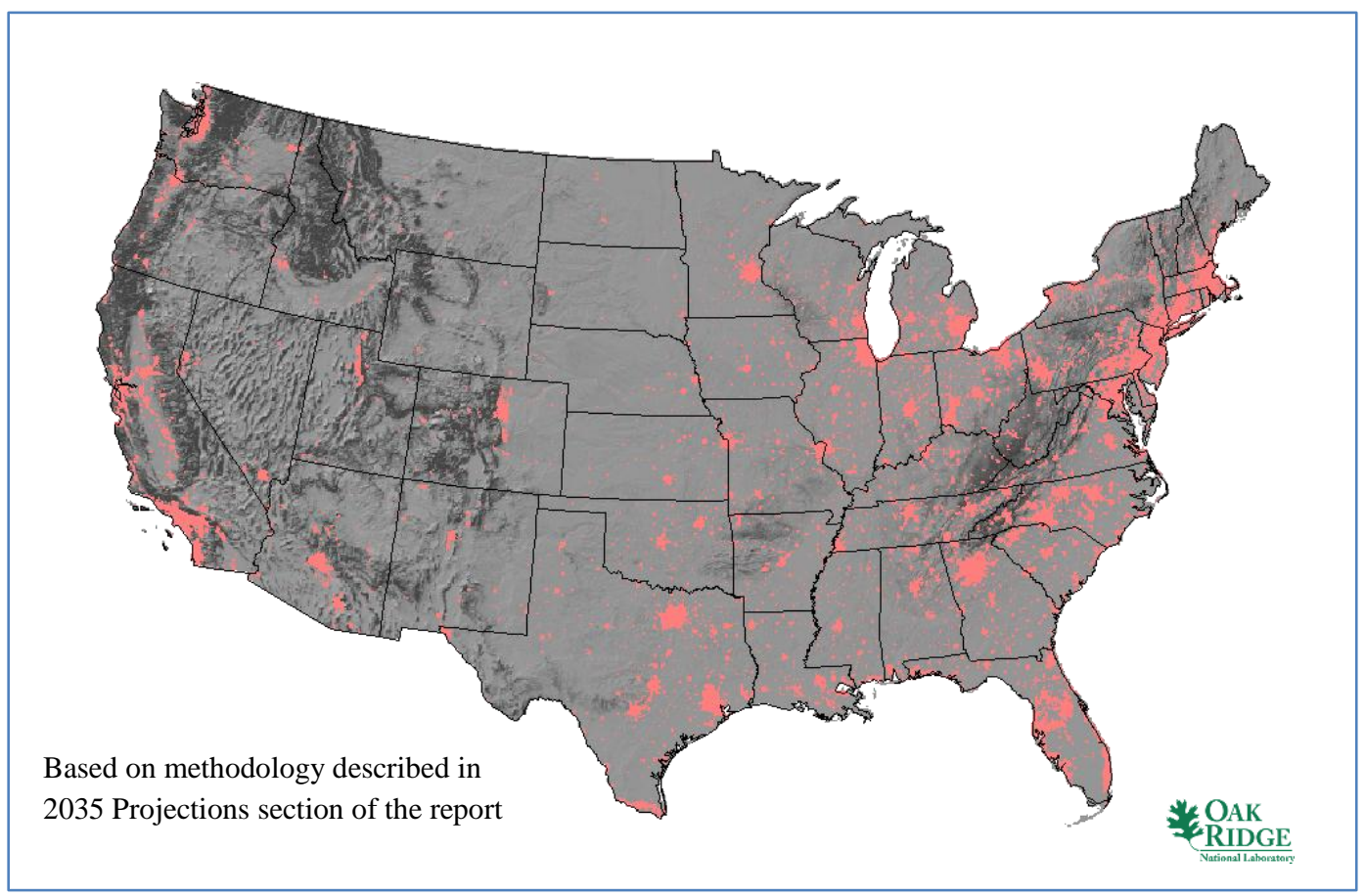

Fig. 119. Solar power 2035 high population SSEC layer.

Likewise, Fig. 120 shows the areas excluded in red, based on a reduced availability of fresh water for CCC makeup in the future for water-cooled CSP applications. To approximate the increased demand on water supplies in the future, it was decided that the simple rule of thumb to apply to the 2035 case would be that a given power source should not take more than $5 \%$ of the available stream flow at a given "new plant" location as opposed to $10 \%$ in the 2010 timeframe. Table 5 shows the resulting effect on stream flow: 30,000 gpm available within 20 miles in the case of water-cooled CSP. Figure 104 provides the comparable stream flow SSEC layer for 2010 based on 15,000 gpm available within 20 miles. It should be noted that dry-cooled CSP applications are impacted only by the projected change in population for the 2035 case. 


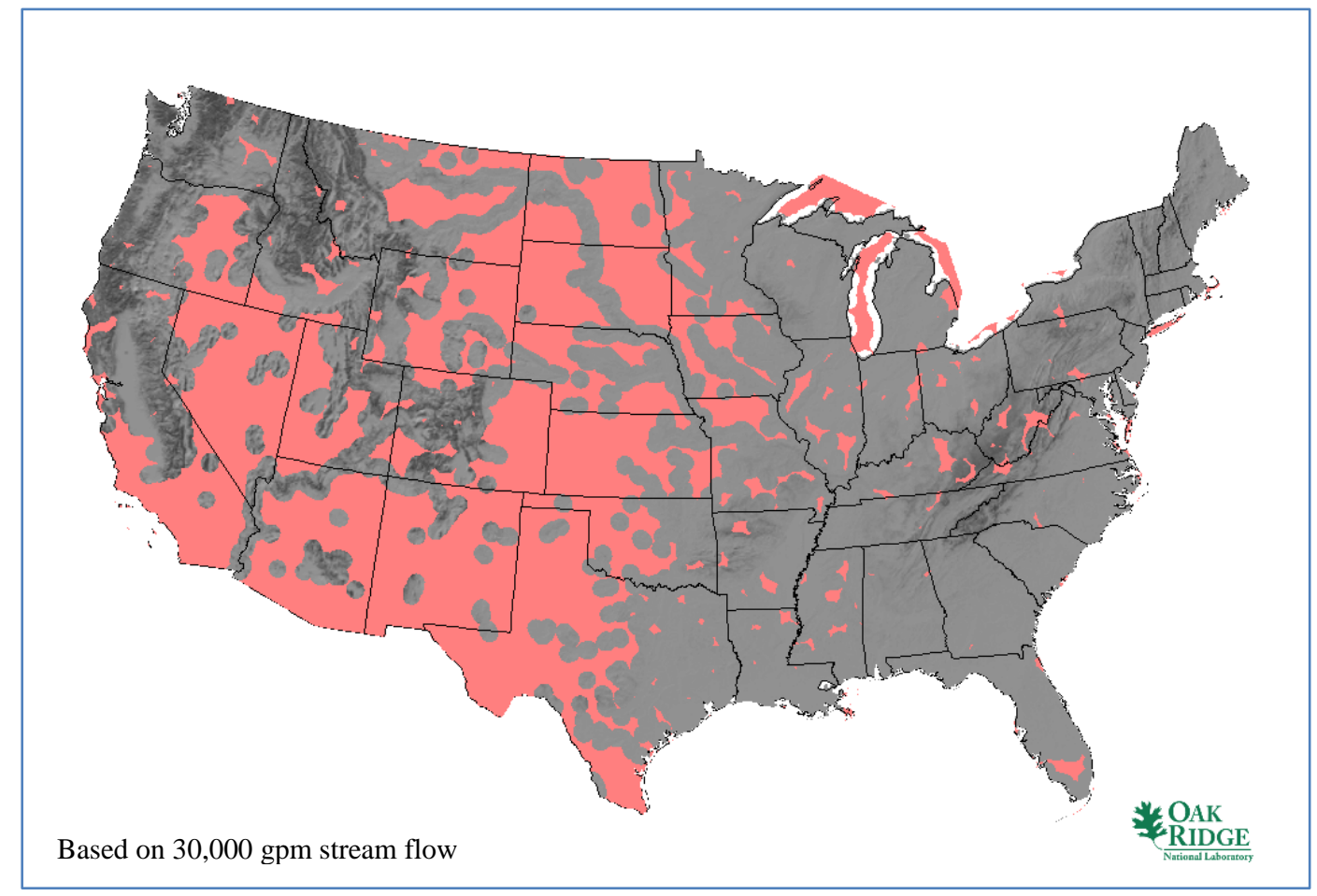

Fig. 120. Solar power 2035 low stream flow SSEC layer.

As a result of substituting the 2035 projected SSEC layers shown in Fig. 119 and Fig. 120, the available land for siting water-cooled CSP is diminished significantly and the available land for siting dry-cooled CSP is diminished slightly for 2035. Based on these projections and the previously selected values for water-cooled CSP siting, Fig. 121 depicts the 2035 water-cooled CSP base map indicating $6.1 \%$ of the contiguous United States is available, or 104 million acres. Compare this value with the 2010 watercooled CSP base map shown in Fig. on which $6.2 \%$ of the contiguous United States is available, or 106 million acres. The 2035 projection for water-cooled CSP indicates a reduction in available land equivalent to $0.1 \%$ of the contiguous United States, or a reduction of 2 million acres before consideration of land aggregation to meet the nominal plant footprint size.

The dry-cooled CSP base map is actually projected to increase by $0.1 \%$ of the contiguous United States from the base map depicted in Fig. 111 based on projected population shifts in 2035. This represents an increase of less than 2 million acres compared with a total of 312 million acres total available for drycooled CSP in 2010. This is not significant and the difference is not visible on a small, report-scale map. 


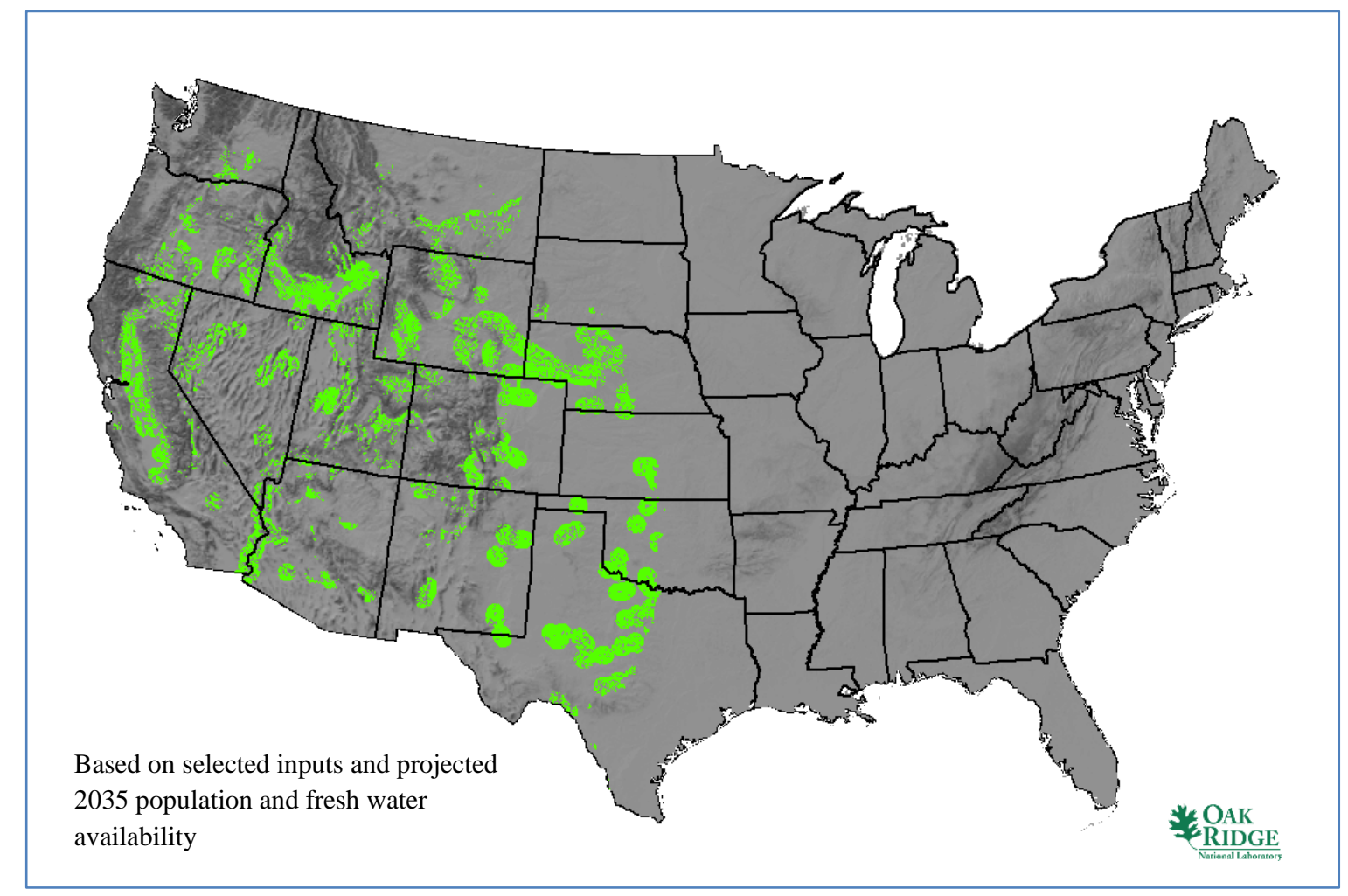

Fig. 121. Water-cooled CSP 2035 base map.

The results of aggregating the projected available land from the base case shown in Fig. 121 are depicted in green in Fig. 122. Land aggregation for a nominal 500-acre water-cooled CSP facility reduces the available land from $6.1 \%$ of the contiguous United States in the 2035 base case to $3.4 \%$ or 58 million acres. This is an actual reduction of $0.1 \%$ of the contiguous United States, or less than 2 million acres, compared with the aggregated land calculation for 2010 shown in Fig. 110, or a relative decrease of 3\%.

As is the case for the dry-cooled CSP base map, aggregating the projected available land increases the amount of available land by $0.1 \%$ of the contiguous United States from the base map depicted in Fig. 112, based on projected population shifts in 2035. This represents an increase of less than 2 million acres compared with a total of 205 million acres total available for dry-cooled CSP in 2010. This is not significant and the difference is not visible on a small, report-scale map.

Figure 123 provides a visual comparison of the aggregated land available for water-cooled CSP siting, based on selected SSEC input parameters, for the 2010 and 2035 scenarios. A rough comparison with the plant placement algorithm calculated for the 2010 water-cooled CSP base case would suggest that available new water-cooled CSP gross capacity would be decreased from $20.0 \mathrm{GW}(\mathrm{e})$ to approximately 19.4 GW(e) by delaying installed new water-cooled CSP capacity to 2035. A reasonable 2035 range for dry-cooled CSP capacity is unchanged at 70 to $400 \mathrm{GW}(\mathrm{e})$. 


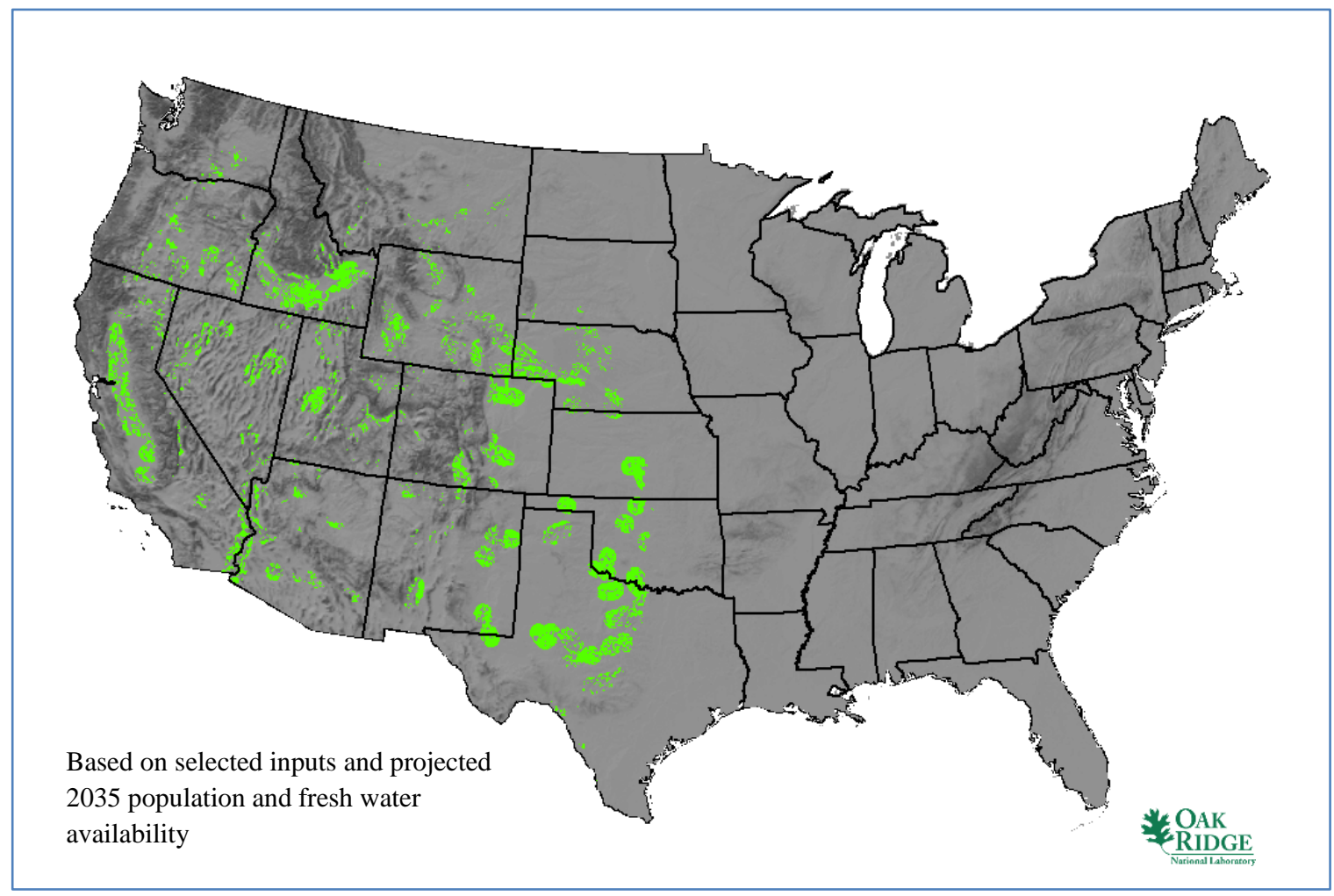

Fig. 122. Water-cooled CSP 2035 siting aggregated at $90 \%$ for 500 acre facility.

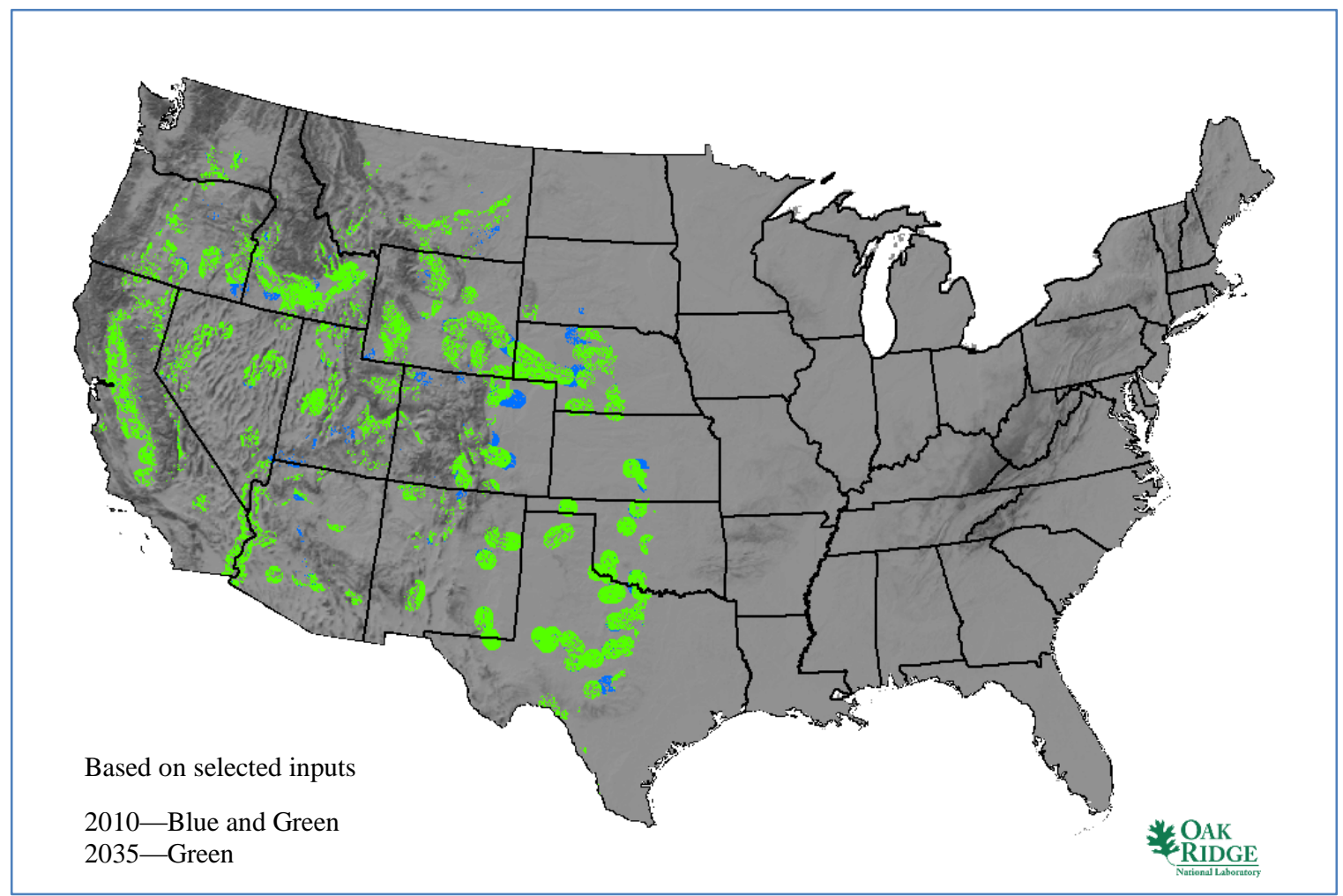

Fig. 123. Solar power visual comparison of 2010 and 2035 aggregated land results. 


\subsection{Tabular Results}

Table 16 shows the water-cooled CSP estimated results by state. An entry of 0.00 indicates a value greater than zero that does not show at two significant digits, and a blank entry implies a zero response. Note that the tabular results are not intended to show a "final" result. These results are based on a selected set of input values and a capacity projection algorithm. The relative values between states are the more significant table information. It should be further noted that Table 16 details only the results of aggregated land cells that had no siting challenges. Engineered solutions for land with one or more siting challenges would impact the entries included in Table 16.

It is interesting to compare the OR-SAGE capacity estimate algorithm results in the right column of Table 16 with the calculated available land in the contiguous United States for water-cooled CSP in the third column of Table 16. The states with the strongest projections for plant installations and capacity as identified by the OR-SAGE capacity estimate algorithm are California, Idaho, Montana, and Utah. The states with the most available land for water-cooled CSP as a percentage of the total land within the contiguous United States are Texas, California, Idaho and Colorado. The difference can be attributed to the location of available cooling water and the clustering of available land around the water. In the case of Colorado and Texas, once a plant is projected, many of the potential sites are subsequently made unavailable because they are clustered in the same general area, and significant space is required to reestablish sufficient cooling water in the respective water basin. Therefore, while calculated available land in the contiguous United States is a significant indicator for water-cooled CSP capacity, it is not a standalone indication of capacity.

Table 16. Water-cooled CSP results by state (no siting challenges, selected SSEC values)

\begin{tabular}{|c|c|c|c|}
\hline State $^{a}$ & $\begin{array}{c}\text { Portion of state } \\
\text { available to support } \\
500 \text { acre sites } \\
(\%)^{b} \\
\end{array}$ & $\begin{array}{c}\text { Portion of contiguous } \\
\text { US available to } \\
\text { support } 500 \text { acre sites } \\
(\%)\end{array}$ & $\begin{array}{c}\text { Estimated capacity } \\
{[\mathrm{MW}(\mathbf{e})]^{c}}\end{array}$ \\
\hline \multicolumn{4}{|l|}{ Alabama } \\
\hline Arizona & 4.24 & 0.16 & 900 \\
\hline \multicolumn{4}{|l|}{ Arkansas } \\
\hline California & 7.34 & 0.38 & 3,300 \\
\hline Colorado & 8.44 & 0.29 & 1,600 \\
\hline \multicolumn{4}{|l|}{ Connecticut } \\
\hline \multicolumn{4}{|l|}{ Delaware } \\
\hline \multicolumn{4}{|c|}{ District of Columbia } \\
\hline \multicolumn{4}{|l|}{ Florida } \\
\hline \multicolumn{4}{|l|}{ Georgia } \\
\hline Idaho & 12.40 & 0.34 & 2,100 \\
\hline \multicolumn{4}{|l|}{ Illinois } \\
\hline \multicolumn{4}{|l|}{ Indiana } \\
\hline \multicolumn{4}{|l|}{ Iowa } \\
\hline Kansas & 4.10 & 0.11 & 200 \\
\hline Kentucky & & & \\
\hline
\end{tabular}


Table 16. (continued)

\begin{tabular}{|c|c|c|c|}
\hline State $^{a}$ & $\begin{array}{c}\text { Portion of state } \\
\text { available to support } \\
500 \text { acre sites } \\
(\%)^{b}\end{array}$ & $\begin{array}{c}\text { Portion of contiguous } \\
\text { US available to } \\
\text { support } 500 \text { acre sites } \\
(\%)\end{array}$ & $\begin{array}{c}\text { Estimate capacity } \\
{[M W(e)]^{c}}\end{array}$ \\
\hline \multicolumn{4}{|l|}{ Louisiana } \\
\hline \multicolumn{4}{|l|}{ Maine } \\
\hline \multicolumn{4}{|l|}{ Maryland } \\
\hline \multicolumn{4}{|l|}{ Massachusetts } \\
\hline \multicolumn{4}{|l|}{ Michigan } \\
\hline \multicolumn{4}{|l|}{ Minnesota } \\
\hline \multicolumn{4}{|l|}{ Mississippi } \\
\hline \multicolumn{4}{|l|}{ Missouri } \\
\hline Montana & 0.88 & 0.04 & 2,100 \\
\hline Nebraska & 9.39 & 0.24 & 1,000 \\
\hline Nevada & 4.93 & 0.18 & 900 \\
\hline \multicolumn{4}{|l|}{ New Hampshire } \\
\hline \multicolumn{4}{|l|}{ New Jersey } \\
\hline New Mexico & 5.94 & 0.24 & 900 \\
\hline \multicolumn{4}{|l|}{ New York } \\
\hline \multicolumn{4}{|l|}{ North Carolina } \\
\hline \multicolumn{4}{|l|}{ North Dakota } \\
\hline \multicolumn{4}{|l|}{ Ohio } \\
\hline Oklahoma & 11.72 & 0.27 & 200 \\
\hline Oregon & 4.47 & 0.14 & 1,500 \\
\hline \multicolumn{4}{|l|}{ Pennsylvania } \\
\hline \multicolumn{4}{|l|}{ Rhode Island } \\
\hline \multicolumn{4}{|l|}{ South Carolina } \\
\hline South Dakota & 0.30 & 0.01 & \\
\hline \multicolumn{4}{|l|}{ Tennessee } \\
\hline Texas & 6.77 & 0.61 & 1,100 \\
\hline Utah & 6.10 & 0.17 & 2,000 \\
\hline \multicolumn{4}{|l|}{ Vermont } \\
\hline \multicolumn{4}{|l|}{ Virginia } \\
\hline Washington & 1.18 & 0.03 & 500 \\
\hline \multicolumn{4}{|l|}{ West Virginia } \\
\hline \multicolumn{4}{|l|}{ Wisconsin } \\
\hline Wyoming & 8.02 & 0.26 & 1,700 \\
\hline Total & - & 3.48 & 20,000 \\
\hline $\begin{array}{l}{ }^{a} \text { Generation capac } \\
{ }^{b} \text { Land for sites is } \\
\text { Size." } \\
{ }^{c} \text { Plant placement/c } \\
\text { upstream or down }\end{array}$ & $\begin{array}{l}\text { S discussed in "Plant Pla } \\
90 \% \text { as discussed in "M } \\
\text { late is completely arbitra }\end{array}$ & $\begin{array}{l}\text { ent Algorithm for Water-D } \\
\text { dology for Aggregating Lal } \\
\text { an unbiased. Shifting the in }\end{array}$ & $\begin{array}{l}\text { dent Power Sources." } \\
\text { or the Typical Plant } \\
\text { plant placement } \\
\text { ect the state capacity. }\end{array}$ \\
\hline
\end{tabular}


Table 17 shows the water-cooled CSP estimated results by water region. Individual states may be wholly contained within a single water region or they may be part of multiple water regions. Figure 20 shows a US state map with the 18 water regions as an overlay. Region 10 has the strongest projection for plant installations and capacity as identified by the OR-SAGE capacity estimate algorithm. Region 10 includes most of Montana and Wyoming, and portions of Nebraska, Colorado, and Kansas. Note that the tabular results are not intended to show a "final" result. These results are based on a selected set of input values and a capacity projection algorithm. The relative values between regions are the more significant table information. It should be further noted that Table 17 details only the results of aggregated land cells that had no siting challenges. Engineered solutions for land with one or more siting challenges would impact the entries included in Table 17.

Table 17. Water-cooled CSP results by region (no siting challenges, selected SSEC values)

\begin{tabular}{|c|c|c|c|}
\hline $\operatorname{Region}^{a}$ & $\begin{array}{c}\text { Portion of region } \\
\text { available to support } \\
500 \text { acre sites } \\
(\%)^{b}\end{array}$ & $\begin{array}{c}\text { Portion of contiguous } \\
\text { US available to } \\
\text { support } 500 \text { acre sites } \\
(\%)\end{array}$ & $\begin{array}{l}\text { Estimated capacity } \\
{[\mathrm{MW}(\mathrm{e})]^{c}}\end{array}$ \\
\hline \multicolumn{4}{|l|}{ 1. New England } \\
\hline \multicolumn{4}{|l|}{ 2. Mid Atlantic } \\
\hline \multicolumn{4}{|l|}{ 3. South Atlantic-Gulf } \\
\hline \multicolumn{4}{|l|}{ 4. Great Lakes } \\
\hline \multicolumn{4}{|l|}{ 5. Ohio } \\
\hline \multicolumn{4}{|l|}{ 6. Tennessee } \\
\hline \multicolumn{4}{|l|}{ 7. Upper Mississippi } \\
\hline \multicolumn{4}{|l|}{ 8. Lower Mississippi } \\
\hline \multicolumn{4}{|l|}{ 9. Souris-Red-Rainy } \\
\hline 10. Missouri & 3.71 & 0.63 & 4,900 \\
\hline 11. Arkansas-White-Red & 8.29 & 0.68 & 1,400 \\
\hline 12. Texas-Gulf & 6.62 & 0.40 & 500 \\
\hline 13. Rio Grande & 5.75 & 0.26 & 900 \\
\hline 14. Upper Colorado & 4.04 & 0.15 & 2,300 \\
\hline 15. Lower Colorado & 4.67 & 0.22 & 1,300 \\
\hline 16. Great Basin & 6.01 & 0.28 & 1,800 \\
\hline 17. Pacific Northwest & 5.48 & 0.50 & 3,700 \\
\hline 18. California & 6.82 & 0.36 & 3,200 \\
\hline Total & - & 3.48 & 20,000 \\
\hline \multirow{2}{*}{\multicolumn{4}{|c|}{$\begin{array}{l}{ }^{a} \text { Generation capacity estimate is discussed in "Plant Placement Algorithm for Water-Dependent Power Sources." } \\
{ }^{b} \text { Land for sites is aggregated at } 90 \% \text { as discussed in "Methodology for Aggregating Land for the Typical Plant Size." }\end{array}$}} \\
\hline & & & \\
\hline \multicolumn{4}{|c|}{$\begin{array}{l}{ }^{c} \text { Plant placement/capacity estimate is completely arbitrary and unbiased. Shifting the initial plant placement upstream or } \\
\text { downstream will affect all subsequent proposed plant placements and could affect the regional capacity. }\end{array}$} \\
\hline
\end{tabular}





\section{COMPRESSED AIR ENERGY STORAGE RESULTS}

CAES is not simply a storage or battery technology. The storage side of CAES involves using off-peak electricity (e.g., grid, solar, wind) to charge an underground reservoir with compressed air. Subsequently, during peak demand periods, energy is generated when the stored compressed air is mixed with natural gas and combusted and then expanded through a turbine to generate power. This is similar to a conventional gas turbine power plant, except that a conventional gas turbine requires a substantial amount of the energy generated to operate air compressors. Therefore, the CAES plant is more efficient than a similarly rated conventional gas turbine. However, the operating cycle time is limited to the available compressed air storage capacity.

In effect, CAES is a hybrid technology that uses electrical-to-physical storage to subsequently power a highly efficient combustion turbine. ${ }^{27}$

\subsection{Site Selection and Evaluation Criteria}

Siting of CAES plants is primarily a function of geology. Nuclear plants must consider seismic restrictions, proximity to fault lines, and nearby hazardous facilities as a public safety issue. For CAES plants, seismic and earthquake fault restrictions are an investment protection issue. Therefore, it is assumed that there are no seismic or earthquake fault issues for CAES plant siting, beyond local building codes. Likewise, proximity to hazardous facilities is not considered applicable to CAES plant placement as a public safety precaution. CAES does require acceptable geological formations such as salt formations and aquifers for compressed air storage. For siting purposes, a CAES plant should be within a mile of an acceptable geological formation. This allows for limited horizontal drilling access to the storage formation. Unlike carbon storage for advanced coal applications, acceptable geological formations for CAES are generally at depths less than $2500 \mathrm{ft}^{28}$

CAES plants generate a reasonable amount of noise. Therefore, more highly populated areas are excluded from consideration for CAES siting. As with the nuclear plant placement case, population densities greater than 500 people per square mile are avoided. However, no buffer for public safety is required.

A CAES plant requires a small physical footprint for operation. Ten acres was considered adequate for a plant similar to the McIntosh plant in Alabama, based on expert judgment. A small footprint reduces the site preparation costs. Therefore, in addition to the small slope of $12 \%$ allowed in nuclear plant siting, a larger slope of $30 \%\left(\sim 17^{\circ}\right)$ is considered as a sensitivity study for siting consideration. No access to cooling water is required.

Engineering judgment indicated that other nuclear SSEC such as wetlands and open water, protected lands, landslide hazards, and floodplains should continue to be excluded for new CAES plant candidate area siting.

The SSEC for the nominal 110 MW(e) CAES plant positioned on 10 acres of land are as follows:

- Land with a population density greater than 500 people per square mile (with no buffer) is excluded.

- Wetlands and open water are excluded.

- Protected lands (e.g., national parks, historic areas, wildlife refuges) are excluded.

\footnotetext{
${ }^{27}$ National Renewable Energy Laboratory, ReEDS Model Documentation: Base Case data and Model Description, prepared for the U.S. Department of Energy, August 2009.

${ }^{28}$ BINE Information Service Energy Expertise, Compressed Air Energy Storage Power Plants, July 2005.
} 
- Land with a slope of greater than $12 \%\left(\sim 7^{\circ}\right)$ is excluded.

- Land with a moderate or high landslide hazard susceptibility is excluded.

- Land that lies within a 100-year floodplain is excluded.

- Land areas that are more than 1 mile from salt dome formations, bedded salt formations, and aquifers are avoided.

Figures 124-131 show the individual SSEC layers for the nominal CAES plants based on the values provided in the list above. Areas shown in red are excluded based on the selected input parameter value. Excluded areas in each individual layer can be modified based on different assumptions or requirements for the SSEC.

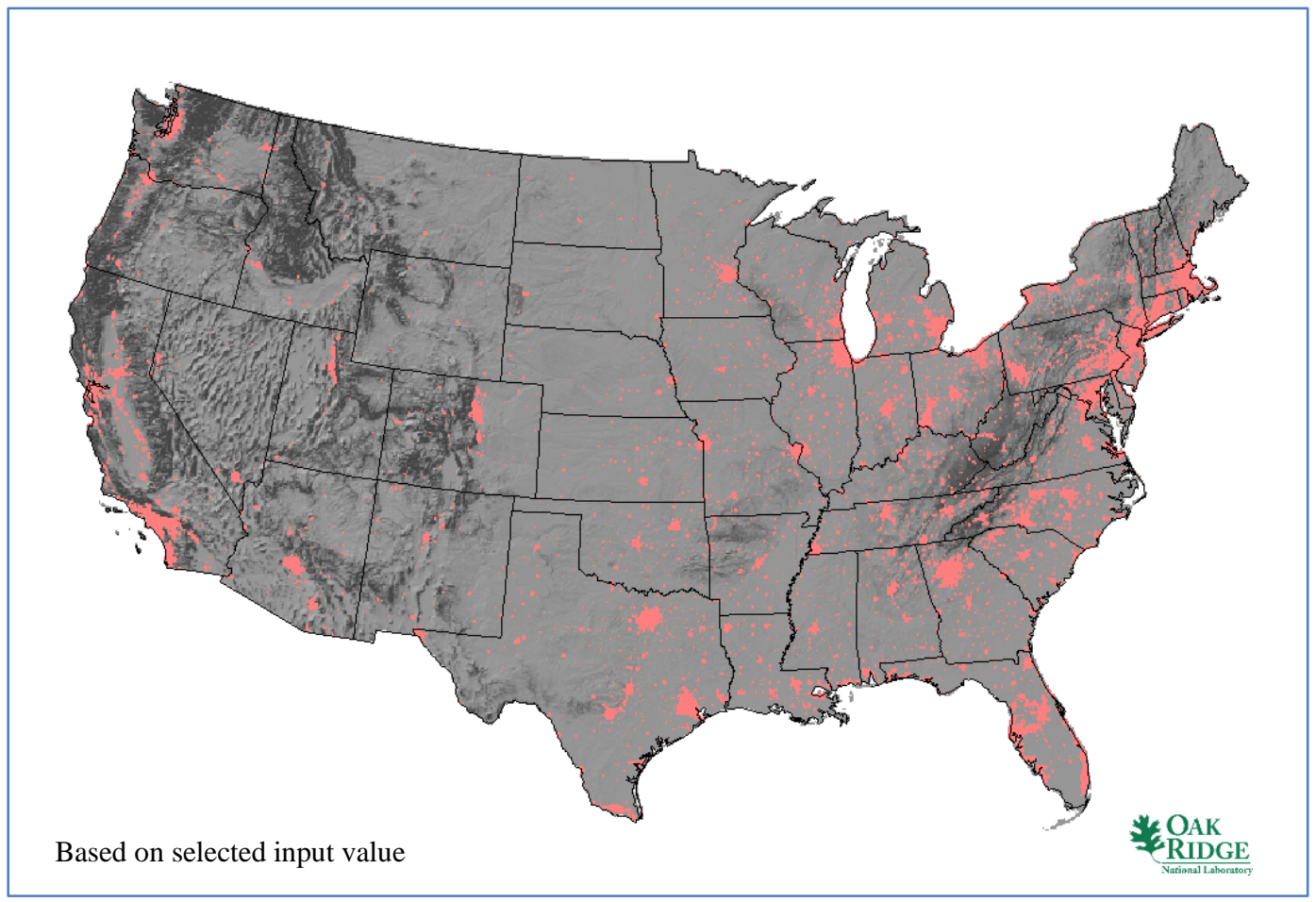

Fig. 124. CAES high population SSEC layer. 


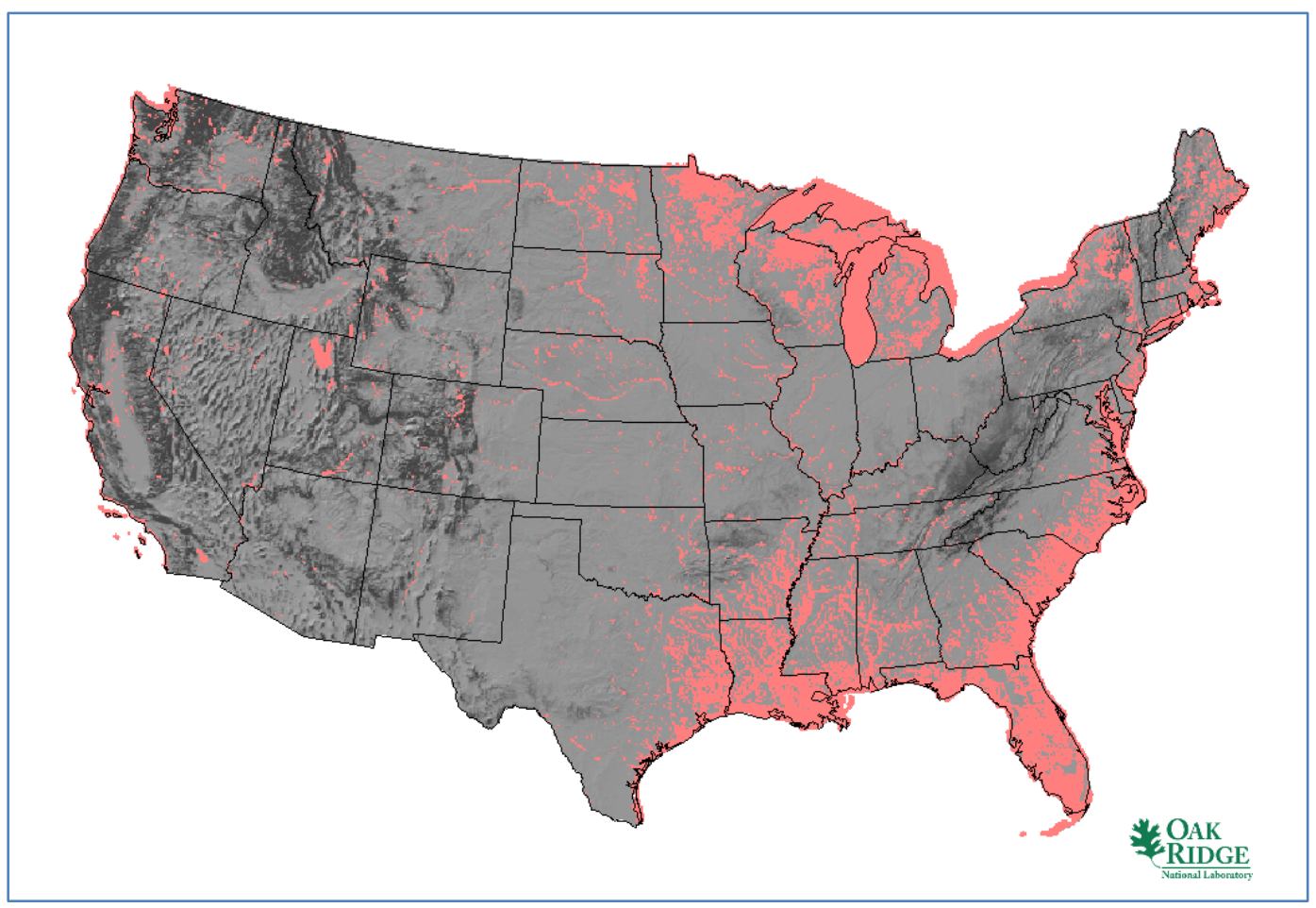

Fig. 125. CAES wetlands and open water SSEC layer.

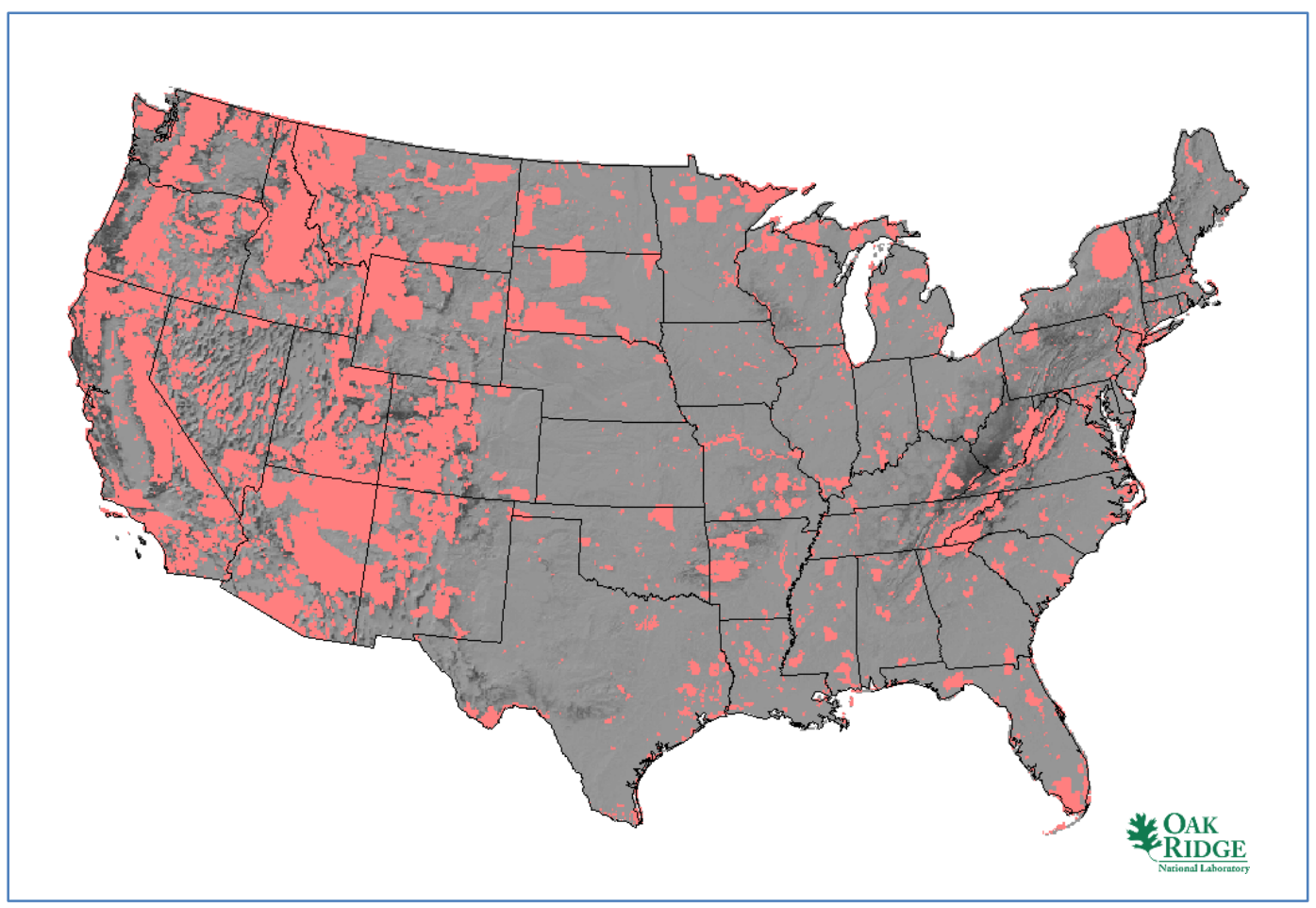

Fig. 126. CAES protected lands SSEC layer. 


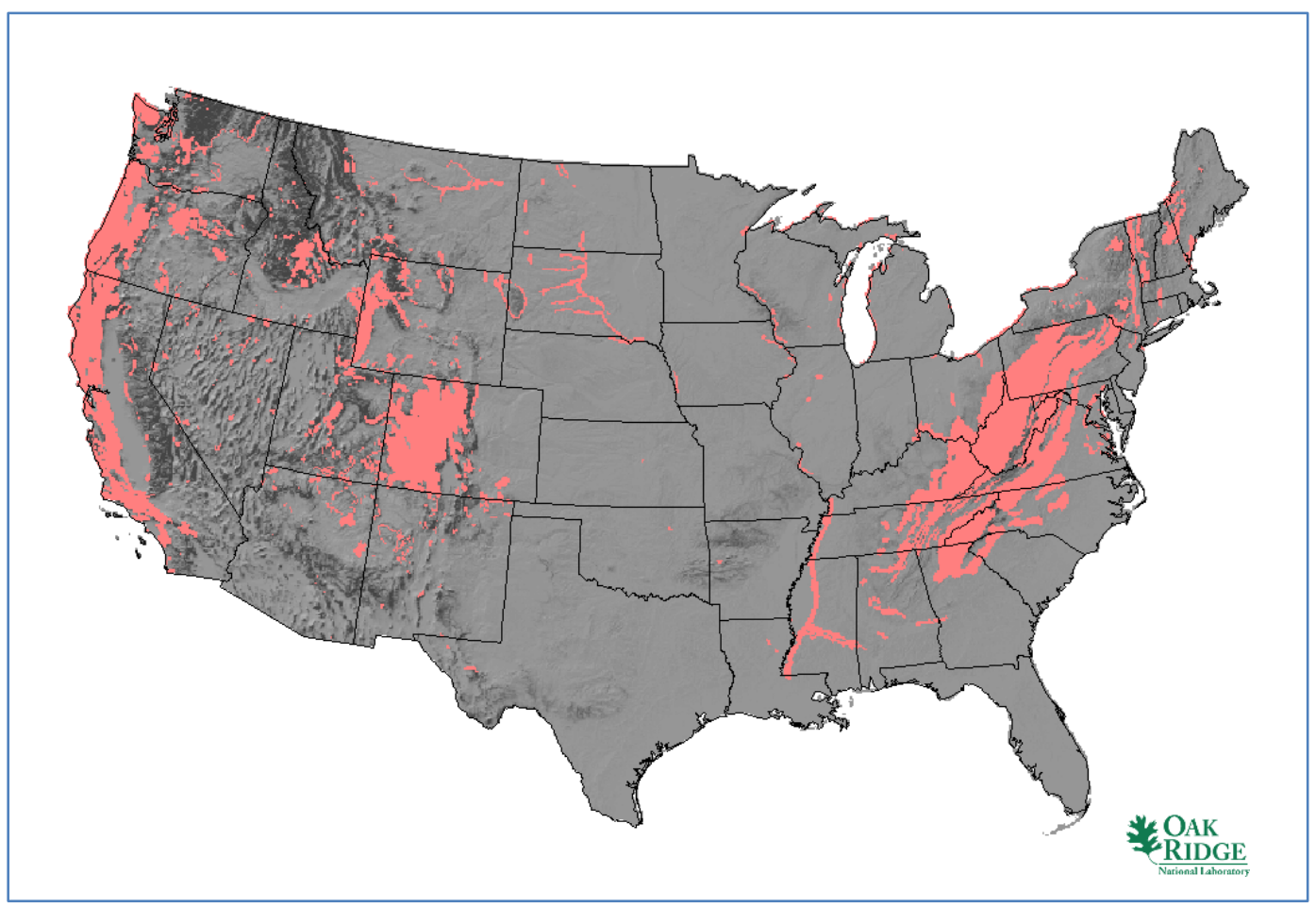

Fig. 127. CAES landslide hazards SSEC layer.

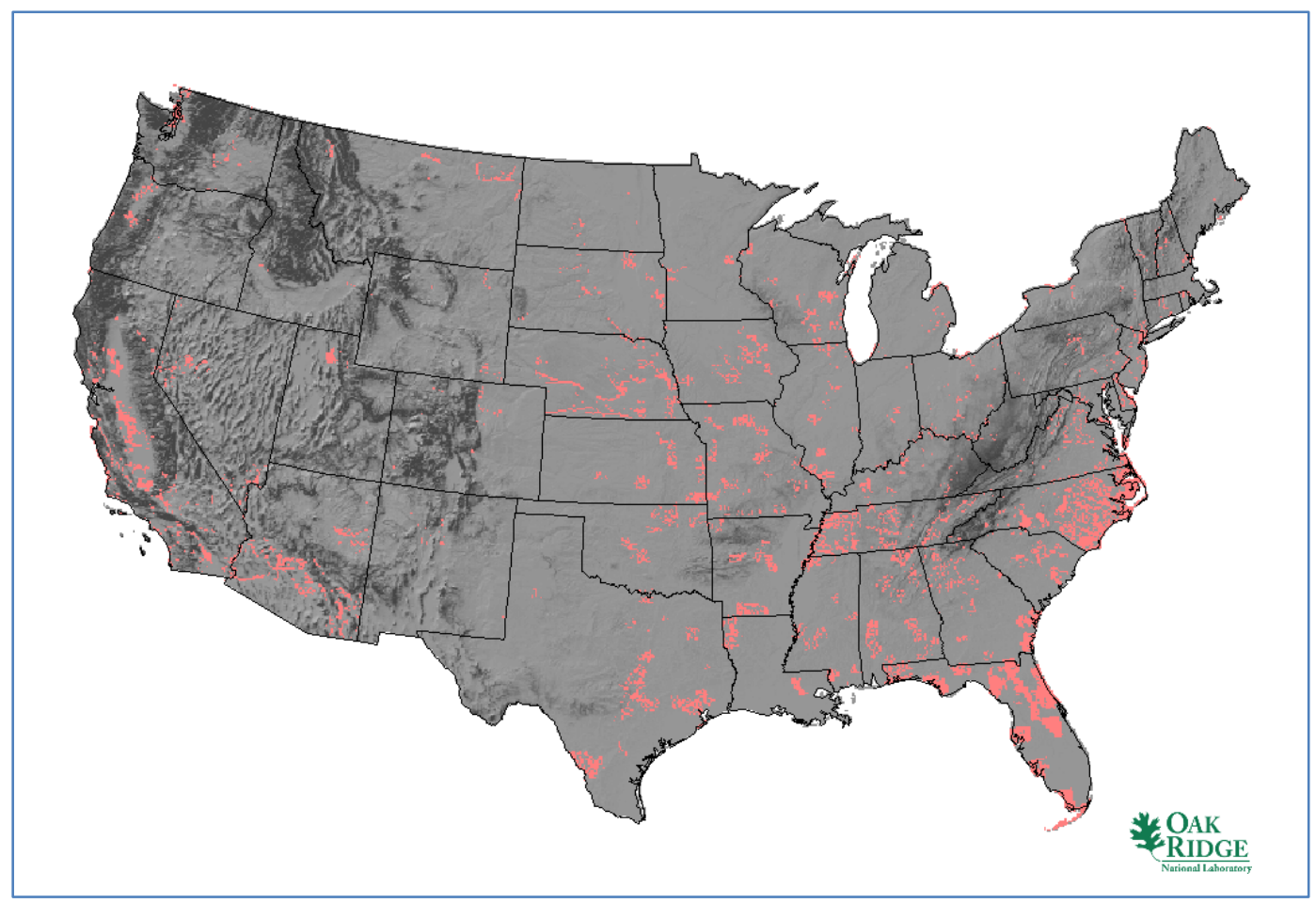

Fig. 128. CAES 100-year floodplain SSEC layer. 


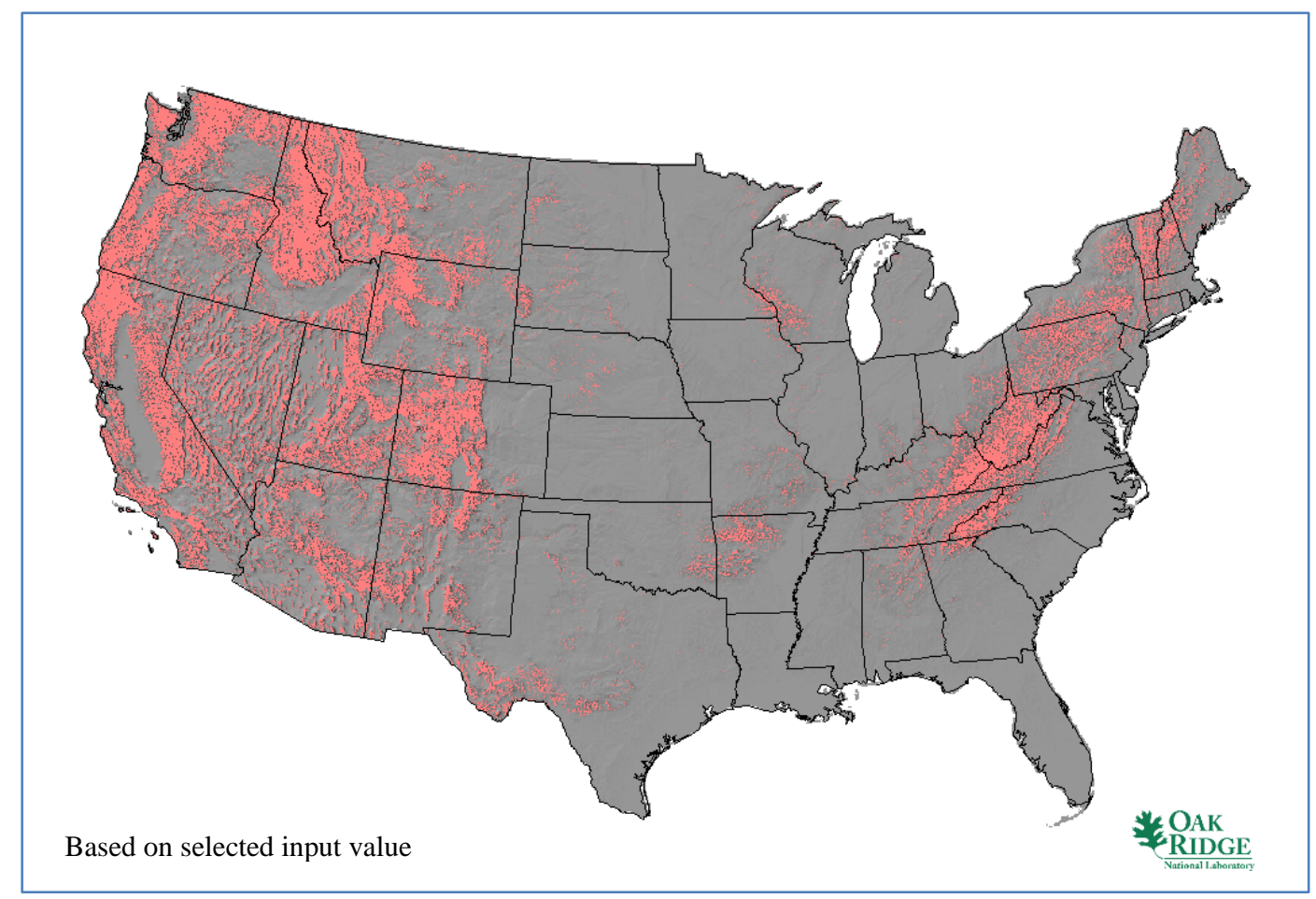

Fig. 129. CAES high slope SSEC layer (greater than 12\%).

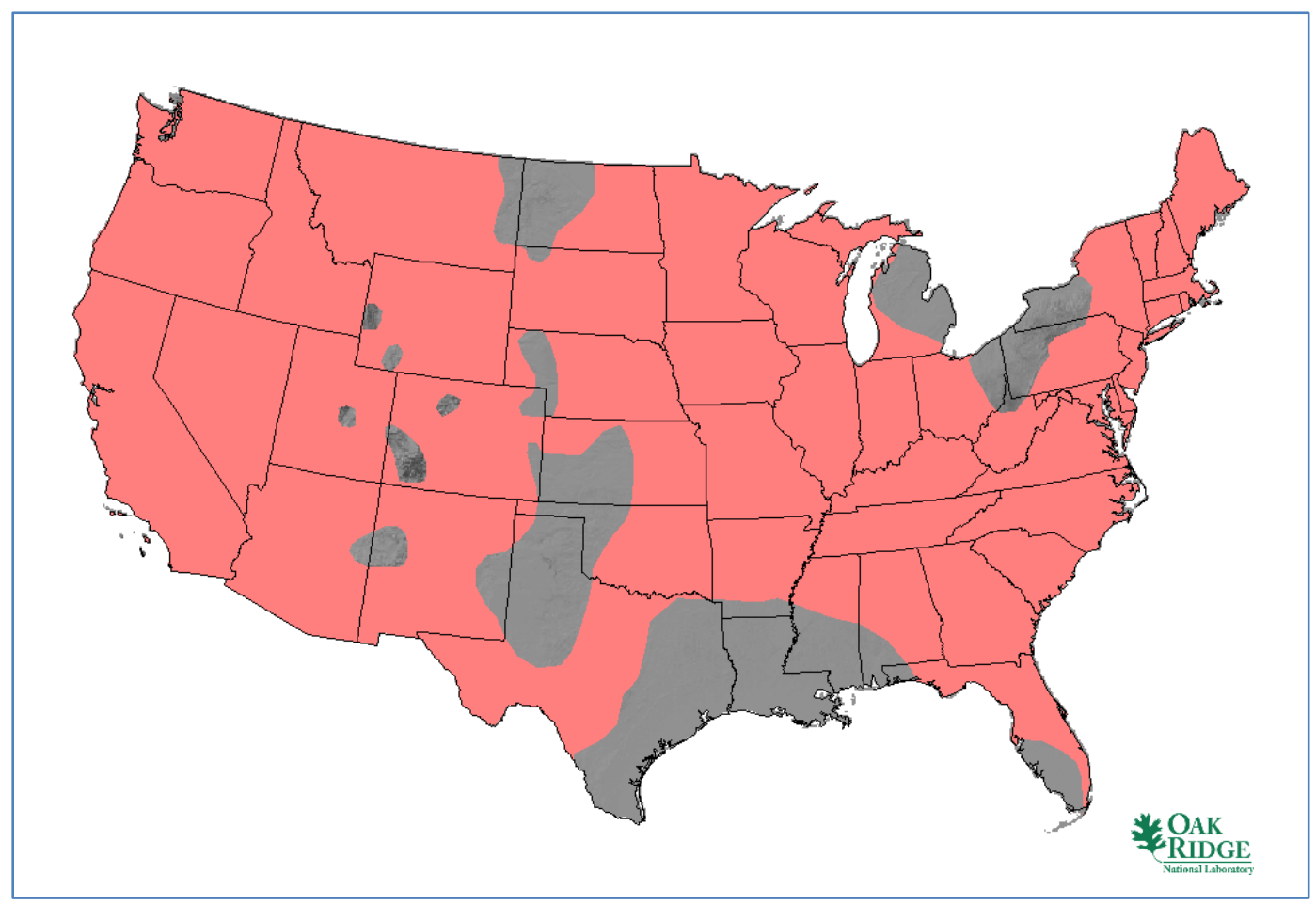

Fig. 130. CAES salt formation SSEC layer. 


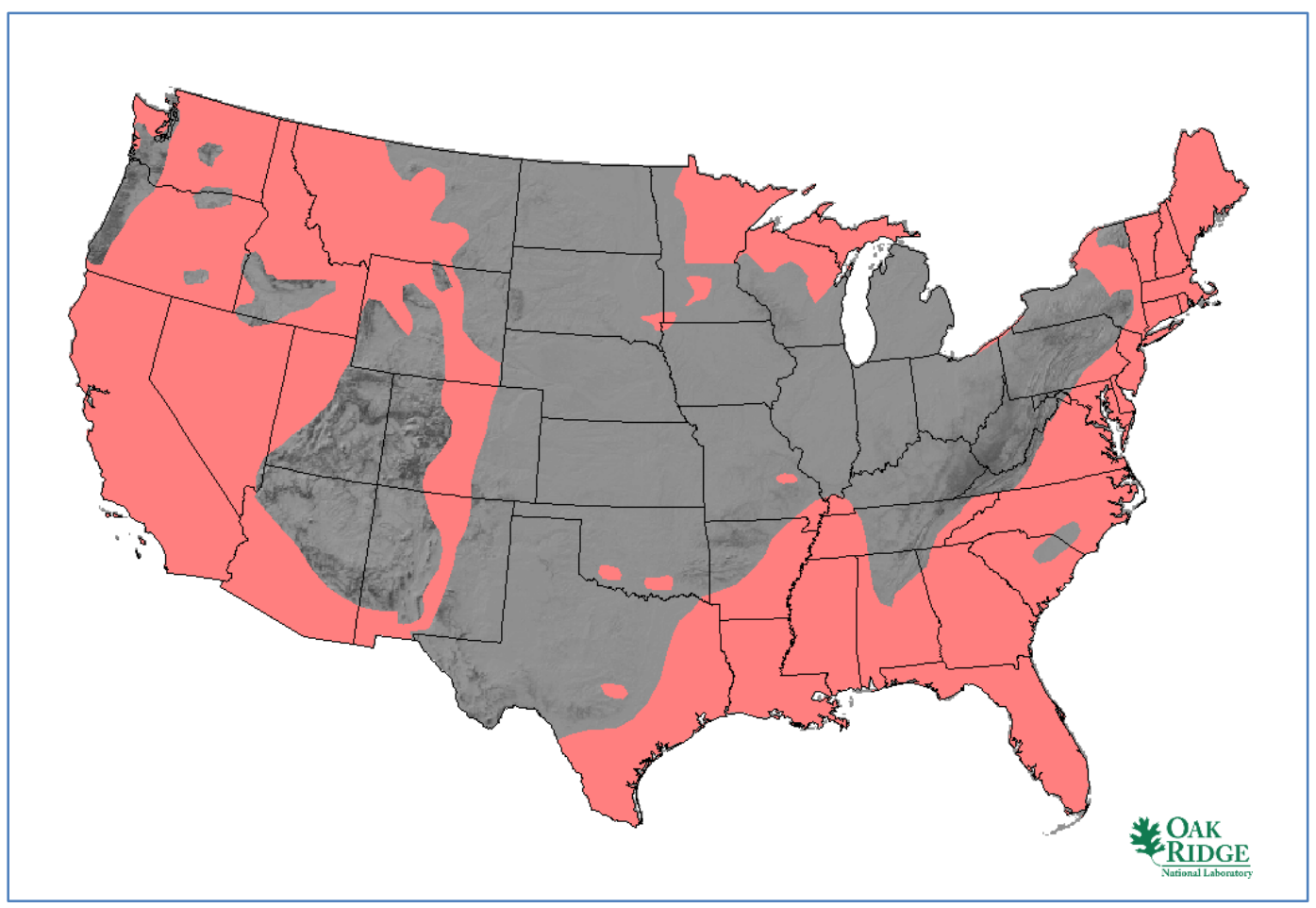

Fig. 131. CAES aquifer formation SSEC layer.

The successive application of each CAES SSEC layer to the overall available land in the contiguous United States can be captured as a step-down histogram as shown in Fig. 132. The SSEC layers are independent. Therefore, the shape of the cumulative histogram is strictly determined by the order in which the SSEC layers (steps) are applied. However, the end result at step 7 is the same no matter what the SSEC layer application order.

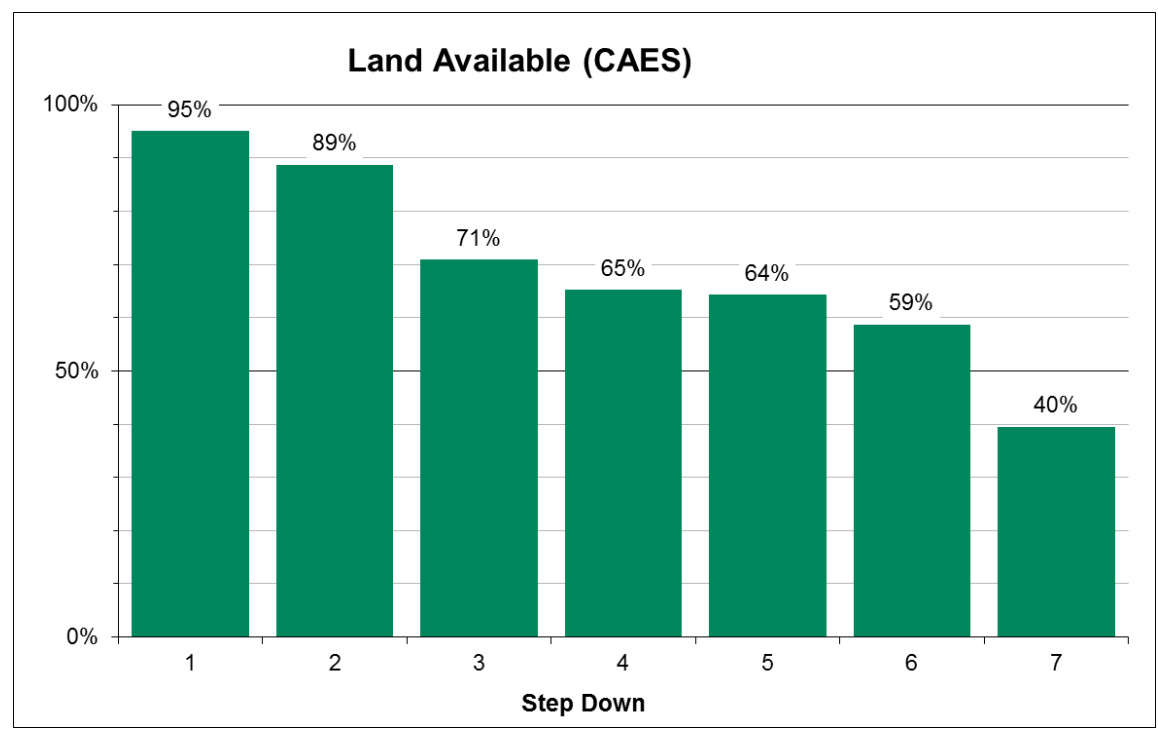

\section{Order of SSEC Layers}

1. Population

2. Wetlands/open water

3. Protected lands

4. Landslide hazard

5. 100-year floodplain

6. Slope

7. All formations

Fig. 132. CAES step-down histogram. 
A review of the individual SSEC layers and the histogram provides the following insights:

- Protected lands, land slide hazards, and slope are significant factors in the west.

- A viable geologic formation for air storage is the most limiting factor.

OR-SAGE tracks the parameters for each individual 100 by $100 \mathrm{~m}$ cell. As a result, not only can the cells that are clear of all the SSEC layer exclusions be displayed visually, but also cells that are tripped by one, two, or three or more exclusions can be tracked and displayed. This is known as the CAES composite map, shown in Fig. 133. This is a powerful aspect of the OR-SAGE tool, because it allows areas with a limited number of siting challenges to also be identified. Engineering solutions for areas with limited siting challenges may be available. The areas in green in Fig. 133 have no siting challenges based on the selected values for the solar SSEC layers. However, the much more prominent areas in yellow have just a single siting challenge. An examination of the individual layers indicates that inadequate compressed air storage formations are the most common siting challenge in the Southeast and the West. Other geologic forms of storage may be available, such as hard rock caverns.

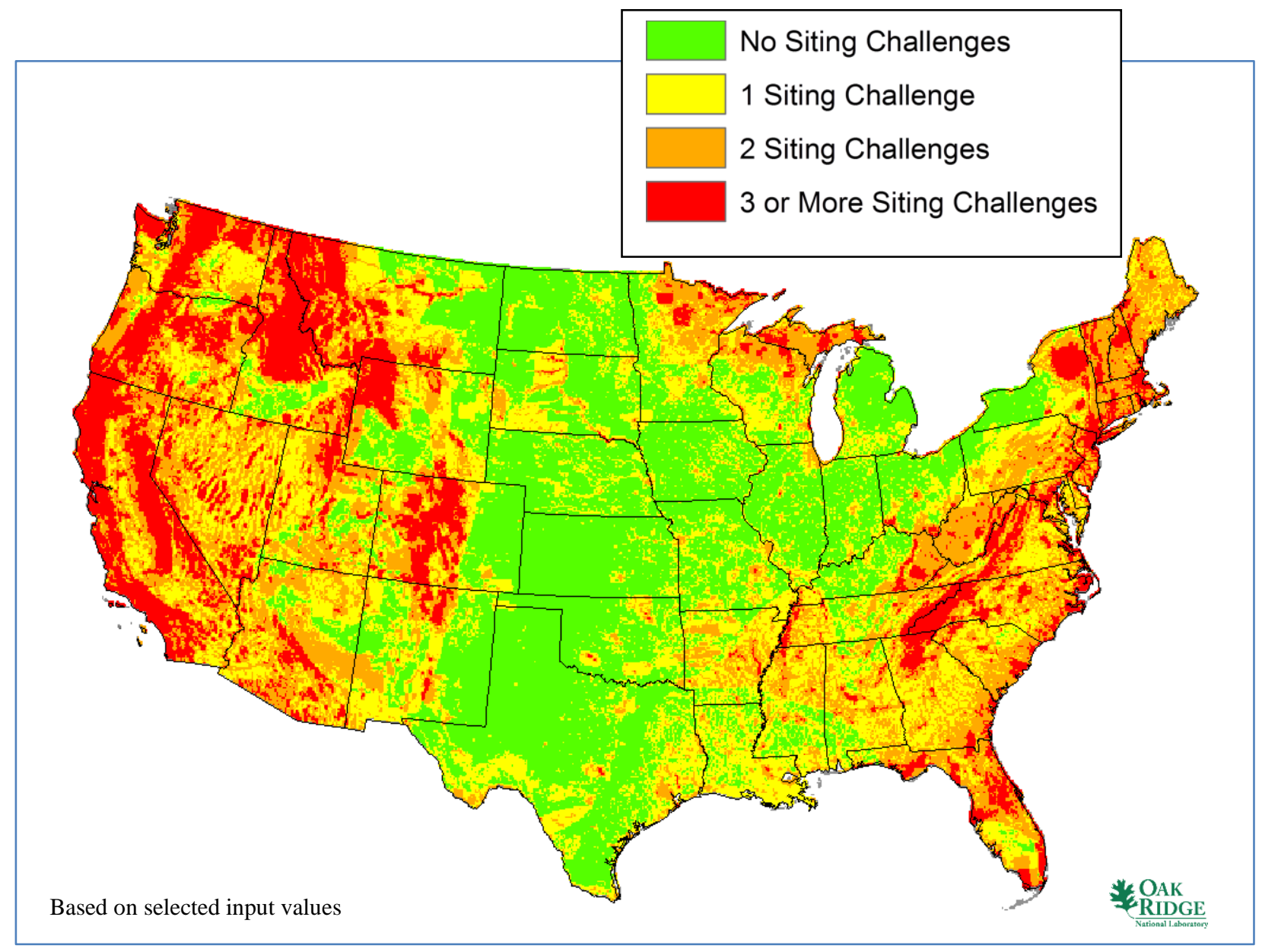

Fig. 133. CAES composite map detailing siting challenges. 


\subsection{Key Assumptions}

There are several key assumptions that bound the CAES plant results:

- Access to natural gas is readily available.

- A CAES plant will have a small physical footprint. Therefore, site preparation will be less extensive. This can allow a reduction in some limitations such as slope.

- No cooling water flow is required. Gas turbine plants are air-cooled.

- Aggregation of GIS land cells into 10 acre parcels requires $100 \%$ of the individual cells to pass SSEC. Small imperfections are difficult to tolerate in a parcel with a small footprint.

\subsection{Base Maps}

A base map is created to reflect one set of values based on the stated assumptions and CAES plant SSEC. The areas depicted in green from the CAES composite map shown in Fig. 133 are used to develop the water-cooled solar base map. Figure 134 shows the CAES base map for compressed air storage in a salt formation. Storage in salt formations is the preferred method of compressed air storage. The limited availability of salt formations limits CAES plant siting opportunities to $11.1 \%$ of the contiguous United States land, or 190 million acres, based on this geological storage method.

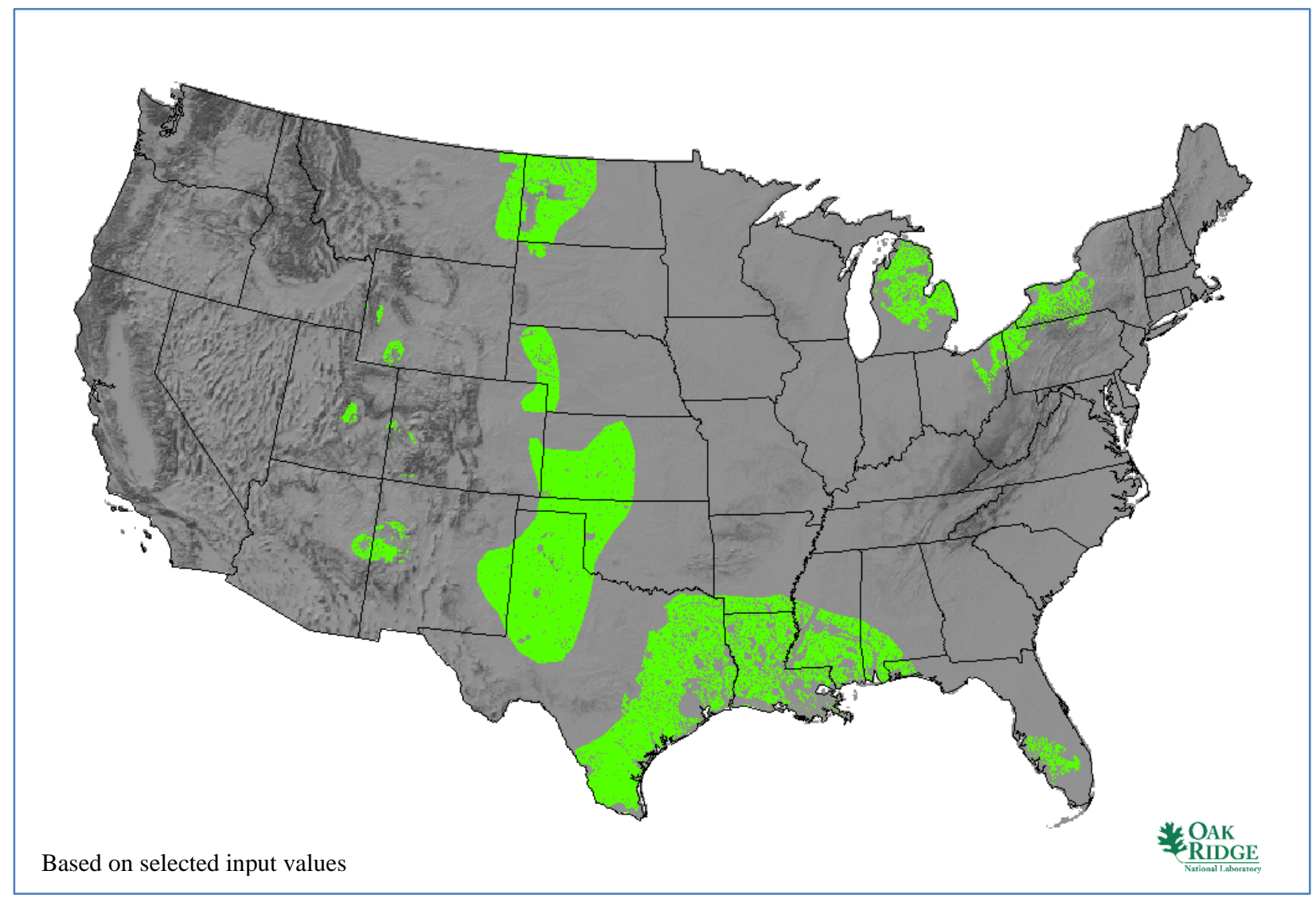

Fig. 134. Salt formations available for CAES plant siting. 
Figure 135 shows the wider availability for CAES plant siting using compressed air storage in aquifers. The independent CAES plant siting opportunities based on this geological storage method are expanded to $34.8 \%$ of the contiguous United States land, or 596 million acres.

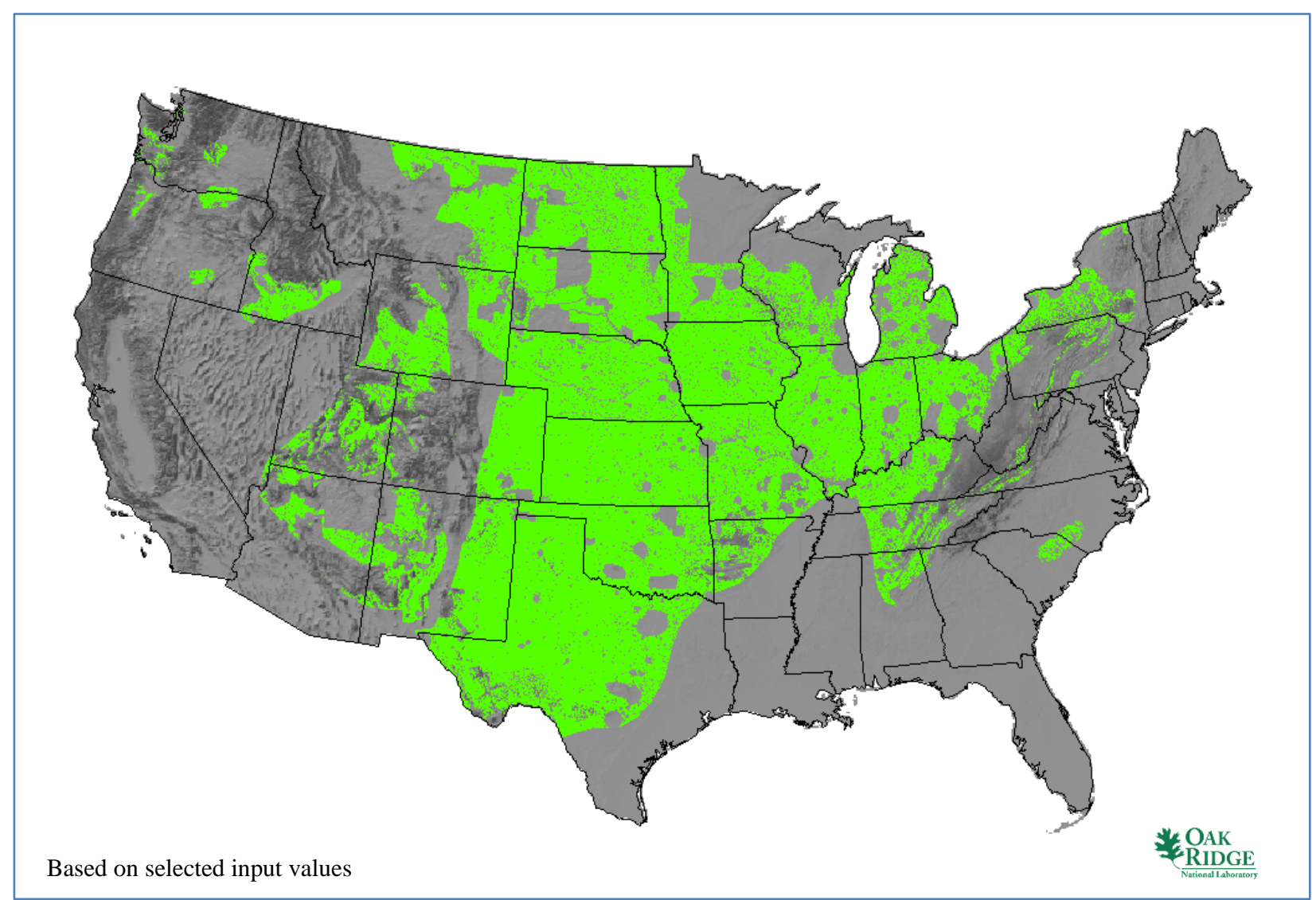

Fig. 135. Aquifers available for CAES plant siting.

Figure 136 shows the availability for CAES plant siting using all acceptable geological formations. The combined CAES plant siting opportunities based on all geological storage methods are extended to $40.3 \%$ of the contiguous United States land, or 690 million acres. When the projected available land is aggregated for 10 -acre CAES plant parcels, the result is a slight reduction to $37.7 \%$ of the contiguous United States land, or 645 million acres, as shown in Fig. 137.

For other generation sources studies, a plant placement algorithm is used to estimate plant siting while tracking available water flow in each of the 18 US water regions. However, the placement estimate is not amenable to air-cooled CAES facilities. Even so, if just $0.1 \%$ of the projected available land for CAES were used for nominal CAES plant construction, more than $7000 \mathrm{GW}(\mathrm{e})$ could be provided for peaking loads.

Most states are projected to have some capacity for CAES plants, including regions where solar and wind generation is viable. Using solar and wind generation for air compression in a CAES plant would provide a reasonable energy storage mechanism. 


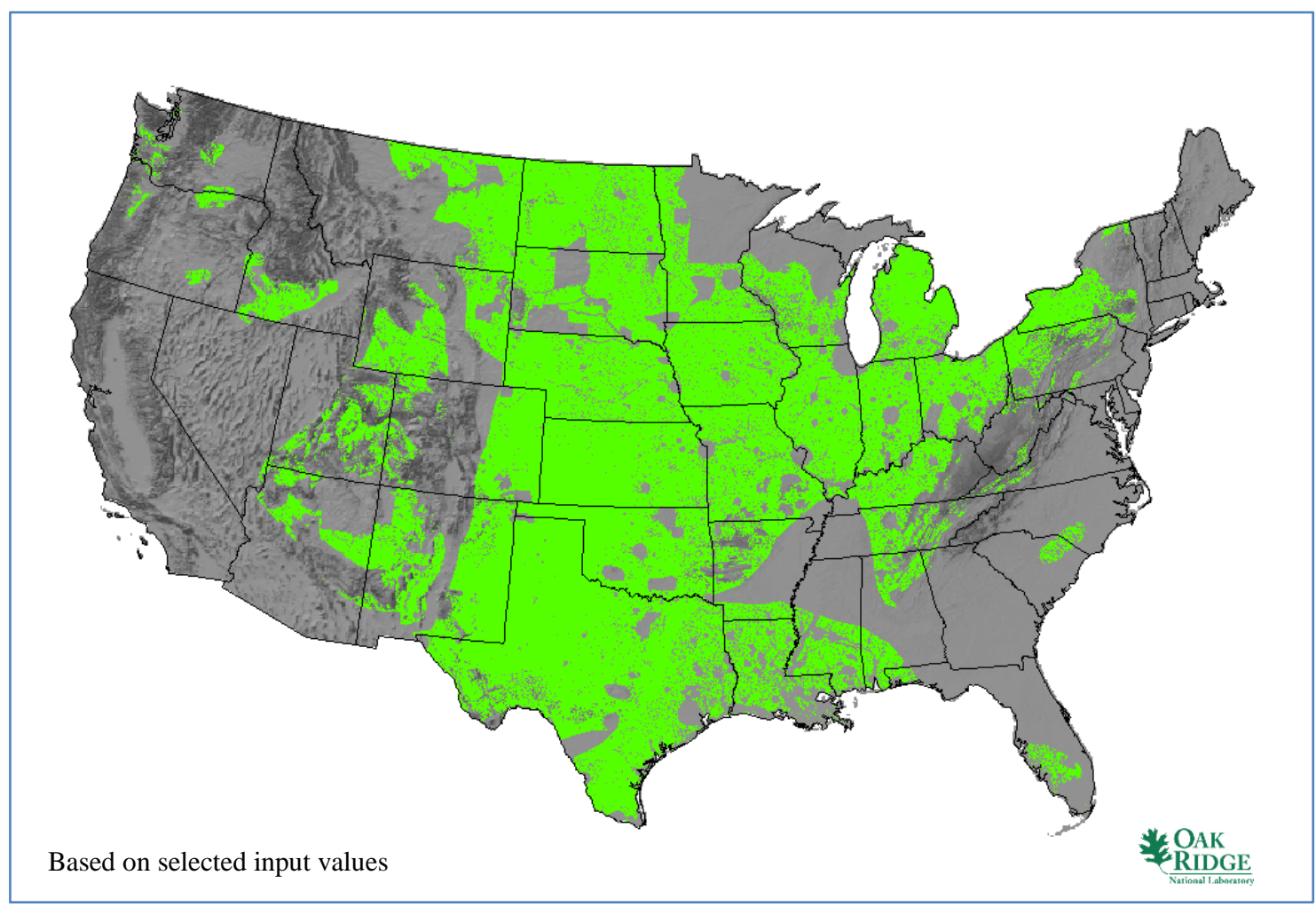

Fig. 136. Combined compressed air storage geology available for CAES plant siting.

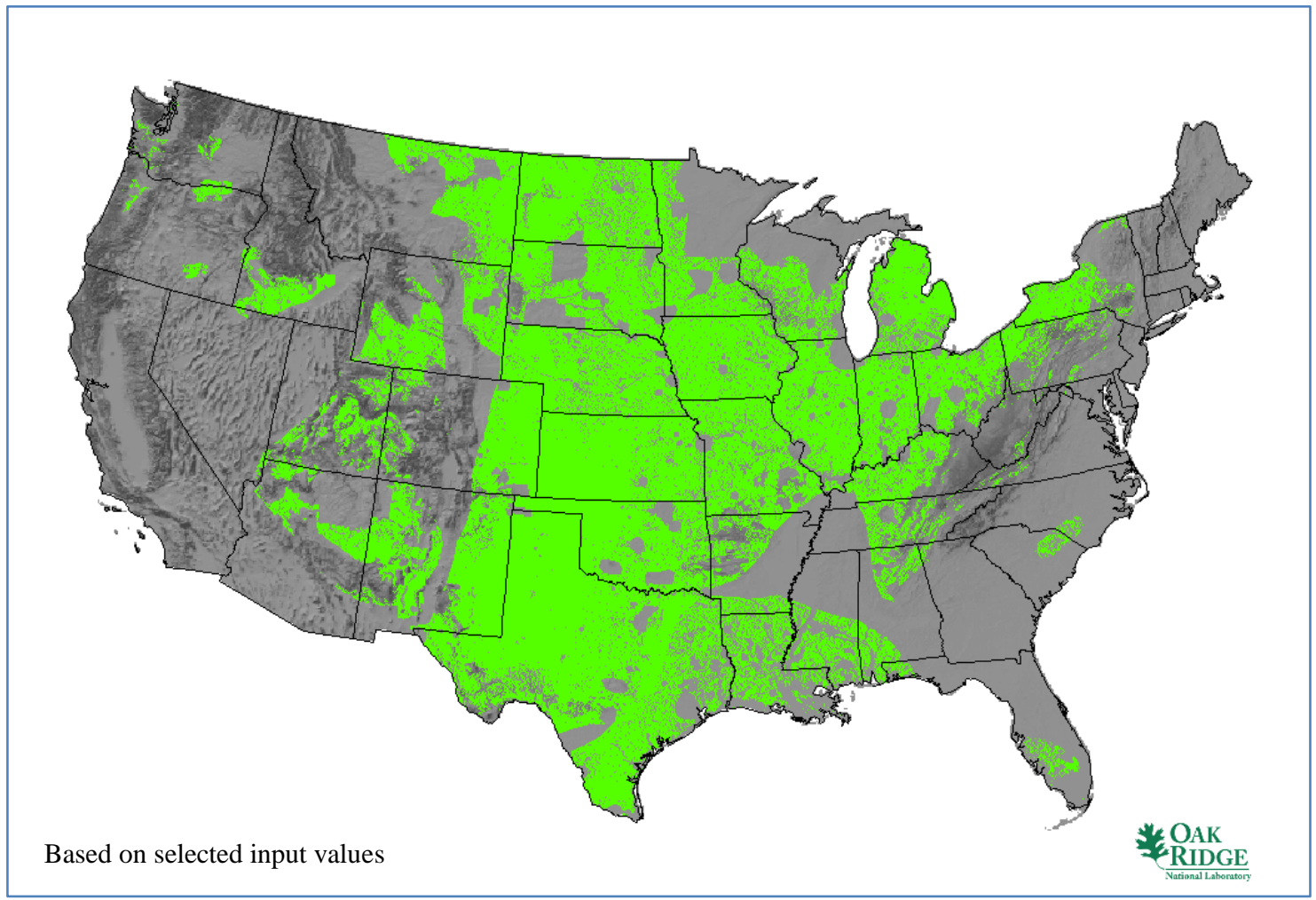

Fig. 137. CAES aggregated for 10 acre facility. 


\subsection{Sensitivity Studies}

A sensitivity study on slope revealed a small increase in available land for siting in the case where the CAES slope SSEC layer is increased from 12 to $30 \%$. The 30\% slope SSEC layer substituted for the nominal 12\% slope layer is shown in Fig. 138. This can be compared with the 12\% SSEC slope layer shown in Fig. 129. A striking difference in excluded land based on the slope SSEC layer is noted in the western and eastern parts of the United States. An additional 2.7\% of the land in the contiguous United States is added in the $30 \%$ slope case compared with the base $12 \%$ slope limit case, after land is aggregated for the nominal 10-acre CAES footprint. This represents an increase of 46 million acres compared with a total of 645 million acres available for the 10-acre aggregated land in the base $12 \%$ case shown in Fig. 137.

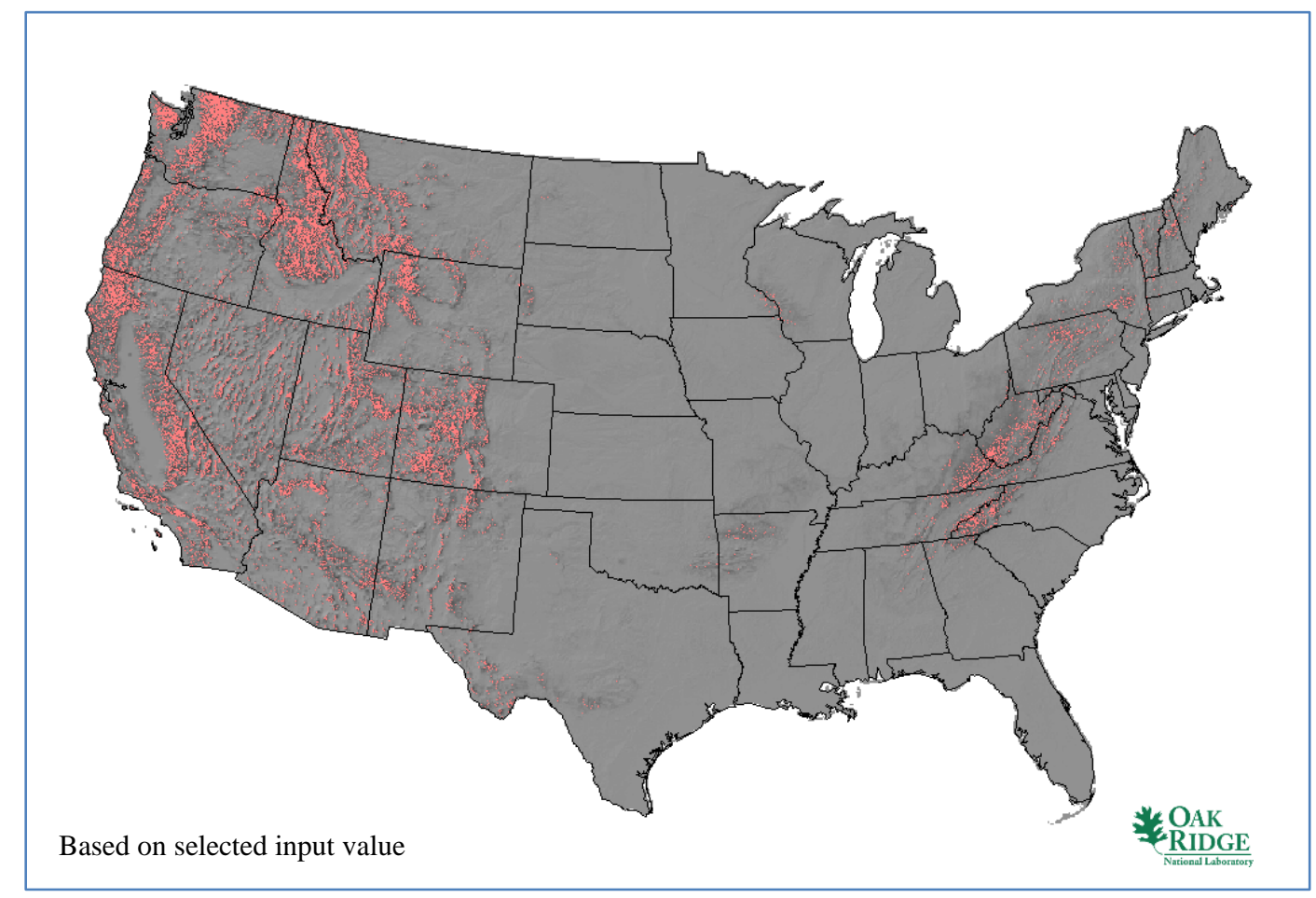

Fig. 138. CAES high slope SSEC layer (greater than 30\%).

\subsubsection{Projections}

Over time, the siting options change depending on a wealth of factors, including load growth, population shifts, changed regulatory environment, climate shifts, and others. In addition, new power generation requires planning, financing, permitting, and construction. For CAES, this process typically takes a few years. GIS projections are only as good as the underlying data, and trends and uncertainty increase with the length of time projected. For these reasons, as discussed in the section "2035 Assumptions2035 Projections," a projection 25 years in the future was prepared for CAES power generation, based on population data and trends available to ORNL in its LandScan USA dataset.

Figure 139 depicts the projected 2035 population SSEC layer for CAES. As discussed previously, a population density of more than 500 people per square mile begins to transition into an urban setting, so new CAES plants in these areas, shown in red, continue to be excluded using the 2035 population projection. There is no need to include a buffer for public safety. Figure 124 provides the comparable population SSEC layer for 2010. 


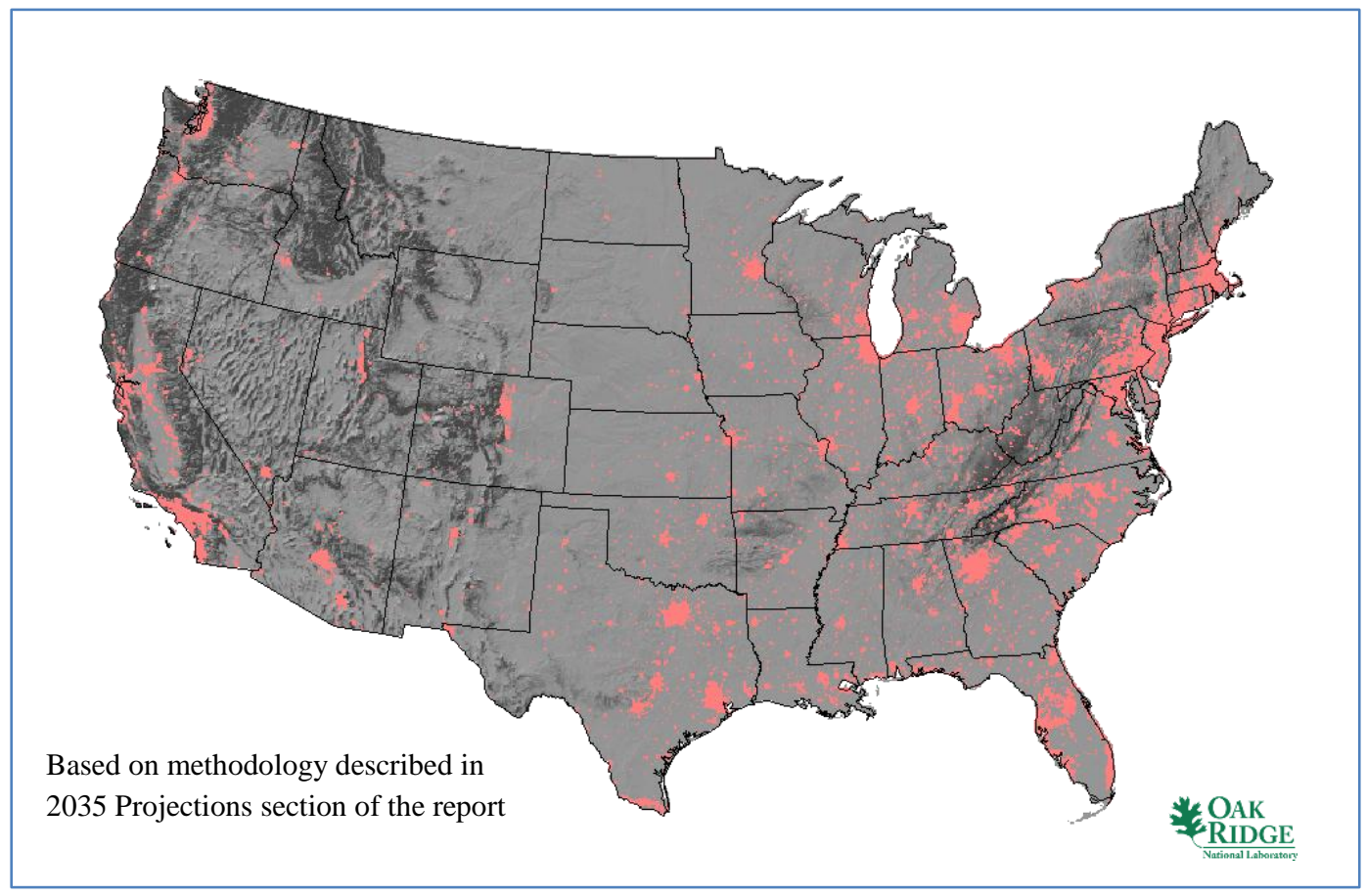

Fig. 139. CAES 2035 high population SSEC layer.

As a result of substituting the 2035 projected SSEC layers shown in Fig. 139, the available land for siting a CAES plant is slightly diminished for 2035. Based on the population projection and the previously selected values for the CAES plant siting, Fig. 140 depicts the 2035 CAES base map indicating 39.2\% of the contiguous United States is available, or 671 million acres. Compare this with the 2010 CAES base map shown in Fig. 136, on which $40.3 \%$ of the contiguous United States is available, or 690 million acres. The 2035 projection for CAES indicates a reduction in available land equivalent to $1.1 \%$ of the contiguous United States, a reduction of 19 million acres before consideration of land aggregation to meet the nominal plant footprint size.

The results of aggregating the projected available land from the base case shown in Fig. 140 are depicted in green in Fig. 141. Land aggregation for a nominal 10-acre CAES facility reduces the available land from $39.2 \%$ of the contiguous United States in the 2035 base case to $36.6 \%$ or 626 million acres. This is an actual reduction of $1.1 \%$ of the contiguous United States, or 19 million acres, compared with the aggregated land calculation for 2010 shown in Fig. 137, or a relative decrease of 3\%.

Figure 142 provides a visual comparison of the aggregated land available for CAES plant siting, based on selected SSEC input parameters, for the 2010 and 2035 scenarios. 


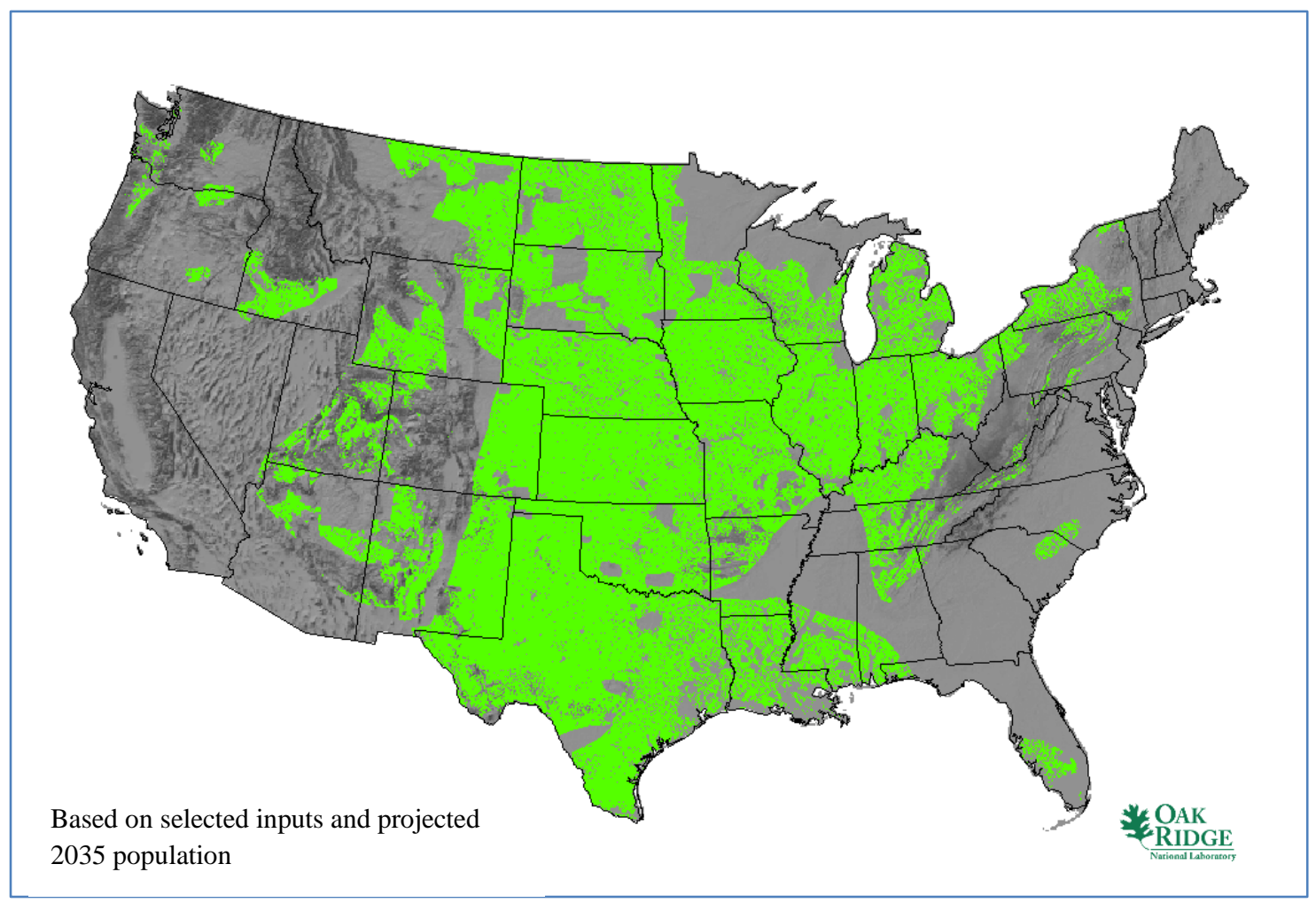

Fig. 140. CAES 2035 base map.

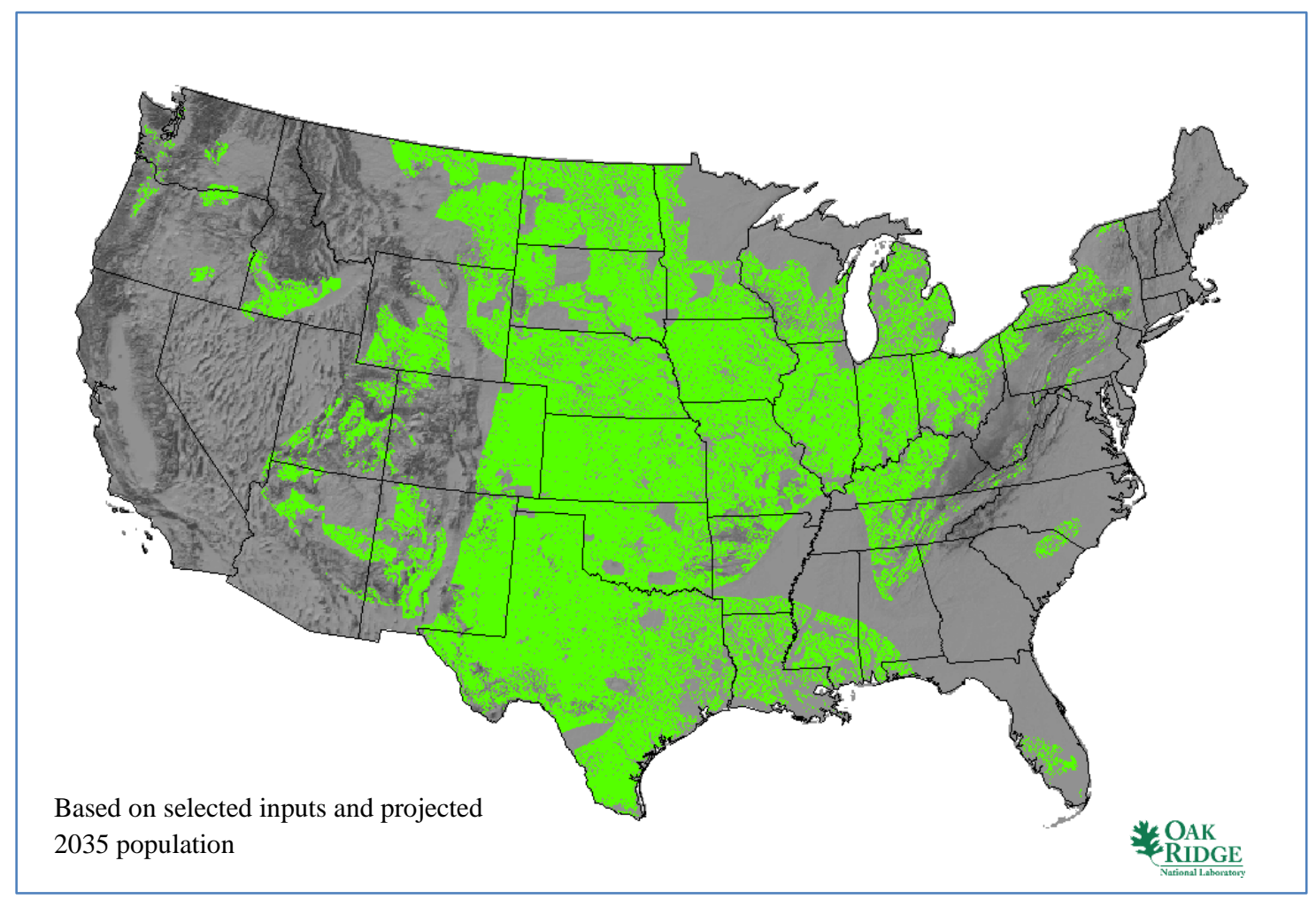

Fig. 141. CAES 2035 siting aggregated for 10 acre facility. 


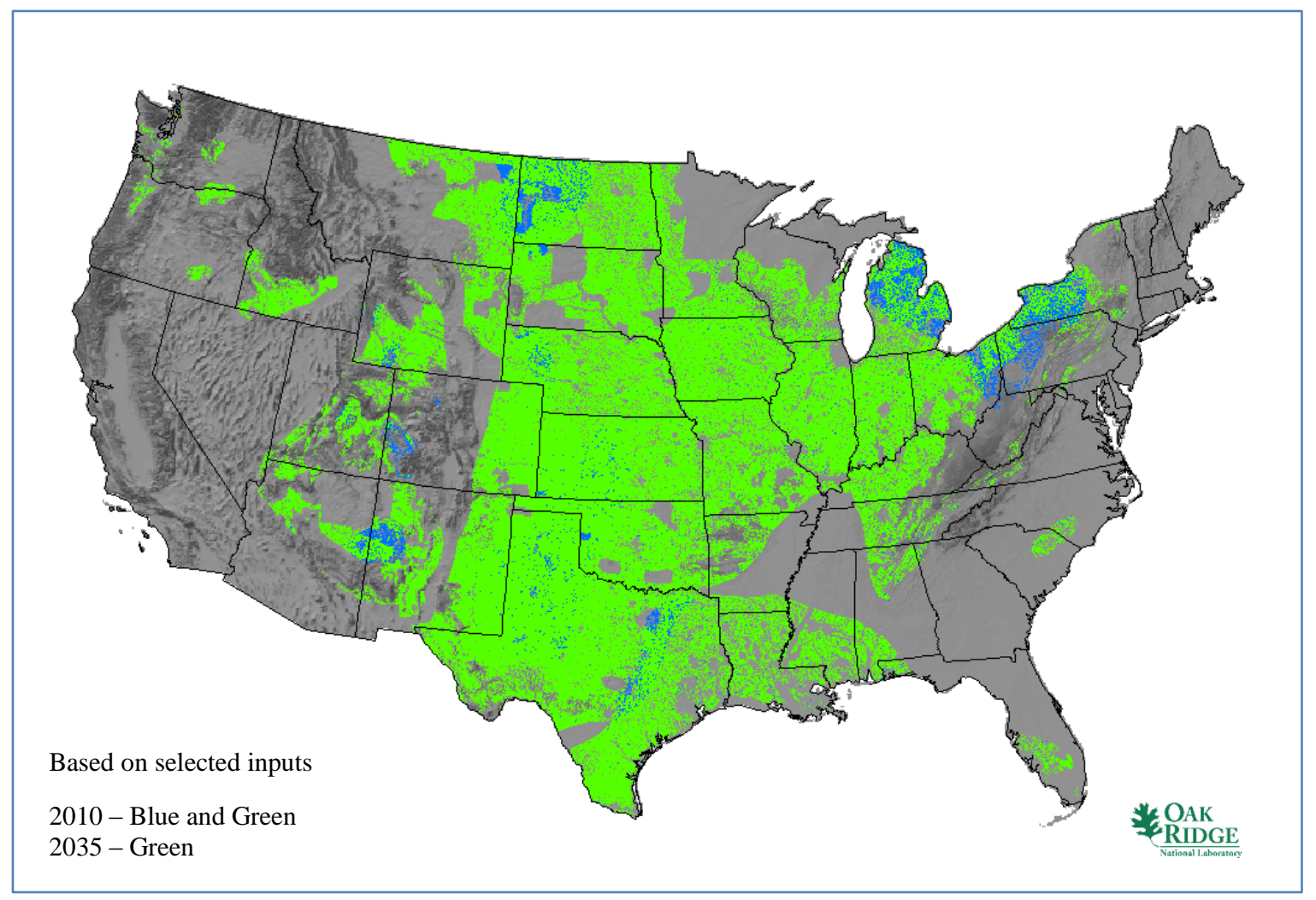

Fig. 142. CAES visual comparison of 2010 and 2035 aggregated land results.

\subsection{Tabular Results}

Table 18 shows the CAES estimate results by state. An entry of 0.00 indicates a value greater than zero that does not show at two significant digits, and a blank entry implies a zero response. Note that the tabular results are not intended to show a "final" result. These results are based on a selected set of input values. The relative values between states are the more significant table information. It should be further noted that Table 18 details only the results for aggregated land cells that had no siting challenges. Engineered solutions for land with one or more siting challenges would impact the entries included in Table 18.

Table 18. CAES results by state (no siting challenges, selected SSEC values)

\begin{tabular}{lcc}
\hline State & $\begin{array}{c}\text { Portion of state available } \\
\text { to support 10 acre sites } \\
(\boldsymbol{\%})^{a}\end{array}$ & $\begin{array}{c}\text { Portion of contiguous US } \\
\text { available to support 10 acre } \\
\text { sites }(\boldsymbol{\%})\end{array}$ \\
\hline Alabama & 21.66 & 0.38 \\
Arizona & 11.09 & 0.42 \\
Arkansas & 29.31 & 0.52 \\
California & & \\
Colorado & 37.24 & 1.28 \\
\hline
\end{tabular}


Table 18. (continued)

\begin{tabular}{|c|c|c|}
\hline State & $\begin{array}{c}\text { Portion of state available } \\
\text { to support } 10 \text { acre sites } \\
(\%)^{a}\end{array}$ & $\begin{array}{c}\text { Portion of contiguous US } \\
\text { available to support } 10 \text { acre } \\
\text { sites (\%) }\end{array}$ \\
\hline \multicolumn{3}{|l|}{ Connecticut } \\
\hline \multicolumn{3}{|l|}{ Delaware } \\
\hline \multicolumn{3}{|c|}{ District of Columbia } \\
\hline Florida & 8.13 & 0.16 \\
\hline Georgia & 0.83 & 0.02 \\
\hline Idaho & 14.63 & 0.40 \\
\hline Illinois & 75.35 & 1.40 \\
\hline Indiana & 73.38 & 0.88 \\
\hline Iowa & 85.05 & 1.58 \\
\hline Kansas & 92.51 & 2.51 \\
\hline Kentucky & 44.51 & 0.59 \\
\hline Louisiana & 42.39 & 0.66 \\
\hline \multicolumn{3}{|l|}{ Maine } \\
\hline Maryland & 1.34 & 0.00 \\
\hline \multicolumn{3}{|l|}{ Massachusetts } \\
\hline Michigan & 54.48 & 1.04 \\
\hline Minnesota & 35.83 & 1.01 \\
\hline Mississippi & 27.26 & 0.44 \\
\hline Missouri & 69.07 & 1.59 \\
\hline Montana & 28.07 & 1.38 \\
\hline Nebraska & 83.37 & 2.13 \\
\hline Nevada & 0.72 & 0.03 \\
\hline \multicolumn{3}{|l|}{ New Hampshire } \\
\hline New Jersey & 0.05 & 0.00 \\
\hline New Mexico & 52.30 & 2.13 \\
\hline New York & 36.01 & 0.58 \\
\hline North Carolina & 1.81 & 0.03 \\
\hline North Dakota & 83.28 & 1.97 \\
\hline Ohio & 60.54 & 0.82 \\
\hline Oklahoma & 78.23 & 1.82 \\
\hline Oregon & 4.70 & 0.15 \\
\hline
\end{tabular}


Table 18. (continued)

\begin{tabular}{lcc}
\hline \multicolumn{1}{c}{ State } & $\begin{array}{c}\text { Portion of state available } \\
\text { to support 10 acre sites } \\
(\boldsymbol{\%})^{a}\end{array}$ & $\begin{array}{c}\text { Portion of contiguous US } \\
\text { available to support 10 acre } \\
\text { sites (\%) }\end{array}$ \\
\hline Pennsylvania & 25.45 & 0.38 \\
Rhode Island & 5.34 & 0.06 \\
South Carolina & 59.66 & 1.52 \\
South Dakota & 23.34 & 0.33 \\
Tennessee & 78.00 & 7.00 \\
Texas & 16.77 & 0.47 \\
Utah & 0.07 & 0.00 \\
Vermont & 2.08 & 0.03 \\
Virginia & 4.17 & 0.09 \\
Washington & 3.35 & 0.03 \\
West Virginia & 35.92 & 0.67 \\
Wisconsin & 36.40 & 1.18 \\
Wyoming & - & $\mathbf{3 7 . 6 7}$ \\
\hline Total & & \\
\hline $\begin{array}{l}{ }^{a} \text { Land for sites is aggregated at } 100 \% \text { as discussed in "Methodology for Aggregating Land for } \\
\text { the Typical Plant Size." }\end{array}$
\end{tabular}




\section{PUMPED HYDRO}

Pumped hydroelectric energy storage systems use water that is pumped to a higher elevation using offpeak electricity (e.g., grid, solar, wind). Subsequently, the water is released and gravity-fed through a turbine that generates electricity when needed during peak demand periods. Conventional hydroelectric storage systems rely on natural elevation differentials between water bodies on the earth's surface to store energy. However, nonconventional hydroelectric storage systems could rely on an elevation difference between a surface body of water and a sub-surface body of water. ${ }^{29}$

Pumped hydro was identified by EPRI as an area of interest. Consultations with ORNL staff researchers investigating national water resources indicated that pumped hydro is not currently subject to geospatial projections. Currently, there is approximately $20 \mathrm{GW}(\mathrm{e})$ of pumped hydro available in the United States, with an additional $30 \mathrm{GW}(\mathrm{e})$ to $40 \mathrm{GW}(\mathrm{e})$ of hydroelectric storage in the application process. ${ }^{30}$ However, much of this additional pumped hydro capacity will not be installed in the near term based on economic issues. Plans for hydroelectric storage systems are currently affected by financing confidence in the ancillary services market. Therefore, further geospatial siting research in this area was discontinued until a clearer set of siting parameters can be established.

\footnotetext{
${ }^{29}$ Gregory Martin, Aquifer Underground Pumped Hydro, Colorado Energy Research Institute (CERI), June 2007.

${ }^{30}$ Brennan Smith, Oak Ridge National Laboratory, "U.S. Hydropower, Fleet and Resource Assessments," National Hydropower Association Annual Conference, April 5, 2011.
} 



\section{WIND}

Wind projects are generally owned and operated by independent power producers, which traditionally sell their power to electric utilities. Wind energy projects may be on land or offshore. Commercial-scale wind projects range in generating capacity from $5 \mathrm{MW}(\mathrm{e})$ to several hundred MW(e) and can consist of a few to hundreds of wind turbines. ${ }^{31}$

Wind power was considered in the initial mix of power generation sources for this study. However, EPRI indicated that a separate wind study had been commissioned internally, and geospatial wind power siting was subsequently replaced with an analysis of CAES.

${ }^{31}$ Tetra Tech EC, Inc., and Nixon Peabody, LLP, Wind Energy Siting Handbook, prepared for the American Wind Energy Association, February 2008. 



\section{COMBINED RESULTS}

Only advanced coal plants and large nuclear plants were considered in a combined placement algorithm. However, the independent results show strong regional biases. For example, Fig. 143 identifies those areas where large and/or small nuclear plants are the only option among CSP, advanced coal, CAES, and nuclear power generation. The areas in green indicate that large and/or small nuclear plants have the strongest potential in the northwestern, north central, northeastern, and southeastern portions of the United States. Figure 144 identifies those areas where water-cooled and/or dry-cooled CSPs are the only option among CSP, advanced coal, CAES, and nuclear power generation. Obviously, solar generation is a strong option in the Southwest.

Figure 145 identifies those areas where advanced coal plants are the only option among CSP, advanced coal, CAES, and nuclear power generation. This tends to be the case where large and/or small nuclear plants are precluded based on seismic restrictions.

Figure 146 identifies those areas where CAES plants are the only option among CSP, advanced coal, CAES, and nuclear power generation. CAES is strongest in a solid band in the middle of the contiguous United States. Based on available information on wind generation, CAES would provide ample opportunity as an energy storage option for both wind energy and solar energy.

The identification of locations where independent power generation sources are the only option among those generation options studied in this report is insightful, but it is also important to observe those areas of the country served by two or more of the options studied in this report. Figure 147 provides this insight by depicting in green all areas where more than one source of power generation among CSP, advanced coal, CAES, and nuclear power are viable. The areas depicted in green in Fig. 147 represent areas with options for a mix of power generation sources to meet the load demands in that region from among the generation sources studied in this report. However, to keep Fig. 147 simple and easy to view, no attempt was made to identify the combination of multiple sources that are feasible. OR-SAGE is able to make this distinction on a cell-by-cell basis.

Finally, it is also insightful to take note of those areas of the United States where siting any of the sources of power generation among CSP, advanced coal, CAES, and nuclear power is not practical. Figure 148 provides this detail - the green marks areas not suitable for any of the generation sources studied in this report. Of course, power provided by CSP, advanced coal, CAES, or nuclear power could be provided via transmission lines from areas in gray. It is important to note that the maps depicted in Figs. 147 and 148 are derived from a select set of input values for all of the SSEC across all generation types considered. Therefore, these maps are highly variable depending on fluctuations in input parameters. Nonetheless, these maps point to the need to consider a wide variety of power generation sources as part of a national energy policy. 


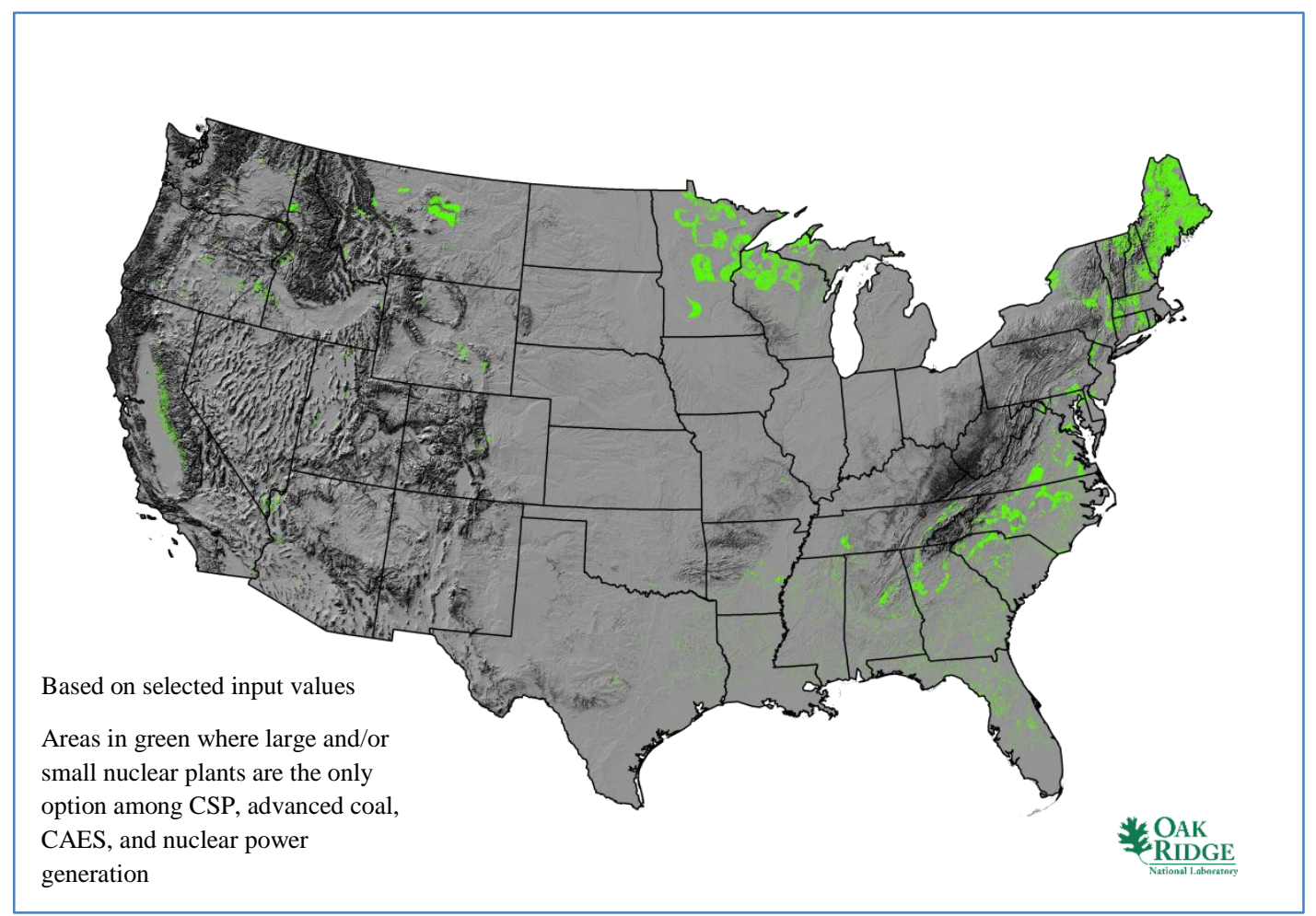

Fig. 143. Areas of the country where nuclear power is the only option of those power sources in this study.

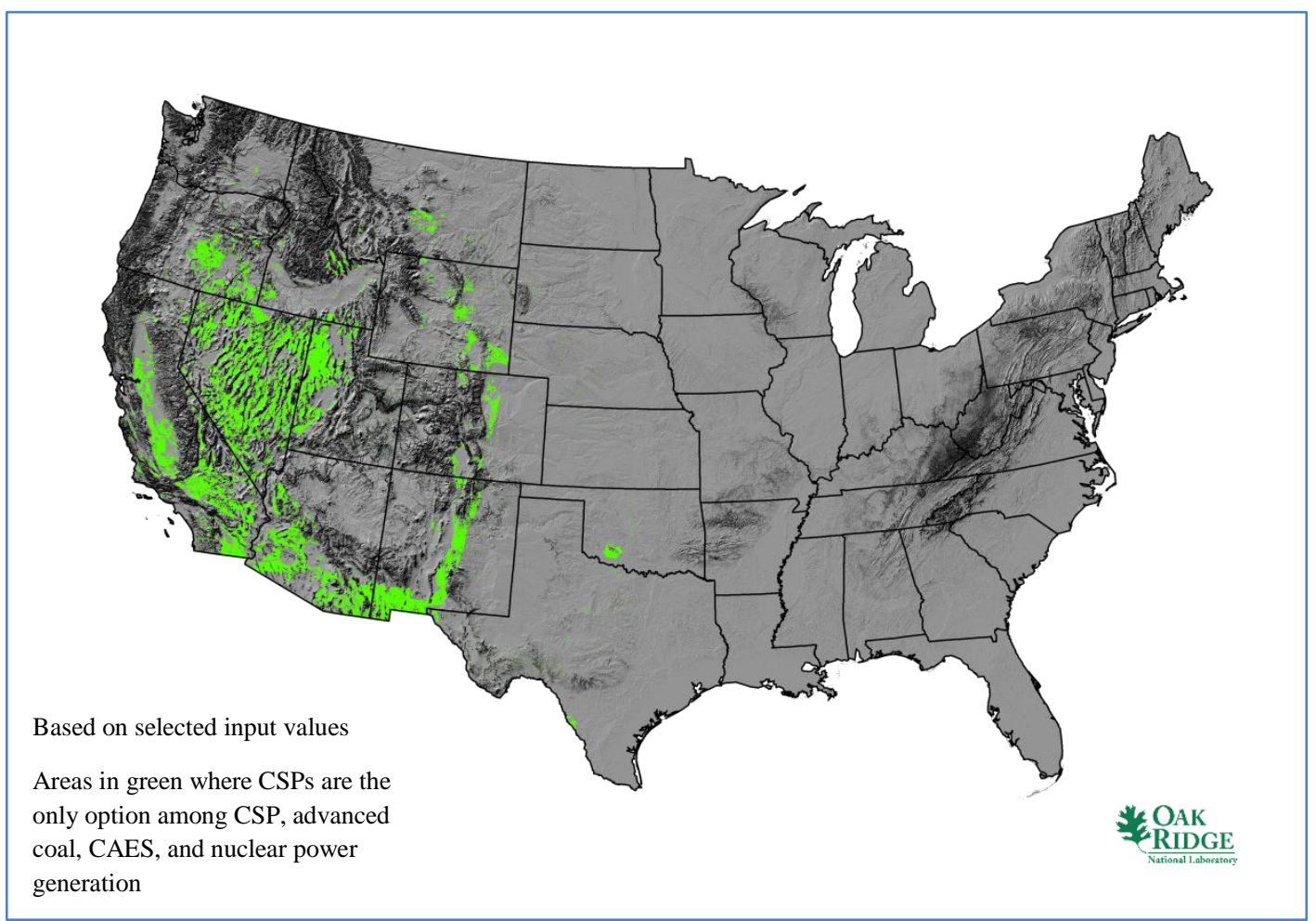

Fig. 144. Areas of the country where solar power is the only option of those power sources in this study. 


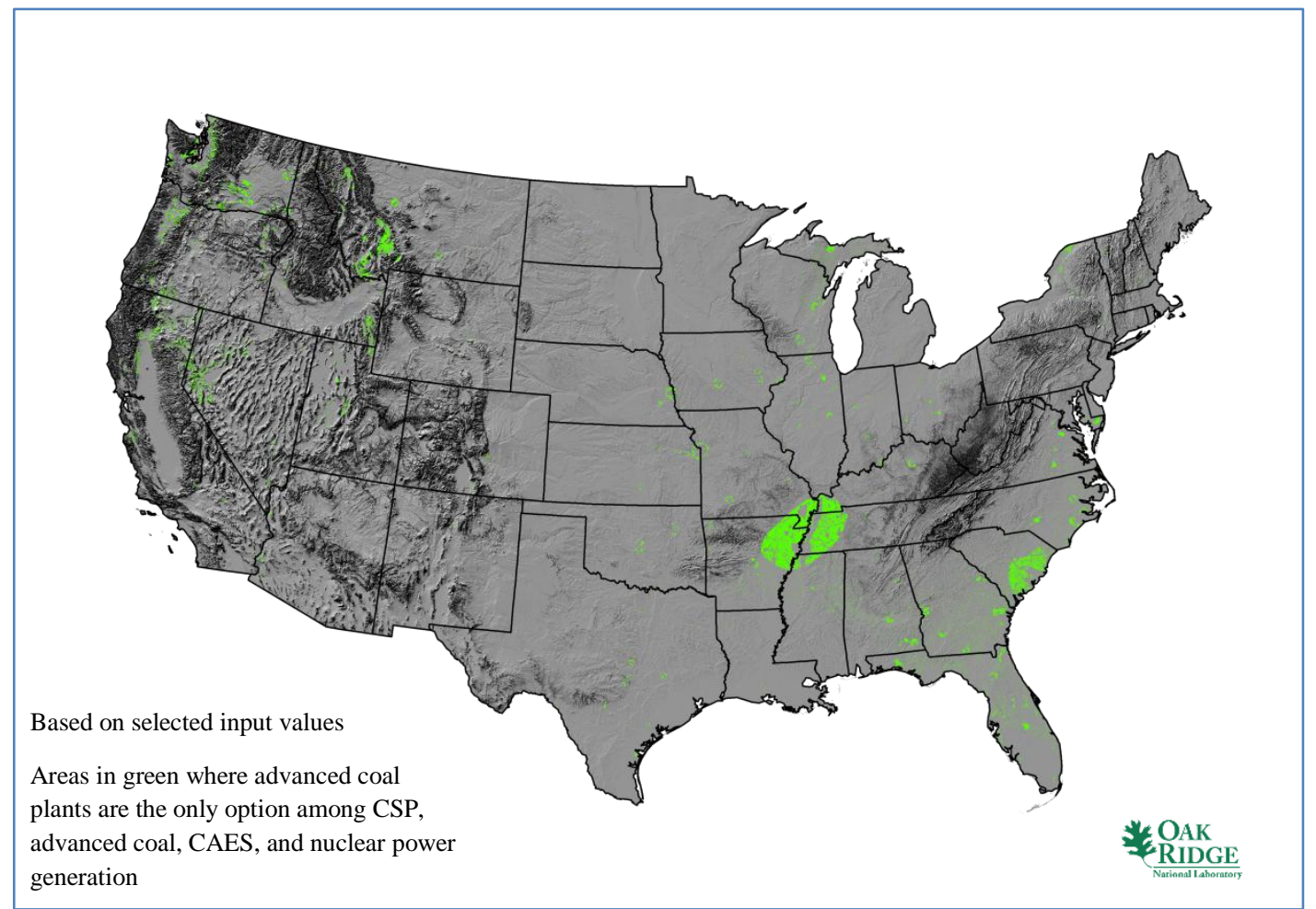

Fig. 145. Areas of the country where advanced coal is the only option of those power sources in this study.

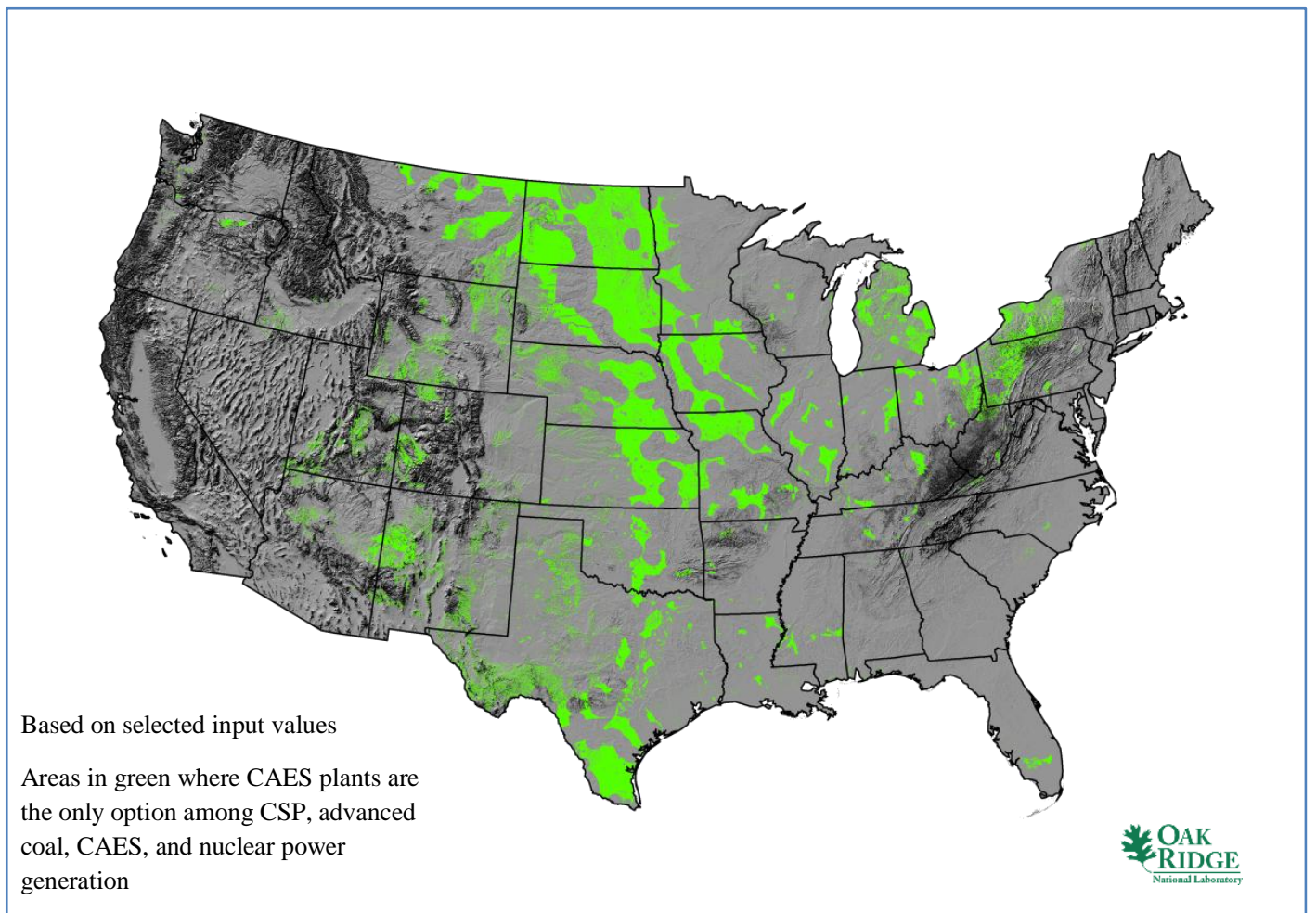

Fig. 146. Areas of the country where CAES is the only option of those power sources in this study. 


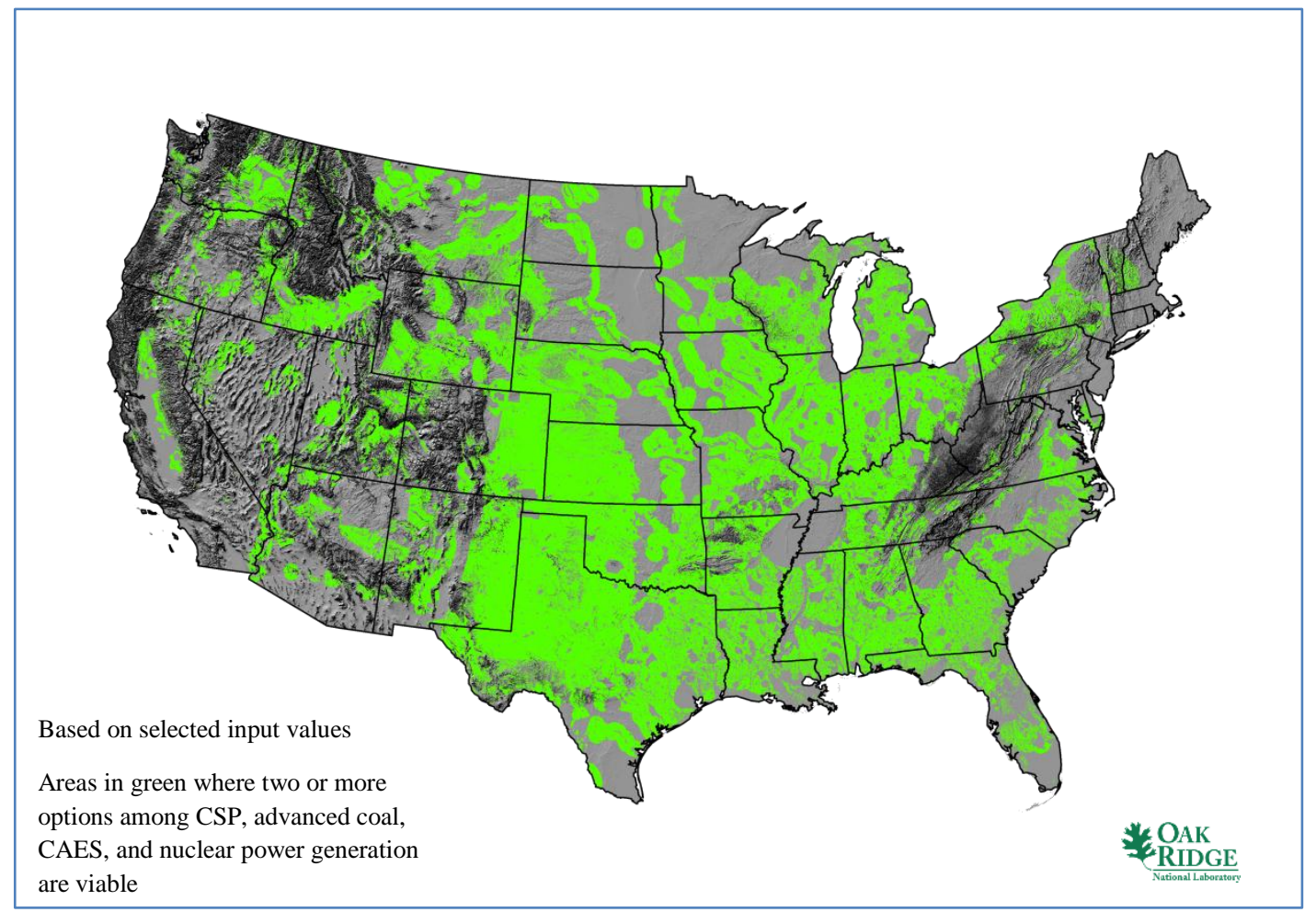

Fig. 147. Areas of the country where more than one power source considered in this study is viable.

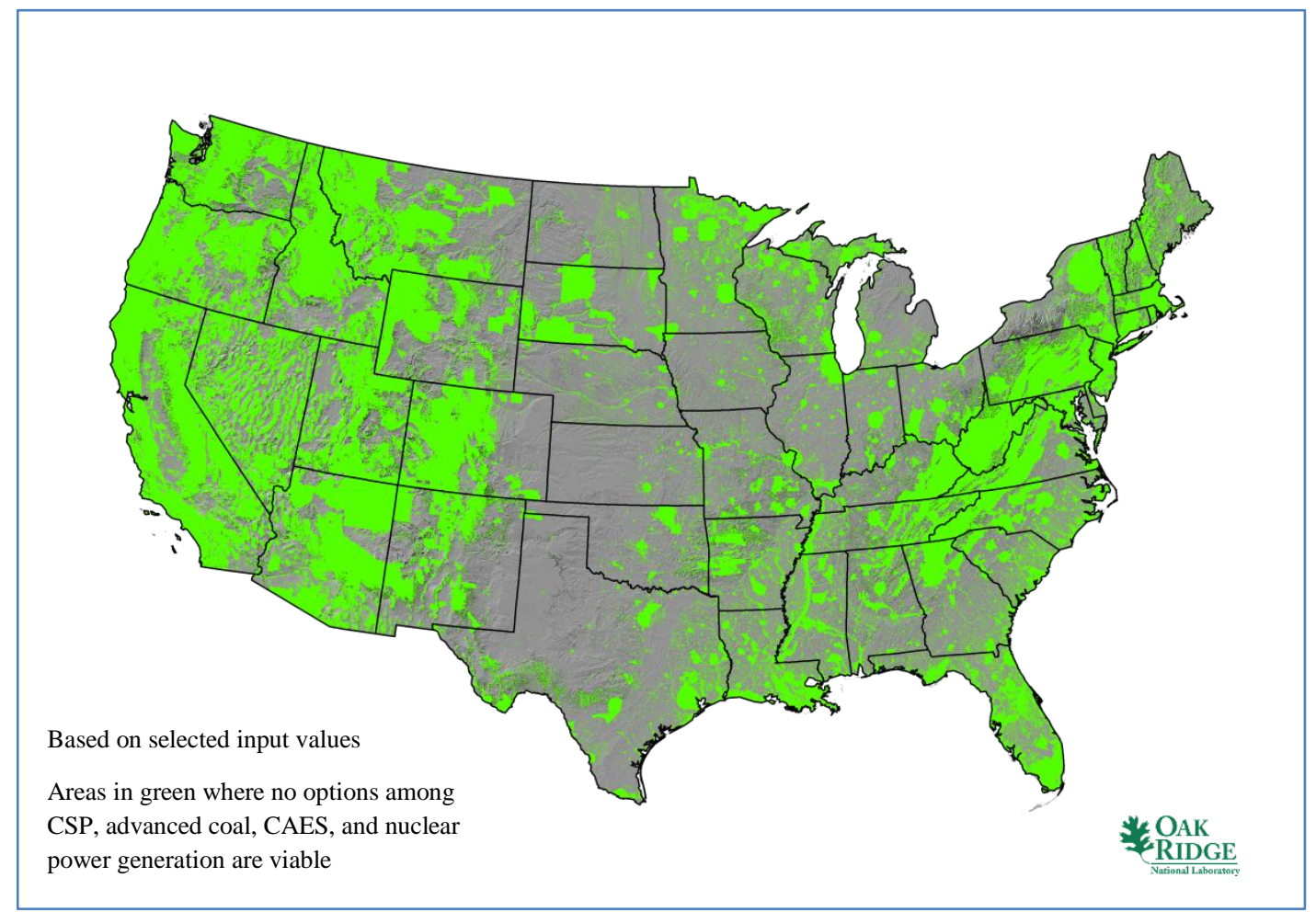

Fig. 148. Areas of the country where no power source considered in this study is viable. 


\section{SUMMARY}

Using a representative set of SSEC as input to the OR-SAGE tool, and employing the accompanying critical assumptions, independent results were calculated for the various power generation sources studied.

OR-SAGE calculations, based on a single set of input parameters, show that sufficient stream flow cooling is available to support the placement of $515 \mathrm{GW}(\mathrm{e})$ in large reactor plants. State-by-state results are affected by the unbiased nature of the initial plant placement in any given water basin, the use of single plant sites, and the arbitrary limit of 20 miles between unit projections. However, the OR-SAGE plant capacity estimate indicates that states in a significant portion of the country can support siting at least $10 \mathrm{GW}(\mathrm{e})$ in large reactor facilities with no siting challenges.

Likewise, independent calculations show that sufficient stream flow cooling is available to support placement of at least $201 \mathrm{GW}(\mathrm{e})$ in small reactor plants. The small reactor capacity estimate of $201 \mathrm{GW}(\mathrm{e})$ is a minimum value based on the constraints of the plant generation capacity estimate algorithm. A direct replacement of a single large reactor projected site with four small reactor sites would provide slightly less capacity per site while using the same amount of water on a smaller footprint. In this alternative, sufficient stream flow cooling is available to support placement of $451 \mathrm{GW}(\mathrm{e})$ in small reactor plant generation. Thus a range of small reactor generation capacity is possible depending on how these plants are deployed.

The OR-SAGE plant capacity estimate projects a gross capacity of $216 \mathrm{GW}(\mathrm{e})$ for new advanced (clean) coal generation. Assuming a parasitic load for scrubbing and carbon capture, this represents a net capacity of approximately $158 \mathrm{GW}(\mathrm{e})$. The states with the strongest projection for advanced coal plant installations and capacity are Montana, Illinois, Missouri, Arkansas, Texas, Louisiana, Tennessee, Alabama, and Georgia.

The OR-SAGE plant capacity estimate projects a total capacity of $20 \mathrm{GW}(\mathrm{e})$ in water-cooled CSP generation. The states with the strongest projection for plant installations and capacity (more than 15 sites each) are California, Idaho, Montana, Ytah, Colorado, and Wyoming. States with good capacity (6 to 15 sites each) are Oregon, Nevada, Arizona, New Mexico, Nebraska, and Texas. Dry-cooled CSP generation does not require placement near a cooling water source, and the tracking of available water by the ORSAGE plant capacity estimate algorithm is not required. A simple comparison of the available dry-cooled CSP land with the water-cooled CSP land indicates that there would be at least $70 \mathrm{GW}(\mathrm{e})$ of dry-cooled CSP capacity.

The combined CAES plant siting opportunities based on all geological storage methods is $38 \%$ (645 million acres) of the contiguous United States land. This land is primarily in the middle portion of the contiguous United States, but most states show at least some siting capacity. This includes regions where solar and wind generation is viable. Using solar and wind generation for air compression in a CAES plant would provide a reasonable energy storage mechanism. As with the dry-cooled CSP case, the OR-SAGE plant capacity estimate algorithm is not amenable to the air-cooled CAES facilities. Therefore, no generation capacity is estimated for CAES. Even so, if just $0.1 \%$ of the projected available land for CAES were used for nominal CAES plant construction, more than $7000 \mathrm{GW}$ (e) could be provided for peaking loads.

Simple projections of 2035 factors indicate that, without technology advances, suitable power generation sites will decrease over time. This projection strongly points to the need for an all-inclusive national energy policy.

This analysis has demonstrated the usefulness of the OR-SAGE siting tool for conducting initial screening of sites for which commercial nuclear power plants, advanced coal plants, wet or dry-cooled solar plants, and CAES plants may be viable. OR-SAGE can provide considerable demographic, 
geotechnical, and infrastructure data and identify initial siting issues or challenges if they exist for providing insights on potential sites.

Although load centers and transmission capacity were not specifically studied, there appears to be ample power generation siting opportunity to meet the near-term electricity needs of the contiguous United States with a mix of electrical generation sources. OR-SAGE can be used to further analyze other power generation types to provide a tool for evaluating national energy policy.

\subsection{National View of Energy Sources}

The scope of work for this geospatial study is aimed at identifying candidate site areas for a variety of electrical generation plants and further characterizing these sites to support their comparison and contrast; for example, for a given site, which type of plant is best suited for that site, how far is it to existing electrical transmission capacity, what is the distance to underground geological formations suitable for carbon sequestration, what should the mix of generation be under certain conditions. The results provide insight into where one generation source may have certain advantages over the others. This is typically a regional debate. Often, the generation source with the best advantage is not conveniently located near any load demand. This necessitates a coordinated energy policy to generate and deliver power where it is needed. The OR-SAGE siting analysis tool provides the capability to evaluate a variety of power generation sources simultaneously. This can factor into policy and economic decision making. The geospatial analysis of additional power generation sources should be included when possible to maintain a well-rounded policy and economic viewpoint. Additionally, as geospatial data sources are updated, currently modeled generation sources need to be revisited.

\subsection{Other Possible Energy Sources to Include in the OR-SAGE Tool Kit}

\subsubsection{Wind}

Based on DOE Energy Information Administration (EIA) data, wind generation capacity is growing the fastest of all renewable energy sources. ${ }^{32}$ Wind generation is conspicuously absent from the available power generation sources in the OR-SAGE tool kit. Onshore wind generation measured at tower heights of $80 \mathrm{~m}$ should be added for a more complete national energy policy overview.

\subsubsection{Biomass}

Commercial biomass energy generation is currently the second leading form of renewable energy behind wind energy. ${ }^{32}$ Biomass fuels for the production of electricity are diverse. Fuels can include timber, agricultural products, and food processing waste. The cost driver is generally fuel transportation distance. Therefore, geospatial analysis of biomass plants is potentially informative for a national energy policy overview of renewable and green energy sources.

\subsubsection{Natural Gas}

The current abundance of natural gas and the corresponding low price make gas competitive with most forms of power generation. Utilities must consider natural gas for new capacity based on the forecasted low cost, causing other forms of energy to be displaced. Natural gas is the cleanest burning of all the fossil fuels and is projected by EIA to increase in generation capacity in the near term. ${ }^{32}$ Therefore, gasfired power generation should be considered in any overall energy policy.

\footnotetext{
${ }^{32}$ U.S. Energy Information Administration, Annual Energy Outlook 2011 With Projections to 2035, prepared for the DOE, April 2011 .
} 


\subsubsection{Hydropower}

There are more than 80,000 dams in the United States. Some 3,000 dams are powered, and approximately 600 unpowered dam sites could support at least $1 \mathrm{MW}(\mathrm{e})$. One ORNL study has shown that there is approximately $12.6 \mathrm{GW}(\mathrm{e})$ in potential at approximately 54,000 nonpowered dams in the contiguous United States. ${ }^{30}$ Tracking these sites for a national energy policy overview would be informative.

\subsubsection{Pumped Hydropower (Future Reexamination)}

When geospatial parameters are generated for potential pumped hydro siting, they should be tracked to maintain a well-rounded national energy policy overview. In addition, a December 2010 report to DOE ${ }^{33}$ on nuclear power plant cooling water issues recommended examining the potential for expanded siting of nuclear power plants on reservoirs capable of providing pumped storage generation.

\subsubsection{Solar Photovoltaic}

The cost of solar photovoltaic (PV) panels continues to decrease dramatically. This form of energy is very conducive to population centers because of the ability to provide rooftop installations. Solar PV is not limited by water cooling and can be utilized in any part of the country. The main driver is PV panel cost versus the intensity of solar irradiation available in a given region. Commercial-scale solar PV installations should be considered for the OR-SAGE tool as federal and regional mandates for green power production are enacted.

\subsubsection{Geothermal}

Geothermal energy capacity currently exceeds the better known solar thermal and PV installed capacity by a factor of five and maintains a better capacity factor. ${ }^{32}$ This form of energy should also be tracked for input into a national energy policy.

\subsection{Other Possible Studies to Conduct Using the OR-SAGE Tool}

\subsubsection{Load}

Current load demand and projected load demand should drive the placement of new power generation sources. The use of OR-SAGE to estimate adding informed or biased placement of new power generation capability while tracking the use of natural resources would be an important additional study.

\subsubsection{Transmission}

The need for added transmission capacity is often overlooked in a discussion of added generation capacity. OR-SAGE provides a good basis for subsequent analyses of transmission needs. This is especially true for renewable energy sources that tend to be regionally based.

\subsubsection{Aging Coal Plants}

Many aging coal plants are reaching the end of their useful or economic life. EPA restrictions can accelerate this process, as well. This leaves a significant gap in power generation capability that must be filled. One of the options being discussed seriously for "repowering" retired coal plants is to deploy small reactors at these sites. Given that much of the infrastructure for siting a small reactor at an existing coal

\footnotetext{
${ }^{33}$ Cooling Water Issues and Opportunities at U.S. Nuclear Power Plants, INL/EXT-10-20208, Rev.1, Dec. 2010.
} 
power plant would be in place, this replacement option is attractive. OR-SAGE has already been used to review a limited set of coal plant replacements as a proof-of-concept study ${ }^{34}$ and this effort should be expanded.

\subsubsection{Plant Cooling}

As coal plants or other water-cooled generation sources are retired, the water demand of that power source is available for other uses. The current study using OR-SAGE focused on new power generation sources and the subsequent new demands on water-based cooling. Additional study should focus on power plant replacement where little or no new demand on water resources is required.

Additionally, new EPA requirements may force power plants using once-through cooling to switch to a CCC loop. This will change the water dynamic with regard to thermoelectric power generation in the United States. This could also force the retirement of older power plants or prompt EPA to allow greater flexibility in response to this requirement. These factors could be explored using the OR-SAGE tool. A bounding case sensitivity run that allows once-through cooling everywhere would be extremely useful for analyzing the impact of the EPA CCC requirement.

The December 2010 report to $\mathrm{DOE}^{33}$ on nuclear power plant cooling water issues recommended examining the water resource and cooling technology options for future thermoelectric power plant construction in the Great Lakes region, with a focus on the relative advantages of CCC vs once-through cooling in this region. This study also recommended examining other areas where once-through cooling remains viable, such as large lakes and multi-purpose reservoirs, and large rivers with high flow rates sufficient to assure good thermal mixing.

\subsubsection{Coupling with an Economic Model}

Numerous economic models, such as the EIA National Energy Modeling System (NEMS), project capacity and plant-type demand in the future. The OR-SAGE tool provides state and regional siting capacity estimates for various energy sources. The OR-SAGE tool can be coupled to an economic forecast model, such as NEMS, to identify future deficiencies and key areas for technology research.

\footnotetext{
${ }^{34}$ T.J. Harrison, G.T. Mays, and B.R. Blevins, Preliminary Report on Evaluating Selected Coal Plant Sites for Repowering with Small Modular Reactors, LTR/DOE-NE/Siting-2011/001, Oak Ridge National Laboratory, February 2011.
} 


\section{BIBLIOGRAPHY}

\subsection{GIS Data Sources}

Population: excluding all areas with population density greater than 500 people per square mile LandScan Global 2009 Population Dataset (ORNL), [30 arcsecond ( $1 \mathrm{~km}$ ) resolution, ambient population distribution], http://www.ornl.gov/sci/landscan.

LandScan USA 2009 Population Dataset (ORNL)

Safe Shutdown Earthquake: excluding areas having a 2\% chance in 50 year return period of peak ground acceleration greater than 0.3

USGS National Seismic Hazard Mapping data (2008),

http://earthquake.usgs.gov/hazards/products/.

Tectonic Sources/Faults: excluding areas using a variable buffer distance based on the length of the fault line

USGS Quaternary Fault and Fold Database,

http://earthquake.usgs.gov/hazards/qfaults/.

Wetlands: excluding areas defined as open water or wetlands through satellite remote sensing of land cover

2001 National Land Cover Dataset,

http://www.mrlc.gov/finddata.php.

Protected Land Uses: excluding managed lands and built environment (see following list)

\begin{tabular}{|c|c|c|c|}
\hline Name & Notes & Date & Link \\
\hline $\begin{array}{l}\text { National parks } \\
\text { National monuments } \\
\text { National forests } \\
\text { Wilderness areas }\end{array}$ & $\begin{array}{l}\text { National Atlas- } \\
\text { Federal Lands }\end{array}$ & $\begin{array}{l}\text { Current, } \\
\text { accessed } \\
9 / 29 / 2009\end{array}$ & http://www.nationalatlas.gov/maplayers.html \\
\hline Other parks & $\begin{array}{l}\text { Contains national, } \\
\text { state, county, } \\
\text { local parks and } \\
\text { forests }\end{array}$ & & ESRI 9.3 mapping data \\
\hline Wild/scenic rivers & $\begin{array}{l}\text { 2-mile buffer } \\
\text { added }\end{array}$ & 2008 & http://www.rivers.gov/maps.html \\
\hline Wildlife refuges & $\begin{array}{l}\text { Merged from all } \\
\text { regions }\end{array}$ & Varies & http://www.fws.gov/refuges/realty/gis.html \\
\hline American Indian reservations & & & HSIP Gold 2008 \\
\hline Hospitals & $\begin{array}{l}0.25 \text { mile buffer } \\
\text { around points }\end{array}$ & & HSIP Gold 2008 \\
\hline
\end{tabular}




\begin{tabular}{|l|l|l|l|}
\hline \multicolumn{1}{|c|}{ Name } & \multicolumn{1}{|c|}{ Notes } & \multicolumn{1}{c|}{ Date } & \multicolumn{1}{c|}{ Link } \\
\hline Correctional facilities & $\begin{array}{l}0.25 \text { mile buffer } \\
\text { around points }\end{array}$ & & HSIP Gold 2008 \\
\hline Schools/colleges & $\begin{array}{l}0.25 \text { mile buffer } \\
\text { around points }\end{array}$ & & HSIP Gold 2008 \\
\hline Inventoried roadless areas & $\begin{array}{l}\text { Merged from state } \\
\text { Aata }\end{array}$ & National Forest Service \\
\hline environmental concern & & Bureau of Land Management \\
\hline
\end{tabular}

Slope: excluding areas with slopes greater than desired (30\% CAES, 12\% coal and nuclear, 5\% solar)

Digital Terrain Elevation Dataset, National Geospatial Intelligence Agency

Landslides: excluding all areas with moderate or high incidence or susceptibility to landslides

USGS Landslide Hazards Program (2002), http://landslides.usgs.gov/learning/nationalmap.

100 year Floodplain: excluding all areas within the 100 year flood plain. Data quality and availability vary by county.

FEMA National Flood Hazard Layer (2009), http://www.msc.fema.gov.

Streamflow-Cooling Water Makeup: excluding areas further than 20 miles from streams with varying flow, depending on the makeup requirements of the energy source. Additionally allows sites within 20 miles of coastlines.

USGS/EPA National Hydrologic Dataset Plus (NHDPlus) (2008), http://www.horizon-systems.com/nhdplus

Low-flow statistics (7-day, 10 year) calculated from USGS National Water Information System (NWIS), data downloaded: 5/24/2010-5/28/2010, http://waterdata.usgs.gov/nwis.

Hazardous Facilities: EPRI siting guidelines consider these existing facilities as avoidance criteria. Major airports have a 10 miles buffer zone; all other facilities have a 1 mile buffer.

Major Airports-Federal Aviation Administration and Bureau of Transportation Statistics (2008).

Military Bases-US Census Bureau (2008), http://www2.census.gov/cgi-bin/shapefiles/national-files.

Refineries-active facilities, HSIP Gold 2008

Solar Radiation: excluding areas with annual direct normal incidence less than $5 \mathrm{kWh} / \mathrm{m} 2$

National Renewable Energy Lab (2009), http://www.nrel.gov/gis/solar.html.

Geological Formations: excluding areas without specific geological formations advantageous to CAES 
Salt domes: Cohn, A., Nakhamkin, M., Abitante, P., Andersson, L., and Patel, M. (1991) ASME 91JPGC-GT-1.

Bedded salt: Cohn, A., Nakhamkin, M., Patel, M., Louks, B., and Swensen, E. (1991) ASME 91-JPGCGT-2.

Aquifers: USGS /national atlas, http://www.nationalatlas.gov/mld/aquifrp.html.

Carbon Sequestration: excluding areas without specific geological formations advantageous to carbon capture

Saline aquifers: National Renewable Energy Lab (2009), http://www.netl.doe.gov/technologies/carbon seq/natcarb/download.html.

Coal Shipments: excluding areas for coal plant construction that are not near railroads or navigable waterways

Railroads: ORNL Dataset (2010)

Navigable waterways: Bureau of Transportation Statistics, National Transportation Atlas Database, http://www.bts.gov/publications/national transportation atlas database.

Particulate Matter and Ozone: excluding areas with high particulate or ozone measurements for new coal plant construction

Nonattainment regions, Environmental Protection Agency (2009), http://www.epa.gov/airquality/greenbk/index.html.

\subsection{Energy Source Materials that Provided Insights on Selecting SSEC}

\section{Nuclear Energy}

US Nuclear Regulatory Commission, Office of Special Studies, Nuclear Energy Center Site Survey-1975 (NECSS-75) (Report NUREG- 0001, Washington, D.C., January 1976).

R. B. Briggs, C. C. Burwell, R. E. Meunier, M. J. Ohanian, D. L. Phung, B. D. Sivazlian, A. M. Weinberg, Feasibility of a Nuclear Siting Policy Based on the Expansion of Existing Sites, ORAU/IEA78-19(R), Institute for Energy Analysis, Oak Ridge Associated Universities, Oak Ridge, TN, November 1978.

C. C. Burwell, M. J. Ohanian, A. M. Weinberg, A Siting Policy for an Acceptable Nuclear Future, Science, Vol. 204, No. 4397 (June 8, 1979), pp. 1043-1051 published by: American Association for the Advancement of Science, URL: http://www.jstor.org/stable/1748705.

Bechtel Power Corporation, Early Site Permit Demonstration Program, Plant Parameter Envelopes, Comparison with Ranges of Values for Four Hypothetical Sites, Gaithersburg, MD, 1992.

Electric Power Research Institute, Siting Guide: Site Selection and Evaluation Criteria for an Early Site Permit Application, Technical Report 1006878, Palo Alto, CA, March 2002.

Dominion Energy, Inc., and Bechtel Power Corporation, Study of Potential Sites for the Deployment of New Nuclear Plants in the United States, prepared for the US Department of Energy, September 2002.

Nuclear Energy Institute, Lessons Learned from Initial Early Site Permit Experience, NEI 08-03, Washington D.C., February 2008. 


\section{Solar Energy}

A. Leitner, RDI Consulting for the National Renewable Energy Lab, Fuel From the Sky: Solar Power's Potential for Western Energy Supply, NREL/SR-550-32160, July 2002.

US Department of the Interior and U.S. Department of Energy, Assessing the Potential for Renewable Energy on Public Lands, DOE/GO-102003-1704, Washington, D.C., February 2003.

B. Kelly, Nexant, Inc., for the National Renewable Energy Lab, Nexant Parabolic Trough Solar Power Plant Systems Analysis, NREL/SR-550-40162, San Francisco, CA, July 2006.

US Department of Energy, Concentrating Solar Power Commercial Application Study: Reducing Water Consumption of Concentrating Solar Power Electricity Generation, Report to Congress, 2007.

California State Auditor, Solar Energy, Report 2007-119, Sacramento, CA, January 2008.

Audubon California, California Wilderness Coalition, Center for Biological Diversity, Defenders of Wildlife, Desert Protective Council, Mojave Desert Land Trust, Natural Resources Defense Council, Sierra Club, The Nature Conservancy, The Wilderness Society, and The Wildlands Conservancy, Renewable Siting Criteria for California Desert Conservation Area, June 2009.

N. T. Carter, R. T. Campbell, Congressional Research Service, Water Issues of Concentrating Solar Power (CSP) Electricity in the U.S. Southwest, June 2009.

C. Turchi, C. Kutscher, National Renewable Energy Lab, Presentation: "Water Use in Concentrating Solar Power (CSP)," Golden, CO.

\section{Advanced Coal Energy}

National Energy Technology Lab, Pulverized Coal Oxycombustion Power Plants, DOE/NETL2007/1291, August 2008.

National Energy Technology Lab, Estimating Freshwater Needs to Meet Future Thermoelectric Generation Requirements, DOE/NETL-402/2008/1339, September 2008.

K. Gerdes, C. Nichols, National Energy Technology Lab, Water Requirements for Existing and Emerging Thermoelectric Plant Technologies, DOE/NETL-402/080108, April 2009.

US Department of the Interior and U.S. Geological Survey, Mapping the Mineral Resource Base for Mineral Carbon-Dioxide Sequestration in the Conterminous United States, Data Series 414, Reston, VA, 2009.

\section{Compressed Air Energy Storage}

BINE Energy Information Service, Compressed Air Energy Storage Power Plants, Bonn, Germany, 2005, URL:

http://www.bine.info/fileadmin/content/Publikationen/Englische_Infos/projekt_0507_engl_internetx.pdf.

Electric Power Research Institute, Presentation: "Utility Scale Energy Storage (with special focus on Compressed Air Energy Storage, CAES)," Palo Alto, CA, November 2008.

PHYSorg.com, “Compressed Air Energy Storage: Renewable Energy,” March 2010, URL: www.physorg.com/news188048601.html. 